\title{
AFFIRMATIVE ACTION
}

\section{A View from the Global South}

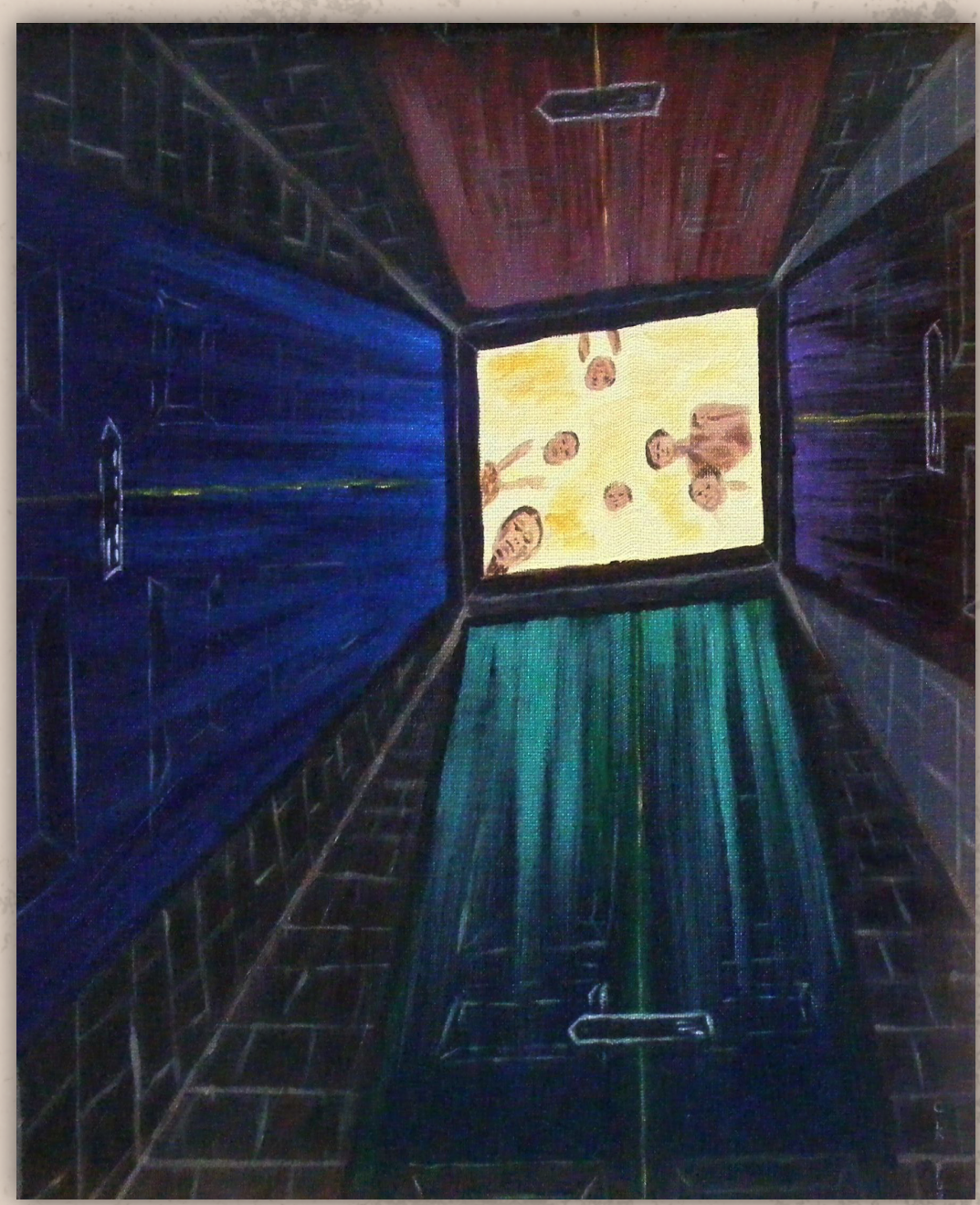

OCKERT DUPPER \& KAMALA SANKARAN

EDITORS 
e 


\title{
AFFIRMATIVE ACTION $\diamond$
} A VIEW FROM THE GLOBAL SOUTH

\author{
EDITORS \\ OCKERT DUPPER \\ KAMALA SANKARAN
}

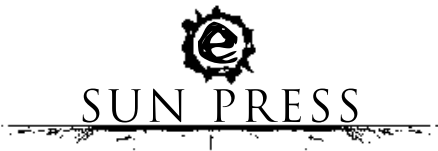


Affirmative Action: A View from the Global South

Published by SUN MeDIA Stellenbosch under the imprint SUN PRESS.

All rights reserved.

Copyright (C) 2014 SUN MeDIA Stellenbosch and STIAS

No part of this book may be reproduced or transmitted in any form or by any electronic, photographic or mechanical means, including photocopying and recording on record, tape or laser disk, on microfilm, via the Internet, by e-mail, or by any other information storage and retrieval system, without prior written permission by the publisher.

First edition 2014

ISBN 978-1-920689-46-9

ISBN 978-1-920689-47-6 (e-book)

Set in Arno Pro 12/14

Cover design: SUN MeDIA Stellenbosch

Typesetting: SUN MeDIA Stellenbosch

Cover artwork: Some Doors are always closed (C) C K Purandare <www.art-non-deco.com>

SUN PRESS is an imprint of AFRICAN SUN MeDIA. Academic, professional and reference works are published under this imprint in print and electronic format. This publication may be ordered directly from www.sun-e-shop.co.za.

Produced by SUN MeDIA Stellenbosch.

www.africansunmedia.co.za

africansunmedia.snapplify.com (e-books)

www.sun-e-shop.co.za 


\section{THE STIAS SERIES}

The Stellenbosch Institute for Advanced Study (STIAS) was born from a simple but powerful conviction: in this part of the world special initiatives are required to create and maintain an environment where we can generate and engage with conceptual frameworks and knowledge that may guide us in tracking and co-shaping global academic developments and that will allow us to address the 'big' questions and issues South Africa and the African continent face, also in a global context.

STIAS has been moulded in the tradition of Institutes for Advanced Study across the globe. It distinguished itself by encompassing all disciplines from the natural to the social sciences and humanities (with a particular emphasis on research grounded in multi-disciplinarity), by maintaining a focus on the African and South African context, and by striving towards contemporary relevance, also by actively creating avenues for communicating the results of its research projects to a wider public.

The STIAS series publications are thus aimed at a broad public which will naturally vary with specific research themes. Straddling the academic world and the forum of an engaging public is a challenge that STIAS accepts; we trust that each STIAS publication will reflect the 'creative space for the mind' in which it is rooted, stimulate public interest and debate, and contribute to informed decision making at various levels of our society.

Further information about STIAS and its research programme may be found at www.stias.ac.za.

Hendrik Geyer

STIAS Director

Stellenbosch

June 2011

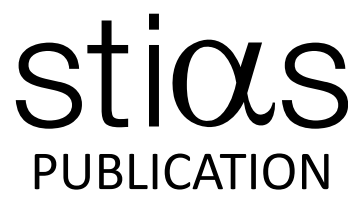




\section{CONTENTS}

List of contributors

Preface

PART 1

COMPARATIVE, THEORETICAL AND INTERNATIONAL PERSPECTIVES

1. Affirmative action in comparative perspective Ockert Dupper

1.1 Introduction

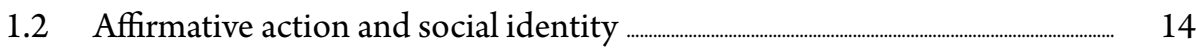

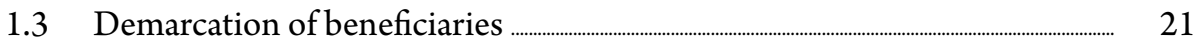

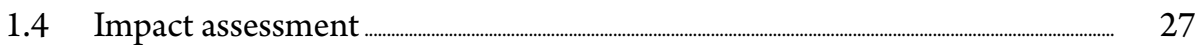

1.5 Justification and termination ....

1.6 Concluding remarks .... -

2. DeMOCRATIC PARTICIPATION IN MAKING AND ENFORCING AFFIRMATIVE ACTION SCHEMES

Bob Hepple

2.1 Introduction

2.2 Reflexive regulation 45

2.3 The failure of command and control 50

2.4 The nature and extent of participation and accountability. 58

2.5 Conclusion 60

3. The CASE against the CASE against afFirmative aCtion 63 Ana Carolina Alfinito Vieira \& Alex Graser

3.1 Introduction 63

3.2 The broader context: AAPs and other EOPs 
3.3 What may be (particularly) wrong about AAPs _..._ 66

$\begin{array}{lll}\text { 3.3.1 Defining AAPs ... _ _ _ } & 67\end{array}$

3.3.2 The unfairness objection in context ...__ $\quad 67$

3.3.3 Specifying the unfairness objection _...____ _ _ _ _ $\quad 68$

$\begin{array}{lll}\text { 3.4 Why this may not be so wrong after all ...__ } & 70\end{array}$

$\begin{array}{ll}\text { 3.4.1 The argument from individual equality ............... } & 70\end{array}$

3.4.2 The argument from personal autonomy ..._. $\quad 77$

3.5 Conclusion ...._.

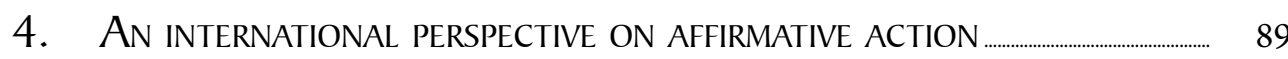
Tzehainesh Teklè

4.1 Introduction ...- - - -89

4.2 Affirmative action and international human rights law ..... _ _ _ _ _ _ _.... 90

4.3 Affirmative action and international labour law …___ _ _ _ 93

4.4 Affirmative action, its objectives and the principle of non-discrimination .... _ _ 97

4.5 Are affirmative action measures mandatory? ___ _ 104

4.6 The content of affirmative action and areas concerned …. 107

4.7 From design to implementation and monitoring of affirmative action measures and conditions for their legitimacy _... _ _ _ _ $\quad 109$

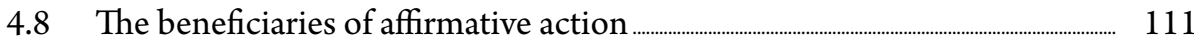

4.9 Conclusions .... _ 113

\section{PART 2}

\section{NATIONAL PERSPECTIVES}

5. NegligenCE AND APPROPRIATE REPRESENTATION: the ISRAELI CASE ......... 121 Moshe Cohen-Eliya

5.1 Introduction $\ldots \ldots \ldots$

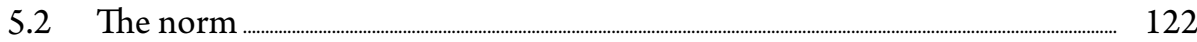

5.3 Negligent violation of the AR norm …_. 126

5.4 The norm, the courts, and negligence _..____ 130

5.5 Conclusion ... 135 
6. Affirmative action in Malaysia: Solid ground, lONG ARMS, SHALLOW ROOTS

Hwok-Aun Lee

6.1 Introduction

6.2 Foundations and motivations

6.2.1 Constitutional provisions and prevalent interpretations 139

6.2.2 Political imperatives and motivations. 142

6.2.3 Socio-economic disparities 143

6.3 Affirmative action programmes 145

6.3.1 Higher education 146

6.3.2 Representation in high-level positions 148

6.3.3 Equity ownership and enterprise development 150

6.4 Affirmative action outcomes 154

6.4.1 Higher education 154

6.4.2 Representation in high-level positions 157

6.4.3 Equity ownership 162

6.5 Conclusions and implications 164

7. DiVERSITY AND INTERSECTIONALITY: AFFIRMATIVE ACTION IN INDIA 169 Kamala Sankaran

7.1 Constitutional mandate for affirmative action

7.2 Distinguishing between general welfare measures and affirmative action 172

7.2.1 Justiciability of affirmative action measures 174

7.2.2 Reservation in public employment 177

7.2.3 Identification of 'beneficiaries'

7.3 Intersectionality of caste, religion and gender. 183

7.4 Dealing with difference 184

8. Justifying afFirmatve action in Mexico Mario Santiago Juárez

8.1 The indigenous people in Mexico: a history of exclusion

8.2 The present situation of indigenous people in Mexico

8.3 Affirmative action as an alternative 190

8.4 Equality as a constitutional principle in Mexico 193

8.5 Conclusions 
9. Affirmative action and the fight against inequalities in Brazil:

THE CASE OF RACE AND EQUAL ACCESS TO HIGHER EDUCATION ................. 201 Ingo Wolfgang Sarlet

9.1 Introductory remarks 201

9.2 Equality-oriented policies and affirmative action as a duty of the state and society in the Brazilian constitutional order

9.3 The policies of affirmative action in court: analysis of the Brazilian Supreme Court decisions

9.3.1 Some general remarks: the public hearing and the major arguments for and against affirmative action

9.3.2 Brief presentation of the Supreme Court decisions and the most important opinions of the different Judges.

9.4 Evaluation of affirmative action policies and programmes: challenges and perspectives

10. Affirmative action in Nigeria Chioma Kanu Agomo

10.1 Introduction 229

10.2 General background .... - _ _ _ _ - 2 - 2 - 230

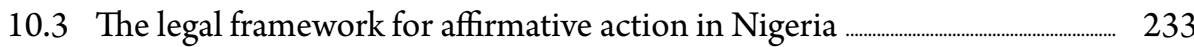

10.3.1 Rationale for affirmative action ................ 233

10.3.2 The Federal Character Commission ...___________... 235

10.4 Gender and affirmative action ...._. _ _ _ _ _ _ _ _ _ _ _ _ 240

10.4.1 Legal and policy framework for gender equality . _ _ _ _ _ _... 241

10.4.2 Some legal and policy measures on affirmative action ...._. _...... 242

10.4.3 CEDAW and affirmative action ....__ _ _ _ _... 244

10.4.4 Gender and employment ... _ _ _ _ _ _ _... 245

10.4.5 Discriminatory practices in the public service ...___ _ _... 247

10.4.6 Gender and access to health care ............... 248

10.4.7 Gender, political representation and participation in governance ...._........ 250

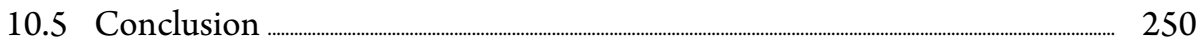


11. Restraint, DEFERENCE AND REASONABLENESS: AFFIRMATIVE ACTION IN SOUTH Africa ............. 253

Ockert Dupper

11.1 Introduction 253

11.2 Affirmative action and the approach of the Constitutional Court 255

11.3 Section 9(2): internal criteria 257

11.3.1 Stage ONE: Does the measure target persons or categories of persons who have been disadvantaged by unfair discrimination?

11.3.2 Stage TWO: Is the measure designed to protect or advance such persons or categories of persons?

11.3.3 Stage THREE: Does the measure promote the achievement of equality?

11.4 Concluding remarks 278

INDEX 281 


\title{
LIST OF CONTRIBUTORS
}

\author{
Chiomo Kanu Agomo \\ Professor of Law, University of Lagos (Nigeria)
}

Moshe Cohen-Eliya

Dean and Professor of Law, College of Law and Business, Ramat Gan (Israel)

\section{Ockert Dupper}

Research Officer, International Labour Organization (ILO),

Geneva (Switzerland);

Extraordinary Professor of Law, Stellenbosch University (South Africa)

\section{Alex Graser}

Professor of Law, University of Regensburg (Germany)

\section{Bob Hepple}

Former Master of Clare College, Cambridge;

Emeritus Professor of Law, University of Cambridge (UK)

\section{Mario Santiago Juárez}

Professor of Law, National Autonomous University of Mexico (Mexico)

\section{Hwok-Aun Lee}

Senior Lecturer, Department of Development Studies, University of Malaya (Malaysia)

\section{Kamala Sankaran}

Professor, Faculty of Law, University of Delhi (India)

\section{Ingo Sarlet}

Professor of Law, Pontifical Catholic University, Rio Grande Do Sul (Brazil)

\section{Tzehainesh Teklè}

Senior Programme Officer, International Training Centre of the International Labour Organisation (ITC-ILO), Turin (Italy)

\section{Ana Carolina Alfinito Vieira}

Researcher, Max Planck Institute for the Study of Societies, Cologne (Germany) 


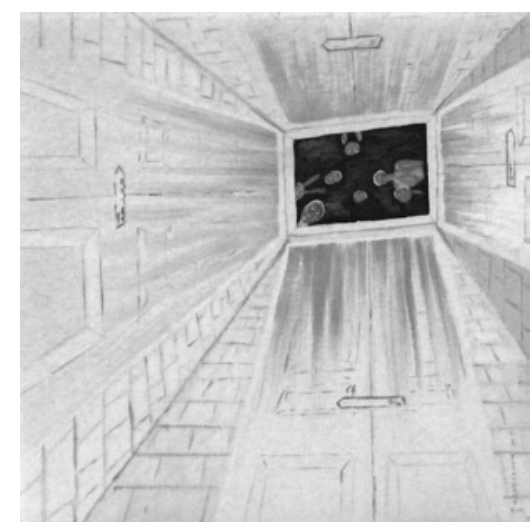

\title{
PREFACE
}

\author{
Ockert Dupper \\ Kamala Sankaran
}

This publication has its genesis in a project entitled 'Affirmative Action: A Comparative Study' that was funded by the Stellenbosch Institute of Advanced Study (STIAS) at the Stellenbosch University, South Africa. In 2009, STIAS hosted an international workshop on the topic, and invited a number of international scholars to consider a topic that had emerged as one of the most controversial and divisive issues in post-apartheid South Africa. Ten years after affirmative action had become part of the legal landscape in South Africa, it was felt that a range of diverse perspectives and experiences could enrich and contribute to the South African debate on the topic.

The volume examines how countries with diverse populations have grappled with the ideas of equality, discrimination, and particularly, the use of affirmative action measures to achieve equality. Giving preference to particular groups in education, in government jobs, in allocation of government contracts or in provision of basic services are all forms of affirmative action considered in this book. For the purpose of this project, we have placed the focus on a number of countries of the global South, 
namely South Africa, Nigeria, India, Malaysia, Brazil, Mexico, and Israel. The choice of jurisdictions was informed by two considerations. The first relates to the dearth of studies on affirmative action in these jurisdictions. Although affirmative action in India, South Africa and Malaysia has been the subject of close study for some time now, the same cannot necessarily be said of Brazil, Mexico and Israel. This alone sets the volume apart from numerous other studies that have focused primarily on the experience of countries of the North (such as the US, Canada and Member States of the EU). In the second place, affirmative action in the countries under review cover a range of different beneficiary groups, namely women (South Africa, Nigeria, India and Israel), disadvantaged groups based on race/colour (South Africa and Brazil), disadvantaged minorities based on religion and nationality (Israel), disadvantaged classes or castes (India) and disadvantaged ethnic groups (Nigeria and Malaysia). This enabled the researchers to study the impact of affirmative action in very different contexts and to determine the advantages and disadvantages of using gender, race, religion, nationality, caste (or class) and ethnicity as the basis of redress measures.

The book consists of two parts. Part 1 considers the topic from a comparative, theoretical and international perspective, and sets the scene for Part 2, which contains all the national perspectives. The introductory chapter by Ockert Dupper critically examines the efficacy of affirmative action as a redistributive strategy and the limits on its transformative capacity. Using examples from multiple jurisdictions, he notes that while some socio-economic benefits have been provided to the disadvantaged, affirmative action may continue to be used in these countries for some time to come. Bob Hepple examines the extent to which democratic participation is present in the decision to adopt affirmative action policies and their design. Stressing the need to tailor affirmative action policies to ensure a good fit with the goals, he points out that developing a 'reflexive' system is part of a broader democratic transformation in some countries.

In their contribution, Ana Alfinito Vieira and Alex Graser identify the critical objections against affirmative action and offer convincing arguments to counter them. In doing so, they contextualise affirmative action policies within the broader spectrum of equality-oriented policies, review the potential objections, and consider these from different disciplinary perspectives. One of the primary objections against affirmative action is that unlike other equality-oriented policies (such as a progressive tax system that finances social benefits to the needy), affirmative action places a disproportionate burden on certain individuals and does not spread it across the entire polity within which the policy operates. This issue also comes under the spotlight in some of the specific country chapters - for example, Malaysia, Mexico and South Africa. Tzehainesh Teklès chapter provides a comprehensive international perspective on affirmative action (or 'special measures' as the concept is referred to 
in international law). She considers the way in which the international human rights system and the international labour law system have approached the topic, and while she acknowledges that the international perspective on affirmative action has evolved and continues to evolve, she argues that more coherence is required both within and between the international human rights and the international labour law systems.

Part 2, which contains the national perspectives, starts with Moshe Cohen-Eliya's contribution on Israel. He argues that there is a duty to provide appropriate representation of women and minorities in public life. Cohen-Eliya analyses the development of case law which indicates that pursuing such a duty for appropriate representation in certain groups does not run counter to Pareto optimality and notions of efficiency in public life. Hwok-Aun Lee traces the development of Malaysia's unique affirmative action programmes for the majority Malay population, the Bumiputeras, that have been in place since the country's independence. His chapter examines the economic and political impact of such programmes on Malays vis-à-vis other groups and the challenges they pose for national unity. Kamala Sankaran's chapter examines the constitutional and legal basis that enables the government to institute affirmative action in public employment and education for 'backward' classes of persons. She analyses the difficulties in identifying beneficiaries for such programmes, particularly when there are intersectionalities of religion, caste and gender.

The contribution on Mexico authored by Mario Santiago Juárez differs somewhat from other contributions in this volume in that it does not describe or discuss a well-developed and entrenched affirmative action programme, but instead provides arguments in favour of bolstering the current weak and underdeveloped efforts to redress the disadvantages suffered by the indigenous population in Mexico. He indicates that centuries of discrimination and exclusion have left an indelible mark on the indigenous population, resulting in distinct disadvantages in all spheres of life, and that affirmative action in favour of indigenous people in Mexico is not only justified, but should be significantly strengthened and expanded. Ingo Wolfgang Sarlet focuses on affirmative action in the form of specific race-based quotas in higher education in Brazil and traces how judicial review has shaped these programmes. He also analyses the outcomes of such programmes to assess how far they have contributed in making higher education more equitable.

In her chapter on Nigeria, Chioma Kanu Agomo argues that while affirmative action measures have to some extent addressed disadvantages based on ethnicity in that country, it has left a critical group - women - out of the process. While affirmative action on the basis of gender takes place under the umbrella of specific legislative programmes, she argues that women as a distinct group ought to be accommodated 
under the Federal Character Principle. Since 1994, the Federal Character Principle has based affirmative action on ethnic origin, and has been bolstered by the establishment of the Federal Character Commission (FCC), a body charged with overseeing its implementation.

Finally, Ockert Dupper's chapter on South Africa reflects on the general approach adopted by the Constitutional Court to determine whether an affirmative action measure falls within the constitutional provision that explicitly authorises such measures. He indicates that while the general approach can be described as one of restraint and deference in recognition of the need to redress past social injustices, South African courts have nevertheless retained a role for themselves that draws a careful line between deference to the judgment of the executive (or, in the employment context, the employer) and appropriate judicial supervision.

We would like to thank STIAS and its Director, Prof. Hendrik Geyer. STIAS provided not only generous financial support, but also a unique and serene setting to allow many of the authors in this volume to study, converse and develop the ideas that eventually became the individual chapters contained in this book. We would also like to thank Prof. Gerhard Lubbe, the former Dean of the Faculty of Law of Stellenbosch University, and the current Dean, Prof. Sonia Human, for supporting the project in both financial and other terms. The chapter on Mexico was expertly translated from Spanish into English by Marta Behar, and Helena Janisch provided exceptional editorial and technical assistance. Both deserve our sincere thanks. Thanks are also due to Sumedha Sarkar for helping with the copy-editing of this manuscript. Finally, we owe a debt of gratitude to Johannes Richter from SUN MeDIA Stellenbosch for his patience, persistence and professionalism in seeing the project through to publication. 


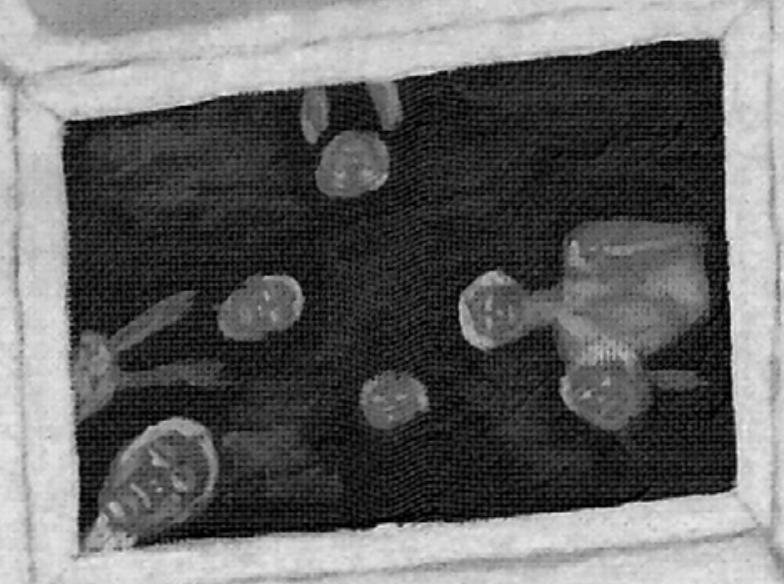

PART I

COMPARATIVE,

THEORETICAL AND

INTERNATIONAL PERSPECTIVES 


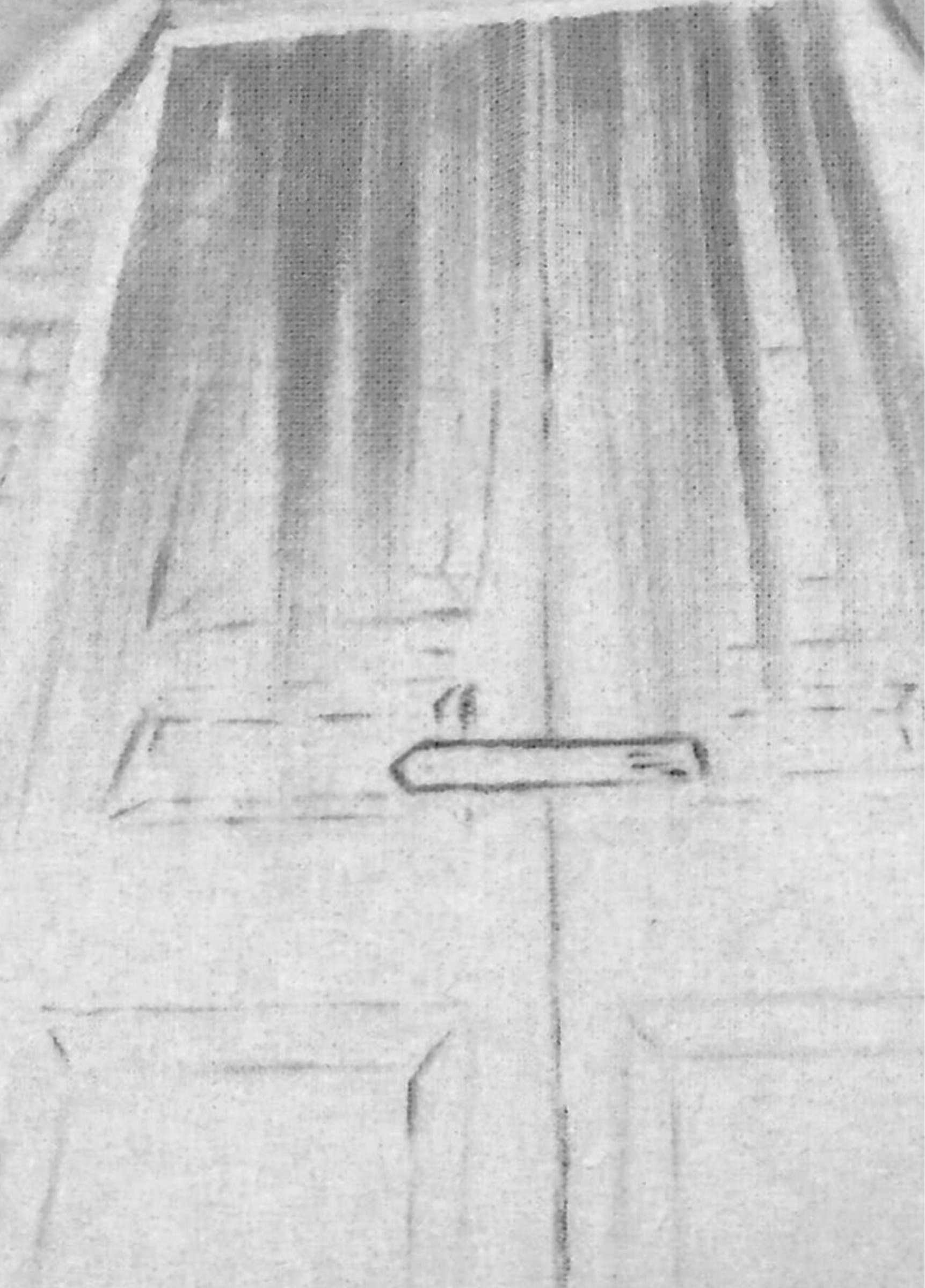




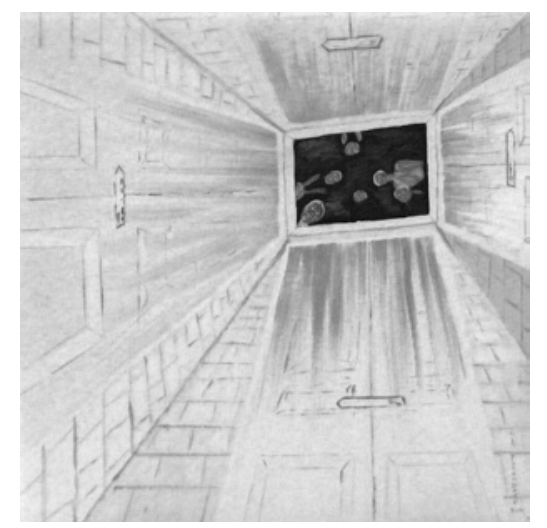

\title{
AFFIRMATIVE ACTION IN COMPARATIVE PERSPECTIVE
}

\author{
Ockert Dupper
}

\section{I.I Introduction}

Recent decades have seen an increasing number of countries acknowledging differences among their populations and developing strategies to deal with such inequalities. The spread of democratic and human rights ideas in the twentieth century has meant that the notion of a homogenous population - the idea of onenation, one-people - has had to be replaced by the notion of a multicultural, diverse nation, and of individuals and groups who can each command their right to equal concern and respect from government and each other. In dealing with diversity and difference, many countries have moved from the relatively passive idea of nondiscrimination to a more pro-active strategy of affirmative action. Variously termed in different countries, ${ }^{1}$ affirmative action refers to a variety of practices, ranging

1 For instance, the following terms are some of those used around the world: 'Positive action' (European Union); 'fair participation' or 'fair access' (Northern Ireland), 'employment equity' or 'equitable representation' (Canada); 'compensatory discrimination,' 'special treatment,' 'protective discrimination,' 'progressive discrimination' and 'reservations' (India). 
from preferential treatment in the award of jobs, places at university or government contracts, to active recruitment and training of members of disadvantaged groups. Affirmative action, thus understood, is practised in many countries. ${ }^{2}$

Preferential treatment amounts to what has been called strong affirmative action, a policy that should be distinguished from weak affirmative action, which merely involves efforts to ensure equal opportunity for members of groups that have been subject to discrimination. ${ }^{3}$ Examples of such efforts are active recruitment of qualified applicants from the formerly excluded groups, special training programmes to help them meet the standards for appointment, and measures to ensure that they are fairly considered in the selection process. Strong affirmative action is undoubtedly considerably more controversial than its weaker counterpart. Most people, I assume, would agree that what is referred to as 'weak affirmative action' is a good policy - essentially fair, just and worth its cost in time and energy. Put into practice, it ensures that members of these groups who would qualify for positions under normal circumstances are not overlooked. European Community Law is a paradigmatic example of a body of law that embraces 'weak' as opposed to 'strong' affirmative action. The approach is best exemplified in the decision of the European Court of Justice (ECJ) in the case of Kalanke. ${ }^{4}$ In Kalanke, the court had to decide whether a 'tie-break' policy pursued by the City of Bremen was allowed under EC law. The policy in question provided that if a man and a woman with the same qualifications applied for promotion, women were to be given priority to the extent that they were under-represented in that job-grade. The policy was held to be irreconcilable with the Equal Treatment Directive. The court stressed that it is permissible to take measures that give an advantage to women with a view to

2 Affirmative action measures as a strategy to achieve equality have been adopted in several demographically diverse countries (see M Tushnet, 'United States: Supreme Court Rules on Affirmative Action', International Journal of Constitutional Law, Vol. 2 (2004): 158). It is important to recognise that the policy is flexible and adaptive and dependent on the specific context for its form and the choice of beneficiary groups - for example, women (European Union), black people (South Africa and Brazil), disadvantaged minorities based on religion and nationality (Israel and Northern Ireland), disadvantaged classes or castes (India) and disadvantaged ethnic minorities (for example, Nigeria and Ethiopia). As Sachs points out, '(affirmative action) is not a fixed formula for governmental action transportable from one country to another, nor is it a precise constitutional or legal arrangement of universal application.' A Sachs, 'Foreword' in Race and Inequality: World Perspectives on Affirmative Action, ed. E Kennedy-Dubourdieu (Hampshire, UK: Ashgate, 2006), p.x.

3 See T Nagel, 'A Defense of Affirmative Action', in Ethical Theory and Business, eds.

T Beauchamp \& N Bowie (Englewood Cliffs, NJ: Prentice-Hall, 1988), 345; and T Scanlon, 'Equality on Divided Societies: A Normative Overview' (unpublished manuscript on file with the author), 7.

4 Kalanke ECJ 17-10-1995, C-450/93, [1995] ECR I-3051, [1995] IRLR 660 ECJ. 
improving their ability to compete equally with men in the labour market. However, once that is achieved, individual merit again becomes paramount. Thus, any policies 'which guarantee women absolute and unconditional priority for appointment or promotion go beyond promoting equal opportunities and overstep the limits of the exception in Article 2(4) of the Directive.'

In contrast, strong affirmative action often evokes a charge of unfairness because, as critics argue, it amounts to a departure from the ideal that people should be judged as far as possible on the basis of individual characteristics that are relevant to the situation, rather than on involuntary group membership, especially when based on arbitrary criteria such as skin colour or sex. ${ }^{5}$

Support for affirmative action is found not only in the national law of various countries, but also in international law. ${ }^{6}$ For example, the International Covenant on Economic, Social and Cultural Rights (ICESCR) requires States Parties to take concrete steps to ensure the full realisation of the rights guaranteed by the Covenant. Article 2(1) of the ICESCR provides:

Each State Party to the present Covenant undertakes to take steps, individually through international assistance and cooperation, especially economic and technical, to the maximum of its available resources, with a view to achieving progressively the full realization of the rights recognized in the present Covenant by all appropriate means, including particularly the adoption of legislative measures. ${ }^{7}$

Direct support for affirmative action can be found in the General Comment No. 5 of the Committee on Economic, Social and Cultural Rights (CESCR). It provides that the adoption of 'special measures intended to bring about de facto equality for men and women and for disadvantaged groups is not a violation of the nondiscrimination [principle].8 This is a significant statement, because in denoting that affirmative action measures do not violate non-discrimination norms provided that the goal is to ensure de facto equality for disadvantaged groups, it reflects a substantive, rather than formal, notion of equality. The CESCR comments on State Party reports similarly display support for affirmative action. For example, in a report on Guatemala's compliance, the Committee recommends affirmative

5 See O Dupper, 'In Defence of Affirmative Action in South Africa', South African Law Journal 121 (2004): 187-215 at 195.

6 For a detailed exposition, see Global Rights, Affirmative Action: A Global Perspective (2005).

7 International Covenant on Economic, Social and Cultural Rights, 993 UNTS 3, 6 ILM 360, (ICESCR) art. 2(1).

8 CESCR, General Comment No. 5: Persons with disabilities (Eleventh session, 1994), UN Doc E/1995/22 at 19 (1995), para 9. 
action measures to benefit indigenous communities. ${ }^{9}$ In addition, Brazil's recent adoption of affirmative action in favour of 'Afro-Brazilians, in particular women' is commended by the Committee. ${ }^{10}$

Two other General Comments also deserve attention, namely General Comment No. 16 on 'The Equal Right of Men and Women to the Enjoyment of All Economic, Social and Cultural Rights' and General Comment No. 20 on 'Non-Discrimination on Economic, Social and Cultural Rights'. General Comment No. 16 sets out a number of principles with regard to 'temporary special measures', the most significant of which arguably are (i) the recognition that the principles of equality and non-discrimination 'by themselves, are not always sufficient to guarantee true equality', meaning that the objective of these measures is the realisation of de facto or substantive equality; and (ii) the affirmation that such measures shall not be considered as discrimination as long as they are terminated once the objective of de facto equality is achieved.

While General Comment No. 20 confirms that special measures are a means to redress de facto and systemic discrimination and that they should be discontinued once substantive equality has been achieved, it goes further than previous General Comments in not only encouraging such measures, but making them mandatory in certain cases:

In order to eliminate substantive discrimination, States parties may be, and in some cases are, under an obligation to adopt special measures to attenuate or suppress conditions that perpetuate discrimination. ${ }^{11}$

While the different notions of equality will not be canvassed in this contribution, ${ }^{12}$ and while it is acknowledged that parameters of the concept of substantive equality are ambiguous, ${ }^{13}$ it can safely be stated that one of the main advantages of substantive

9 CESCR, Consideration of Reports Submitted by States Parties Under Art. 16 and 17 of the Covenant, Guatemala (1996), para 27 (as cited in Global Rights, Affirmative Action: A Global Perspective (2005), 10).

10 Conclusions and recommendations of the CESCR, Brazil, UN Doc E/C.12/1/Add.87 (2003).

11 General Comment No. 20, para 9. For a comprehensive discussion of the General Comments of the CESCR in respect of special measures (or affirmative action), see Chapter 4 of this book: Tzehainesh Teklè, 'An International Perspective on Affirmative Action.'

12 For an excellent treatment of this topic, see Sandra Fredman, Women and the Law (Oxford: Clarendon Press, 1997) and Sandra Fredman, Discrimination Law (Oxford: Oxford University Press, 2011). See also Bob Hepple, 'Work, Empowerment and Equality', public lecture, International Institute for Labour Studies, Geneva, November 2000.

13 What precisely is meant by the notion of 'substantive equality' will not be explored in this chapter, save to say that I acknowledge that equality is an elusive notion (see N Bamforth, 
equality over formal equality is its asymmetry. This means that it is not race or gender or disability per se that is regarded as problematic, but the detriment and disadvantage associated with disadvantaged groups such as black people, women, or people with disabilities. ${ }^{14}$ This asymmetry means that equality is not necessarily breached by measures that specifically use race or gender or disability as a means of distributing benefits and burdens. Indeed, provided that they aim to benefit the subordinated group, specific measures that take race or gender or disability into account may be necessary to achieve substantive equality. ${ }^{15}$ Thus, whereas formal equality would regard affirmative action as a breach of equality or an exception to a notion of formal equality, substantive equality views such programmes as a means to achieve equality.

This understanding of affirmative action has, for example, been endorsed by the South African Constitution, which makes express provision for affirmative action as a means of achieving substantive equality. According to section 9(2):

Equality includes the full and equal enjoyment of all rights and freedoms. To promote the achievement of equality, legislative and other measures designed to protect or advance persons, or categories of persons, disadvantaged by unfair discrimination may be taken. ${ }^{16}$

It is arguable that a similar conception of equality - one that regards affirmative action measures as a means to promote the achievement of substantive equality rather than as an exception to a notion of formal equality - underpins the legislative design

'Conceptions of Anti-Discrimination Law', Oxford Journal of Legal Studies 24 (2004): 693 at 703), and that our numerous appeals to (substantive) equality are often an appeal to some deeper normative value (such as human dignity, redistribution, participative democracy, etc.) rather than to the value of equality (in this regard see, for example, J Raz, The Morality of Freedom (Oxford: Oxford University Press, 1986), 235; and E Holmes, 'Anti-Discrimination Rights Without Equality', The Modern Law Review 68 (2005): 175).

14 These are the three 'designated groups' identified in South Africa's Employment Equity Act 55 of 1998.

15 See S Fredman, 'Facing the Future: Substantive Equality Under the Spotlight', University of Oxford Legal Research Paper Series (57/2010) 12, available at SSRN: <http://ssrn.com/ abstract=1649991 >; originally published in Equality in the Workplace: Reflections from South Africa and Beyond, eds. O Dupper \& C Garbers (Cape Town: Juta, 2009), 14-39. References are to the former.

16 Constitution of the Republic of South Africa, 1996. See also Minister of Finance and others $v$ Van Heerden 2004 (11) BCLR 1125 (CC), paras 26 and 27 (and the authorities referred to there). 
and jurisprudence in India, ${ }^{17}$ Canada ${ }^{18}$ and the European Union. ${ }^{19}$ On the other hand, the opposite is true as far as the approach to affirmative action in the United States is concerned. The absence of specific authorisation for affirmative action or of a provision exempting affirmative action programmes from the general equality provision in the US Constitution, together with a general hostility to the ideals of substantive equality that is characteristic of rights theories in the United States, ${ }^{20}$ have combined to severely restrict affirmative action - in particular affirmative action based on race. This has led one commentator to speculate that the drafters of post-1950 constitutional bills of rights may have learned from, inter alia, the US

17 See sections 15(4) and 16(4) of the Indian Constitution. Despite initial arguments to the contrary, these provisions (which mandate the State to implement special measures to advance 'socially and educationally backward classes' or for the 'Scheduled Castes and Scheduled Tribes') are generally considered to be measures that advance substantive equality rather than a proviso or an exception to the principle of equal treatment. See, for example, Triloki Nath Tiku v State of Jammu and Kashmir, AIR 1967 SC 1283 at 1285. For a detailed discussion, see M Galanter, 'Symbolic Activism: A Judicial Encounter with the Contours of India's Compensatory Discrimination Policy', in Judges and the Judicial Power: Essays in Honour of Justice V.R. Krishna Iyer, eds. R Dhavan, R Sudarshan \& S Khurshid (London: Sweet \& Maxwell; Bombay: N.M. Tripathi, 1985), 229-49.

18 See Section 15(2) of the Charter of Rights and Freedoms (Part I of the Constitution Act, 1982, being Sch B to the Canada Act 1982 (UK), 1982, c11), which provides that the equal treatment guarantee contained in section 15(1) 'does not preclude any law, program or activity that has as its object the amelioration of conditions of disadvantaged individuals or groups including those that are disadvantaged because of race, national or ethnic origin, colour, religion, sex, age or mental or physical disability'. See also R. v Kapp 2008 SCC 41. For a detailed discussion of the tension between formal and substantive equality in the Canadian context, see J Fudge 'The Supreme Court of Canada, Substantive Equality, and Inequality at Work', in Equality in the Workplace, eds. O Dupper \& C Garbers (Cape Town: Juta, 2009), 40-60.

19 Increasing support for the notion of substantive equality is evident in the Treaty of Amsterdam and in the most recent equality directives. Article 141(2) of the Treaty Establishing the European Community reads as follows: 'With a view to ensuring full equality in practice between men and women in working life, the principle of equal treatment shall not prevent any Member State from maintaining or adopting measures providing for specific advantages in order to make it easier for the under-represented sex to pursue a vocational activity or to prevent or compensate for disadvantages in professional careers.' Similar wording is contained in the Directives: see Article 2(8) of Directive 2002/73/EC of 23 September 2002 ('Equal Treatment Directive'); Article 7 of Directive 2000/78/EC of 27 November 2000 ('Employment Equality Directive'); and Article 5 of Directive 2000/43/EC of 29 June 2000 ('Race Directive'). See also H Collins, 'Discrimination, Equality and Social Inclusion', Modern Law Review 66 (2003): 16-43 at 17.

20 M Horwitz, 'Rights', Harvard Civil Rights-Civil Liberties Law Review 23 (1988): 393-406 at 405 . 
experience that a general equality provision (such as the equal protection clause of the US Constitution) might be interpreted to bar affirmative action programmes, and that they should include specific provisions dealing with affirmative action if they wish to ensure their constitutionality. ${ }^{21}$

As mentioned above, one of the main characteristics of a substantive notion of equality is its asymmetry, meaning that it acknowledges the connection between status (race, gender etc.) and (socio-economic) disadvantage. Affirmative action, in facilitating substantive equality, specifically attaches socio-economic benefits such as jobs or government contracts to those disadvantaged by status. However, as Sandra Fredman has pointed out, 'the power of this insight is matched by the challenges it raises. ${ }^{22}$ These challenges, Fredman points out, relate to the interaction between the status and disadvantage, and to the manner in which each is to be formulated. ${ }^{23}$

In this chapter, a number of these challenges will be explored. The first challenge relates to one of the central features of affirmative action - namely, the aim to redress discrimination along group lines. One of the dangers of doing this is that it inevitably makes the group identities (such as race, sex, caste) seem all the more real and entrenched. On the other hand, however, denying the significance of group-based experiences leaves legacies of harm and stereotyping in place. Martha Minow captures this paradox very neatly: 'When are the uses of group categories a valuable remedy, and when a further mistake?' 24 This question will be addressed in section 1.2 of this chapter.

The second, and related challenge, is the delineation of the beneficiary groups. The familiar charge often levelled against affirmative action is that it is both under- and over-inclusive: over-inclusive because some members of the disadvantaged groups have not experienced disadvantage, and under-inclusive because individuals of groups other than those targeted have suffered disadvantage. ${ }^{25}$ How have different jurisdictions dealt with this criticism? While it is clear that there must be some correlation between the beneficiaries and the previous disadvantage it is meant to address, demarcating beneficiary groups has been done with varying degrees of

21 See Mark Tushnet, 'United States: Supreme Court Rules on Affirmative Action', International Journal of Constitutional Law 2(1) (2004): 158 at 173.

22 See Fredman, 'Facing the Future', 38-9.

23 Ibid., 39

24 Martha Minow, Not Only for Myself: Identity, Politics and the Law (New York: New Press, 1997), 9.

25 Elizabeth Anderson, The Imperative of Integration (Princeton: Princeton University Press, 2010), chapter 7. See also Fredman, 'Facing the Future'. 
precision around the world. The manner in which different jurisdictions have dealt with the demarcation of beneficiaries will be discussed in section 1.3 of this chapter.

Thirdly, because affirmative action attaches socio-economic benefits to those disadvantaged by status, it raises the questions as to its impact. Some critics point out that while affirmative action addresses the maldistribution of privileged positions, it leaves the underlying mechanisms that generate the maldistribution intact, thereby limiting its impact. As Nancy Fraser writes, 'because [affirmative action] leave[s] intact the deep political-economic structures that generate injustice, [it] must make surface reallocations again and again.26 The question of the impact of affirmative action will be discussed in section 1.4.

Finally, it is widely acknowledged that affirmative action is a temporary measure with a specified goal or goals. Once these are achieved, the case for affirmative action is correspondingly weakened and continued efforts to implement affirmative action might well be regarded as discriminatory. The question of the duration of affirmative action programmes is therefore closely tied up with the justification that is offered for its existence. If the justification is purely backward-looking, as a form of compensation for past discrimination, then a convincing argument may exist for establishing a specific expiry date for its demise. ${ }^{27}$ However, affirmative action can also be justified in a more forward-looking manner, ${ }^{28}$ placing less emphasis on the injustices of the past. These goals (for example, integration, diversity, equitable representation) are more amorphous and make the establishment of a specific expiry date difficult, if not impossible. The question of justification and the termination of affirmative action measures will be discussed in section 1.5. Section 1.6 will contain some concluding remarks.

\subsection{Affirmative action and social identity}

One of the central features of affirmative action is to redistribute social goods (such as jobs and places at university) along group lines. However, one of the dangers in this is that it may promote rather than undermine the differentiation of social groups. It may, as Fredman points out, 'freeze' individuals into the very

26 Nancy Fraser, 'Social Justice in the Age of Identity Politics: Redistribution, Recognition, and Participation', Tanner Lectures on Human Values (1996): 45-6.

27 See E Anderson, 'Integration, Affirmative Action, and Strict Scrutiny', New York University Law Review 77 (2002): 1195 at 1251.

28 The distinction between backward-looking and forward-looking does not imply that all justifications for affirmative action are either located in the past or the future. Often, they may also be located in (or informed by) what Elizabeth Anderson terms 'present-oriented concerns', such as addressing the current position of disadvantaged groups. See Anderson, The Imperative of Integration, chapter 7. 
status identity that substantive equality aims to eliminate. ${ }^{29}$ In addition, it may also perpetuate stereotypes. This is because '[v]irtually any politics of redistribution, be it affirmative or transformative, will have some recognition effects, whether intended or unintended, explicit or implicit, overt or subliminal. ${ }^{30}$ Redistributive proposals, Nancy Fraser writes, have 'an irreducible expressive dimension' and inevitably affect the status and social identities of everyone concerned, especially those who are cast as the beneficiaries. ${ }^{31}$ Both these aspects will be discussed in turn.

To illustrate the potential danger of the entrenchment of categorical thinking, the South African example provides some valuable insights. The South African Employment Equity Act, ${ }^{32}$ which regulates affirmative action in the workplace, defines 'black people' (one of the groups to be advanced in terms of the policy) as all those previously classified as 'African', 'Coloured' and 'Indian', meaning that it reproduces what are in fact the same racial categories and divisions that underpinned apartheid. ${ }^{33}$ This has fittingly been called 'one of the great paradoxes of South Africa's constitutional transition. ${ }^{34}$ Critics have alluded to the dangers inherent in replicating apartheid's racial grid in the pursuit of affirmative action. ${ }^{35}$ One of the consequences of making these racial categories salient is that it gives them, to borrow Melissa Nobles's phrase, an 'illusion of ordinariness', which prevents a critical and reflective consideration of the social meaning of the existence of races. ${ }^{36}$ There is no need to question apartheid's race allocations. Race - especially the idea that South African society is comprised of four distinct races - simply becomes a

29 Fredman, 'Facing the Future', 50.

30 Fraser, 'Social Justice in the Age of Identity Politics', 47.

31 Ibid.

32 Act 55 of 1998.

33 See the Population Registration Act 30 of 1950, s 1 (xv), (x) and (iii). See also D Posel, 'What's in a name? Racial categorizations under apartheid and their afterlife', Transformation 47 (2001): 50, 56.

34 H Botha, 'Equality, Plurality, and Structural Power', South African Journal on Human Rights (2009): 1 .

35 See, for example: Ockert Dupper, 'Affirmative Action: Who, How, and How Long?', South African Journal on Human Rights (2008): 425-44; N Alexander, 'Affirmative Action and the Perpetuation of Racial Identities in Post-Apartheid South Africa', lecture delivered at the East London Campus of the University of Fort Hare, 25 March 2006: 19; Posel, 'What's in a name? Racial categorizations under apartheid and their afterlife', 50; Gerhard Maré, 'Race Counts in Contemporary South Africa', Transformation 47 (2001): 75; Kristina Bentley, 'Rethinking the Ultimate Goal of Affirmative Action: Who and What is it for?', paper prepared for the 61st Harold Wolpe Memorial Trust Open Dialogue, 19 July 2007.

36 Melissa Nobles, Shades of Citizenship: Race and the Census in Modern Politics (Stanford: Stanford University Press, 2000), 180. 
given in the manner in which South Africans think of society. It becomes a habit of thought and experience. In addition, critics argue, it gives legitimacy to thoroughly discredited bioculturalist categorisations of race, which may be one of the more disturbing ironies of post-apartheid redress. ${ }^{37}$

Those who defend the use of racial identification in the project of transformation point to the fact that after decades of formal racial classifications, on the basis of which some of South Africa's most fundamental social goods such as employment, land, housing and education were distributed, it is only to be expected that racial categories (African, Coloured, Indian and White) will continue to be used in South African society for some time to come. These racial groups were in effect created by the original unjust practice of racial discrimination, and to deny that fact (by pursuing a policy of colour blindness) would be to deny a social reality - a reality that morally should not be ignored as long as the wrongs that created it have not yet been rectified. ${ }^{38}$ This standard argument is succinctly captured in Justice Blackmun's well-known aphorism in the Bakke-decision:

In order to get beyond racism, we must first take account of race. There is no other way. And in order to treat some persons equally, we must treat them differently. 39

While defenders in both South African and the United States assert the relevance of the current social reality on which race-based redress policies is based, few would deny that the perpetuation of racial consciousness has harmful effects. What they do assert, however, is that the harm of ignoring this reality in South Africa (and the US) currently outweighs the harm of perpetuating race consciousness. ${ }^{40}$ Nonetheless, even if this view is accepted, it does not relieve us of the burden to ensure that, in the words of former Justice Sachs of the South African Constitutional Court, 'the baby

37 See Posel, 'What's in a name? Racial categorizations under apartheid and their afterlife, 50,56 . Studies also indicate that people still overwhelmingly claim a racialised identity as their primary means of describing themselves (see A Zegeye, I Liebenberg \& G Houston, 'Resisting Ethnicities from Above: Social Identities and Democracy in South Africa', in Democracy and Governance Review: Mandela's Legacy 1994-1999, eds. Y Muthien, M Khosa \& B Magubane (Pretoria: HSRC Publishers, 2000), 164).

38 See Ockert Dupper, 'In Defence of Affirmative Action in South Africa', South African Law Journal 121 (2004): 187 at 213. See also See PW Taylor, 'Reverse Discrimination and Compensatory Justice', Analysis 33 (1973): 81.

39 Regents of Univ. of Cal. $v$ Bakke, 438 US 265, 407 (1978) (Blackmun J dissenting).

40 See Dupper, 'In Defence of Affirmative Action in South Africa', 187. For a similar argument in the American context, see David B Wilkins, 'Two Paths to the Mountaintop? The Role of Legal Education in Shaping the Values of Black Corporate Lawyers', Stanford Law Review 45 (1993): 2004. 
of non-racialism is not thrown out with the bath-water of remedial action.'41 There may come a point where the benefits of race-based redress no longer outweigh the harm of perpetuating race consciousness. If it is agreed that identities are not given but constructed, the State has a particular responsibility to reshape the way in which people identify themselves.

For critics in South Africa and the US, race consciousness militates against the vision of a society in which race will have much less salience than it did during decades of formal racial classifications. There is a recognition that the race consciousness inherent in affirmative action may work against the vision of that ideal society. In Brazil, on the other hand, the recent introduction of affirmative action measures along racial lines did not occur against the background of a practice of formal racial classifications. In fact, Brazil had prided itself for years on being a multi-hued 'racial democracy'. Despite having the largest Afro-descendent population in the world outside of the African continent, Brazil had avoided the state-sponsored segregation of South Africa and the US. ${ }^{42}$ To many, the introduction of affirmative action in favour of black people (pretos) and brown people (pardos) ${ }^{43}$ in the admission to state universities threatens the very core of Brazilian national identity, "which was built around ideas of a melting-pot society and successful integration of races and cultures. ${ }^{\prime 4}$ Nevertheless, the reality is that Brazilian society is characterised by a distinct racial hierarchy in which black people ${ }^{45}$ do worse than white Brazilians on all social indicators. ${ }^{46}$ Affirmative action was introduced to address these disadvantages. However, the State could not - as was the case in South Africa - base the policy of affirmative action on previous official racial classifications. The Brazilian state had always been unwilling to define 'races' in Brazil, and as a result, black people in Brazil

41 Minister of Finance and others $v$ Van Heerden 2004 (11) BCLR 1125 (CC) at para 137.

42 See Mala Htun, 'From "Racial Democracy" to Affirmative Action: Changing State Policy on Race in Brazil', Latin American Research Review 39 (2004): 61. See also Sérgio Da Silva Martins, Carlos Alberto Medeiros \& Elisa Larkin Nascimento, 'Paving Paradise: The Road from "Racial Democracy" to Affirmative Action in Brazil', Journal of Black Studies 34 (2004): 787; Leone Campos de Sousa \& Paulo Nascimento, 'Brazilian National Identity at a Crossroads: The Myth of Racial Democracy and the Development of Black Identity', International Journal of Politics, Culture and Society 19 (2008): 129.

43 Pardo, which literally means 'brown', is the official term used to refer to mixed-race individuals. See Campos de Sousa \& Nascimento, 'Brazilian National Identity at a Crossroads', 130.

44 Ibid.

45 Htun points out that 'black people' is now the most accepted generic term to use to refer to both black and brown people, and will be used as such in this article. See Htun, 'From "Racial Democracy" to Affirmative Action', 63.

46 Ibid. 
have a weaker 'racial consciousness' or identification of themselves as members of a distinct group, than people recognised as 'black' in the United States. ${ }^{47}$

Thus, while the introduction of affirmative action in Brazil does not run the risk of perpetuating an already existing strong racial consciousness (as is the case in South Africa and the US), it arguably has the potential to bolster current weak forms of racial consciousness. Ironically, critics of what became referred to as 'the myth of racial democracy' have insisted that a solution to actual inequality requires the development of a 'racial consciousness' among black Brazilians as a precondition for the formation of an effective political movement. ${ }^{48}$ As one commentator points out, it may yet be that the State will succeed (by means of affirmative action) where Afro-Brazilian movements have thus far failed - namely, in cementing a widespread racial consciousness among black Brazilians. ${ }^{49}$

Nevertheless, despite these differences between South Africa and the US on the one hand, and Brazil on the other, the common denominator remains race and the danger that affirmative action based on race can promote rather than undermine the differentiation of social groups by strengthening race consciousness. The dilemma can be captured as follows: while affirmative action as a redistributive policy seeks to 'level out differences' on the one hand, the 'normative power of the law lends fixity to racial categories. ${ }^{50}$ There thus remains a tension between trying to move beyond race on the one hand and developing practical strategies to redress the disadvantages based on race on the other hand.

Amy Gutmann may provide some guidance on how to resolve this seemingly irresolvable tension. She argues that one needs to distinguish between 'essentialist' race consciousness and 'contingent' race consciousness. ${ }^{51}$ Essentialist race consciousness is troubling because it is the kind of consciousness that makes race a mark of morally relevant differences between human beings. In contrast, contingent race consciousness means an awareness of how individuals are identified by superficial differences (such as skin colour and facial features), which then in turn serve as the basis for invidious discriminations and other injustices associated with

47 However, this assertion of a 'weak' racial consciousness has been challenged as being exaggerated. See Htun, 'From "Racial Democracy” to Affirmative Action', 64 and the studies referred to there.

48 Campos de Sousa \& Nascimento, 'Brazilian National Identity at a Crossroads', 133.

49 Htun, 'From "Racial Democracy" to Affirmative Action', 75.

50 Htun, 'From “Racial Democracy” to Affirmative Action', 85.

51 Amy Gutmann, 'Responding to Racial Injustice', in Color Conscious: The Political Morality of Race by K Anthony Appiah and Amy Gutmann (Princeton: Princeton University Press, 1996), 335. 
race. Were we to lack race consciousness of this contingent kind, as Gutmann points out, we would be blind to a basic source of social injustice. 'Just as some kinds of race-conscious policies are better than others from a moral point of view, so too are some kinds of race consciousness.' 52 It is arguable that affirmative action in South Africa, the US and more recently Brazil may contribute to race consciousness of this contingent type. However, this may be less of a danger than the risks inherent in ignoring reality.

While this part of the discussion has been devoted to race, the same concerns apply, for example, to caste. In India, disquiet has been expressed (and confirmed by studies) about indications that affirmative action (or 'reservations') entrenches caste identities. ${ }^{53}$ Despite the fact that the Indian Constitution has been described as 'egalitarian, casteless and classless', ${ }^{54}$ it expressly sanctions quotas for the so-called Scheduled Castes and Scheduled Tribes, and also provides for reservations for what is referred to as the 'Other Backward Classes' (OBCs). ${ }^{55}$ Although identification of the OBCs is based on a set of neutral (not related to caste) criteria such as social, educational and economic backwardness, caste nevertheless remains one of the criteria by which a group is initially identified. ${ }^{56}$ Evidence for the continued salience of caste among the OBCs can be found in the increasing number of caste associations that have been formed to demand their share of the reservations pie. ${ }^{57}$ The heightened demand for recognition as a 'backward class' is primarily driven by two considerations. In the first place, 'reservations' are absolute, meaning that

\section{Ibid.}

53 See Judith Heyer and Niraja Gopal Jayal, 'The Challenge of Positive Discrimination in India', Centre for Research on Inequality, Human Security and Ethnicity (CRISE) Working Paper No. 55 (February 2009): 17-18; Laura Dudley Jenkins, 'Race, Caste and Justice: Social Science Categories and Antidiscrimination Policies in India and the United States', Connecticut Law Review 36 (2004): 758; André Béteille, 'Caste, inequality and affirmative action', paper delivered at the International Institute for Labour Studies, Geneva (2002): 18, available at <http://www.oit.org/public/english/bureau/inst/download/andre.pdf > .

54 Ashwini Deshpande, 'Affirmative Action in India' in Race and Inequality: World Perspectives on Affirmative Action, ed. Elaine Kennedy-Dubourdieu (Aldershot: Ashgate Publishing, 2006), 63-76 at 72 .

55 For a more detailed discussion of affirmative action (or reservations) in India, see section 1.3 below.

56 In fact, in several states, OBCs have been defined 'mostly' in terms of caste. See Devanesan Nesiah, Discrimination with Reason: The Policy of Reservations in the United States, Indian and Malaysia (New Delhi: Oxford University Press, 1999), 66. See also Indra Sawhneyv Union of India, AIR 1993 SC 447.

57 See Dharma Khumar, 'The Affirmative Action Debate in India', Asian Survey 32 (1992): 290-302 at 299. 
positions are reserved for members of a particular caste. Secondly, although 'Other Backward Classes' (OBCs) make up more than 50 per cent of the Indian population, their share of reservations has been limited to 27 per cent in order to keep total reservations to below 50 per cent (for Scheduled Castes, Scheduled Tribes, and OBCs), which makes competition for the positions more exacting. ${ }^{58}$ Finally, it has also been pointed out that the policy of reservations in India solidifies a group categorisation that is in reality inherently fluid and ambiguous. ${ }^{59}$

A brief final word is needed on the concern expressed by Fraser - namely, that redistributive strategies such as affirmative action, because of their 'expressive dimension', inevitably affect the status and social identities of especially the beneficiaries of such policies. One example is social welfare. Welfare benefits tend to stigmatise recipients as 'deviants and scroungers' as distinct from wage earners and taxpayers 'who pay their own way', thereby 'creat(ing) strongly cathected antagonistic group differentiation. ${ }^{\prime} 0$ In other words, improvements in economic position do not automatically translate into enhancement of status. ${ }^{61}$

Affirmative action policies can have similar 'recognition effects', often strengthening rather than weakening stereotypes and causing rather than eliminating resentment.

For example, there is some indication that affirmative action may reinforce beliefs that members of the benefited group are unqualified for the positions they hold and cannot compete successfully on their own merits. In a survey done in the US, whites were more likely to agree with negative statements about African Americans when they were first asked about their attitudes toward affirmative action than they were when affirmative action was not mentioned. ${ }^{62}$ The same study indicates that affirmative action is so intensely disliked in the US that it has led some whites to dislike blacks - 'an ironic example of a policy meant to put the divide of race behind us in fact further widening it.63 An actively and openly pursued policy of affirmative action may also produce resentment in those otherwise qualified persons who are passed over for a certain job. It could also lead them to believe that the successful candidate from the disadvantaged group was selected solely because of such a policy

58 See Kamala Sankaran, 'Towards Inclusion and Diversity: India's Experience with Affirmative Action' in Equality in the Workplace: Reflections from South Africa and Beyond, eds. O Dupper \& C Garbers (Cape Town: Juta, 2009), 271.

59 Lance Liebman, 'Equalities Real and Ideal', Harvard Law Review 98 (1995): 1679-92 at 1689.

60 Fraser 'Social Justice in the Age of Identity Politics', 48.

61 Ibid., 47.

62 See Paul Brest \& Miranda Oshige, 'Affirmative Action for Whom?', Stanford Law Review 47 (1995): 870 at 871 and the study referred to there.

63 Brest \& Oshige, 'Affirmative Action for Whom?', 872. 
and not because he or she was in fact suitably qualified. The end result could be that even those who would have failed to a gain a desired position on the basis of their qualification may feel that they lost out only because of a legally enforced policy of affirmative action. ${ }^{64}$ And this, of course, could only lead to a worsening of intergroup relations, contrary to the original aim of affirmative action.

Irrespective of the validity and magnitude of these 'recognition effects', it remains imperative that these effects be scrutinised. It is clear that no policy involving redistribution (such as affirmative action) can be evaluated on distributive grounds alone. ${ }^{65}$ Failure to attend to the recognition effects of redistributive policies can 'end up fueling misrecognition in the course of remedying maldistribution. ${ }^{6}$

\section{I.3 Demarcation of beneficiaries}

Affirmative action, in facilitating substantive equality, specifically attaches socioeconomic benefits such as jobs or government contracts to those disadvantaged by status (such as race and gender). ${ }^{67}$ This arguably places affirmative action in the realm of redistributive rather than regulatory policy measures. However, in order for

64 See Thomas Nagel, 'Equal Treatment and Compensatory Discrimination', Philosophy and Public Affairs 2 (1973): 362.

65 Fraser 'Social Justice in the Age of Identity Politics', 48.

66 Ibid.

67 This chapter will not address the selection of the groups that are the object of affirmative action but merely how the selected groups have been demarcated. The choice of groups to benefit from affirmative action has been the topic of considerable debate and scholarship. For example, in the United States, some critics of affirmative action have characterised as arbitrary the selection of the groups that should benefit from affirmative action (see John Kekes, 'The Injustice of Strong Affirmative Action' in Affirmative Action and the University: A Philosophical Inquiry, ed. Steven M Cahn (Philadelphia: Temple University Press, 1993), 151; Lisa H Newton, 'Reverse Discrimination as Unjustified', Ethics 83 (1973): 311; Robert Simon, 'Preferential Hiring: A Reply to Judith Jarvis Thomson', Philosophy and Public Affairs 3 (1974): 313). Briefly stated, their argument is that if there are other groups that have been discriminated against, such as Native Americans, Appalachian Mountain whites, Puerto Ricans, Jews, gays and lesbians, the physically unattractive, the obese, and so forth, why should they not be able to make the same claims to compensation as the groups that are selected to benefit from compensatory programmes of affirmative action? For a response to the charge of 'arbitrariness', see Ockert Dupper, 'In Defence of Affirmative Action', South African Law Journal 121 (2004): 187. See also Laura Dudley Jenkins, 'Race, Caste and Justice: Social Science Categories and Antidiscrimination Policies in India and the United States', Connecticut Law Review 36 (2004): 747; Brest and Oshige, 'Affirmative Action for Whom?, 870; Satish Deshpande and Yogendra Yadav, 'Redesigning Affirmative Action', Economic and Political Weekly (17 June 2006): 2419. 
affirmative action policies to have more than a 'remote distributive effect', ${ }^{6}$ a tight fit between status and disadvantage is required. If not, it invites the familiar objection that affirmative action is both over- and under-inclusive. To put it succinctly: if the aim of affirmative action measures is to address socio-economic disadvantage, then a group demarcated by status, such as race or gender, might, for example, be both over-inclusive by including wealthier black or female people, and under-inclusive, by excluding poor white men. ${ }^{6}$

Of the two objections, it is arguable that the critique of over-inclusiveness is the most persuasive. By focusing attention on groups rather than individuals, critics argue, some individuals who are not needy will in fact receive benefits at the expense of those who have been handicapped most by the effects of discrimination and are thus most in need of advancement under such a policy. If what we truly want is to advance those who have been disadvantaged, they argue, then the emphasis should be on the disadvantaged individuals of a deprived group, not the deprived group as a whole. But, they go on to say, the policy of affirmative action does not mandate or even recommend finding out whether individuals who benefit have actually been the victims of any injustice that could warrant redress. ${ }^{70}$

There are a number of potential replies to the above argument. ${ }^{71}$ One of the more convincing arguments for not engaging in such individual inquiries is that since almost all members of the disadvantaged groups have in fact been disadvantaged by discrimination, it is surely not unjustifiable to design and institute programmes to confer special benefits to the groups as such. ${ }^{72}$ The argument presupposes that there is in fact a very high correlation between being a black person or a woman or a member of a disadvantaged caste and being a victim of discriminatory and harmful treatment.

Courts are often called upon to resolve the tension between the equal treatment principle and more distributive or substantive conceptions of equality. ${ }^{73}$ One of the

68 A Graser, 'Equality Oriented Policies: A New Concept in Public Policy?' (18 February 2013), 11, available at SSRN: <http://ssrn.com/abstract=2220289> accessed 14 September 2014.

69 Fredman, 'Facing the Future', 60.

70 See Kekes, 'The Injustice of Strong Affirmative Action', 150.

71 For a more detailed discussion of these arguments, see Dupper, 'In Defence of Affirmative Action'.

72 See James W Nickel, 'Should Reparations be to Individuals or to Groups?', Analysis 34 (1974): 155.

73 See Hugh Collins, 'Discrimination, Equality and Social Inclusion', Modern Law Review 66 (2003): 17. What precisely is meant by the notion of 'substantive equality' will not be explored in any detail in this contribution, save to say that it is acknowledged that equality is an elusive notion (see Nicholas Bamforth, 'Conceptions of Anti-Discrimination Law', 
areas of tension indeed relates to the manner in which legislation or policy defines 'beneficiaries' and what the parameters of the selected categories are. In general, courts in South Africa and Canada have adopted an approach that does not shine too penetrating a light on the question of the demarcation of beneficiaries of affirmative action as these groups have been defined by legislation or policy. Although the majority judgment of the South African Constitutional Court in the Van Heerden decision emphasises that 'the beneficiaries must be shown to be disadvantaged', this requirement relates to the identified group and not to each individual member of the group. The court made it clear that a measure will not fail because it benefits individual persons who have not in fact been disadvantaged. It is sufficient, the court said, that 'an overwhelming majority' have been so disadvantaged. ${ }^{74}$

In her minority judgment, Justice Mokgoro provided the rationale for the groupbased approach in instances where the targeted groups are defined with reference to the unfair discrimination suffered specifically under the policy of apartheid:

The approach of apartheid was to categorize people and attach consequences to those categories. No relevance was attached to the circumstances of individuals. Advantages or disadvantages were metered (sic) out according to one's membership of a group.

The significance of this, she points out, 'is that it is unnecessary for the state to show that each individual member of a group that was targeted by unfair discrimination was in fact individually discriminated against when enacting a measure under s 9(2): ${ }^{\prime 5}$ This view has also found support in the High Court. In Stoman v Minister of Safety and Security and others, the court confirmed that the intention of the legislature 'could not have been to make [affirmative action] measures dependent on the individual circumstances of each particular case. ${ }^{76}$

In the Canadian decision of R. $v$ Kapp, ${ }^{77}$ the Supreme Court of Canada adopted a similar approach to the question. In this case, the Canadian government conferred a communal fishing licence to particular 'aboriginal bands'. The question arose as to whether the three 'bands' were an 'identifiable disadvantaged group' for the purposes

Oxford Journal of Legal Studies 24 (2004): 693 at 703), and that our numerous appeals to (substantive) equality are often an appeal to some deeper normative value (such as human dignity, redistribution, participative democracy, etc.) rather than to the value of equality (in this regard see, for example, Joseph Raz, The Morality of Freedom (Oxford, Clarendon Press, 1986), 235; and Elisa Holmes, 'Anti-Discrimination Rights Without Equality', The Modern Law Review 68 (March 2005): 175).

74 At para 40.

75 At para 85.

762002 (3) SA 468, 483J-484A.

77 R. v Kapp 2008 SCC 41. 
of section 15(2) of the Canadian Charter of Rights and Freedoms, which permits ameliorative measures. The court adopted a distinctly group-based approach to the matter. It determined that the bands targeted by the ameliorative measures were in fact disadvantaged in terms of income, education and a host of other measures, and the fact that 'some individual members of the bands may not experience personal disadvantage does not negate the group disadvantage suffered by band members. ${ }^{78}$

The issue of the over-inclusive nature of affirmative action thus causes little concern when there is a substantial overlap between status and disadvantage, as is the case, for example, in respect of black South Africans in South Africa and First Nation tribes in Canada. However, an effective affirmative action project might over time allow an increasing number of the disadvantaged group to prosper, which may loosen the earlier tight fit between status and disadvantage.

For example, in South Africa, there is evidence that while the gap between black people and white people has decreased in recent years (although it still remains a matter of concern), there has been a sharp increase in the levels of inequality within racial groups, especially among Africans. ${ }^{79}$ Thus while inter-racial inequality has declined (even if only marginally), intra-racial inequality has increased. While this intra-racial inequality has its origins in the political and economic changes that occurred during the last twenty years of apartheid, it has increased significantly during the past fifteen years as the race-based redress project begins to take effect. ${ }^{80}$ Affirmative action has been remarkably successful at deracialising the apex of the class structure, but has left the lower levels largely untransformed. ${ }^{81}$

78 Kapp para 59.

79 See S Terreblanche, The History of Inequality in South Africa: 1652-2002 (Pietermaritzburg: University of KwaZulu-Natal Press, 2002), 400; J Seekings \& N Nattrass, Class, Race, and Inequality in South Africa (New Haven: Yale University Press, 2005), 307-8.

80 Terreblanche, The History of Inequality, 133. The most widely used measure of the degree of inequality in a household income distribution is the Gini coefficient. The lower the value of the Gini coefficient, the more equally household income is distributed. A Gini of 0 denotes perfect equality (all individuals in the population receive the same income), while a Gini of 1 denotes perfect inequality (one individual in the population earns everything). The most recent Gini coefficient figures for the South African population are as follows: African 0.63; Coloured 0.59; Indian 0.57; White 0.56. See Statistics South Africa, Income and expenditure of households 2005/2006: Analysis of results, 2008: 35.

81 K Bentley \& A Habib 'Racial Redress, National Identity \& Citizenship in Post-Apartheid South Africa' in Racial Redress and Citizenship in South Africa, eds. K Bentley \& A Habib (Cape Town: HSRC Press, 2008), 22. 
In the long run, this may necessitate a different approach to the delineation of beneficiaries. One response is to overlay status with socio-economic disadvantage in demarcating the group of beneficiaries. To qualify for the benefit, the individual must show both membership of the status group as well as socio-economic disadvantage. ${ }^{82}$ Such an approach can be found in India. Affirmative action (or 'reservations') in India target three 'backward classes', ${ }^{83}$ namely the scheduled tribes $(\mathrm{STs}),{ }^{84}$ scheduled castes (SCs) ${ }^{85}$ and the other backward classes (OBCs). ${ }^{86}$ The first two groups are specified by the President, while the OBCs are specified in a list drawn up by the National Commission for Backward Classes. The latter list is drawn up with specific reference to social, educational and economic criteria. ${ }^{87}$ In 1992, the Supreme Court of India held that the so-called 'creamy layer' among the OBCs should be excluded from the ambit of reservations. ${ }^{88}$ The 'creamy layer' refers to the upper strata among OBCs, castes that have become prosperous, partly as a result of land reform policies in the 1970s and partly as a result of effectively mobilising political power. ${ }^{89}$ Individual entitlements for members of OBCs may therefore depend on whether the relevant individuals have been raised in privileged circumstances, i.e. whether they form part of the 'creamy layer' of their group. ${ }^{90}$ However, as Fredman points out, the requirement that a group display both

82 Fredman, 'Facing the Future', 62.

83 The term is used in a non-pejorative sense.

84 STs are members of 'tribal groups' spread across 16 states in concentrations varying from less than $1 \%$ to almost $95 \%$. They comprise approximately $8 \%$ of the population. Heyer \& Javal, 'The Challenge of Positive Discrimination in India', 4.

85 SCs, comprising about $16 \%$ of the Indian population, are the former 'untouchables', those at the very bottom of the caste hierarchy. Heyer \& Javal, 'The Challenge of Positive Discrimination in India, 4.

86 Sankaran, 'Towards Inclusion and Diversity', 274.

87 For a more detailed discussion of the identification of the OBCs, see Sankaran, 'Towards Inclusion and Diversity', $278 \mathrm{ff}$.

88 Indra Sawhney $v$ Union of India AIR 1993 SC 477. This was confirmed in the recent decision of Ashok Kumar Thakur $v$ Union of India (2008) 6 SCC 1.

89 Heyer \& Jayal, 'The Challenge of Positive Discrimination in India', 9.

90 Vikraman Nair, 'The search for equality through constitutional process: the Indian experience', Acta Juridica 2001: 255, 265. Thus there is a careful, elaborate and quite refined method for determining how affirmative action will counteract or even dismantle disadvantage. See CD Cunningham \& NR Madhava Menon, 'Race, Class, Caste ...? Rethinking Affirmative Action', Michigan LR 97 (1999): 1296; CR Sunstein, 'Affirmative Action, Caste, and Cultural Comparisons', Michigan LR 97 (1999): 1311, 1316. 
misrecognition and socio-economic disadvantage is only 'imperfectly executed. ${ }^{91}$ In the first place, there is no creamy layer exclusion for the Scheduled Tribes or Scheduled Castes. ${ }^{92}$ Secondly, there is no provision for reservation in favour of disadvantaged Muslims. ${ }^{93}$

Despite the fact that such an individualised scrutiny is rare in American affirmative action programmes, some programmes do attempt to create a closer fit between status and socio-economic disadvantage along the lines of the 'creamy layer' exception discussed above. One of the purposes of the Small Business Act (SDA ${ }^{94}$ is to ensure that 'small business concerns owned and controlled by socially and economically disadvantaged individuals [...] shall have the maximum practicable opportunity to participate in the performance of contracts let by any Federal agency. ${ }^{\prime} 95$ The Act defines 'socially disadvantaged individuals' as 'those who have been subjected to racial or ethnic prejudice or cultural bias because of their identity as a member of a group without regard to their individual qualities, ${ }^{96}$ and 'economically disadvantaged individuals' as 'those socially disadvantaged individuals whose ability to compete in the free enterprise system has been impaired due to diminished capital and credit opportunities as compared to others in the same business area who are not socially disadvantaged. ${ }^{97}$

In implementing the directive of the Act, the Small Business Administration has created a number of programmes; the most relevant for our purposes is what is known as the ' $8(\mathrm{a})$ program. The $8(\mathrm{a})$ programme confers a wide range of benefits on participating businesses, one of which is automatic eligibility for subcontracting in respect of federal contracts. ${ }^{98}$ To participate in the $8(\mathrm{a})$ programme, a business

91 Fredman, 'Facing the Future', 63.

92 Sankaran points out that the reason is based on the different justification offered for the reservations of SCs and STs on the one hand and OBCs on the other hand. The basis of the reservations in favour of SCs and STs is compensatory in nature, whereas redistribution is the main justification for reservations in favour of OBCs. Sankaran, 'Towards Inclusion and Diversity', 277.

93 This despite the fact that recent data shows that the position of Muslims is inferior to that of SCs or STs across India. Sankaran, 'Towards Inclusion and Diversity', 281.

9415 USC s 631 et seq.

9515 USC s 637(d)(1).

9615 USC s 637(a)(5).

9715 USC s 637(a)(6)(A).

98 The SDA provides that not less than $5 \%$ of the total value of all federal prime contract and subcontract awards for each fiscal year shall be awarded to small business concerns owned and controlled by socially and economically disadvantaged individuals. See 15 USC s 644 (g (1). 
must be 51 per cent owned by individuals who qualify as 'socially and economically disadvantaged.' A presumption exists that Blacks, Hispanics, Pacific Asians, Subcontinent Asians, and Native Americans, as well as 'members of other groups designated from time to time by Small Business Administration' are 'socially disadvantaged. ${ }^{99}$ It also allows any individual not a member of a listed group to prove social disadvantage 'on the basis of clear and convincing evidence.'100 Social disadvantage is not enough to establish eligibility, however. Each 8(a) programme participant must also prove 'economic disadvantage' according to certain criteria. ${ }^{101}$ The result, as Fredman points out, is that businesses which, regardless of race, are not in fact socially or economically disadvantaged are excluded, a similar effect to that achieved by the Indian 'creamy layer' provisions. ${ }^{102}$

\subsection{Impact assessment}

An important question that needs to be addressed is whether affirmative action can be genuinely redistributive and thereby bring about structural change, or whether it simply changes the colour or gender composition of classes within the existing structure? ${ }^{103}$ Nancy Fraser draws the useful distinction between affirmative redistribution and transformative redistribution. ${ }^{104}$ Affirmative action, she argues, falls into the first category. She points out that affirmative redistributive strategies 'seek to redress maldistribution by altering end-state patterns of allocation, without disturbing the underlying mechanisms that generate them.' Because the underlying political-economic structures are left intact, 'affirmative redistribution reforms must make surface reallocations again and again. ${ }^{105}$ In other words, by inserting members of disadvantaged groups into some higher paid occupations in an organisation or granting them places in elite higher education institutions, the structural and institutional causes of exclusion are left intact. In contrast, transformative redistribution strategies involve efforts to 'redress end-state injustices precisely by altering the underlying framework that generates them. ${ }^{106}$ In other words,

99 Section 124.105(b)(1).

100 As described in $\mathrm{s} 124.105$ (c).

101 Set out in s 124.106(a).

102 Fredman, 'Facing the Future', 64.

103 Ibid., 15.

104 See Nancy Fraser, Justice Interruptus (New York: Routledge, 1997).

105 Nancy Fraser, 'Social Justice in the Age of Identity Politics: Redistribution, Recognition, and Participation', The Tanner Lectures on Human Values (1996), 45-6, available at <http:// tannerlectures.utah.edu/_documents/a-to-z/f/Fraser98.pdf> accessed 14 September 2014. This point is taken up again in part 5 , infra.

106 Fraser, 'Social Justice in the Age of Identity Politics', 46. 
transformative redistribution would restructure the relations of production, including changing the division of labour in the home, the interaction between work in the family and work in the paid labour force, education and others. ${ }^{107}$

While these are undoubtedly valid criticisms, highlighting as it does the limitations of affirmative action as a redistributive strategy, many argue that to consider affirmative action primarily in those terms is unnecessarily limiting. ${ }^{108}$ Cornel West, for example, assigns a rather limited role to affirmative action:

Progressives should view affirmative action as neither a major solution to poverty nor a sufficient means to equality. We should see it as primarily playing a negative role - namely, to ensure that discriminatory practices against women and people of colour are abated [...] Even if affirmative action fails significantly to reduce black poverty or contributes to the persistence of racist perceptions in the workplace, without affirmative action, black access to America's prosperity would be even more difficult to obtain and racism in the workplace would persist anyway. ${ }^{109}$

Elsewhere, I have argued that affirmative action should be viewed as performing a dual role. ${ }^{110}$ First, affirmative action is a way of overcoming prejudice by changing widely held attitudes towards members of disadvantaged groups (what I refer to as the attitude-changing argument), and second, affirmative action is a necessary tool for integrating disadvantaged groups into a democratic society, thereby breaking what would otherwise be an endlessly continuing cycle of poverty, subservience and social inequality (what I refer to as the integration argument). I will briefly elaborate on both these aims.

The underlying idea of the attitude-changing argument is the plausible assumption that people's views of the abilities of others are often shaped by what they have seen such people do in the past. In other words, if members of a certain group have only been seen to perform menial tasks, then people are likely to think that this is all that they are capable of. ${ }^{111}$ Arguably the best way to change such attitudes is to make sure that black people and women are placed in positions requiring higher levels of ability and skill, in which they can be seen to perform as well as others do. Not only could this have an effect on the beliefs of members of these groups themselves about

107 Fredman, 'Facing the Future', 30.

108 Ibid., 65.

109 C West, Race Matters (New York: Vintage, 1994), 95.

110 Ockert Dupper, 'Remedying the past or reshaping the future? Justifying race-based affirmative action in South African and the United States', The International Journal of Comparative Labour Law and Industrial Relations 21 (2005): 89.

111 Cf. Scanlon, 'Equality on Divided Societies: A Normative Overview', unpublished manuscript on file with the author, 8 . 
what they can do and what they can achieve, but equally, if not more important, also on the attitudes of others towards members of disadvantaged groups. This sets the argument apart from the familiar and more narrowly constructed rolemodel argument, which focuses on the effect that such measures can have on group members themselves (inspiring young women and black people, for instance, to pursue academic or professional careers), ${ }^{112}$ and pays little or no attention to the goal of changing the prejudicial attitudes of privileged groups towards traditionally disadvantaged groups. But the one without the other is not enough if what we want is to pave the way for a change in the way people are perceived both within and outside of the labour market. Note that this argument is in practical terms quite farreaching. In fact, I would go even further and say that it is of sufficient importance not only to justify affirmative action measures in situations in which there is a tie between two applicants, but also where one of the candidates is not as qualified as the others. ${ }^{113}$ It is nevertheless acknowledged that the strength of the phenomenon

112 The role model argument - widely recognised as it is - has nevertheless not enjoyed universal appeal. For example, Brest \& Oshige note the following caveats: First, little is known about the strength of the phenomenon. Second, in an age of mass media, it seems intuitively plausible that roles played by a few fictitious characters on television may have greater impact than a hundred actual professionals. Third, there is reason to believe that role modelling is more effective for the children of stable working-and middle-class families than for children from severely economically disadvantaged families. The sense of hopelessness of youth from very disadvantaged families makes them less likely than working- or middle-class youth to contemplate or plan for their futures. Finally, the putative benefits of role modelling may be offset by the feelings of inferiority that affirmative action can engender by implying that minority group members cannot succeed on their own 'merits'. See Brest \& Oshige, 'Affirmative Action for Whom?', 870.

113 Although, in the South African context, still 'suitably qualified' as the term is defined in the Employment Equity Act 55 of 1998 (EEA). In Stoman v Minister of Safety \& Security \& Others (2002) ILJ 1020 (T), the High Court in South Africa recognised that only allowing affirmative action to play a role when two candidates are 'equally qualified', therefore as a tie-breaking measure, would be inadequate in a society such as South Africa. 'To allow [...] affirmative action measures to play a role only where candidates otherwise have the same qualifications and merits, where there is virtually nothing to choose between them, will not advance the ideal of equality in a situation where a society emerges from a history of unfair discrimination' (at 1034). In contrast, The European Court of Justice (ECJ) has made it clear that one of the criteria for lawful affirmative action is that the two candidates must be 'equally qualified' - see Abrahamsson v Fogelquist Case C-407/98 [2000] IRLR 732). This feature of current EC law has been criticised: 'While their validity by EC standards is beyond question, the effectiveness of positive action plans is a different matter. Where these schemes have been applied, the proportion of women in the workplace has remained static rather than having improved. One reason for this may lie in the plans' most debatable feature - the need to demonstrate equivalent qualifications of male and female candidates before any preferential criterion is triggered' (see Daniela Caruso, 'Limits of the Classic 
of changing attitudes by means of affirmative action - while intuitively convincing - is still uncertain when opposed to other, more material benefits such as wealth, power, and connections. ${ }^{114}$ This brings me to the second important function of affirmative action, namely integration.

The integrative argument focuses on affirmative action as a necessary tool for integrating disadvantaged groups into a democratic society. However, the attitudechanging and integrative arguments are not unrelated. Indeed, one could argue that the attitude-changing argument is really one aspect of the integrative argument.

One of the strongest proponents (in the US context) of the integrative, forwardlooking model of affirmative action is Elizabeth Anderson. ${ }^{115}$ Anderson proposes that affirmative action be viewed not as a form of compensation for past discrimination, but as a tool for dismantling current barriers to access by blacks to mainstream opportunities. To be more specific, she argues that racial integration as such should be a central goal of race-based affirmative action. ${ }^{116}$ Racial integration, she writes, is the 'full inclusion and participation as equals of citizens of all races in American institutions.' ${ }^{117}$ Anderson illustrates convincingly that racial segregation in the residential, educational, and occupational spheres is the cause of multiple, systematic, mutually reinforcing race-based inequalities, operating independently of and in conjunction with discrimination: (i) it isolates people from social networks (which are important in securing job opportunities); (ii) it leads to a spatial mismatch of residence from job opportunities (because blacks live primarily in cities and near suburbs with declining job opportunities); (iii) it causes increased discrimination (because job segregation heightens the salience of race as a marker of employees in ways that encourage unconscious discrimination - for example, if a job is held only by members of a particular race, the employer's unconscious stereotype of the sort of employee most suited for that type of job will tend to be racialised); (iv) it leads to reduced opportunities for capital accumulation and access to credit (because confinement to segregated neighbourhoods systematically reduces their access to investment opportunities and consequently their ability to obtain credit); (v) it reduces business opportunities (because racial segregation depresses housing appreciation and reduces access to credit, it results in fewer African American entrepreneurs); and (vi) it results in lower access to professional services (because

Method: Positive Action in the European Union after the New Equality Directives', Harvard International Law Journal 44 (2003): 331 at 341-2).

114 See Brest \& Oshige 868-72.

115 See E Anderson, 'Integration, Affirmative Action, and Strict Scrutiny', New York University Law Review 77 (2002): 1195; Anderson, The Imperative of Integration, especially chapter 7.

116 Anderson, 'Integration, Affirmative Action, and Strict Scrutiny', 1212.

117 Ibid., 1197. 
fewer professionals - like doctors - are likely to locate in economically depressed and segregated areas, where most black people are concentrated). ${ }^{118}$ Affirmative action, Anderson concludes, can be a tool for dismantling racial segregation, which, as pointed out above, is the major cause of unjust race-based disadvantage. ${ }^{119}$

A final non-distributive justification for affirmative action that warrants brief discussion is that people of different races (or genders or castes, for that matter) have different life experiences that affect their relations with other groups and influence their views on a range of issues. Their presence in workplaces or in universities could therefore have a positive impact: it could lead to structural changes in organisations ${ }^{120}$ and enhance classroom discussion in the higher education setting.

This tight fit between one's race, gender or caste and one's life experience means that the exclusion or under-representation of a particular race, gender or caste in a workplace will make it unlikely that the experience and perspectives of the excluded or under-represented group will be articulated. ${ }^{121}$ As Fredman writes, 'on this view, it is possible to characterise the presence of women and historically disadvantaged groups as functioning to open up new perspectives on decision-making, to cast light on assumptions that the dominant group perceives as universal, and to enhance the store of "social knowledge". 122 Along similar lines, Anderson argues that the articulation of the unique experiences of disadvantaged groups not only reduces stigmatisation and discrimination against disadvantaged groups, but also 'increases responsible deliberation by the advantaged.'123

In the higher education-setting, this justification finds expression in the wellknown diversity model, which represents affirmative action as promoting a 'robust exchange of ideas. ${ }^{124}$ In other words, a diverse student body brings with it distinct educational benefits. ${ }^{125}$ Because people of different races and ethnicities often have

118 Ibid., 1202-4.

119 Anderson, The Imperative of Integration, chapter 7, 13.

120 Fredman, 'Facing the Future', 66.

121 Ibid., 67.

122 Ibid., 67.

123 Anderson, The Imperative of Integration, chapter 7, 16.

124 Regents of the University of California $v$ Bakke 438 US 265 (1978) at 313.

125 The court in Grutter v Bollinger (539 US 306 (2003)) cited (with approval) the District Court's view that a diverse student body promotes 'cross-racial understanding, helps to break down racial stereotypes, and enables [students] to better understand persons of different races.' In addition, 'classroom discussion is livelier, more spirited, and simply more enlightening and interesting when the students have the greatest possible variety of backgrounds.' (at 18 - per O'Connor J) 
different life experiences, it has important implications both for the interpersonal and intellectual lives of students and faculty. ${ }^{126}$ On the interpersonal level, as Brest and Oshige argue, the opportunity to encounter people from different backgrounds and cultures allows students to explore the nature of those differences and to learn to communicate across the boundaries they create; ${ }^{127}$ on the intellectual level, it contributes to a 'multiplicity of intellectual perspectives.' ${ }^{128}$ In a recent study, Jeffrey Milem evaluates the empirical evidence upon which the 'diversity' rationale is based. ${ }^{129} \mathrm{He}$ examines the benefits that accrue to individuals (ways in which diversity enhances the educational experiences of individual students), the institutions (ways in which diversity enhances the effectiveness of the organisation or institution), and society (ways in which diversity in universities impacts quality of life issues in the larger society, such as the achievement of democratic ideals, the development of an educated and involved citizenry, and the ways in which groups who are underserved in society are able to receive the services that they require). In respect of all three levels, he concludes that the benefits of diversity are 'persuasive'. Benefits that accrue to individuals include improved racial and cultural awareness

126 'For example, African Americans regularly encounter discrimination not experienced by whites and often scarcely believable to them. Policies that seem "neutral" to a dominant group may have quite different meaning for the members of other racial or ethnic groups.' Brest \& Oshige, 'Affirmative Action for Whom?' 862 (footnotes omitted).

127 Amy Gutmann articulates the interpersonal benefits of diversity in educational institutions as follows: 'Were it not for the presence of black students and teachers in schools and universities, non-blacks would have far less sustained contact with significantly different life experiences and perceptions, and correspondingly less opportunity to develop the mutual respect that is a constitutive ideal of democratic citizenship. Educational institutions in a liberal democracy should be dedicated to cultivating not only tolerance - an attitude of live and let live - but also mutual respect - a positive reciprocal regard based on understanding - among people with diverse life experiences and perceptions.' See Amy Gutmann, 'Responding to Racial Injustice', The Tanner Lectures on Human Values (Stanford University, 16-19 May 1995) 307.

128 Brest \& Oshige 862-3. For a critique of the diversity model, see Anderson, The Imperative of Integration, chapter 7 . One important point Anderson makes is that the diversity model does not fit the scope of the practice. She argues that it best suits educational institutions and the award of broadcast licences. However, even in the context of educational institutions, its current scope is too broad. While it is plausible that the racial diversity of a classroom would enhance discussion of social, political, and cultural subjects by enriching the variety of perspectives voiced, she writes, it is hard to see the cognitive relevance of racial diversity to investigations in mathematics, engineering, or the 'hard' sciences. Yet schools extend racial preferences in admission to graduate programmes in the latter fields.

129 See Jeffrey F Milem 'The Educational Benefits of Diversity: Evidence From Multiple Sectors' in Compelling Interest: Examining the Evidence on Racial Dynamics in Higher Education, eds. Mitchell Chang, Daria Witt, James Jones \& Kenji Hakuta (Stanford: Stanford University Press, 2003). 
and an enhanced critical thinking ability; institutional benefits include higher levels of creativity and innovation (private enterprises) and more diverse curricular offerings and research focused on issues of race/ethnicity and gender (educational institutions); and, finally, society at large benefits from diversity through a more educated citizenry and greater equity. ${ }^{130}$

To be sure, this justification is not without its shortcomings. The obvious danger inherent in such a justification for affirmative action is that it may end up essentialising the status group, - that is, assume that all members share the same interests or perspectives. ${ }^{131}$

The alternative roles assigned to affirmative action discussed above (changing attitudes; facilitating integration, helping to overcome hidden barriers, effecting structural changes etc.) each have different strengths and weaknesses and may not always find universal application. The integration argument, for example, may be more compelling in the context of the United States, where certain 'minority' groups such as African-Americans, Hispanics and Native-Americans are segregated from mainstream society, and where there is an urgent need for their integration to counter the effects of segregation. In South Africa, by contrast, the beneficiaries of affirmative action constitute a numerical majority, and the proponents of the policy enjoy overwhelming political power. Integration as a policy objective may have less traction in South Africa than do arguments emphasising the importance of redressing the disadvantages caused by colonialism and apartheid. ${ }^{132}$ Nonetheless, what all the arguments canvassed in this part point to is the simple but undeniable fact that affirmative action, despite its admittedly redistributive character, cannot be reduced to that aim alone.

130 Ibid., 130-1.

131 Fredman, 'Facing the Future', 67. Avoiding this danger would require the adoption of a different notion of what a 'group' entails. In this regard, the work of Iris Young is instructive. (See Iris Marion Young, Justice and the Politics of Difference (Princeton: Princeton University Press, 1990).) She argues that groups should be understood as a set of relationships between different people and not as watertight categories with fixed boundaries. Such a relational understanding of groups moves beyond the notion that a group consists of members who all share the same fixed attributes and have nothing in common with members of other groups. Instead, a group is characterised as a social process of interaction in which some people have an affinity with each other. As Fredman points out, assertion of affinity with a group may change with social context and with life changes; and members may have interests that differ from other members of the group but are similar to members of other groups. See Fredman at 31 .

132 Integration as a goal is also of course of particular historical significance in the United States. It was the rallying call of the Civil Rights Movement in the 1960s and the main thrust of the Supreme Court's decision in Brown v Board of Education 347 US 483 (1954). See Anderson, The Imperative of Integration. 


\section{I.5 Justification and termination}

It is widely acknowledged that affirmative action is a temporary measure that should end once the goals it has set for itself have been achieved. For example, article 4(1) of the Convention on the Elimination of All Forms of Discrimination against Women (CEDAW) provides as follows:

Adoption by States parties of temporary special measures ${ }^{133}$ aimed at accelerating de facto equality between men and women shall not be considered discrimination as defined in the present Convention, but shall in no way entail as a consequence the maintenance of unequal or separate standards; these measures shall be discontinued when the objectives of equality of opportunity and treatment have been achieved.

Other international human rights instruments and policy documents adopted in the United Nations system also contain provisions on special measures to support the achievement of equality, which are meant to be discontinued after achieving its objectives. The question of the duration of affirmative action programmes is therefore closely tied up with the justification that is offered for their existence. If the justification for affirmative action is purely backward-looking, as a form of compensation for past discrimination, then a convincing argument may exist for establishing a specific expiry date for its demise. ${ }^{134}$ In other words, if the goal of affirmative action is truly remedial, then such programmes should end once the problem is solved. For example, if an employer decides to make differentiated employer contributions to a pension scheme in order to ameliorate past disadvantage, it may be appropriate to attach a time limit to such a scheme. ${ }^{135}$

However, affirmative action can also be justified in a more forward-looking manner, ${ }^{136}$ in which less emphasis is placed on the injustices of the past and more attention is given to a vision of the society ultimately to be attained where

133 Which includes 'affirmative action' and all its euphemisms, such as 'positive action' and 'positive measures'. See CEDAW Committee, Recommendation 25 part III B.

134 See Anderson, 'Integration, Affirmative Action, and Strict Scrutiny', 1251

135 This issue was at stake in the South African decision of Minister of Finance and others $v$ Van Heerden 2004 (11) BCLR 1125 (CC), where the State decided to make higher pension fund contributions in respect of those members of the South African Parliament who were unable to serve as members of parliament during apartheid. The scheme of differentiated contributions had a finite lifespan of five years. It was upheld by the majority of the court.

136 The distinction between backward-looking and forward-looking does not imply that all justifications for affirmative action are either located in the past or the future. Often, they may also be located in (or be informed by) what Elizabeth Anderson terms 'present-oriented concerns', such as addressing the current position of disadvantaged groups. See Anderson, The Imperative of Integration (Princeton: Princeton University Press, 2010), chapter 7. 
people are treated as civic equals, and this in part by means of affirmative action measures. The justifications for affirmative action that have more forward-looking aspirations are numerous and defy neat categorisation. However, what unites them is the focus on promoting highly desirable forms of social change rather than solely on compensating individuals for wrongs perpetrated in the past. Since these rationales focus on the future rather than the past, they avoid the need to establish a complicated causal connection between past wrongs and the current positions of particular individuals. Instead, they take as a given that wrongs have been committed, and attempt by means of affirmative action (together with other socio-economic and political measures) to create a different society where individuals are treated as civic equals. ${ }^{137}$ This set of justifications corresponds broadly to a paradigm of distributive justice, which seeks a more just distribution of resources and goods, such as employment and educational opportunities. ${ }^{138}$ These are more amorphous goals, which make the establishment of a specific expiry date difficult, if not impossible.

To be sure, justification for affirmative action is not a zero-sum game. This means that the presence of a compensatory justification necessarily excludes other more forward-looking arguments. In most countries in which the policy of affirmative action is pursued, one finds evidence of both forward-looking and backward-looking arguments. For example, in India, affirmative action for historically deprived groups (scheduled tribes (STs) and scheduled castes (SCs)) is justified along compensatory lines, whereas affirmative action in favour of the so-called 'other backward classes' (OBCs) is justified along distributive lines - namely, as a way in which to increase the presence of certain categories of persons in public employment and in education. ${ }^{139}$

A mixture of backward- and forward-looking arguments also characterises the debate about affirmative action in the United States. Other than in the case of university admissions, judicial opinion in the United States leans heavily in favour of a backward-looking approach (compensation for past discrimination). ${ }^{140}$ After initially endorsing affirmative action as a way to remedy societal discrimination in general, ${ }^{141}$ subsequent decisions have narrowed this down to compensation for

137 Dupper, 'Remedying the past or reshaping the future?', 114.

138 See Fraser, 'Social Justice in the Age of Identity Politics', 3. Fraser characterises affirmative action as an example of 'affirmative redistribution' as opposed to 'transformative redistribution'.

139 Sankaran, 'Towards Inclusion and Diversity', 276.

140 See Dupper, 'Remedying the past or reshaping the future?', 101.

141 In Regents of the University of California v Bakke 438 US 265 (1978), the US Supreme Court's first decision on the issue of affirmative action, the majority of Justices held that affirmative action measures at the medical school of UC Davis could be upheld if they served the important government objective of eliminating 'serious and persistent 
specified past discrimination. ${ }^{142}$ For example, in City of Richmond vJ.A. Croson Co., ${ }^{143}$ Justice O'Connor, for the majority, rejected an argument that affirmative action could rest on the goal of compensating for past societal discrimination. Instead, her opinion endorsed the view that affirmative action had to be limited to compensation for specifically identified past discrimination. This means that employers will have to acknowledge their own complicity in past discrimination before implementing an affirmative action programme, which, as Kathleen Sullivan has pointed out, inevitably 'casts a chill over efforts to implement affirmative action voluntarily'. ${ }^{144}$ On the other hand, in the context of higher education, the US Supreme Court has held that race can be taken into account as one element in an admissions programme designed to diversify the student body - a distinctly forward-looking rationale. ${ }^{145}$

In South Africa, a similar mix of backward- and forward-looking arguments characterises the debate about affirmative action. However, present- or futureoriented concerns dominate current discourse. In the only Constitutional Court judgment on affirmative action (to date), affirmative action was endorsed as a means to rectify existing inequality resulting from past discrimination:

$[\mathrm{W}]$ hat is clear is that our Constitution and in particular section 9 thereof, read as a whole, embraces for good reason a substantive conception of equality inclusive of measures to redress existing inequality. Absent a positive commitment progressively to eradicate socially constructed barriers to equality and to root out systematic or institutionalised under-privilege, the

underrepresentation of minorities in medicine', which could be seen as a consequence of past societal discrimination (even if no specific guilt could be attributed to the medical school itself) (Bakke at 370-1 (per Brennan J)).

142 See, for example, Wygant v Jackson Board of Education 476 US 267 (1986); City of Richmond v J.A. Croson 488 US 469 (1989); Adarand Constructors, Inc. v Pena 515 US 200 (1995).

143488 US 469 (1989).

144 Kathleen Sullivan, 'Sins of Discrimination: Last Term's Affirmative Action Cases', Harvard Law Review 100 (1986): 92.

145 The seeds for the diversity rationale were first sown in Regents of the University of California $v$ Bakke 438 US 265 (1978) and confirmed in Grutter v Bollinger 539 US 306 (2003). While the majority of the court in Bakke focused on remedying past societal injustice as a rationale, Justice Powell specifically rejected the argument that compensation for past societal discrimination could be a compelling state interest. Instead, he permitted raceconscious admissions to advance the university's compelling interest in a 'robust exchange of ideas', which would be promoted by diversity in the student body - a distinctly forwardlooking rationale (at 313). In Grutter v Bollinger, the court went one step further than Justice Powell did in Bakke when endorsing the diversity rationale. Relying on a set of amici briefs in support of affirmative action, the court acknowledged not only that a diverse student body has educational benefits, but also that diversity is compelling because universities are gateways to leadership in American institutions (at 332-3). 
constitutional promise of equality before the law and its equal protection and benefit must, in the context of our country, ring hollow. ${ }^{146}$ (italics added)

These more open-ended goals (for example, redress in South Africa, and diversity in the United States) are vague and not easily quantifiable. When have we had enough redress, or when is a classroom sufficiently diverse? Is this ultimately a decision that has to be taken at a political level, or do courts have a role to play? In Grutter, Justice O'Connor seems to assign some of that responsibility to the judiciary, stating that 'the Court expects that 25 years from now, the use of racial preferences will no longer be necessary.' ${ }^{\prime 47}$ Similarly, in the South African decision of George v Liberty Life Association of Africa Ltd, ${ }^{148}$ the (then) Industrial Court placed a clear time limit on affirmative action measures, and saw itself as the arbiter of when that time had been reached. Although not clear on when that point will be reached, the court referred to the time at which '[...] a state of general equality has been achieved' or when the 'normalisation of our society' has been achieved. ${ }^{149}$ This of course brings us no closer to the answer as to when that point has been reached: when have we achieved 'a state of general equality' or when do we consider our society to have achieved 'normality'?

However, often these fluid goals are given more precise meaning in enabling legislation. A good example can be found in the South African context, where the Employment Equity Act ${ }^{150}$ (which regulates affirmative action in employment) makes it clear that inequality in the employment context manifests itself in the under-representation of members of disadvantaged groups. The goal is therefore one based on more 'equitable representation', determined primarily with reference

146 Minister of Finance and others $v$ Van Heerden 2004 (11) BCLR 1125 (CC), para 31 (per Justice Moseneke). In the same Constitutional Court decision, Justice Sachs elaborated on this justification against the background of South Africa's discriminatory past, and the lingering effects of the discriminatory practices on black people and women: 'The necessary reconciliation between the different interests of those positively and negatively affected by affirmative action should, I believe, be done in a manner that takes simultaneous and due account both of the severe degree of structured inequality with which we still live, and of the constitutional goal of achieving an egalitarian society based on non-racism and nonsexism. In this context, redress is not simply an option, it is an imperative. Without major transformation we cannot heal the divisions of the past and establish a society based on democratic values, social justice and fundamental human rights.' (paras 136-7).

147 Grutter v Bollinger 539 US 306 (2003) at 343.

148 (1996) 17 ILJ 571 IC.

149 At 593-4.

150 Act 55 of 1998. 
to the relevant regional, provincial or national demographic data. ${ }^{151}$ In practice, designated employers must adopt policies that contain numerical goals and timetables for the establishment of 'equitable representation.' ${ }^{152}$ Does this mean that once the workplace is more representative (however this may be defined by the employer), affirmative action should end? In a number of decisions, courts have concluded that this is indeed the case. In other words, where employers had adopted affirmative action policies stating that once targets have been reached, 'merit' should then be the only consideration for appointment, and continued consideration of race and gender after the targets had been met was unfair. ${ }^{153}$

However, in at least one decision, the court expressed doubt that a policy committing an employer to end affirmative action once targets had been reached 'advances the spirit and purpose of employment equity and the notion of substantive equality.' ${ }^{154}$ It is thus not for the employer to decide when to call an end to affirmative action, even if that decision may have been the result of agreement between the employer and employees. ${ }^{155}$ The implication is that affirmative action measures may be used not only to attain equitable representation, but also to maintain it once the targets set have been reached. To be sure, maintaining rather than attaining the goals set under an affirmative action policy will undoubtedly impact on the status of affirmative action. It may mean a supporting rather than a leading role, but a role nonetheless.

In the United States, on the other hand, the Supreme Court made it clear that an employer may only aim to 'attain' but never to 'maintain' a racial balance in the workforce. ${ }^{156}$ This arguably reflects the narrow compensatory idea that employers may practise affirmative action only to compensate for their own past sins a significant constraint on workplace affirmative action measures in the United States as already alluded to earlier. ${ }^{157}$

151 Section 42 of the EEA lays down an objective criterion in this regard, referring to the 'demographic profile of the national and regional economically active population'. See also the Code of Good Practice on Preparation, Implementation and Monitoring of Employment Equity Plans 7.3.2(b).

152 Section 20 of the EEA.

153 Willemse v Patelia NO \& Others (2007) 28 ILJ 428 (LC); Reynhardt v University of South Africa (2008) 29 ILJ 725 (LC); University of South Africa v Reynhardt (2010) 31 ILJ 2368 (LAC).

154 Alexandre v Provincial Administration of the Western Cape Department of Health (2005) 26 ILJ 765 (LC) 777.

155 One of the duties of a designated employer is to consult with its employees on the content of the Employment Equity Plan. See sections 16 and 17 of the EEA.

156 See Johnson $v$ Transport Agency 480 US 616, 639 (1987).

157 See Anderson, 'Integration, Affirmative Action, and Strict Scrutiny', 1215. See also Sullivan, 'Sins of Discrimination', 78. 
There is considerable evidence in the United States that the end of affirmative action at certain universities led to an immediate and calamitous drop in black admissions. ${ }^{158}$ This provides impetus to the claim that, should affirmative action only be used to attain certain goals but not to maintain them once they are reached, all the gains achieved as a result of affirmative action policies will be lost. ${ }^{159}$ The reason for this is the fact that inequality and disadvantage are often of a structural nature, which the policy of affirmative action is unable to address. As Nancy Fraser writes, affirmative action does not disturb the underlying mechanisms that generate 'maldistribution' (in jobs, places at university etc.), which means that it continuously has to make 'surface reallocations. ${ }^{160}$ In other words, affirmative action aims to open up employment and educational opportunities to disadvantaged groups without challenging the "hierarchy of economic classes under capitalism [or] the hierarchy of elite educational institutions.' ${ }^{161}$

This is a powerful critique, and one that forces us to revisit the generally accepted view (contained both in international instruments and in the discourse surrounding the debate) that affirmative action is (and should be) of a temporary nature. In the absence of measures that are, to cite Fraser again, 'transformative' 162 rather than merely 'affirmative,'163 it may very well be that affirmative action is likely to be part of the legal landscape for some time to come. In fact, the political reality may be such that once affirmative action preferences are established, they are almost impossible to dismantle. ${ }^{164} \mathrm{I}$ have argued elsewhere that this is certainly

158 See S Issacharoff, 'Can Affirmative Action be Defended?', Obio State LJ 59 (1998): 669, 675.

159 One commentator refers to this as the 're-segregation nightmare'. See PH Schuck 'Affirmative Action: Past, Present, and Future', Yale Law and Policy Review 20 (2002): 1, 73.

160 See Fraser, 'Social Justice in the Age of Identity Politics', 45-6.

161 Elizabeth Anderson, 'Affirmative Action and Fraser's Redistribution-Recognition Dilemma' in Adding Insult to Injury: Nancy Fraser Debates Her Critics, ed. Kevin Olson (London: Verso, 2008), 164.

162 Meaning that they are aimed at correcting inequitable outcomes precisely by restructuring the underlying generative framework. See Fraser, Justice Interruptus, 23.

163 See Fraser, Justice Interruptus, 16.

164 As Schuck writes, this has been the universal experience of all countries that have established them. See Schuck, 'Affirmative Action: Past, Present, and Future' 84. However, there have been instances in which the necessary political support has been mustered to end affirmative action. The most well known of these is California's Proposition 209, which in 1996 prohibited preferential treatment on the basis of race, sex, colour, ethnicity, or national origin in public employment, public education, and public contracting. Although Malaysia has practised affirmative action in favour of indigenous Bumiputras or Sons of the Soil (commonly referred to as Malays) since 1997, the government has recently announced that it intends to revise these policies. However, to date reforms in this area have been small and piecemeal, leading at least one commentator to comment recently that ' $\mathrm{t}$ ] hey do not 
a danger in the South African context. ${ }^{165}$ In agreeing to respect the 'market' and implement neoliberal, supply-side policies in exchange for the acquiescence of state and capital to democracy, the new democratic government has severely limited its ability to narrow economic inequalities and eradicate poverty. ${ }^{166}$ This makes all the more important the improvements that have occurred, namely the broadening of the racial composition of the elite. Under these circumstances of limited options, the strategy of embracing identity politics as an alternative to a more broad-based economic redistribution is an attractive option. ${ }^{167}$ This may result in continued government support for affirmative action even when it no longer works or is no longer necessary because its stated aims (however defined) have been achieved.

\section{I.6 Concluding remarks}

As a redistributive strategy, affirmative action specifically attaches socio-economic benefits such as jobs or government contracts to those disadvantaged by status. However, this raises a number of challenges, some of which were explored in this chapter.

Firstly, because it (re)distributes benefits along group lines, affirmative action may entrench racial and other categories and strengthen stereotypes. In focusing on 'race' as a category, I have indicated that there will always exist a tension between trying to move beyond race on the one hand, and developing practical strategies to redress the disadvantages based on race on the other hand. Negotiating this tension will always be a challenge but should not be a reason to abandon affirmative action as a strategy to ameliorate the situation of the disadvantaged. Instead, it should intensify our efforts to pursue remedies that minimise the valorisation of racial (or other) identities. Following Nancy Fraser, I have also illustrated that affirmative action as a redistributive strategy will have recognition effects, which makes it imperative not to evaluate the policy on redistributive grounds alone. We should oppose policies that strengthen stereotypes and induce resentment.

yet represent the significant roll-back or reform of existing affirmative action policies in any meaningful sense' (see John Lee, 'Malaysian Dilemma', Foreign Policy Analysis 6 (2011): 15).

165 Dupper, 'Affirmative Action: Who, How, and How Long?', 438-43.

166 See, for instance, M MacDonald, Why Race Matters in South Africa (Cambridge: Harvard University Press, 2006), 172-4; Terreblanche, The History of Inequality, 439.

167 As MacDonald notes, racialism operates on a seductive logic, because it 'maintains that helping some members of the group helps the group, and helping the group helps all of its members' (MacDonald, Why Race Matters, 175). In other words, the assumption is that all black people benefit when some of them join the capitalist elite. This assumption of a shared identity of interest of all black people serves to legitimise the exclusion of the majority of blacks from sharing in the benefits of redistribution. 
Secondly, in order for affirmative action policies to have more than a remote distributive effect, a tight fit between status and disadvantage is required. A familiar charge often levelled against affirmative action is its over-inclusiveness; in other words that it includes members of the disadvantaged groups who have not experienced disadvantage. I have illustrated that this criticism has little traction when there is a substantial overlap between status and disadvantage, as is the case, for example, in respect of black South Africans in South Africa, African-Americans in the US and First Nation tribes in Canada. However, an effective affirmative action project might over time allow an increasing number of the disadvantaged group to prosper, which may loosen an earlier tight fit between status and disadvantage and necessitate a different approach to the delineation of beneficiaries. One response is to overlay status with socio-economic disadvantage in demarcating the group of beneficiaries, as the Indian example in particular illustrates.

Thirdly, affirmative action is often criticised as bringing about mere cosmetic change. It addresses the maldistribution of privileged positions, critics argue, but it leaves the underlying mechanisms that generate the maldistribution intact, thereby limiting its impact. While this criticism is undoubtedly valid, I have argued that to evaluate affirmative action on a distributive basis alone is unnecessarily limiting. In doing so, I pointed out that affirmative action performs many other functions, such as changing attitudes; facilitating integration, and helping to overcome hidden barriers.

Finally, it is widely acknowledged that affirmative action is a temporary measure with a specified goal or goals. Once these are achieved, the case for affirmative action is correspondingly weakened and continued efforts in the interest of affirmative action might well be regarded as discriminatory. The question of the duration of affirmative action programmes is therefore closely tied up with the justification that is offered for their existence. It may be that the goal is set in concrete terms, which makes the establishment of an end-point plausible. ${ }^{168}$ However, many of the goals of affirmative action are more amorphous (promoting diversity, ensuring 'equitable' representation), which makes the establishment of a cut-off point more difficult, if not impossible. I have argued that the fluid nature of these goals - coupled with the fact that affirmative action is (to use Nancy Fraser's terminology) an 'affirmative,' rather than a 'transformative', redistributive strategy - may mean that the policy is likely to be part of the legal landscape for some time to come. Over time, affirmative action's role might change from a leading one to a supportive one, but its role will continue nonetheless.

168 See, for example, the Canadian decision of $R . v$ Kapp (2008 SCC 41), where a communal fishing licence was granted to members of three aboriginal bands, which gave them the exclusive right to fish for salmon in the mouth of the Fraser River for a period of 24 hours. The granting of the licence was part of a larger effort of the federal government to enhance aboriginal involvement in the commercial fishery industry in Canada. 

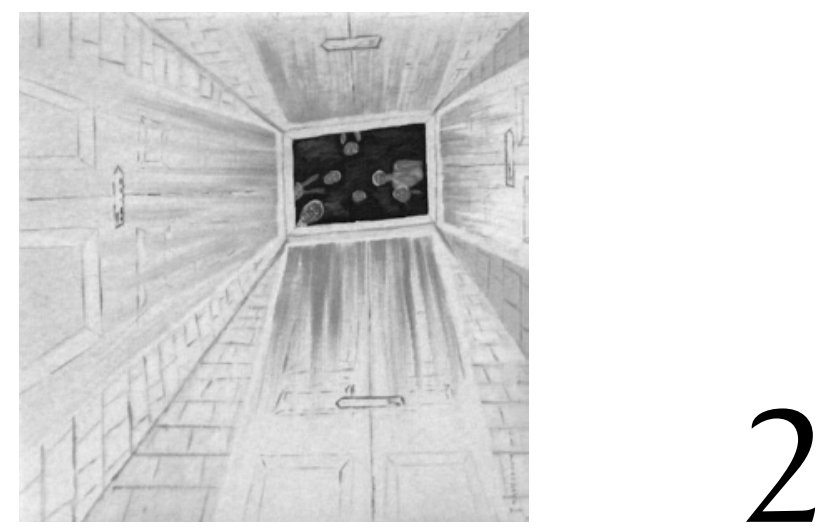

\title{
DEMOCRATIC PARTICIPATION IN MAKING AND ENFORCING AFFIRMATIVE ACTION SCHEMES
}

\author{
Bob Hepple
}

\subsection{Introduction}

There is a paradox in affirmative action schemes. This is that while one of the main aims of such schemes is to increase the participation of disadvantaged groups in institutions, the introduction and implementation of the schemes only rarely involve the active participation of those groups. Instead, most schemes are designed by the holders of power (such as government and employers) and rely on top-down, command-and-control mechanisms for their enforcement. The result is that many schemes end up being 'paper tigers, fierce in appearance but missing in tooth and claw.' ${ }^{1}$ The scheme may alter the colour or gender composition of those in power but deep structural inequalities remain - for example, the inequality between middle class white men and black women may diminish, but the gap between poor black women and rich black women may increase. ${ }^{2}$

1 Bob Hepple, ed., Social and Labour Rights in a Global Perspective (Cambridge: Cambridge University Press, 2002), 238.

2 Sandra Fredman, Discrimination Law, 2nd ed. (Oxford: Oxford University Press, 2011), 232. 
Democratic participation in the making and implementation of affirmative action schemes is central to the idea of transformative equality - that is, the dismantling of systemic inequalities and the eradication of poverty and disadvantage. ${ }^{3}$ This involves ensuring what Amaryta Sen has called an 'equality of capabilities, ${ }^{4}$ enabling people to have the skills they need to participate in society, to engage in productive activities and to participate in decision-making. The measures needed to achieve this include a positive role for institutions in removing barriers, and in ensuring that those who need more resources than others get them. In other words, it involves an element of redistribution. ${ }^{5}$ However, Sen has emphasised that 'equality of capabilities' does not mean uniformity. For example, there may be a need to reward individual efforts and productivity, and equality has to be weighed with other aspects of justice, such as the equity of procedures. ${ }^{6}$

The aim of 'inducing large-scale social change through non-violent political processes grounded in law'7 can be successful only if those who are directly affected have an effective voice in the making and implementation of transformative measures. There are two principal arguments for the presence of representatives of women, racial groups that have suffered discrimination in the past, disabled people and other disadvantaged groups in the processes of change. First, these representatives are likely to articulate the needs of their particular group, and so help ensure that there is a 'fit' - that is 'proportionality' between the aims of an affirmative action scheme and the means used to enforce it. This reduces the risks of over- or under-inclusiveness and increases the likelihood that the appropriate groups are identified and targeted for affirmative action. There is, of course, no guarantee that representatives will effectively voice the needs and interests of the affected groups; indeed there may be differing interests and conflicts within particular groups. This makes it essential that there should be mechanisms to ensure accountability of the representatives to their constituencies.

A second argument for democratic participation in the making and implementation of affirmative action schemes is that this makes restorative justice possible. This is 'a process where all the stakeholders in an alleged injustice have an opportunity to

3 C Albertyn, 'Substantive Equality and Transformation in South Africa', South African Journal on Human Rights 23 (2007): 257.

4 Amaryta Sen, Development as Freedom (New York: Alfred A. Knopf, Inc., 1999).

5 Sandra Fredman, Human Rights Transformed (Oxford: Oxford University Press, 2008), 226-40.

6 Amaryta Sen, The Idea of Justice (Cambridge: Harvard University Press, 2009), 296.

7 Karl Klare, 'Legal Culture and Transformative Constitutionalism', South African Journal on Human Rights 14 (1998): 146 at 150. 


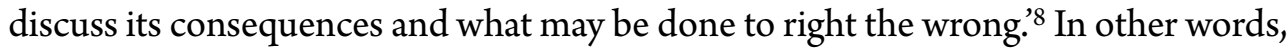
'meaningful engagement' between interested parties, going beyond 'consultation' but possibly different from 'negotiation', should be a feature of affirmative action schemes.

The first part of this chapter considers some theoretical arguments and proposes a model of 'reflexive regulation' as a basis for participation. The second part looks critically at why 'command-and-control' models have largely failed, using examples from the United Kingdom and South Africa. The third part examines the nature and extent of participation, and of accountability.

\subsection{Reflexive regulation 9}

There are least two reasons in theory why affirmative action schemes fail. The first is that these schemes often involve an interference with rights of private property. By its nature, the free exercise of property rights in a market system generates inequality, cyclical unemployment, and poverty, the very evils that affirmative action plans seek to remedy. After the crisis of the First World War, a new generation of social democratic lawyers, notably the Austro-Marxist Karl Renner, detected a functional transformation in the institution of private property. Using the example of state regulation of a privately owned railway company, he observed that private property had in effect become a public utility, although it had not become public property. 'The sovereign owner of private property has suddenly, by one stroke of the pen, been converted into a subject who has public duties. ${ }^{10} \mathrm{He}$ believed that the development of public law institutions and procedures regulating labour, housing, education etc. represented the 'first unavoidable step to nationalisation." ${ }^{11}$

By the end of the Second World War, however, the experience of the Great Depression of the 1930s and its outcome in fascism and war, made theorists of the post-1945 welfare state take a more pessimistic view about the possibility of restricting private property rights through sociallegislation in a democratic capitalist state. For example, Polanyi argued that this would undermine the functioning of the market system, and said it was implausible that there could be a lasting solution to the problem of

8 J Braithwaite, Regulatory Capitalism: How it Works, Ideas for Making it Better (Northampton: Edward Elgar Publishing Limited, 2008), 76.

9 This part draws extensively on the author's article: Bob Hepple 'Negotiating Social Change in the Shadow of the Law', South African Law Journal 129 (2012): 248-273.

10 Karl Renner, The Institutions of Private Law and their Social Functions, ed. O Kahn-Freund (London: Routledge \& Kegan Paul, 1949), 118-22 at 120; for a critique, see Richard Kinsey, 'Despotism and legality' in Capitalism and the Rule of Law, eds. Bob Fine et al. (London: Hutchinson, 1979), 46-64.

11 Ibid., at 121. 
poverty and unemployment in a market-based economy. ${ }^{12}$ This conclusion is shared by those neo-liberal economists who see social and labour regulation as contributing to rising labour and social costs, increasing unemployment, and putting a country having such rights at a competitive disadvantage in the global economic system. ${ }^{13}$ In the present period of almost unrestrained financial capitalism, when large sums of capital can be moved around the globe at the touch of a computer, the weakness of nation states in protecting the poor and vulnerable against the growing power of corporate private property is self-evident.

The tension between the enforcement of rights to substantive equality, on the one hand, and the right to property, on the other hand, is widely recognised. For example, the South African Constitutional Court has arrived at the conclusion that the best way of balancing these rights in order to achieve just and fair outcomes is through dialogue. In the words of Justice Sachs, one has to 'balance out and reconcile the opposed claims in as just a manner as possible, taking account of all the interests involved and the specific factors relevant to each particular case. ${ }^{14} \mathrm{After}$ pointing out that there are some contradictory values that are so intrinsic to the way our society operates that neither the legislature nor the courts can solve them with 'correct' answers, Justice Sachs continued:

In seeking to resolve [these] contradictions, the procedural and substantive aspects of justice and equity cannot always be separated. The managerial role of the courts may need to find expression in innovative ways. Thus one potentially dignified and effective mode of achieving sustainable reconciliations of the different interests involved is to encourage and require the parties to engage with each other in a proactive and honest endeavour to find mutually acceptable solutions. Wherever possible, respectful face-to-face engagement or mediation through a third party should replace arms-length combat by intransigent opponents. ${ }^{15}$

Although these remarks were made in relation to housing rights, ownership rights also have to be counterposed to other fundamental rights - such as the right to a basic education. ${ }^{16}$ Courts may seek to 'balance' these rights, depending on the specific context, but would generally prefer to encourage the parties to reach a negotiated

12 Karl Polanyi, The Great Transformation: The Political and Economic Origins of our Time (Boston: Beacon Press, 1944), 234.

13 For a critique of these conclusions, see Bob Hepple, Labour Laws and Global Trade (Oxford: Hart Publishing, 2005), chapter 10.

14 Port Elizabeth Municipality v Various Occupiers 2005 (1) SA 217 (CC), para 23.

15 Ibid., para 39.

16 For example, Governing Body of Juma Musjid Primary School and others v Ahmed Asruff Essay N.O. et al. [2011] ZACC 13. 
agreement. The critical issue, to be discussed later, is whether a just 'balance' can be achieved in negotiations between unequal parties and what role the court or administrative authority has in ensuring such a balance.

A second theoretical reason for the failure of affirmative action schemes lies at the heart of the use of law as an instrument of social change. This was expressed by Eugen Ehrlich (1862-1922), a founder of the sociology of law. ${ }^{17}$ He distinguished the 'living law' from abstracted judicial understandings of law. 'Living law' is the outcome of social processes, the way in which people act within and outside legal institutions. Abstracted law, unlike living law, demands specificity and relatively clear obligations; it operates by individualising conflict between specific parties in a bipolar way. Disputes about affirmative action schemes aimed at reducing social disadvantage and exclusion, on the other hand, are polycentric, involving many different causes and interests. Every time a court is asked to enforce a positive obligation to advance a socio-economic right or a right to equality of opportunity, it is confronted by the complexity and multidimensional nature of social disadvantage. There are many causes of disadvantage, including social class, lack of opportunities to work or to acquire education and skills, childhood deprivation, inadequate housing, illness and lack of access to health services. There is also discrimination on grounds of age, gender, disability and ethnicity. To focus on only one dimension may neglect and aggravate other causes of disadvantage. Attempts to reduce the cycle of disadvantage to a single set of positive obligations determined through an adversarial process cannot in themselves deliver substantial social justice. For Ehrlich, law can never control the factual order itself. '[O]nly a better form of legal decision-making could - and should - do justice to the facts of the living law. ${ }^{18}$ The critical question is then whether legal methods such as 'meaningful engagement' and 'consultation' provide an appropriate bridge with the 'living law'.

In recent decades, Ehrlich has been seen as a forerunner of the Continental school of sociology of law associated with Niklas Luhmann's systems analysis. ${ }^{19}$ This attributes

17 Eugen Ehrlich, Fundamental Principles of the Sociology of Law, with an introduction by Roscoe Pound (Cambridge, Mass.: Harvard University Press, 1936), a translation of Grundlegung des Soziologie des Rechts (1913). A new translation, with an introduction by Klaus Ziegert, was published in 2002. See generally Marc Hertogh, ed., Living Law: Reconsidering Eugen Ehrlich (Oxford: Hart Publishing, 2009).

18 David Nelken, 'Ehrlich's Legacies: Back to the Future in the Sociology of Law?' in Hertogh, ed., Living Law, 237-73 at 262.

19 Luhmann, Law as a Social System, trans. Karl A Ziegert, (Oxford: Oxford University Press, 2004). The following paragraphs of this and the next section draw on Bob Hepple, 'Enforcing Equality Law; Two Steps Forward, Two Steps Backwards for Reflexive Regulation', Industrial Law Journal [UK] 40 (2011): 315-35. 
failures of social regulation to deliver desired outcomes to the limited role that law can play in changing other social sub-systems. By analogy with the biological theory of autopoiesis, ${ }^{20}$ it is argued that society is not structured hierarchically with law at the top. One should not expect law to change behaviour by simple 'command and control'. There are multiple sub-systems including the market, the workplace and the administration. Each sub-system operates autonomously to a greater or lesser degree, and each has its own 'language' and operates according to its own internal logic. There is no 'shared' language: each sub-system is operationally 'closed' in the sense that it is capable of self-reproduction without direct reference to the outside environment. At the same time, it is cognitively open to indirect influence. It can adapt to external stimuli 'reflexively', that is by acts of communication with other sub-systems and by adjusting to the common environment in which they operate. So when the sub-system of the workplace receives a communication from the legal system, this filters through its own internal norms and culture. The outcomes may be significantly different from what is desired by those initiating legal intervention. Teubner describes this as a 'regulatory trilemma': either the targeted sub-system ignores the intervention, or the intervention damages the sub-system's ability to reproduce itself (for example, the juridification of autonomous collective bargaining by legal intervention), or the legal system loses its legitimacy because it is ineffective. Teubner's solution is to create a new model of 'reflexive law' that does not seek to impose substantive rules on sub-systems but instead works with the internal dynamics of those systems and co-ordinates them through 'proceduralisation. ${ }^{21}$

A conclusion that has been drawn from this theory is that if legal intervention is to be successful it must concentrate on improved communication that enables the targeted sub-system to adjust and re-configure itself. Braithwaite, one of the leading advocates of what he calls responsive regulation, explains:

$[\mathrm{T}]$ he core idea of responsive regulation (whether by government or other actors who regulate) should be responsive to the motivational postures of the regulated, to their customs, their actual conduct and to structured facts [...] $[\mathrm{R}]$ esponsive regulation makes the explanatory claim that legally pluralist deliberative institutions that engage multiple stakeholders are most likely to secure the regulatory purposes of such institutions. [It] values flexibility, citizen participation in crafting contextually attuned solutions to problems and parsimony in recourse to coercion. Yet deterrence and incapacitation have vital roles in responsive regulation. ${ }^{22}$

20 G Teubner, Law as an Autopoietic System, trans. Anne Bankowska \& Ruth Adler, ed. Zenon Bankowski (Oxford: Blackwell, 1993), at 64-99.

21 G Teubner, 'Juridification: concepts, aspects, limits, solutions', in Juridification of Social Spheres: A Comparative Analysis in the Areas of Labour, Corporate, Antitrust and Social Welfare Law, ed. G Teubner (Berlin: Walter de Gruyter \& Co., 1987), 3-48.

22 Braithwaite, Regulatory Capitalism, 163. 
This kind of regulation involves three interlocking mechanisms. The first is internal scrutiny by the organisation itself to ensure effective self-regulation. The second is the involvement of interest groups (such as managers, employees and service users) who must be informed, consulted and engaged in the process of change. The third is an enforcement agency that should provide the back-up role of assistance, building capabilities, and ultimately sanctions where voluntary methods fail. These interlocking mechanisms create a triangular relationship among those regulated (for example, employers), others whose interests are affected (for example, workers and consumers), and the enforcement agency as the guardian of the public interest.

The 'most distinctive part of responsive regulation is the regulatory pyramid. It is an attempt to solve the puzzle of when to punish and when to persuade. ${ }^{23} \mathrm{At}$ the base of the pyramid is what Braithwaite has called 'restorative dialogue. ${ }^{24}$ This involves information, persuasion, and voluntary agreement. A crucial element in the design of the enforcement pyramid is to identify and involve the potential participants in the regulatory process. As one moves up the regulatory pyramid, increasingly demanding interventions are involved. When persuasion and dialogue fail, progressively more serious sanctions are required until there is compliance. ${ }^{25}$

An objection that is sometimes raised against the theory of reflexive regulation is that it either ignores or underestimates the importance of power in securing or avoiding compliance. How can one mitigate the undoubted imbalance between the institutional power of mega-corporations and public bodies and the individuals, work groups, and communities affected by their activities? One way is to strengthen the political and legal power of independent regulatory agencies, but that has often failed to work in the past when done on its own, because of judicial hostility, lack of resources, and the absence of transformative positive duties to bring about change. Another, more promising strategy to oppose corporate and institutional power is to strengthen the countervailing power of individuals, work groups and communities. This may be achieved by legally imposed procedures for engagement. The nature of that engagement will depend on the context. It includes information, consultation and other forms of participation, and, in the labour relations context, collective bargaining.

23 J Braithwaite, Restorative Justice and Responsive Regulation (Oxford: Oxford University Press, 2002), 30.

24 Ibid.

25 Bob Hepple, Mary Coussey \& Tufyal Choudhury, Equality: A New Legal Framework? Report of the Independent Review of UK Anti-Discrimination Legislation (Oxford: Hart Publishing, 2000), 59. 
One may conclude that the disadvantage of the reflexive regulation model is that it may simply serve to legitimise or rubber-stamp the exercise of corporate and institutional power unless individuals and groups affected by their actions have the legal power to compel engagement, and the courts or an enforcement agency have the power to ensure that agreements uphold the values of the legislation and, where necessary, to impose deterrent sanctions.

\subsection{The failure of command and control 26}

In the context of affirmative action, 'command and control' means that the State or an agency sets the aims and outcomes that an organisation is required to meet, and enforces this through investigations and legal proceedings. This is distinguished from 'reflexive' or 'responsive' regulation (as discussed above), which is based on the idea that the regulators need to be responsive to the motivations, customs and structures of those who are being regulated. This involves providing incentives to organisations to undertake internal scrutiny and to engage with interest groups. The role of the State or agency is that of providing information and advice and negotiating change, with deterrent sanctions available as a last resort when voluntary methods fail.

The model of administrative enforcement of anti-discrimination law had its origins in United States' Fair Employment agencies and Canadian Human Rights commissions. These were adapted in Great Britain in the forms of the Race Relations Board (RRB) (1965-76), Commission for Racial Equality (CRE) (1976-2007), Equal Opportunities Commission (EOC) (1975-2007) and Disability Rights Commission (DRC) (1999-2007). The Commissions were given powers to investigate specific organisations on their own initiative, and to stop directly and indirectly discriminatory practices, backed by deterrent sanctions. This was classic command-and-control regulation, supplemented by a right for individuals to make complaints of unlawful discrimination. Research indicates that the positive effect of individual cases is generally short-lived and can lead to defensive and negative attitudes to change. ${ }^{27}$

The early UK anti-discrimination legislation made specific but limited provision for forms of positive or affirmative action (such as special training) to help protected groups overcome barriers to employment. Prior to the introduction of public sector equality duties (below), a limiting feature of the race and sex discrimination legislation was that it relied exclusively on negative duties prohibiting discrimination,

26 This part draws on the author's chapter: Bob Hepple 'Agency Enforcement of Workplace Equality' in Making Employment Rights Effective, ed. L Dickens (Oxford: Hart Publishing, 2012).

27 Hepple, Coussey \& Choudhury, Equality, Appendix 1. 
rather than on positive duties to eliminate discrimination and advance equality. The limiting feature of the disability discrimination legislation, before the public sector duty was introduced, was that the duty to make reasonable adjustments applied only to a specific disabled person, such as one who applied for a job or was already an employee requesting an adjustment because of their disability. The concept of indirect discrimination was not applied to disability, and there was no general duty to ensure a workplace friendly to disabled people.

More generally, by the turn of the century, after 35 years of agency enforcement, there was still little sense that the majority of organisations had a sustained and coordinated strategy to improve diversity and equal opportunities in the workforce. ${ }^{28}$ Such a strategy requires a commitment by managers and workers' representatives to participate in bringing about changes, and a system for measuring progress. The early agencies were devised on the basis of a model of organisations that were hierarchical, vertically integrated and centralised. The top-down, rulemaking, command-and-control approach depends on individual fault-finding and retrospective investigation of an act alleged to be motivated by an unlawful ground of discrimination. This tends to breed negative, defensive and adversarial responses. However, the reality is that organisations cannot survive in the new globalised economy unless they are flexible and adaptable to market changes and technological innovation. Organisations are flattening their hierarchies, giving more authority to lower-level managers and demanding a high quality workforce, with the active participation of managers, workers and customers or service-users. Equality of opportunity at work increasingly depends not simply on avoiding negative discrimination, but on training and improving skills, developing wider social networks, and encouraging adaptability. In the new environment, the traditional command-and-control approach places too much emphasis on state regulation, and too little on the responsibility of organisations and individuals to generate change.

The weaknesses of command-and-control regulation and individual enforcement led the Cambridge Independent Review of the Enforcement of UK Anti-Discrimination Legislation, ${ }^{29}$ using the insights of modern regulatory theory, to design an 'optimal' form of regulation that could help to reduce, if not eliminate, under-representation, exclusion and institutional barriers to equal opportunities. This was described as 'enforced self-regulation', involving the three interlocking mechanisms described earlier. ${ }^{30}$ The Cambridge Review argued that this broad strategy needed to be developed in several specific ways: (i) a single commission covering all protected

28 Ibid., 19-20.

29 Ibid.

30 Above, in section 2.2. 
characteristics; (ii) a positive duty on public authorities to advance equality; (iii) positive duties on private sector employers to achieve employment equity or fair participation; (iv) positive duties on employers to introduce pay equity schemes; and (v) the improvement of deterrent sanctions including the use of contract and subsidy compliance.

Only the first two parts of this strategy were embraced in the Equality Acts of 2006 and $2010 .{ }^{31}$ First, a single Equality and Human Rights Commission (EHRC) was created with more extensive powers than the earlier commissions. The EHRC has two powers, largely modelled on those of the DRC - one to conduct an inquiry, and the other to conduct a formal investigation. ${ }^{32}$ An inquiry can relate to any of the Commission's duties, but leads only to a report and recommendations. These are not legally binding, but a court or tribunal may have regard to a finding, and the Commission may use information or evidence acquired in the course of an inquiry for the purpose of a formal investigation. The Commission has heavily circumscribed powers to obtain information, documents and oral evidence, under judicial control. One of the virtues of a single commission is that the inquiry can cut across strands, for example to investigate possible instances of multiple forms of discrimination. The inquiry may relate to a particular sector. For example, the EHRC has held inquiries into gender equality in the financial services sector, race equality in the construction industry, and the employment of migrant and agency labour in meat and poultry processing. Alternatively, the inquiry may be thematic - for example, the EHRC has held one into harassment. The Commission may not use an inquiry to find whether a named person has committed an unlawful act; it needs to commence a formal investigation (see below) for that purpose.

The second power of theEHRC is to conduct a formal investigation. The Commission may do so only if it 'suspects' that the person concerned may have committed an unlawful act. This follows the DRC model and sets a 'threshold test' of 'reasonable belief'. It has been argued that only if the Commission's decision to investigate is irrational or strongly disproportionate should a court interfere. ${ }^{33} \mathrm{~A}$ single complaint of unlawful conduct is unlikely to suffice as the basis for initiating an investigation, but a series of complaints over time might be sufficient. The suspicion may (but need not) be based on the matters arising in the course of an inquiry (above). There are stringent procedural requirements. Named-person investigations may lead to

31 Northern Ireland has separate legislation, which has pioneered affirmative action in the UK, enforced since 1999 by a single Equality Commission.

32 For details, see Bob Hepple, Equality: The New Legal Framework (Oxford: Hart Publishing, 2011), 151-4.

33 C O'Cinneide, 'The Commission for Equality and Human Rights: A New Institution for New and Uncertain Times', Industrial Law Journal 36 (2007): 141. 
an unlawful act notice against which there is a right of appeal to an appropriate court or tribunal. The notice may require the person to prepare an action plan for the purpose of avoiding a repetition or continuation of the unlawful act, and may recommend action to be taken by the person for that purpose. The action plan has to be approved by the Commission, which has power to apply to a county court (in England and Wales) or sheriff (in Scotland) for an order requiring a person to give the Commission a draft or revised action plan. During the period of five years beginning with the date on which the plan comes into force, an order may be sought and granted requiring the person to act in accordance with the action plan or to take specified action for a similar purpose. Failure to comply with an order without reasonable excuse may lead to a fine. The EHRC also has powers to assess compliance with the public sector equality duty (below) and, where it thinks that a public authority has failed to comply with a duty, the power to issue a noncompliance notice.

The Equality Act 2011 has harmonised and extended the circumstances in which positive action may be taken. ${ }^{34}$ It allows a person to take any action which is a proportionate means of achieving any one of three aims: enabling a person to overcome disadvantage connected with a protected characteristic (for example, race, gender, disability), meeting special needs of persons with a protected characteristic, and enabling or encouraging participation in an activity where participation by persons with a protected characteristic is disproportionately low. Although positive action remains voluntary in the private sector, there has been a radical reconstruction of equality law in the public sector by the imposition of a positive legal duty on public bodies to eliminate discrimination, advance equality of opportunity, and foster good relations between different groups. ${ }^{35}$ This duty provides an incentive for organisations to examine their employment practices, to remove barriers to the employment of black minority ethnic groups, women and disabled persons, and to take positive action. It can be seen that the EHRC remains largely within the enforcement models of its predecessors. In particular, it cannot launch a formal investigation in the absence of evidence of unlawful acts. The EHRC was not given the power to conduct equality audits in the public and private sectors, as was the Irish Equality Authority, which has this power even in the absence of specific evidence of discrimination. In Northern Ireland, the Equality Commission is able to use the results of triennial reviews that employers are required to submit relating to representation of Catholic and Protestant communities, as well as their investigatory powers, in order to negotiate agreements designed to remedy underrepresentation of either community. These are affirmative action agreements that

34 See Hepple, Equality, 128-30 for details.

35 Ibid., at 134-7. 
usually require undertakings to change the way they recruit, advertise, promote, and dismiss, often setting numerical goals and timetables. Most of the agreements reached have been voluntary but a number are legally enforceable. The voluntary ones usually follow a triennial review, while the legally binding ones tend to follow a formal investigation. Research shows that agreements focussing on institutional changes have been more effective in securing progress towards fair employment than lawsuits. ${ }^{36}$ Voluntary agreements have been more effective than the legally enforceable ones. The researchers suggest that one explanation for this may be that legally binding agreements have had to be negotiated where employers are resistant to change. 'Voluntary agreements where senior staff (with whom agreements are typically negotiated) have been persuaded of the legitimacy of the exercise may thus be more wholeheartedly implemented than are legally enforceable agreements where the leadership of the concern had to be compelled to accept their intervention.' ${ }^{37}$ The research suggests that leadership and commitment from the top of the organisation is crucial for the implementation of reforms.

The failure of the Labour and Coalition Governments to introduce employment equity and pay audits means that there is little incentive in Britain for employers to enter into voluntary agreements with the EHRC. However, a step in the direction of legally binding agreements has been made. The Equality Act 2006 gives the EHRC, like the former DRC, the power to make legally binding agreements in lieu of enforcement. It may do so only if it thinks that the person has committed an unlawful act. The inducements for a person to make such an agreement are that the Commission must undertake not to proceed with a formal investigation or unlawful act notice, and the person is not taken to be admitting to the commission of an unlawful act by reason only of entering into the agreement. If the Commission thinks that a party to an agreement has failed to comply, or is not likely to comply with an undertaking in the agreement, it may apply to a county court (in England and Wales) or sheriff (in Scotland) for an order requiring the person to comply or take such other action as the court may specify.

Although the Equality Acts 2006 and 2010 took important steps towards a model of reflexive regulation of equality, the Coalition Government, elected in 2010, has taken two backward steps. First it has cut the EHRC's budget by almost two-thirds, and proposes to limit the EHRC's powers to so-called 'core' functions. Secondly, the duties on public bodies to have due regard to the need to advance equality

36 A Heath, P Clifford, H Hamill, C McCrudden and R Mubarak, The Enforcement of Fair Employment Law in Northern Ireland: The Effect of Commission Agreements, McBride Agreements and Fair Employment Tribunal Cases' (unpublished paper on file with the author, 2009). For a summary, see C McCrudden, Equal Rights Review 4 (2009): 7.

37 Ibid. 
have been amended so as to remove any specific duty of engagement with those whose interests are affected. The prospects for reflexive regulation have suffered a serious setback. ${ }^{38}$

A second example of command-and-control regulation is the South African Employment Equity Act 1998 (EEA), which aims to achieve equity in the workplace by negative obligations prohibiting unfair discrimination and also by positive obligations on designated employers ${ }^{39}$ to take 'affirmative action' measures to ensure the equitable representation of black persons, women and disabled persons (the 'designated groups') in all occupations and levels in the workplace. ${ }^{40}$ The enforcement of the positive obligations provides an example of 'command and control' administrative regulation. The enforcement of the affirmative action duties is the responsibility of the Department of Labour. The details of the legislation are discussed by Ockert Dupper in chapter 11 of this volume. Here it is intended only to suggest some reasons why the Act has apparently had only a limited impact.

First, participation is limited to an obligation on designated employers to 'consult and reach agreement' on specified matters with a trade union representing members at the workplace, or, if there is no such union, with its employees or their representatives. ${ }^{41}$ South African trade unions have historically been hostile to forms of workplace consultation that they believe may result in co-option by management and the blunting of class struggle. ${ }^{42}$ Moreover, there are many workplaces in which there is no representative trade union or in which the union represents only one section of workers. In that event, the employer must consult with its employees as a whole (across all occupational groups and both designated and non-designated categories of employees), or their nominated representatives. This raises the question of how employment equity consultation relates to other forms of workplace consultation. The Labour Relations Act 1995 (LRA) sought to encourage nonadversarial consultation on issues such as productivity and workplace grievances by establishing workplace forums, but in practice trade unions have prevented

38 See Bob Hepple, 'Enforcing Equality Law; Two Steps Forward Two Steps Backwards for Reflexive Regulation', Industrial Law Journal [U.K.] 40 (2011): 315, for details.

39 'Designated employers' are those with 50 or more employees or with an annual turnover above a certain limit. Municipalities, organs of state and employers are bound by a collective agreement that appoints them as designated employers: EEA $s$ 1.

40 This part draws on the author's article Hepple, 'Negotiating Social Change in the Shadow of the Law', South African Law Journal 129 (2012): 248-73.

41 Sections 16 and 17, EEA.

42 For a recent overview, see Sakhela Buhlungu, Mick Brookes and Geoffrey Wood, 'Trade Unions and Democracy in South Africa: Union Organisational Challenges and Solidarities in a Time of Transformation', British Journal of Industrial Relations 46 (2008): 439-68. 
them from being set up by exercising their veto powers. The EEA makes it clear that the obligation to consult on employment equity does not affect the obligation to consult and reach 'consensus' with a workplace forum where one exists. However, unlike the LRA, the EEA does not define the content of the duty to consult. Consultation under the LRA means: (a) putting proposals rather than completed decisions to employee representatives; (b) disclosing all relevant information; (c) allowing representatives to respond to these proposals; and (d) responding to alternative proposals, and, if not acceptable to the employer, explaining the reasons for the rejection. There is a Code of Good Practice under the EEA, issued by the Department, which recommends a much more informal approach including an opportunity to meet and report back, a reasonable opportunity to meet employers, and to request, receive and consider information. The Code suggests that either an existing workplace forum should be used or that a consultative forum representing both designated and non-designated employees should be established. There is no reliable data on the extent to which employment equity issues are discussed by the few workplace forums that exist or how many special employment equity forums are in operation.

A review of trade union consultation by employers under the EEA, conducted in 2005 by Harish Jain, Loyiso Mbabane and Frank Horwitz of the Graduate School of Business UCT (the UCT study), ${ }^{43}$ found that there was consensus among trade unions that they are not properly consulted by employers on equity planning and implementation, and that equity planning has been kept separate from other aspects of human resources development, such as skills. According to this report, EE planning appears to be at the 'information giving' or 'basic consultation' level. They also found that trade unions themselves do not place EE planning and implementation high on their employment relations agenda, and there are not enough people, especially shop stewards, capacitated to monitor EE compliance. They rely on government to deal with the issue and expect a more aggressive role by labour inspectors.

The UCT study found that a common complaint was that too few inspectors had been appointed. For example, in Gauteng there were 120 inspectors, not all of whom could carry out employment equity inspections. According to the inspectors, their training was inadequate, and a directive was believed to have been issued to them by their head office 'not to prosecute' but to focus on advocacy. A study in 2008 by Andries Bezuidenhout and others at the Sociology of Work Unit, Wits University,

43 Trade Union Consultation by Employers under Employment Equity Legislation', paper delivered at the 4th Regional Congress of the International Industrial Relations Association (IIRA), Mauritius 28-30 November 2005. 
commissioned by the Department of Labour (the Wits study), ${ }^{44}$ found that the most common issue identified by inspectors is that the company employment equity plan is not reflected at the workplace and in the makeup of the stakeholders in the employment equity forum. One informant from the Department of Labour's Head Office told the researchers that the Department had not seriously enforced the EEA since its inception, but had concentrated on cases of procedural compliance (213 cases in the period 1998-2008). This was in part due to internal problems in the Department. An informant said that it could take an inspector the whole day to analyse a company's employment equity reports in order to assess whether stakeholders were adequately represented. Employment equity questions did not have priority in inspections. The Wits study found that many workplaces had never been visited by an inspector. The researchers were handicapped by the absence of accurate and complete records in the Department's Employment Equity Register. The number of reports submitted every second year varied greatly and they contained many errors. The general levels of non-compliance were high with a clear lack of monitoring by the Department. The failure of the EEA to bring about significant progress towards equitable representation is revealed by the statistical profile in the Commission for Employment Equity (CEE) Report for 2010/11. ${ }^{45}$ For example, white males still dominate the top echelons of business, despite the fact that the majority of professionals are now black and the output of black graduates has tripled over ten years.

Although research on the effects of the EEA is limited, several reasons for the failure of the legislation can be identified. First, the EEA relies mainly on 'command and control' by an under-resourced, under-trained, and bureaucratic administration for enforcement. This would have been reinforced by the amendments to the EEA proposed in 2010 and later withdrawn, which means that opportunities for dialogue with the employer through the process of negotiating written undertakings have been removed. Second, the inspectorate is also charged with enforcing basic conditions of employment and this dilutes the enforcement of the very different obligation of affirmative action, and increases the risks of 'agency capture', such as where inspectors decide as a general rule 'not to prosecute.' The role of the CEE is largely limited to producing statistical profiles based on reports by employers. ${ }^{46}$ Third, the

44 Andries Bezuidenhout, Christine Bisschoff, Sakhela Buhlungu and Kezia Lewins, 'Tracking Progress on the Implementation and Impact of the Employment Equity Act since its inception', research commissioned by Department of Labour South Africa, March 2008, <www.labour.gov.za/downloads/documents/research documents/Employment\%Equity_ DoL_Report\%20SWOP\%20Final\%2031.102008.pdf>.

45 Department of Labour, 11 th CEE Annual Report 2010/11.

46 The number of such reports received by the CEE has progressively increased from 6876 in 2006 to 18534 in 2010: 11th Annual CEE Report 2010/11. 
obligation to undertake affirmative action is placed solely on the employer who has a wide and ill-defined discretion, easily capable of manipulation. The achievement of equitable representation is not seen as the joint obligation of the employer and its workforce as a whole - that is, as a matter for partnership and co-determination. Fourth, the duty is process-based rather than outcome-focused. This leads to a rigid bureaucratic or 'tick-box' approach to compliance rather than a concentration on objectives, the achievement of which can be objectively measured. Fifth, only a very weak form of 'consultation' is prescribed, and this may be with parties who are disinterested or do not see themselves as having a direct stake in achieving change, or who have adversarial attitudes and do not see affirmative action as a matter for mutual co-operation. Finally, while sanctions should be available where negotiations fail, this should be only at the end of the line of a negotiating process. If sanctions are disproportionate, employers will be pushed into increasingly defensive or obstructive positions, or will simply ignore the law, in order to protect their businesses from the external threat to their survival.

\subsection{The nature and extent of participation and accountability}

Active responsibility of all the stakeholders, and engagement between them is the foundation of reflexive regulation of affirmative action. Engagement is neither an avoidance technique nor a truce between adversaries. It is a means to achieve the 'progressive realisation' of the goal of equality of opportunity and to develop substantive norms within organisations that promote equality.

Imbalance of power is often seen as an objection to effective participation. In a bipolar adversarial system, the substantive outcome of negotiations rests in the hands of the parties. This will depend on the skills and resources available to each party, and their respective strategies. The classic example is collective bargaining between employers and trade unions where the ability of each side to deploy actual or threatened lock-outs and strikes is an essential element in the process. This leads to the characterisation of labour negotiations as power struggles in which the stronger party can dominate the weaker.

In an attempt to strike a balance in favour of the weaker party, the law may intervene - for example, by courts granting interdicts (injunctions). In some jurisdictions, labour courts or similar bodies may seek to ensure the fairness of the bargaining process by interpreting the duty as being to bargain in 'good faith'. If the duty to engage is treated as a form of bargaining, the logic of this would be to examine the relative power of each party and to determine whether they are each making the appropriate contribution towards achieving a just and equitable outcome. These pitfalls can be avoided by treating 'engagement' in disputes about affirmative action not as bargaining, but primarily as a process of exchange of information and learning 
about the parties' respective positions. This should lead to a better understanding of the issues, followed by opportunities for persuasion based on reasoned argument with a view to reaching agreement. This goes beyond 'consultation', which, as usually interpreted, gives only a passive role to, those consulted to respond to proposals made by the holder of power. What is required is a process that involves active participation from all the parties. This approach recognises that there is no single source of power (such as government or employer) but that power comes from many sources and at different levels, and that the factors that influence the exercise of power are usually not straightforward: they may include respect for dignity, the need for political legitimacy, and business interests as well as material resources. It is essential that this participation does not take place in a normative vacuum. The parties must come to the table ready and willing to discuss and address how the principle of substantive equality is to be implemented. The role of the court or administrative authority is to ensure that the parties deliberate in a way that gives effect to the substantive rights.

This approach to participation is consistent with a modern understanding of deliberative democratic decision-making. Fredman defines this as 'a situation in which citizens share a commitment to a resolution of problems of collective choice through public reasoning [...] Moving from a bargaining model to a deliberative model therefore requires a substitution of interest-governed action by valueoriented action. ${ }^{37}$ Fredman explains that deliberative democracy does not mean that there has to be consensus on all questions of principle or their application. However, there must be reciprocity, harmony and respect, which allows consensus to develop over time.

A persistent problem with deliberative democracy is that of inadequate representativity and accountability. Who represents the poor, the disadvantaged and the excluded? The role of non-governmental organisations and of community groups is often stressed. But these bodies are nearly always under-resourced and may filter community interests through a particular lens. ${ }^{48}$ There is a danger that some interests will be neglected and that the communities may not be fully aware of the issues. In real life, engagement is usually not with a single monolithic entity, but involves heterogeneous groups with different interests. There is likely to be argument and internal negotiation between these groups; some will be well-organised and experienced, while others may be ad hoc coalitions.

47 Fredman, Human Rights Transformed, 33-8.

48 Martin Minogue \& Ledivina Carino, eds., Regulatory Governance in Developing Countries (Cheltenham: Edward Elgar, 2006), 10. 
The EEA in South Africa confers the exclusive right to be consulted on trade unions deemed to be 'representative' under the LRA, but we have seen that trade unions have not used this right effectively. The legitimacy of engagement will depend on the way in which the courts review and supervise the process. Where there is constitutional litigation, the court can retain supervisory jurisdiction to ensure that the agreement is fair to minority groups and is properly implemented. 'Consultation' requirements need to allow for the involvement of elected employee representatives.

The success of reflexive regulation depends on the independence of the regulatory agency, so as to ensure relative insulation from political and business pressures. The independence of the enforcement agency, like the independence of the judiciary, helps to ensure a pluralistic democracy in which no one power can dominate the others. The UN Paris Principles set out the desirable status and functions of human rights agencies. ${ }^{49}$ These include accountability to the directly elected legislature rather than the executive. A government inspectorate may be vulnerable to 'capture' by interest groups. In principle, an independent agency has more autonomy than inspectors attached to a government department. Another lesson is that the primary role of the agency should be to develop the capabilities of those who are regulated the goal is enforced self-regulation, not command and control. This means providing the parties with the space and capabilities for balanced deliberation.

In the case of both models of participatory democracy, deterrent sanctions remain important. Voluntary negotiation and deterrent sanctions are not alternatives. Although courts and administrative regulators should start with attempts to persuade parties to co-operate, they need to be able to rely on progressively more serious sanctions until there is compliance. There must be a gradual escalation of sanctions and, at the top of the enforcement pyramid, sufficiently strong sanctions to deter even the most persistent offender. It is a mistake to rely solely on harsh punitive fines to bring about compliance without incentives to negotiate change. This may lead to avoidance of the law or, worse still, may bring the law into disrepute. Participation needs to be under the shadow of legal sanctions rather than in their full glare.

\subsection{Conclusion}

This chapter has put forward two principal arguments for democratic participation in the making and enforcement of affirmative action schemes: to ensure a 'fit' or 'proportionality' between the aims of the scheme and the means used to achieve those aims, and to recognise that restorative justice is a process in which conflicting interests have to be reconciled. It has been suggested that most schemes fail because

49 Principles Relating to the Status of National Institutions, UN General Assembly, December 1993, available at <http://www.un.org/documents/ga/res/48/a48r134.htm>. 
of the conflicts in a market-based economy between the right to private property and the right to equality, and also because of the inherent limits of law as an instrument of social change. The response to this must be through dialogue and participation of those whose interests are affected in the process of change, and there is a need for mechanisms to ensure the accountability of those who represent these interests.

This approach is supported by the theory of reflexive or responsive regulation. For legal intervention to be successful, it must concentrate on improved communication and engagement between the legal system and other social sub-systems, and enable institutions targeted for change to adjust and reconfigure themselves. There is, however, a danger that the imbalance of power between institutions, trade unions and other social groups may make engagement a one-way process that brings about only cosmetic changes. Strategies to avoid this include the activities of wellresourced and powerful independent regulatory agencies and the strengthening of the countervailing power of trade unions and other social groups.

Such strategies will not succeed if the regulatory agency or government is locked into a command-and-control approach to enforcement. The examples of Britain and South Africa show that such an approach is incompatible with the modern shift from hierarchical institutions to flatter, more flexible structures in which training and flexibility are paramount. Successful models, like those in Northern Ireland, depend essentially on leadership and commitment within organisations, with incentives to make voluntary agreements, backed by deterrent sanctions. 

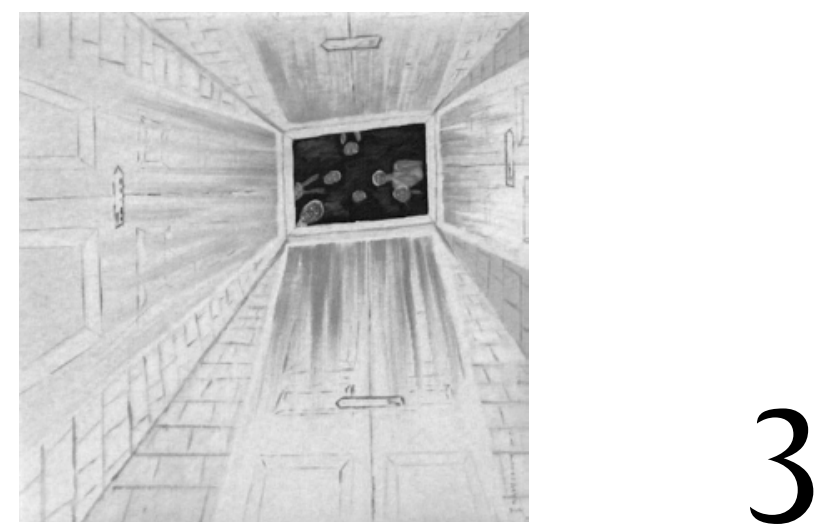

\title{
THE CASE AGAINST THE CASE AGAINST AFFIRMATIVE ACTION
}

\author{
Ana Carolina Alfinito Vieira \& Alex Graser ${ }^{1}$
}

\subsection{Introduction}

Affirmative action policies (AAPs) have spurred heated debates ever since they came into existence. They have been attacked ${ }^{2}$ and defended ${ }^{3}$ over and over again, and yet,

1 Alex Graser is Professor of Public Law and Policy at the University of Regensburg and Fellow of the Hertie School of Governance, Berlin; Ana Carolina Alfinito Vieira is a doctoral fellow at the Max Planck Institute for the Study of Societies, Cologne. The present research was supported by grants from the Deutsche Forschungsgemeinschaft and MaxnetAging, a project of the Max Planck Society.

2 The 'case against affirmative action' has been made far more often than could be cited here. Suffice it therefore at this point that we pick two articles that were published under that very title and hence may serve as a point of reference for ours: Louis P Pojman 'The Case Against Affirmative Action', International Journal of Applied Philosophy 12, no. 1 (1998): 97-115; Terry Eastland, 'The Case Against Affirmative Action', William and Mary Law Review 34, no. 1 (1992): 33.

3 As the defences also abound, we limit ourselves to the very succinct attempt at rebutting the common objections by Stanley Fish, 'The Nifty Nine Arguments Against Affirmative Action in Higher Education', The Journal of Blacks in Higher Education 27 (2000): 79-81. 
to this point, the issue does not seem to be settled. Indeed, it is quite unlikely that it ever will be, as it involves questions of distributional justice upon which political preferences might in most societies be irreconcilably divided. Nonetheless, there is still hope for at least an increased consensus on the desirability of this kind of policy - and thus a point in continuing the debate.

The present article sets out to advocate a more widespread use of AAPs by countering what we perceive to be a critical (set of) objection(s) to these policies. Namely, we refer to the argument that AAPs are unfair because they entail undue burden upon two classes of individuals that are affected by these policies: disadvantaged competitors and burdened addressees. We call this objection 'critical' because we think it is difficult to counter and implicit in most debates about AAPs. At the same time, it seems to be rarely addressed, let alone discussed thoroughly, neither by policy makers nor in the literature. It is our hope that by directly and systematically addressing this objection, we may help not only to clarify the terms of the debate surrounding AAPs, but also to further develop and consolidate the arguments in favour of these policies.

The basic structure of our argument is simple and comprises two steps. As there are many objections against AAPs, we will first filter out and develop what we consider to be the critical objection (3.3). In a second step, we will build up a counter argument that systematically tackles all facets of the critical objection, thereby seeking to weaken the case against AAPs (3.4). We shall end our contribution with a brief concluding section (3.5). Since we are dealing with a question of policy choice, it will be necessary to consider at the outset what alternative policy options exist besides AAPs to tackle inequality. Our chapter will therefore begin with a brief and introductory account of the broader array of equality-oriented policies (EOPs).

\subsection{The broader context: AAPs and other EOPs}

For most governments today, the promotion of equality - or conversely: the reduction of inequalities - is one of their central goals. Accordingly, they typically pursue a broad set of what we have here labeled EOPs. ${ }^{4} \mathrm{O}$ course, equality can mean different things, and the perceived obstacles to its achievement also vary across time and across polities. Therefore, the composition of the basket of EOPs deployed by any specific government at any given time also varies substantially. ${ }^{5}$

4 For an in-depth presentation of the concept of equality-oriented policies, see Alexander Graser, 'Equality-oriented policies: A new concept in public policy?' (18 February 2013), available at <http://papers.ssrn.com/sol3/papers.cfm?abstract_id=2220289>.

5 For a comparative overview of EOPs in various jurisdictions, see Alexander Graser, Ana Alfinito Vieira \& David Jackson, eds., Equality-Oriented Policies - The Concept, forthcoming with Nomos in 2015. 
Despite such variability, we would like to introduce a categorisation that distinguishes in broad terms between three 'layers' of EOPs. ${ }^{6}$ The metaphor suggests that the policies belonging to these 'layers' have emerged roughly in the corresponding historical sequence. But we speak of 'layers' rather than 'waves' or 'stages' because they do not typically replace, but rather add to one another, so that, in fact, all three layers of EOPs typically coexist nowadays, and each of them continues to evolve. Also, there is a lot of variation across systems with regard to the exact shape of these layers.

The policies of the three layers differ with regard to the cause of inequality that they seek to tackle. First-layer EOPs aim at guaranteeing general equality before the law. They entail the abolition of status differences and the concurrent operation of a cross-cutting equality principle that is typically situated at some elevated rank within the normative hierarchy. While EOPs of this layer are fundamental, the kind of equality they implement remains formal. They do not target differences in material wealth among the members of a polity.

This is where second-layer EOPs come into play. These are the (re)distributive policies that seek to promote material equality within the polity and typically take the form of social benefits, taxes, or institutional spending. To the formal status equality, second-layer EOPs add materially equalised starting positions. Nonetheless, these policies do not achieve full equality in material terms across all individuals in a polity. In fact, they are not meant to do so, as it is widely accepted that differences in individual achievement or choice of lifestyle should be reflected in some degree of material inequality. ${ }^{7}$ Some inequalities that persist despite the operation of second-layer EOPs may hence be viewed as intended.

But this does not explain all persisting inequalities because second-layer EOPs, too, fail to address important drivers of inequality and are, therefore, also insufficient. It is not only differences in legal status or material endowment that cause inequality; inequality is also generated and regenerated at the level of interactions among individuals day by day. In fields such as employment relations, medical care, education, rental agreements, and many others, individual decisions can have a

6 For a more thorough exposition of this categorisation, see Alexander Graser and Ana Alfinito Vieira, Taming the Biased Black Box? On the Potential Role of Behavioral Realism in AntiDiscrimination Policy', Oxford Journal of Legal Studies (2014).

7 For an exposition of the causes of inequality considered as legitimate by different approaches of political philosophy, see Gerald A Cohen, Why not Socialism?, (Princeton and Oxford: Princeton University Press, 2009). The position presented here is in line with what Cohen (at $18 \mathrm{ff}$.) calls 'socialist equality of opportunity'. This is the most egalitarian among the positions he presents. Hence, our statement in the text applies a fortiori for the other positions that Cohen distinguishes. 
major impact on other people's situation. It is hence critical to target any bias with regard to skin colour, gender, age, or other features that may inhabit such individual decision-taking. This is what third-layer EOPs do - some of them by addressing the existence of widespread popular bias in general (for example, through educational programmes and public awareness campaigns) and others by intervening on the individual level by targeting individual decisions and the processes through which they are made.

It is the latter type of third-layer EOPs with which this article is primarily concerned. They, in turn, comprise a variety of policies. Among others, these include, first, rules that prohibit certain criteria from being taken into account in the decision-making process - that is, anti-discrimination laws (ADLs). Second, they also include rules that prescribe a certain outcome to some or all decisions of a certain type. AAPs often fall in this second category.

It is apparent that these policies may interfere with individual autonomy. That is the price of intervening in individual decision-taking. At the same time, it should be noted that they do so with different intensities. ADLs would appear to be particularly respectful of individual autonomy as they only prohibit the consideration of specific criteria while otherwise leaving individual preferences untouched. This may be a reason that ADLs seem now to be the most widespread among third-layer EOPs. Across many systems, we have witnessed an impressive expansion of these policies over the last decades. This pertains to both the criteria they target as well as the realm of social life to which they apply. ${ }^{8}$

At this point, we conclude our brief survey of EOPs. We shall return to the observation of the predominance of ADLs again later on when we consider their relative attractiveness compared to AAPs. First, however, our focus in the ensuing sections will be on the policies that are central to this article.

\subsection{What may be (particularly) wrong about AAPs}

In this section, we will spell out what we perceive to be the core objection raised against AAPs - namely, their perceived unfairness. For this purpose, we shall sketch the different types of objection that can be raised against public policies in general and position the unfairness objection within this context (3.3.2). We will then further specify this objection and explain why it requires us to distinguish between

8 See Sandra Fredman, Discrimination Law, 2nd ed. (New York: Oxford University Press, 2011), for a thorough account of the historical development within the context of EU and UK law ( $38 \mathrm{ff}$.) and a systematic normative discussion of the proper scope of discrimination law (at $109 \mathrm{ff}$.). 
two categories of individuals: disadvantaged competitors and burdened addressees (3.3.3). But as a first step, we shall clarify what exactly we mean by AAPs (3.3.1).

\subsubsection{Defining AAPs}

The term affirmative action is widely used in different regional and disciplinary contexts. It commonly denotes policies that are meant to help members of minority groups or other disadvantaged groups to get better access to various spheres of social life such as education, employment and political representation. The exact boundaries of the term may vary depending on the specific context. In the following discussion, we will give the term a somewhat narrower but also more precise meaning, and will understand AAPs as legal rules that target individual decisions and require (or in some circumstances just allow) decision-takers to afford preferential treatment to a certain group of individuals who are subject to these decisions. Prominent examples are quotas, say, for women in political or managerial leadership positions, or rules that afford members of disadvantaged ethnic groups a competitive advantage within formalised assessment schemes, be it for hiring purposes, for university access or tenders for public contracts.

\subsubsection{The unfairness objection in context}

In our perception, such AAPs face continued and at times fierce opposition in many jurisdictions. As indicated before, the critical objection against them seems to be that they are unfair. This may at first appear to be a rather unspecific statement. But in fact, it serves to exclude a broad range of potential objections from the scope of the present discussion.

This is because unfairness is only one of multiple reasons why a policy may be judged as bad. ${ }^{9}$ One might disagree with a policy's ends, or on the means that are employed to achieve them. With regard to the means, one may focus on the output and conclude that the policy is ineffective, causes unforeseen side-effects, or is even counter-productive. Or, looking also at input, it may appear that a policy is too costly or at least inefficient.

This is true not only for policies in general, but can also be applied to AAPs in particular. In principle, all of these objections could be launched at AAPs. Whether they obtain can hardly be discussed in the abstract as this will ultimately depend on the specific policy and its context. But to the extent that generalisation is possible, our impression is that, typically, neither the ends of AAPs nor their implementation is particularly contested.

9 Stuart Nagel, Handbook of Public Policy Evaluation, (Thousand Oaks: Sage Publications, 2011). See also Albert Hirschman, Rhetoric of Reaction, (Cambridge: Harvard University Press, 1991). 
This is not to say, first, that everybody has always agreed on the need for AAPs. Any particular AAP may be considered unwarranted, be it because its beneficiaries do not really need that support, or because of a general hesitance about governmental intervention to achieve more equality. But it seems that AAPs are usually employed in situations in which there is a blatant under-representation of their beneficiaries. This makes consensus regarding the ends more likely.

Second, AAPs may, of course, also suffer from implementation deficits. It is hard to conceive of any kind of policy that could not, and AAPs are no exception. But it seems that AAPs can be framed in ways that render them hard to circumvent and hence relatively easy to enforce. The aforementioned examples testify to this: a fixed quota is a case in point, as is a minority bonus within a formalised application scheme. Implementation does not have to be a critical issue with these policies.

There is, to be sure, some debate about undesired side-effects of AAPs. The argument is that these policies may corroborate the negative public perception of their beneficiaries as a distinct group that is in need of special protection. ${ }^{10}$ While this is not implausible per se, it is highly doubtful that this potential long-term effect is strong enough to outweigh the short-term benefits to the group of beneficiaries. But this is mere speculation. Despite the advances that social psychology has made in the field of stereotype research, ${ }^{11}$ there seems to be no prospect that this alleged side-effect could be verified in the foreseeable future.

In sum, there are, of course, multiple objections that can be raised against AAPs. But the ones reviewed so far do not seem particularly salient. They can hardly explain the level of controversy that has accompanied AAPs so far.

\subsubsection{Specifying the unfairness objection}

This takes us back to the initial proposition that the most important objection against AAPs is their perceived unfairness, which can now be further specified. We have said already that the problem is typically not that the beneficiaries of AAPs are not considered deserving of the support they are afforded. Hence, the perceived unfairness of AAPs primarily lies in the burden that AAPs entail for others.

However, the fact that there is a burden to others is not per se unusual. Most EOPs - and all of those that aim at some distributional effect - do entail such a burden. Whatever their beneficiaries receive must be taken from someone else. This is true

10 For a thorough discussion of this argument and its potential implications for policy making, see Ockert Dupper, 'Affirmative Action: Who, How and How Long?', South African Journal on Human Rights 24 (2008): 425; for a brief discussion see also Stanley Fish, 'The Nifty Nine Arguments Against Affirmative Action in Higher Education', 81.

11 On this research, see 3.4.2.2. 
for any tax-financed social benefit to needy persons, and for all social insurance schemes that have a distributional dimension, and it is also for true income tax schemes, especially progressive ones.

\subsubsection{The perceived unfairness of individual burdens}

What is different in the case of AAPs is that there is a burden to others that is not spread across the entire polity within which the policy operates. In other words, there is a burden that is not a collective, but an individual one. AAPs may, to be sure, also bring about some collective burden. To the extent that leaving individual decisions untouched would lead to an efficient allocation of resources ${ }^{12}-$ in this context, of human capital - the efficiency loss due to the intervention by way of an AAP could be viewed as a collective burden. But arguably, this is not the main burden that AAPs cause, and definitely, such collective burdens are nothing uncommon. What is special about AAPs is that they impose a significant burden upon some individuals.

\subsubsection{The two categories of unduly burdened individuals}

Among these individuals, we can distinguish two categories. One is that of burdened addressees, the other that of disadvantaged competitors. For purposes of illustration, imagine an employment context in which an affirmative action rule prescribes preferential hiring of a certain group. This will, at least in some cases, imply that the employer has to hire a candidate other than the one who is (judged to be) most qualified. The latter person we term the 'disadvantaged competitor', while the employer in this setting will be labeled 'burdened addressee'. Obviously, the terms can be applied equally to other settings in which AAPs are used - such as, most notably, in admissions to tertiary education.

Both categories of persons are negatively affected, but in different ways. The disadvantaged competitor, first, is deprived of a benefit to which she is not entitled, to be sure, but which she would have enjoyed if the AAP were not in place. The above examples show how important this foregone benefit can be. Access to a certain job or a university may well have a significant effect on a person's life. ${ }^{13}$

12 On this argument, see 3.4.2.1.

13 For a pointed discussion of the situation of who we label as the 'disadvantaged competitor' and a critique of the individualistic premises underlying the presumption of disadvantage in that context, see Stanley Fish, 'Reverse Racism, or How the Pot Got to Call the Kettle Black', November 1993 (at subheading: 'Why me?' and below), available at <http://www. theatlantic.com/magazine/archive/1993/11/reverse-racism-or-how-the-pot-got-to-call-thekettle-black/304638/4/>. 
The burdened addressee, second, is imposed a choice that is not hers, and that - at least in her perspective - is also sub-optimal. The importance of this disadvantage is harder to gauge than that of the disadvantaged competitor. The infringement of the burdened addressee's autonomy may be viewed as more or less important from a principled perspective, but cannot be quantified. The loss related to the sub-optimal choice, by contrast, can better be assessed, albeit only for the specific case as it depends on the difference between the beneficiary of the AAP and the disadvantaged competitor. It may be marginal if they are almost equally qualified, but if not, it becomes more relevant. ${ }^{14}$ AAPs can and indeed often do address that latter issue by stipulating threshold criteria for the beneficiary to meet, thus ensuring that the difference is not too large.

\subsection{Why this may not be so wrong after all}

We have now spelled out what we consider the critical objection to AAPs. It is their unfairness against burdened individuals. When in the following discussion we turn to examining this objection, we shall do so from two perspectives that are distinct, but related.

The first is, what we will label the 'argument from individual equality' (3.4.1). This perspective is relevant for both categories of burdened individuals, because both suffer a disadvantage that is greater than that of all other persons in the polity in which the AAP operates. So, the problem here is that the AAP in effect singles out these burdened individuals for disparate negative treatment.

The other perspective is termed the 'argument from personal autonomy' (3.4.2). It is not relevant to the category of disadvantaged competitors, but only to that of burdened addressees. In the following, we will deal with both perspectives separately, but take account of their interdependence.

\subsubsection{The argument from individual equality}

We have said before that it is not unusual for policies that promote equality to do so in a fashion that distributes goods from some individuals to others; the benefit they afford to their beneficiaries comes at the expense of someone else. And we have also pointed out that one main problem with AAPs may be that this expense rests upon the shoulders of certain individuals rather than being borne collectively. This is the reason that AAPs, although intended to promote equality, might be viewed as resulting in an unequal treatment of the burdened individuals.

14 For a rule that allows for a wide differential of qualifications, see the South African Employment Equity Act 55 of 1998, especially the definition of 'suitable qualification' in s $20(3)$ (d), which stipulates that it may be sufficient if the beneficiary is capable of acquiring the abilities relevant for the job within reasonable time. 
We may note at this point that collective burden-sharing does not necessarily imply that everybody formally shoulders the same share of burden. In practice, quite the opposite is true. Tax systems usually do not implement formal equality, but take more from those who have more. Accordingly, the costs related to benefits that are financed from this resource are borne collectively but cause disparate burdens on different individuals. The same applies, mutatis mutandis, to social insurance schemes. Here, too, redistribution often takes place not just on the benefit side, but also in relation to revenues because the level of contributions differs. So, formal inequality is typically involved also when the burden is shared collectively.

Consequently, the particular problem with AAPs is not the unequal distribution of the related burden per se. However, unlike AAPs, in the cases of collective burdensharing referred to above, the uneven distribution is deliberately designed so as to take account of disparate capabilities of shouldering the burden across the polity. The idea, put simply, is that richer individuals carry higher burdens than poorer ones. There is, to be sure, reason to challenge this as an unrealistic idealisation. Probably, one could spot inconsistencies - and maybe even blatant injustices - in most countries' systems of collective burden-sharing. But at least in principle, such burden-sharing follows a distributional scheme, however imperfect it may be in practice.

AAPs, by contrast, do not appear to implement any systematic scheme of burdensharing, at least not at first sight. Rather, they seem to place a significant burden on only a few individuals. At the same time, it is open to question whether these burdened individuals are peculiarly well equipped to shoulder this burden - hence the suspicion that such unequal treatment could be unjustified, and hence the related objection specifically to AAPs.

Thus, the key question is whether and how the disparate and seemingly unsystematic burdening of certain individuals that is characteristic of AAPs can be justified. Finding such a justification, or at least justificatory strategies, is essential to our overall endeavour of weakening the case against AAPs. In order to do so, we point first to similar patterns in other regulations (3.4.1.1), in a second step, we identify the respective justifications for their existence (3.4.1.2), and third, we discuss whether these can be transferred to our case of AAPs (3.4.1.3).

\subsubsection{Burdened individuals in other contexts}

We have shown that collective - and systematic - burden-sharing is common in EOPs. However, this observation does not always apply. In fact, we can find exceptions in different branches of the law.

\subsection{Burdened individuals in employment law}

Many of these exceptions belong to the field of employment law. Think, for instance, of rules concerning maternity or sick pay, or of minimum wage regulation. In these 
cases, as in ours, the respective policy aims at promoting equality - here, it is a kind of distributive equality for sick employees, mothers(-to-be), and low-paid workers. And in all these cases, it is not the entire polity, but the employer who bears the (immediate) burden.

\subsection{Burdened individuals in family law}

The pattern we can discern in employment law is not confined to this field. We find the same structure in family law when dealing with duties of maintenance. Here again, individual persons are obliged to maintain other individuals, typically their relatives or current or former spouses. This is a goal which otherwise the entire polity would pursue, at least to the extent that we are dealing with minimum subsistence and - in some countries - deserving individuals. From this perspective, maintenance law appears as a substitute for policy instruments that are partially equivalent and would implement a collective burden-sharing scheme.

\subsection{Burdened individuals in the enforcement of judgments}

Another example is the law relating to the enforcement of judgments. Here, we find rules that prevent the creditor from recovering a debt to the extent that the debtor would then become destitute. The aim is to prevent individual impoverishment (which might in turn lead to a subjective entitlement to governmental support), but the burden is placed on the shoulders of the individual creditor.

\subsection{Burdening individuals - an exception?}

This list of exceptions could be extended. But it is already long enough so that we might ask whether it is appropriate that we speak of this pattern as an exception. In fact, the reason for calling it an exception is not so much quantitative as it is systematic. The underlying idea seems to be one of the fundamental individualist premises of liberal polities - namely, the separation between a public and a private sphere, with the latter being the realm of communicative and the former that of distributive justice. ${ }^{15}$

This does not mean, on the level of individual morality, that one person is not responsible for another. But it implies that one can, when confronted with the neediness of another person, legitimately point to the primary responsibility of the polity as a whole rather than accepting primary responsibility oneself. The view may

15 For this widespread notion based on Aristotelean categories, see e.g. Gustav Radbruch, Rechtsphilosophie, 2nd ed. (Heidelberg: C.F. Müller, 2003), 120; for more recent and differentiated discussions see Claus-Wilhelm Canaris, Die Bedeutung der iustitia distributiva im deutschen Vertragsrecht (München: C.H. Beck, 1997), 33 ff. Olha O Cherednychenko, Fundamental rights, contract law and the protection of the weaker party (München: Sellier, 2007), 44; and Christian Helmrich, Mindestlohn zur Existenzsicherung, dissertational manuscript on file with the authors, 190; the dissertation is forthcoming with Nomos in 2015. 
well be contestable, especially if one lives in a system that is less than perfectly just. ${ }^{16}$ But it seems to correspond quite well with how people behave (and believe they may legitimately behave) in their daily lives. Imagine meeting a beggar on the street. Some people might be willing to give, but very few would accept a duty to do so, even if they thought that the beggar should receive help.

The reason is, and we are back to the objections to AAPs, that the burden on the helper would seem coincidental. Others might never encounter the beggar and thus go unburdened. Or they might be much richer, but not burdened according to their increased capability of helping. It is the issue of disparate burdening, or of the absence of systematic burden-sharing that these cases have in common. What is at stake, hence, is a violation of the equality principle. ${ }^{17}$ This is why exceptions to the rule of systematic burden-sharing require a justification - no matter how frequent they are.

The long list of examples, therefore, does not serve to remove the requirement of a justification. But it might indicate what kinds of justification are acceptable. This is the next section's focus.

\subsubsection{Justifications for burdening individual actors}

We have shown what the exceptions and AAPs have in common. However, the reasons that might justify these exceptions are different. In the following discussion, we will review these justifications and consider to what extent they may be transferred to AAPs and the two categories of burdened individuals.

\subsection{Justifications based on the assumption of a moral responsibility}

Maybe the most straightforward way of justifying an exception is to argue that there is a moral duty for the burdened individual to care for the beneficiary. And the most obvious case in point is maintenance law. Here, it is indeed likely to be widely accepted that, say, parents owe such a duty to their children, that this duty should be prior to any such obligation of the general public, and that it should be implemented by law. The sources of such a moral obligation may, on a closer look, differ. Among spouses, the voluntary act of marriage is probably the most plausible source of such an obligation nowadays. Similarly, the duty of parents towards their children could be viewed as arising from the deliberate act of procreation. But in practice, deliberateness may in some cases be doubtful, so one might consider replacing it with kinship as a source of such obligation. The opposite case (the duty

16 For an extensive treatment of the issue see Gerald A Cohen, If You're an Egalitarian, How Come You Are So Rich? (Cambridge: Harvard University Press, 2000), 148 ff.

17 For a thorough treatment of the issue and a plea for dealing with it primarily from the perspective of equality, see Christian Helmrich, Mindestlohn zur Existenzsicherung, dissertational manuscript on file with the authors, 190; the dissertation is forthcoming with Nomos in 2015; Part IV. 
of children towards their parents) - provided that it is acknowledged at all - is also complex. Again, kinship is a possible explanation, but so is (some abstract notion of) reciprocity. In short, the exact line of reasoning might differ. But, in all these cases, the personal relationship is the reason for ascribing an increased obligation among individuals and which legitimises a policy that benefits one and burdens the other.

This pattern need not be confined to family relationships, but might be found also in other contexts. Employment law is a case in point. In this field, contracts typically come with an increased degree of permanence and maybe personal proximity between the parties. Hence, the justification for burdening an employer with sick or maternity pay, for example, may be sought in a moral duty of (arguably reciprocal) care and loyalty between employer and employee.

This justification is certainly more contestable here than in the context of family law. But it is still not implausible, especially not in legal systems whose employment law recognises such mutual duties. However, it does not necessarily work for all relevant examples from employment law. Minimum wage regulation, for instance, is harder to justify in this way because it applies already at the beginning of any employment contract, when there is no pre-existing relationship upon which the assumption of such an increased obligation could be based. ${ }^{18}$

\subsection{Justifications based on practical considerations}

Minimum wage regulation is not the only case in which the above line of reasoning does not work. The same is true for other contractual relationships without a comparable degree of permanence and proximity. From our list of examples, enforcement law comes to mind. It would hardly be plausible to claim that any creditor bears an increased moral responsibility for the debtor.

So, we need to look for another kind of justification. Here, and in other cases, it seems to be not moral, but practical considerations that account for burdening the private individual. Burdening the creditor is necessary to prevent a circle in which whatever the creditor takes from the debtor will be substituted by welfare grants that the destitute debtor might receive. And it might be justifiable because it only increases a risk that the creditor bears anyway - that is, the risk of the debtor's insolvency.

Similarly, minimum wage rules may be justified on pragmatic grounds. The same purpose, to be sure, could be achieved by relying solely on tax-financed benefits. But a plausible rationale that may justify burdening the employer instead is that wage regulation gives an incentive to work and prevents employers from keeping wages artificially low because of supplementary public assistance to the poor.

18 Ibid. 


\subsection{Assessing the relevance of these justifications}

The considerations that we have sketched here may or may not be viewed as sufficient justifications. One might disagree with the moral ascriptions of responsibility as suggested before, and in the case of merely practical justifications, it might be all the more contestable whether they are important enough to outweigh the unequal burden to the individual. Accordingly, it is not just the kind and weight of the justification that is important. It is also relevant to identify on whom the burden is placed and how intense it is.

The above examples differ significantly with regard to these aspects. Most notably, we have to ask especially in the employment context whether the burden could possibly be passed on so it would ultimately be borne by consumers and hence spread much more widely. Similarly, one should recall that de jure we often treat entities as individuals which de facto they are not. The 'employer' will often be a corporation (which is why it seems more appropriate in such cases to speak of individual actors rather than individuals or individual persons). This, too, entails that the burden is spread. And even if either type of burden-spreading is not systematic in the way it is true for the collective burden-spreading schemes described before, both types do reduce the impact of the unequal burden on each individual person involved.

\subsection{Interim summary}

We end our sketchy review of potential justifications here. We have raised many issues and, admittedly, left most of them unresolved. However, it is not only impossible to solve any of them in the abstract setting of this article, without reference, that is, to any specific positive legal order, but it is also unnecessary for the purposes of our argument. We had shown before that it is not unusual for policies to place an unsystematic and disparate burden on individuals, but that such unequal treatment requires a justification, and we have now presented a variety of considerations that are relevant when considering the justifiability of such disparate burdens and of AAPs in particular.

\subsubsection{Transferring justifications}

AAPs differ from the policies we reviewed in the previous sections in that we can identify not just one, but two distinct individual actors who incur a disparate burden. These are the burdened addressee and the disadvantaged competitor. Any justification for AAPs will have to distinguish between their respective situations. We will do that when we now apply the above considerations to AAPs.

\subsection{The unavailability of individual moral obligations as justification for AAPs}

In the context of AAPs, it is hard to postulate a moral obligation on the burdened individual actors towards the beneficiaries. At least, personal proximity is unlikely 
to play a role. This is evident in the case of the disadvantaged competitor who will typically not even (get to) know the beneficiary. The same is true for the burdened addressee if the AAP is targeted at the first contact between burdened addressee and beneficiary. This is likely to be the case for admission, appointment, or hiring scenarios. A counter example is the case of promotion decisions within one enterprise when there is indeed a pre-existing relationship. However, such situations will be less frequent, and they are also ambivalent because the employer will then be similarly proximate to the disadvantaged competitors, resulting in a collision of responsibilities.

A basis for assuming a moral obligation that is more plausible than personal proximity may be past injustice. AAPs are employed against the background of longstanding discrimination, and they might hence be interpreted as an attempt to rectify the disadvantages that their group of beneficiaries suffered in the past and that have persisted into the present. Today's benefits may hence be seen as a means to compensate for yesterday's injustice. The problem with this reasoning, however, is that the individual link across time cannot typically be established. AAPs cannot ensure that their beneficiaries have indeed suffered any disadvantage, nor that the burdened individual actors (disadvantaged competitor and burdened addressee) have enjoyed any advantage or caused any disadvantage.

This is not to say that such a personal link is indispensable to justify AAPs. We acknowledge that this issue is contested and reserve judgment on it. But we maintain that such a link would indeed be necessary if the justification for AAPs were to be based on a moral obligation on the burdened individual actors towards the beneficiaries to compensate them for injustice suffered in the past.

\subsection{Justifying AAPs through practical considerations}

While we cannot see how individual moral obligation might justify the disparate burden that AAPs entail, we think that practical considerations may be more successful in this regard. AAPs differ from the other examples we have listed in that their aim is usually not purely pecuniary. Of course, getting a job or a university degree may have positive pecuniary effects for the beneficiary. But that is not the only purpose of AAPs, and arguably not even the primary one.

Rather, they guarantee access to and representation in spheres of social life that would otherwise be foreclosed to many of their beneficiaries. This additional, nonpecuniary purpose renders them harder to replace. While in the case of pecuniary purposes there is always the alternative of employing a policy financed through a systematic burden-sharing scheme instead, this is not possible for AAPs.

If you want, for instance, more members of a disadvantaged group in tertiary education, it is not possible to just 'buy admission' for them instead of using an AAP. 
There may be other options, to be sure, such as investing in their primary and secondary education so they may eventually not need an AAP. This could indeed lead to the same outcome, but only in the long-term and with less certainty - which illustrates our point. When dealing with AAPs, it is harder to find policies that are functionally equivalent than it is for policies whose purpose is pecuniary.

This is an important aspect, and it makes the justification of AAPs easier. It does not mean, though, that they are always justified. It may well be that their aim is not (considered) important enough to outweigh the disparate burden they entail. One needs to look, hence, to the other side and assess the weight of that burden. This weight will differ considerably for the two categories of burdened individual actors.

For the burdened addressee, there are various factors that may reduce this burden. First, the burdened addressee may not get the candidate of its preference. But it does get another candidate instead. As pointed out before, it will depend on the circumstances of the specific case - and on the design of the AAP - how relevant that burden is. Second, it may well be that this burden is spread on many shoulders - namely, when the burdened addressee is a corporation consisting of many individuals or when it is able to pass the burden on to its 'customers'.

For the disadvantaged competitor, by contrast, none of these mitigating factors comes into play. She does not get anything instead, and must alone bear the burden, which may, as we have pointed out before, be significant.

\subsubsection{Interim summary}

Our discussion of the 'argument from equality' has shown that the unsystematic disparate burdening of individual actors that is characteristic of AAPs is by no means uncommon for policies that seek to promote equality. Nonetheless, such burdening requires a justification. This will, in turn, ultimately depend on the specific policy and the legal system in question. But it could be shown in our discussion above that the absence of alternative policy options that are functionally equivalent will typically serve as a relatively strong practical consideration in favour of AAPs, while the countervailing objections are different for either category of burdened individual actor. The disparate treatment that the burdened addressee suffers is mitigated by a number of factors and is thus easier to justify. However, this is not the case for disadvantaged competitors. It is here in particular that our defence of AAPs still needs to be expanded. We will come back to this aspect in particular once we have discussed the 'argument from personal autonomy' in the next section.

\subsubsection{The argument from personal autonomy}

As mentioned in the first section, there is yet a second critical objection directed against AAPs. Unlike the 'argument from equality', this second objection is not 
concerned with the unequal distribution of the burden resulting from AAPs, but rather with the very nature of such burden. The perceived unfairness of AAPs stems in this case from the fact that the burden they create is per se problematic and should, at least in principle, be eschewed. The burden at hand refers to the unwarranted intervention in the personal autonomy of the addressees of AAPs who will have their decisions at least in part determined by these policies. The central claim of the 'argument from autonomy', then, is that AAPs unduly infringe upon the individual autonomy of their addressees.

Our discussion of this argument will begin by specifying the reasons that individual autonomy, according to common paradigms, is considered worthy of protection, and how this relates to our context (3.4.2.1). In a second step, we shall call into question the core premises of these paradigms. In order to do so, we will briefly introduce findings from research in social psychology (3.4.2.2), explain how they weaken the autonomy-based arguments in our context (3.4.2.3), and discuss their implications for the choice of EOPs in particular (3.4.2.4).

\subsubsection{Why personal autonomy may be worth protecting}

Infringement of personal autonomy is problematic for different reasons. One may, first, consider autonomous decision-taking an element of individual liberty. Any restriction will then be undesirable for the sake of the affected individual. Autonomy, in this view, is an end in itself.

But it may also, second, be considered a means to another collective end, and that is economic efficiency. Autonomy, in this perspective, is not only a source of personal well-being, but also a means of attaining an optimal allocation of scarce economic resources in society. Individuals in economic environments are taken to have the goal of maximising the utility they derive from the allocation of scarce resources, and therefore a rational and self-serving individual makes choices that she considers most 'efficient' - that is, suitable to attain the desired ends with the minimum amount of inputs. The aggregation of such efficient individual choices leads to collective utility maximisation. External interference in decision-making - inherent to AAPs - reduces such efficiency. Employers, for instance, are not allowed to choose the job candidates they consider best. Universities are not allowed to enrol the students whom they find most suitable. The efficiency of utility-maximising decision-making is impaired, and all of society is negatively affected through aggregate utility losses.

As these examples illustrate, the second efficiency-related argument is but the flipside of what we have discussed before within the context of the argument from equality. ${ }^{19}$ This is because the alleged collective loss consists of the aggregated losses that the burdened addressees of an AAP incur by being forced to take (what they

19 See 3.4.1. 
perceive as $)^{20}$ sub-optimal decisions. This loss is quantifiable in pecuniary terms. As EOPs often come with such a burden, AAPs face particular objections only to the extent that the individual is burdened disparately. This aspect is what we have discussed in the preceding section. It may therefore be disregarded here.

In our context, autonomy is therefore relevant only from the first perspective that views it as a component of individual liberty. This is not to say it is not important. Quite to the contrary, liberty is among the core values that modern polities commonly subscribe to, and individual autonomy no doubt is an important component of it, arguably even its most fundamental one.

It should be noted, however, that in our specific context the actors subject to such restrictions of their liberty are often not individuals, but corporate entities, such as universities and firms that act as employers. It is true, to be sure, that it is ultimately individual persons who act for such collective bodies. But the fact that they do not act for themselves, but for and as parts of such bodies may weaken the concern for their autonomy. The efficiency effects will be no different. But as we are focusing on the dimension of personal liberty, the difference would seem relevant. Corporations are not as such capable of personal liberty, and while the individuals who act for them are, it is quite common that the law requires these individuals to accept limitations of their liberty as long as they act for a corporation.

In sum, this section was meant to explicate why personal autonomy is worthy of protection - and to what extent this is relevant in our context. We have thus identified the object now of the 'argument from personal autonomy'. In the next section, we will take a closer look at its underlying premises.

\subsubsection{The notion of autonomy and its behavioural premises}

The argument from autonomy is rooted not only in philosophical, but also behavioural assumptions. The latter are typically left implicit or underdeveloped in policy and legal debates. Both the value of individual autonomy and the presumed economic efficiency that results from it are based on the premise that individuals are capable of such autonomy - that is, that they can choose the goals to pursue as well as the reasons for doing so, and that they can decide and act accordingly.

Over the last decades, however, research from the field of implicit social cognition (ISC) has demonstrated that such behavioural assumptions rest on empirically shaky grounds. The idea of a rational and self-governing mind (the very behavioural underpinning of personal autonomy as a value and principle) has suffered severe blows from empirical research that reveals how little deliberate control and intent are actually involved in many of our most fundamental cognitive processes.

20 On the relevance of the difference between perceived and real loss in this context see 3.4.2.4. 
This field of research is of crucial significance for understanding the causes and nature of inequality in contemporary societies. If its findings are reliable - and the depth and range of empirical evidence suggests they $a^{21}$ - then individuals constantly stereotype, evaluate and discriminate without typically being aware of doing so. Beyond this - and even more problematic for the notion of a selfgoverning and 'autonomous' mind - such implicit constructions and processes often contradict the consciously endorsed values of actors and operate against their deliberate intentions, values and goals.

\subsection{The implicit dimensions of bias and behaviour}

Scientific interest in the unconscious dimensions of cognition and behaviour has existed since the development of psychoanalytic theory in the late nineteenth century. Nevertheless, it was not until the 1970s that a systematic and empirically oriented research programme emerged to study the unconscious mechanisms underlying mental processes and action. ${ }^{22}$ It was at this time that social psychologists, drawing from methods developed in cognitive psychology, began to discover that people's actual judgements and behaviour systematically diverged from their consciously endorsed attitudes and beliefs. In seeking to understand these discrepancies, researchers found that in certain contexts, attitudes and behaviour could be better explained by mental processes that were neither controlled nor known by the individual. ${ }^{23}$ These were referred to as automatic and implicit.

21 Anthony G Greenwald \& Linda Hamilton Krieger, 'Implicit Bias: Scientific Foundations', Cal. L. Rev 94 (2006): 945, 946. For partial reviews of the emergence and consolidation of research in implicit social cognition, see: Anthony Greenwald, 'New Look 3: Unconscious Cognition Reclaimed', Am. Psychol. 47 (1992): 766, on early empirical evidence and measurement of implicit cognition; Nilanjana Dasgupta, 'Implicit Ingroup Favoritism, Outgroup Favoritism, and Their Behavioral Manifestations', Soc. Jus. Research 17 (2004): 143 , on the specific development of research on implicit ingroup and outgroup preferences and their impacts on social interaction; and Irene V Blair, 'Implicit Stereotypes and Prejudice', in Cognitive Social Psychology: the Princeton Symposium on the Legacy and Future of Social Cognition, ed. Gordon B Moskowitz (Hillsdale: Erlbaum, 2001), 359. On the methodological validity and political relevance of implicit bias research, see John T Jost, Laurie A Rudman, Irene Blair et al., 'The Existence of Implicit Bias is Beyond Reasonable Doubt: A Refutation of Ideological and Methodological Objections and Executive Summary of Ten Studies that no Manager Should Ignore', Research in Organizational Behavior 29 (2009): 39-69.

22 Patricia Devine \& Margo Monteith, 'Automaticity and control in stereotyping', in Dualprocess Theories in Social Psychology, eds. Shelly Chaiken \& Yaacov Trope (New York: Guilford Press, 1999), 339.

23 For one of the first demonstrations of implicit intergroup bias, see Samuel L Gaertner \& John P McLaughlin, 'Racial Stereotypes: Associations and Ascriptions of Positive and Negative Characteristics', Soc. Psychol. Q. 46 (1983): 23. The authors sought to assess the 
Social psychologists use these terms to designate mental processes that operate outside the realm of conscious awareness and control, distinguishing them from their explicit and controlled counterparts. The terms 'implicit' and 'explicit' refer to the perceiver's level of awareness of a psychological process. A process is explicit if it can be consciously detected and reported (regardless of whether it was triggered spontaneously), and implicit if it cannot be directly inferred through introspective awareness. ${ }^{24}$ The terms automatic and controlled are used to indicate whether a process is intentional - that is, desired by the perceiver - or unintentional. ${ }^{25}$

\subsection{Measuring implicit bias}

But what exactly are implicit mental processes and how can they be measured? Obtaining access to mental constructs of which subjects are unaware posed important methodological challenges for empirical researchers. In fact, the development of a research programme on implicit cognition is directly linked to the development of new empirical tools that allowed scientists to access and measure processes that would, under normal conditions, be distorted by intentional dissimulation or concealed by introspective inaccessibility. Such 'indirect' (that is, unobtrusive) measurement techniques used devices such as time constraints and subliminally activated cues in order to access and measure mental processes that operated automatically (that is, without the subject being able to exert control) or implicitly (that is, without the subject's awareness).

strength of implicit stereotypes by measuring how quickly and easily certain traits and attributes 'pop into mind' when people see the name or picture of a particular social group. Their hypothesis was that implicit stereotypes should facilitate stereotype-congruent associations, and that the strength of such associations could be measured by the time it took individuals to identify stereotype-congruent words after being exposed to a cue of a social group. The researchers found that participants categorised African-American stereotype words more quickly when they were paired with the group label 'black' than the label 'white'. Respondents were faster to identify word pairs such as white-ambitious and black-lazy, and this was taken as evidence that the prime (social category) and target word (attribute) were included among common semantic networks that operate without the perceivers' awareness or control. Furthermore, the degree of bias on priming tasks was often unrelated to subjects' selfreported racial attitudes and beliefs. See also Patricia Devine, 'Stereotypes: their Automatic and Controlled Components', J. Personality and Soc. Psychol. 56 (1989): 5, on the dissociation between the implicit and explicit components of stereotyping and their impact on behaviour.

24 Anthony G Greenwald \& Mahzarin R Banaji, 'Implicit Social Cognition: Attitudes, SelfEsteem, and Stereotypes', Psychol. Rev. 102, no. 1 (1995): 4-5. See also Timothy D Wilson, Samuel Lindsey \& Tonya Y Schooler, 'A Model of Dual Attitudes', Psychol. Rev. 107 (2000): 101 , for an account of the dissociation between implicit and explicit attitudes, and on the persistence of implicit attitudes even after explicit attitudes have been changed.

25 It is important to state that the dichotomy between implicit and explicit is a somewhat artificial one, and it would be more accurate to represent mental processes along a continuum that ranges from more implicit to more explicit - see e.g. Blair, 'Implicit Stereotypes and Prejudice', 361. 
The development of the Implicit Association Test (IAT) in the late 1990s represented a crucial step in the implicit bias research programme. The IAT is 'a reaction-time measure that captures the strength with which social groups (and other attitude objects) are implicitly and automatically associated with good/bad evaluations and other characteristics. ${ }^{26}$ The test is used to assess strengths of associations between concepts by measuring response latencies in computer-administered categorisation tasks. ${ }^{27}$ The implicit nature of the associations measured through the IAT is reinforced by the accelerated speed at which responses are required. The speed of the test is assumed to reduce or eliminate the interference of conscious awareness or control.

The use of such methods has allowed researchers to demonstrate that stereotypes and prejudice operate largely on implicit and automatic levels, meaning that individuals rely on stereotypes and prejudiced evaluations without realising or controlling these processes. The presence of implicit biases is widespread, and even consciously low-prejudiced individuals who subscribe to egalitarian values and condemn prejudice and discrimination have been shown to possess high levels of implicitly biased attitudes and judgements. And this is true for the vast majority of individuals. Bias against women, ethnic and cultural minorities, the elderly and other historically disadvantaged social groups is pervasive. A recent study compiling accumulated results of the IAT revealed that the majority of respondents had implicit preferences for young relative to old people, for European Americans relative to African Americans, for heterosexuals relative to homosexuals, and the list goes on.$^{28}$

26 See Jost et al., 'The Existence of Implicit Bias is Beyond Reasonable Doubt: A Refutation of Ideological and Methodological Objections and Executive Summary of Ten Studies that no Manager Should Ignore'

27 The IAT is designed in the following way: in an initial block of trials, exemplars of two contrasted categories (e.g. face images of young or old people) appear on the screen and subjects classify them by pressing one of two keys (e.g. 'i' for young people and 'e' for old people). Next, exemplars of another pair of contrasting concepts are also classified using the same keys (e.g. key 'i' for words with positive valence and ' $e$ ' for words with negative valence). Then, in a first combined task, participants categorise the four words using the two keys, each of which has two response options mapped into it (e.g. 'e' for young or positive and ' $i$ ' for old and negative). In a second combined task, the complimentary pairing is used (e.g. 'e' for young or negative and ' $i$ ' for old and positive). The difference in average response latency between these two sets is known as the IAT effect, meaning that larger IAT effects reflect stronger implicit associations between concept pairings. In the example above, faster responses for the [young-positive] and [old-negative] task than for the [young-negative] and [old-positive] task indicate a stronger association of young than of old with positive valence, and the greater the difference between average response latencies, the more the participant is biased towards the category 'young'.

28 Greenwald \& Krieger, supra 'Implicit Bias: Scientific Foundations'. 
It is worth pausing at this point to revisit our initial categorisation of different layers of EOPs in light of these findings. It may be hard to gauge exactly how relevant a factor individual discriminatory decisions are for social inequality - and how much need there is, hence, for third-layer EOPs that target this factor. But the pervasiveness of bias, as shown by these studies, no doubt underscores the relative weight of this particular cause of inequality, and of the importance of the policies that we are discussing in this article.

\subsection{From implicit bias to behaviour}

The implicit mental processes as described above would not be a problem for policymakers and legal practitioners if automatic and uncontrolled prejudices and stereotyping remained only in the minds of individuals and were never translated into biased responses and discriminatory conduct. But unfortunately, this does not seem to be the case. A growing body of evidence suggests that people do make significant social decisions and behave according to their implicit stereotypes and prejudices, without intending to or even being aware of doing so.

Furthermore, implicit biases have been shown to affect behaviour even in situations in which time constraints or attention manipulations do not pose major challenges to reflexive decision-making. A meta-analysis of 122 studies correlating implicit and explicit biases with behaviour has shown that in settings that involve inter-group interactions - that is, interactions between groups that differ in respect of ethnicity, age, skin colour or gender - the predictive validity of implicit bias measures significantly exceeds that of self-report measures. This data strongly suggests that the terms of such inter-groups interactions and discrimination are largely driven by implicit biases and not by explicit beliefs or attitudes. The majority of people judge and discriminate unknowingly, and this poses a definite challenge to how traditional $\mathrm{ADL}$ addresses this type of behaviour.

A further challenge stems from the fact that, in addition to being unaware of the biases that lead to discrimination, individuals have a very limited ability to correct these implicit mental processes. In studying how individuals reconcile their consciously endorsed egalitarian values with implicit stereotypes and prejudice, researchers have found that, when reminded of such values, actors are more likely to rationalise biased decisions than to reduce their level of bias. ${ }^{29}$ This is done by reconstructing or adapting the criteria used in decision-making in a way that will justify the biased decision in a neutral matter. Such ex-post rationalisation process is termed casuistry,

29 See Michael I Norton, Joseph A Vandello \& John M Darley, 'Casuistry and Social Category Bias', J. Personality and Soc. Psychol. 87 (2004): 817, for a general account of how, given the time and resources, individuals will tend to implicitly mask biased decision-making by deploying more acceptable criteria to justify their choices. 
and it occurs independently of conscious awareness or control. This demonstrates that even when the individual has time and cognitive energy at her disposal, these resources may be used to rationalise bias instead of suppressing it. ${ }^{30}$

Even more importantly for anti-discrimination policy, it has also been shown that certain social cues that increase pressure on the decision-maker to be objective will enhance casuistry instead of reducing bias. In a hiring-scenario experiment, Lindner et al. have demonstrated that, when an equity norm prohibiting discrimination is enunciated during the decision-making process, participants retrospectively reported their decisions to be based on more bias-neutral criteria and less on social category information. Nevertheless, on average, the decision of participants remained just as biased in the presence of the equity norm as in its absence, showing that stating such a norm had the effect of increasing casuistry rather than reducing bias. ${ }^{31}$

\subsubsection{Why personal autonomy may not be that worthy of protection after all}

As we have seen in this section, the cognitive underpinnings of social interaction in general and of discriminatory behaviour in particular are difficult to reconcile with the notion of personal autonomy that underlies public policies in this field. We discriminate without even being aware of it - not all, to be sure, but most of us, and most of the time. What is more, even if made aware of it, we have only very limited capacity to control and correct our behaviour accordingly. And all of this applies regardless of, and often despite, our deliberate intentions and consciously endorsed values.

The question we are left with in light of this evidence, then, is: what autonomy are we talking about? Our mind does still appear to be capable of a situative will, of course. And it is plausible to label this mind 'autonomous' in the sense that it is not governed by anyone else (although there is growing evidence on its dependence upon external cues and thus on its susceptibility to manipulation). ${ }^{32}$ But does this

30 Ibid.

31 Nicole M Lindner, Brian A Nosek \& Alexander Graser, 'Age-Based Hiring Discrimination as a Function of Equity Norms and Self-Perceived Objectivity' (31 May 2012), available at SSRN: <http://ssrn.com/abstract=2071447> or <http://dx.doi.org/10.2139/ ssrn.2071447>.

32 For partial reviews of the literature on the malleability of implicit bias, see Irene V Blair, 'The Malleability of Automatic Stereotypes and Prejudice', Personality and Soc. Psychol. Rev. 6 (2002): 242; and Margo J Monteith \& Corrine I Voils, 'Exerting Control Over Prejudiced Responses', in Cognitive Social Psychology: The Princeton Symposium on the Legacy and Future of Social Cognition, ed. Gordon B Moskowitz (Hillsdale: Erlbaum, 2001), 375. See Nilanjana Dasgupta \& Anthony G Greenwald, 'On the Malleability of Automatic Attitudes: 
mind really deserve respect for its autonomy? Or rather, as our unitarian notion of the mind becomes increasingly doubtful, does the part of our mind that is particularly determinative of our social interactions deserve such respect, at least when dealing with matters of discrimination? And would it not, conversely, even be warranted to intervene in favour of the deliberate, conscious part of our minds?

It would seem that this conscious, deliberate will is what traditional notions of autonomy presume. If this presumption is eroded, so is the basis for affording autonomy the close-to-sacred position that it enjoys in our law and morality. And this is true for both perspectives from which this position can be justified - the efficiency and the individual liberty perspective.

This is not to say that we need to abandon the idea(l) of personal autonomy altogether. There are elements left of it, and the degree of its erosion depends on the specific context. But - and that is our core conclusion here - the reasons for protecting personal autonomy are particularly weak when we deal with the kinds of social interaction that are targeted by third-layer EOPs in general and by AAPs in particular.

\subsubsection{What this may imply for public policy}

What this means for the initial question of this section is evident. In light of the findings from ISC, the 'argument from personal autonomy' loses much of its weight. AAPs will hence be easier to justify in that regard.

This point can be reinforced if we consider not just AAPs and their absolute desirability, but widen the perspective so as to look at their relative attractiveness compared to other policies. More specifically, we pointed out before that the most widespread among those EOPs that target individual decisions - among third-layer EOPs, that is - are not AAPs, but ADLs. Further, we speculated that such prevalence of ADLs may be explicable by the fact that they are less intrusive with regard to the personal autonomy of their addressees than is the case with AAPs. Now, in light of the evidence presented above, such preference should be reconsidered. This is partly because, as we have just pointed out, any argument from personal autonomy becomes less powerful when assessed against this background. But it is also because ADLs appear much less promising. For how could a command not to discriminate achieve its goal if its addressee is not even aware of her bias, let alone able to control it? The implication is that the relative attractiveness of AAPs compared to ADL should increase.

Combating Automatic Prejudice with Images of Admired and Disliked Individuals, J. of Personality and Soc. Psychol. 81, no. 5 (2001): 800, for evidence on the impact of exposure to counter-stereotypic group members on automatic prejudice. 
Moreover, as we have said, our considerations on the argument from personal autonomy have an impact also on the argument from equality. We ended our discussion of that latter argument stating, that the disparate treatment that the burdened addressee suffers was typically easier to justify than that of the disadvantaged competitor because in the latter case, we could identify fewer mitigating factors. ${ }^{33}$

Now, the findings presented in this section add such a mitigating factor for this case in that they cast new light on the term 'disadvantaged competitor'. Taking into account the data on the pervasiveness of implicit bias, these competitors are very likely to be advantaged on innumerable occasions in daily life. In many and maybe the majority of cases, the effect of AAPs may thus be described more properly as an attempt to level out advantage, rather than as bringing about disadvantage for these competitors.

Along the same lines, the pervasiveness of bias also entails that the perceived economic loss that the burdened addressee incurs from being prescribed a choice different from its first priority will in many cases not be real. This is because such preferences of the burdened addressee are likely to be affected by implicit bias and hence not to be governed exclusively by economic rationality. This in turn means that one cannot generally presume that the foregone choice would have been the best choice, and necessarily better for the burdened addressee than the one imposed upon the addressee by the AAP in question. In other words, given the quantitative dimensions of implicit bias, there are likely to be many cases in which an AAP does not constitute a 'burden' to its addressee, but rather helps her avoid a biased and economically unwise decision and replaces it with an economically wiser one.

\subsection{Conclusion}

Our conclusion comes as no surprise. We announced from the outset that we were making a case for AAPs - or rather 'the case against the case against AAPs', because our strategy was to identify the critical objections against AAPs and then to counter them. For this purpose, we contextualised AAPs within the broader spectrum of related policies, reviewed the potential objections briefly, distinguished between equality and autonomy-related ones, and discussed them from different disciplinary perspectives.

More specifically, regarding the 'argument from equality', we suggested that a core problem with AAPs is that the burden that they entail is mainly borne by certain individual actors, and we discussed how such unequal treatment can be justified. In

33 See 3.4.1.4. 
this regard, we distinguished between two categories of individual actors, burdened addressees and disadvantaged competitors, and found that unequal treatment of the former category will typically be justifiable. With regard to the latter category, our preliminary conclusions were more ambivalent. Although the same justificatory considerations apply as for the other category, the burden seemed weightier here, and its justification hence more difficult. This initial assessment could be corrected, though, in light of our discussion of the 'argument from autonomy', an implication of which is that the burden is likely to be less relevant in many of these cases than is commonly perceived.

Regarding the 'argument from autonomy', we showed how the idea of an autonomous mind has suffered a hard blow from recent findings in the field of implicit social cognition. Individual decisions are constantly made based on criteria and premises that the individual is not aware of and cannot control, and that are systematically biased against disadvantaged social groups. These findings call into question the behavioural underpinnings that justify the protection of individual autonomy in various contexts, including ours in particular. It becomes clear against this background that the ideal of personal autonomy cannot justify the preference for other third-layer EOPs to the detriment of AAPs. Moreover, it also follows from these findings that with regard to the 'argument from equality', the unequal burden that a 'disadvantaged' competitor incurs due to an AAP may often prove not to be a burden at all, but rather may just level out the undue advantage that this competitor enjoys because of implicit biases on part of decision-takers.

In sum, the result of our endeavours has obviously not been to sweep away the critical objections to AAPs. It would have been naïve to try to do so after decades of learned debates on this matter. But we hope to contribute to sharpening the issues, and indeed also to weaken these objections considerably. So, in short, the game is not over. The justification of AAPs is still contestable. But we are playing the ball back to their opponents. Our article, hence, is an extensive 'Why not?' 


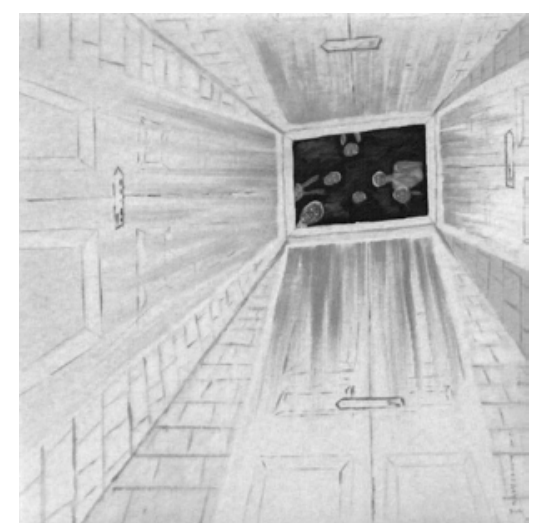

\title{
4
}

\section{AN INTERNATIONAL PERSPECTIVE ON AFFIRMATIVE ACTION}

\author{
Tzehainesh Teklè
}

\section{I Introduction}

The concept of affirmative action does not appear as such in the great majority of international legal instruments, but it is encompassed in the expression 'special measures', which is found in a number of human rights treaties and international labour standards (ILS). The bodies supervising the application of these international instruments at national level have played a significant role in clarifying that these measures include affirmative action and have provided guidance on its parameters and their implementation.

* The views expressed here are solely those of the author in her private capacity and do not in any way represent the views of the International Training Centre of the ILO, or the ILO, or any other entity of the UN system. The author is grateful to Mark Bell and Martin Oelz for their comments and Pietro Messina for his research assistance. 
The purpose of this chapter is to examine and compare the approach to affirmative action adopted by the international human rights system and the international labour law system respectively, with references also made to non-legal contributions on the subject coming from the United Nations (UN) and the International Labour Organisation (ILO). Looking at international human rights instruments and international labour standards, as well as the pronouncements of the relevant supervisory bodies, the chapter examines how the objectives of affirmative action have been conceived and it analyses the relationship between affirmative action and the principles of equality and non-discrimination. The chapter also looks at the typology of measures included under the notion of affirmative action and its areas of application. It assesses whether and how the identification of beneficiaries is dealt with and examines the conditions established for the legitimacy of affirmative action measures, as well as the modalities for their adoption and follow-up. It also looks at whether affirmative action is considered obligatory or merely to be encouraged. The chapter concludes with a synthesis of the similarities and differences existing between the international human rights law system and the international labour law system and within the two respective systems. It, finally, reflects on the adequacy of the construction of affirmative action in these two systems in response to the pervasive phenomenon of discrimination.

\subsection{Affirmative action and international human rights law}

Special measures are provided for in the international human rights instruments concerning racial discrimination and discrimination against women - that is, the United Nations Declaration on the Elimination of All Forms of Racial Discrimination; the International Covenant on the Elimination of All Forms of Racial Discrimination (ICERD); and the International Convention on the Elimination of All Forms of Discrimination against Women. Moreover, they are encompassed in the UN Convention on the Rights of Persons with Disabilities; and in the International Covenant on Civil and Political Rights (ICCPR); and in the International Covenant on Economic, Social and Cultural Rights (ICESCR).

The United Nations Declaration on the Elimination of All Forms of Racial Discrimination adopted in 1963 has been the first UN human rights instrument dealing with special measures. Article 2(3) states:

Special concrete measures shall be taken in appropriate circumstances in order to secure adequate development or protection of individuals belonging to certain racial groups with the object of ensuring the full enjoyment by such individuals of human rights and fundamental freedoms. These measures shall in no circumstances have as a consequence the maintenance of unequal or separate rights for different racial groups. (italics added) 
This article constitutes the predecessor of two similar provisions included in the ICERD adopted in 1965 - that is, articles 1(4) and 2(2). Article 1(4) clarifies that special measures do not constitute discrimination:

Special measures taken for the sole purpose of securing adequate advancement of certain racial or ethnic groups or individuals requiring such protection as may be necessary in order to ensure such groups or individuals equal enjoyment or exercise of human rights and fundamental freedoms shall not be deemed racial discrimination, provided, however, that such measures do not, as a consequence, lead to the maintenance of separate rights for different racial groups and that they shall not be continued after the objectives for which they were taken have been achieved. (italics added)

Article 2(2) goes further and provides that special measures may be required in certain circumstances:

States Parties shall, when the circumstances so warrant, take, in the social, economic, cultural and other fields, special and concrete measures to ensure the adequate development and protection of certain racial groups or individuals belonging to them, for the purpose of guaranteeing them the full and equal enjoyment of human rights and fundamental freedoms. These measures shall in no case entail as a consequence the maintenance of unequal or separate rights for different racial groups after the objectives for which they were taken have been achieved. (italics added)

The relevant article in the Convention on the Elimination of All Forms of Discrimination against Women of 1979 is article 4(1), which states:

Adoption by States Parties of temporary special measures aimed at accelerating de facto equality between men and women shall not be considered discrimination as defined in the present Convention, but shall in no way entail as a consequence the maintenance of unequal or separate standards; these measures shall be discontinued when the objectives of equality of opportunity and treatment have been achieved. (italics added)

The human rights treaty bodies of the ICERD and the Convention on the Elimination of All Forms of Discrimination against Women - that is, respectively the Committee on the Elimination of Racial Discrimination (CERD) and the Committee on the Elimination of Discrimination against Women (CEDAW) - have issued recommendations on special measures, providing guidance on the interpretation of the articles providing them.

The International Covenant on Civil and Political Rights (ICCPR) and the International Covenant on Economic, Social and Cultural Rights (ICESCR) do not explicitly talk of special measures. These measures result from the interpretative statements of article 2(2) of the ICESCR and article 2(1) of the ICCPR included in the records of the respective drafting committees as a response to a proposal made 
by the representative of the Government of India. Drawing from the experience of his country, in respect of both the Covenants, the Indian representative had asked for either the insertion of an article expressly providing that ' $[\mathrm{s}]$ pecial measures for the advancement of any socially and educationally backward sections of society shall not be construed as distinctions under this article [art. 2]' or the formulation of a 'statement, which would make that interpretation clear.' 1 The same interpretation was made in regard to article 26 of the ICCPR ${ }^{2}$ which contains a general principle of equality extending beyond the enjoyment of the rights enshrined in the Covenant and which says:

\begin{abstract}
All persons are equal before the law and are entitled without any discrimination to the equal protection of the law. In this respect, the law shall prohibit any discrimination and guarantee to all persons equal and effective protection against discrimination on any ground such as race, colour, sex, language, religion, political or other opinion, national or social origin, property, birth or other status.
\end{abstract}

Both in the case of the ICESCR and the ICCPR, the relevant supervisory bodies (respectively, the Committee on Economic, Social and Cultural Rights (CESCR) and the Human Rights Committee) have adopted general comments clarifying the meaning and scope of special measures.

Special measures are also encompassed in the Convention on the Rights of Persons with Disabilities adopted in 2006 and which states that ' $[\mathrm{s}$ ] pecific measures which are necessary to accelerate or achieve de facto equality of persons with disabilities shall not be considered discrimination under the terms of the present convention. ${ }^{3}$

Special measures are also provided for outside the framework of the core international human rights treaties. ${ }^{4}$ This is the case in the 1978 UNESCO Declaration on Race and Racial Prejudice, which is considered to have become part of the international law of human rights.' ${ }^{5}$ Article 2 provides an obligation on States, where necessary, to take special measures. The objective of these special measures is 'to ensure equality in dignity and rights for individuals and groups [...], while ensuring that they are not such as to appear racially discriminatory'. Particular attention is requested to be paid to:

1 See United Nations Economic and Social Council, Prevention of Discrimination: The Concept and Practice of Affirmative Action, final report submitted by M Bossuyt, Special Rapporteur, in accordance with resolution 1998/5 of the Sub-Commission on the Promotion and Protection of Human Rights, Doc E/CN.4/Sub.2/2002/21, 17 June 2002, paras 40-1, 47.

$2 \quad$ Ibid., paras 47-8.

3 Art. 5(4).

4 See <http://www.ohchr.org/EN/HRBodies/Pages/HumanRightsBodies.aspx >.

5 Bossuyt, Prevention of Discrimination, para 62. 
racial or ethnic groups which are socially or economically disadvantaged, so as to afford them, on a completely equal footing and without discrimination or restriction, the protection of the laws and regulations and the advantages of the social measures in force, in particular in regard to housing, employment and health; to respect the authenticity of their culture and values; and to facilitate their social and occupational advancement, especially through education. ${ }^{6}$

\subsection{Affirmative action and international labour law}

The ILO Discrimination (Employment and Occupation) Convention, 1958 is the first international labour standard providing for special measures. Article 5(2) constitutes the legal basis for affirmative action under this convention and reads:

Any Member may, after consultation with representative employers' and workers' organizations, where such exist, determine that other special measures designed to meet the particular requirements of persons who, for reasons such as sex, age, disablement, family responsibilities or social or cultural status, are generally recognized to require special protection or assistance, shall not be deemed to be discrimination. ${ }^{7}$ (italics added)

The intention of encompassing affirmative action measures under the expression 'special measures' clearly results from the process that led to the adoption of the convention. The first report submitted to ILO member states by the secretariat of the organisation (that is, the International Labour Office), as part of the process of adoption of the Convention referred to 'distinctions [...] but with a favourable intention' such as 'special legislation for women workers; the granting of temporary privileges to indigenous workers to assist their integration into the community's As in the case of the above-mentioned human rights treaties, the committee of independent experts monitoring the implementation of international labour standards in member states (together with the tripartite Application Committee of the International Labour Conference) - namely, the Committee of Experts on

6 The UNESCO Convention against Discrimination in Education adopted in 1960 did not say anything about special measures. Reference to them is, however, contained in the travaux préparatoires, according to which these measures should be directed at meeting special requirements of persons such as backward children, the blind, immigrants and illiterate populations, thus pursuing equality.

7 Discrimination (Employment and Occupation) Recommendation No. 111 of 1958, which accompanies Convention No. 111, clarifies that '[A]pplication of the policy [the national policy designed to promote equality of opportunity and treatment as for art. 2] should not adversely affect special measures designed to meet the particular requirements of persons who, for reasons such as sex, age, disablement, family responsibilities or social or cultural status are generally recognised to require special protection or assistance' (para 6).

8 ILO, Discrimination in the Field of Employment and Occupation, Seventh Item on the Agenda, Report VII(1), International Labour Conference, 40th Session (Geneva, 1957), 30. 
the Application of Conventions and Recommendations (CEACR) - has often dealt with special measures. It has done so both in its comments to member states and in the general surveys, ${ }^{9}$ notably in the General Survey 1988 and the Special Survey $1996,{ }^{10}$ and in the General Survey $2012 .{ }^{11}$ However, unlike the human rights treaty bodies, the CEACR has not adopted any general observation on the subject.

Other international labour standards provide for special measures or for affirmative action, or similar expressions. Article 5 of the ILO Employment Agencies Convention No. 181 of 1997 establishes that ratifying states shall ensure that:

private employment agencies treat workers without discrimination on the basis of race, colour, sex, religion, political opinion, national extraction, social origin, or any other form of discrimination covered by national law and practice, such as age or disability.

Paragraph 2 of the same article clarifies that this should not prevent private employment agencies from providing 'special services or targeted programmes designed to assist the most disadvantaged workers in their jobseeking activities. The accompanying Recommendation No. 188 goes further and at paragraph 10 says, '[p]rivate employment agencies should be encouraged to promote equality in employment through affirmative action programmes' (italics added).

The Promotion of Cooperatives Recommendation No. 193 of 2002 also encourages the adoption of special measures 'to enable cooperatives, as enterprises and organizations inspired by solidarity, to respond to their members' needs and the needs of society, including those of disadvantaged groups in order to achieve their social inclusion. ${ }^{\prime 2}$

A number of international labour standards deal with special measures addressing specific groups. One of them is the Employment Policy Recommendation No. 122 of 1964, which provides that special measures should be taken to provide suitable

9 General Surveys are in-depth studies on member states' national law and practice on subjects chosen by the Governing Body of the ILO and produced on the basis of reports received from member states.

10 CEACR, Equality in Employment and Occupation: General Survey of the Reports on the Discrimination (Employment and Occupation) Convention (No. 111) and Recommendation (No. 111), 1958, Report III (Part 4B), International Labour Conference, 75th Session (Geneva, 1988); CEACR, Equality in employment and occupation: Special Survey on Equality in Employment and Occupation in respect of Convention No. 111, Report III (Part 4B), International Labour Conference, 83rd Session (Geneva, 1996).

11 CEACR, General Survey on the fundamental Conventions concerning rights at work in light of the ILO Declaration on Social Justice for a Fair Globalization, 2008, Report III (Part 1B) International Labour Conference, 101st Session (Geneva, 2012).

12 Art. 5. 
work [... and to alleviate hardship'13 of 'older workers, disabled persons and other workers who may find it particularly difficult to change their places of residence or their occupations.' ${ }^{14}$ The Employment Policy (Supplementary Provisions) Recommendation No. 169 of 1984 provides for the adoption of special measures for young people. ${ }^{15}$

A further instrument explicitly referring to special measures is the Vocational Rehabilitation and Employment (Disabled Persons) Convention, No. 159 adopted in 1983. Article 4 reaffirms the approach contained in Convention No. 111 affirming that ' $[\mathrm{s}]$ pecial positive measures aimed at effective equality of opportunity and treatment between disabled workers and other workers shall not be regarded as discriminating against other workers'.

Moreover, the Workers with Family Responsibility Recommendation No. 165 of 1981 affirms the non-discriminatory nature of 'special measures aimed at achieving effective equality between men and women' 'during a transitional period.' ${ }^{16}$

Two other conventions that provide for special measures are the ones concerning indigenous and tribal peoples - that is, the Indigenous and Tribal Populations Convention No. 107 of 1957, and the Indigenous and Tribal Peoples Convention No. 169 of 1989. Both provide for the adoption of 'special measures to ensure the effective protection with regard to recruitment and conditions of employment of workers' from indigenous and tribal peoples. ${ }^{17}$ Convention No. 107 envisages that these measures should last 'so long as they are not in a position to enjoy the protection granted by law to workers in general. ${ }^{18}$ Convention No. 169 emphasises that these measures are to be adopted 'to the extent that they [indigenous peoples] are not effectively protected by laws applicable to workers in general. ${ }^{19}$ A reading of these articles reveals that under Convention No. 169 the rationale for special measures is not the inability of indigenous peoples to enjoy the protection of the law, but rather the ineffectiveness of existing general legislation to protect members of these peoples. The other important innovation of Convention No. 169 vis-à-vis Convention No. 107 is that it provides that these measures should be adopted in co-operation with the peoples concerned. ${ }^{20}$

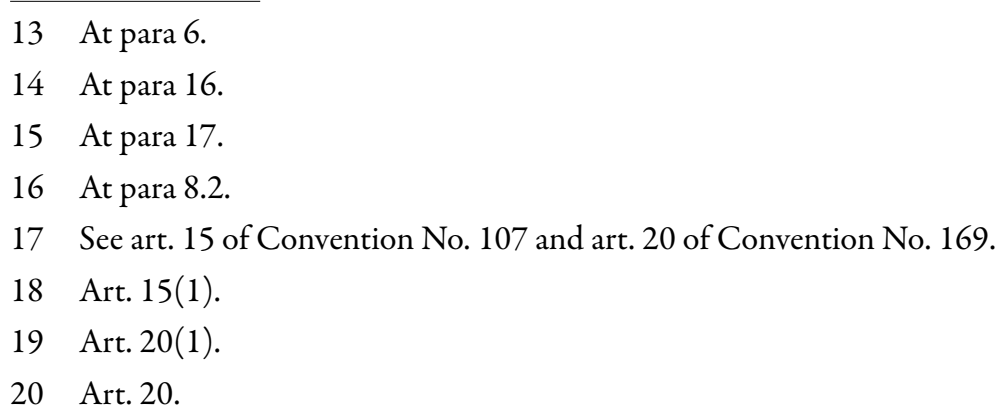


Both conventions envisage special measures in the framework of vocational training: 'Whenever existing programmes of vocational training of general application do not meet the special needs of the peoples concerned', special training facilities under Convention No. 107 and special training programmes under Convention No. 169 are adopted. ${ }^{21}$ Once again, the approach of the two conventions differs. Convention No. 169 provides: ' $[\mathrm{M}]$ easures shall be taken to promote the voluntary participation of members of the peoples concerned in vocational training programmes of general application.' ${ }^{22}$ In case of need, special programmes, and not special facilities that physically separate indigenous and non-indigenous people, should be developed.

Moreover, Convention No. 169 provides for the co-operation and consultation of indigenous peoples in the organisation and operation of special programmes and 'where feasible' and 'if they so decide', they 'shall progressively assume responsibility' for them. ${ }^{23}$ The patronising and assimilationist philosophy pervading Convention No. 107 shapes the formulation and implementation of the special training facilities. Their formulation is based on 'a careful study' not only of the economic environment but also of the 'stage of cultural development' and the 'practical needs of the various occupational groups among the said populations' (italics added). The special facilities are meant to 'enable the persons concerned to receive the training necessary for occupations for which these populations have traditionally shown aptitude'24 (italics added). On the other hand, the special training programmes under Convention No. 169 are to be developed on the basis of 'the economic environment, social and cultural conditions and practical needs of the peoples concerned ${ }^{25}$ and are inserted in a broader context where indigenous peoples' culture, traditional occupations and economies are recognised and promoted. ${ }^{26}$

Affirmative action also appears in instruments regarding gender equality other than international labour standards, that is, Conventions and Recommendations. This is the case in the ILO Declaration on Equality of Opportunity and Treatment for Women Workers of 1975, and the Resolution on Equal Opportunities and Equal Treatment for Men and Women in Employment adopted in 1985. ${ }^{27}$ They were both adopted by the International Labour Conference (ILC) and therefore obtained

\footnotetext{
21 Art. 17(1) of Convention No. 107 and art. 22(2) of Convention No. 169.

22 Art. 22(1).

23 Art. 22(3).

24 Art. 17(2) of Convention No. 107.

25 See art. 22(3).

26 See art. 23.

27 ILO, Resolution on Equal Opportunities and Equal Treatment for Men and Women in Employment, International Labour Conference, 71st Session, 1985.
} 
the endorsement of the highest body of the ILO where all member states in their tripartite composition are represented. The Resolution and the Declaration referred more than once to positive action as measures that should be part of the package of policies aimed at achieving gender equality.

In 2009, the International Labour Conference of the ILO adopted a new Resolution concerning Gender Equality at the Heart of Decent Work. In the debate leading to its adoption, the evaluation of the usefulness of affirmative action laws raised some controversy. ${ }^{28}$ The compromise reached was that the "[a]ffirmative action laws have proven to be successful in many cases in redressing past and continuing sex-based inequalities in the labour market' 29 (italics added). A straightforward recognition of the usefulness of affirmative action measures, including quotas, was made in regard to an equitable representation in tripartite bodies. ${ }^{30}$

A recent reaffirmation of the importance of affirmative action within the ILO was provided by the follow-up mechanism provided in the 1998 Declaration on Fundamental Principles and Rights at Work. ${ }^{31}$ Part of the follow-up has been the preparation of periodical reports (called 'Global Reports') providing a global picture on each fundamental principle and right every four years. ${ }^{32}$ These reports have been drafted by the International Labour Office and have then been discussed by the International Labour Conference. Three global reports have been published on equality and non-discrimination at work in 2003, 2007 and 2011.

\subsection{Affirmative action, its objectives and the principle of non-discrimination}

Both the international human rights system and the international labour standards system are explicit in considering that special measures and, thus affirmative action, shall not be deemed to constitute discrimination. But they have done more than this. They have clarified the relationship between special measures and the principle of equality and non-discrimination and explained the objectives of these measures.

28 See ILO, Gender equality at the heart of decent work, Report VI, International Labour Conference.

29 Ibid., para 32.

30 Ibid., para 44.

31 ILO Declaration on Fundamental Principles and Rights at Work, ILC, 86th Session (Geneva, 18 June 1998).

32 The four fundamental principles and rights at work under the 1998 Declaration are freedom of association and the effective recognition of the right to collective bargaining; the elimination of all forms of forced or compulsory labour, the effective abolition of child labour; the elimination of discrimination in respect of employment and occupation. 
The CERD's General Recommendation No. $32^{33}$ has elucidated the relationship between special measures and the principle of equality and non-discrimination by defining this principle as 'the basis for special measures.. ${ }^{34}$ Therefore, special measures are not an exception to the principle. General Recommendation No. 32 has also explained that when article 1(4) of the ICERD refers to adequate advancement' and article 2(2) of ICERD talks of 'adequate development and protection', they refer to the purpose of 'alleviating and remedying disparities in the enjoyment of human rights and fundamental freedoms affecting particular groups and individuals, protecting them from discrimination. ${ }^{35}$ Therefore, the CERD conceives the aim of special measures as remedial vis-à-vis past discrimination and preventive vis-à-vis future discrimination. The General Recommendation specifies that 'disparities' in the enjoyment of human rights and freedoms include (not exclusively) 'persistent or structural disparities and de facto inequalities resulting from the circumstances of history' that continue to have effect today by denying 'to vulnerable groups and individuals the advantages essential for the full development of the human personality. ${ }^{36}$ The language is thus different from that of the Convention. The General Recommendation presents the objective of special measures as to ensure the full development of the human personality, while the Convention, inspired by an 'integrationist philosophy, ${ }^{37}$ aimed to secure 'adequate advancement' of beneficiary groups. ${ }^{38}$

The General Recommendation specifies that while special measures address discrimination rooted in past circumstances and of which disparities and inequalities are indicators, they can be adopted without the need to prove the 'historic' nature of discrimination.

The CEDAW has also expressed itself on the relationship between the principle of equality and non-discrimination and special measures. General Recommendation

33 CERD, General Recommendation No. 32: The meaning and scope of special measures in the International Convention on the Elimination of All Forms Racial Discrimination, 75th Session, 3-28 August 2009.

34 Ibid., section II.

35 Ibid., para 22.

36 Ibid.

37 See P Thornberry, International Law and the Rights of Minorities (Oxford: Clarendon Press, 1993), 286.

38 The original version of para 4 of art. 1 of the Convention used the term 'under-developed'. Owing to the objections that it raised, the expression 'under-privileged' was suggested, but this was also not adopted. See N Lerner, The U.N. Convention on the Elimination of All Forms of Racial Discrimination (Leyden: Sijthoff \& Noordhoff, 1980), 33. 
No. 25 of $2004,{ }^{39}$ which is the most comprehensive pronouncement on this theme by the CEDAW, ${ }^{40}$ affirms that temporary special measures are not an exception to or a derogation from the principle of equality and non-discrimination but rather are among the means to achieve de facto or substantive equality:

The Convention targets discriminatory dimensions of past and current societal and cultural contexts which impede women's enjoyment of their human rights and fundamental freedoms. It aims at the elimination of all forms of discrimination against women, including the elimination of the causes and consequences of their de facto or substantive inequality. Therefore, the application of temporary special measures in accordance with the Convention is one of the means to realise de facto or substantive equality for women, rather than an exception to the norms of non-discrimination and equality. ${ }^{41}$

Similarly to CERD, the CEDAW affirms that the obligation of states parties to realise substantive equality 'exists irrespective of any proof of past discrimination. ${ }^{42}$ However, unlike the CERD, the CEDAW presents special measures as a tool to bring about 'the structural, social and cultural changes necessary to correct past and current forms and effects of discrimination against women, as well as to provide them with compensation. ${ }^{43}$ What the CEDAW does is to combine the traditional approach to special measures seen in terms of compensation or remedy for past discrimination with a more forward-looking view of equality - that is, equality as transformation. ${ }^{44}$ The latter implies tackling the structural dimensions of discrimination. Thus, General Recommendation No. 25 indicates that special measures do not intervene simply to modify the situation of the disadvantaged or discriminated groups, but they do so to change the institutions and structures so that they take into account the diversity of

39 CEDAW, General Recommendation No. 25, on art. 4, para 1, of the Convention on the Elimination of All Forms of Discrimination against Women, on temporary special measures, 30th Session, 2004.

40 See R Holtmaat, 'Building Blocks for a General Recommendation on Article 4(1) of the CEDAW Convention' Report of the Expert Meeting in Maastricht (Valkenburg), 10-12 October 2002.

41 CEDAW, General Recommendation No. 25, para 14.

42 Ibid., para 18.

43 Ibid., para 15.

44 See S Fredman, 'Beyond the Dichotomy of Formal and Substantive Equality: Towards a New Definition of Equal Rights', in Temporary Special Measures. Accelerating de facto Equality of Women under Article 4(1) UN Convention on the Elimination of All Forms of Discrimination Against Women, eds. I Boerefijn, F Coomans, JE Goldschmidt \& R Holtmaat (Antwerpen: Intersentia, 2003), 122. 
needs and concerns of both men and women. This approach is consistent with the vision of the Convention resulting from articles 3 and $5 .{ }^{45}$ Article 3 states:

States Parties shall take in all fields, in particular in the political, social, economic and cultural fields, all appropriate measures, including legislation, to ensure the full development and advancement of women, for the purpose of guaranteeing them the exercise and enjoyment of human rights and fundamental freedoms on a basis of equality with men.

Article 5 states:

States Parties shall take all appropriate measures: (a) To modify the social and cultural patterns of conduct of men and women, with a view to achieving the elimination of prejudices and customary and all other practices which are based on the idea of the inferiority or the superiority of either of the sexes or on stereotyped roles for men and women; (b) To ensure that family education includes a proper understanding of maternity as a social function and the recognition of the common responsibility of men and women in the upbringing and development of their children, it being understood that the interest of the children is the primordial consideration in all cases.

Another specificity of General Recommendation No. 25 is that it presents the achievement of equality of results as a 'logical corollary' of de facto or substantive equality. ${ }^{46}$ According to paragraph 8 , 'the Convention requires that women be given an equal start and that they be empowered by an enabling environment to achieve equality of results'. Equality of results is defined as either 'quantitative or qualitative in nature' and as corresponding to women 'enjoying their rights in various fields in fairly equal numbers with men, enjoying the same income levels, equality in decisionmaking and political influence, and women enjoying equal freedom from violence' 47 (italics added).

The CESCR has also defined the relationship between the principle of equality and special measures. This can be found in three general comments.

General Comments Nos. $13^{48}$ and $20^{49}$ have specified that the objective of special measures is the achievement of 'de facto equality for men and women and for disadvantaged groups' and to redress de facto and systemic discrimination. With

45 Ibid., 123.

46 CEDAW, General Recommendation No. 25, para 9.

47 Ibid.

48 CESCR, General Comment No. 13: The Right to Education (Art. 13 of the Covenant), 8 December 1999, E/C.12/1999/10.

49 CESCR, General Comment No. 20: Non-discrimination in economic, social and cultural rights (art. 2, para 2, of the International Covenant on Economic, Social and Cultural Rights), 2 July 2009, E/C.12/GC/20. 
General Comment No. 16, the CESCR has stated that the aim of special measures is to attenuate or suppress 'conditions that perpetuate discrimination, ${ }^{50}$ and also to bring 'disadvantaged or marginalized persons or groups of persons to the same substantive level as others.' ${ }^{11}$ Under General Comment No. 20, affirmative action measures are meant to attenuate or eliminate the causes of discrimination. With the two latest general comments, the CESCR has thus gone beyond a mere remedial approach suggesting that special measures should tackle the underlying causes of discrimination. General Comment No. 16 even envisages equality of results.

The Human Rights Committee (HRC) conceives special measures as cases of 'legitimate differentiation' as long as they are needed to correct de facto discrimination. ${ }^{52}$ Moreover, similarly to the CESCR, with General Comment No. 18, the HRC understands the objective of affirmative action as being 'to diminish or eliminate conditions which cause or help to perpetuate discrimination prohibited by the Covenant.'53

The most recent of the UN human rights treaties providing for these measures namely, the Convention on the Rights of Persons with Disabilities - conceives them as non-discrimination as long as they are 'necessary to accelerate or achieve de facto equality. ${ }^{54}$ Moreover, interestingly, it does not define them as 'special' but 'specific'. It has, thus, abandoned the traditional qualification in international law that could suggest that these measures, while not amounting to discrimination, were an exception to the principle.

Within the international labour standards system, looking at states' practices, the CEACR has explained that the rationale for affirmative action lies in the 'observation that the banning of discrimination is not enough to eliminate it in actual practice. 55 With the Special Survey 1996, the CEACR has further elaborated the reasons for

50 CESCR, General Comment No. 16: The Equal Right of Men and Women to the Enjoyment of All Economic, Social and Cultural Rights (Art. 3 of the Covenant), 11 August 2005, E/C.12/2005/4, para 15.

51 Ibid.

52 HRC, General Comment No. 18: Non-discrimination, 37th Session, 10 November 1989, para 10. The Human Rights Committee has stated that affirmative action does not constitute discrimination also in response to individuals' complaint presented under the Optional Protocol; see HRC, Stalla Costa v Uruguay, Communication No. 198/1985; and HRC, Guido Jacobs v Belgium, Communication No. 943/2000.

53 HRC, General Comment No. 18, para 10.

54 Art. 5(4).

55 CEACR, Equality in Employment and Occupation: General Survey, para 166. The same has been acknowledged by the CESCR in General Comment No. 16 and the CEDAW in General Recommendation No. 23: Public and Political Life, 16th Session, 1997. 
the need of affirmative action. It has observed that a mere formal, individual and complaint-based approach to equality is insufficient. The CEARC has said: 'If courts had limited themselves to awarding the traditional remedies (reinstatement with back pay or damages) to victims of discrimination, progress might have been so slow as to be imperceptible. ${ }^{56}$

The CEACR has recently defined affirmative action measures as being 'aimed at ensuring equality of opportunity in practice, taking into account the diversity of situations of the persons concerned, so as to halt discrimination, redress the effects of past discriminatory practices and restore a balance. ${ }^{57}$ Previously it had defined the objective of affirmative action as aiming to 'compensate for imbalances resulting from discrimination against certain workers or certain sectors ${ }^{\prime 58}$ with the ultimate aim of ensuring 'equality of opportunity and treatment in practice. 59 The interpretation of article 5(2) of Convention No. 111 in light of article 1, which covers indirect discrimination, could lend itself to conceive of affirmative action as a tool to tackle the systemic and structural dimensions of discrimination. The CEACR, while not explicitly affirming this view, has not hesitated to include promotional measures aimed at changing behaviours and attitudes among affirmative action measures.

Outside the ILS system, but still within the ILO, interesting developments have been marked by the 2003 and 2007 Global Reports. The 2003 Global Report, Time for Equality at Work, has taken a clear position that affirmative action is a key instrument to attain equality in practice and it has adopted the definition elaborated by the Special Rapporteur Mark Bossuyt, according to which this term encompasses 'a coherent packet of measures, of a temporary character, aimed specifically at correcting the position of members of a target group in one or more aspects of their social life, in order to obtain effective equality: ${ }^{60}$ The Report also indicates that the aim of these measures is to 'redress through temporary policies, the problems of economic disadvantage or social exclusion faced by certain groups, such as women or racial and ethnic minorities, which arise out of past and present societal discrimination. ${ }^{\prime} 1$ Elsewhere, the Report presents the aim of affirmative action as 'to accelerate the pace of participation of members of under-represented groups in gaining access to jobs, education, training and promotion, among other

56 Ibid., para 287.

57 CEACR, General Survey 2012 (Fundamental Conventions), para 862.

58 CEACR, Equality in employment and occupation: Special Survey, para 135.

59 Ibid., para 146.

60 Bossuyt, Prevention of Discrimination, 3.

61 ILO, Time for equality at work - Global report under the follow-up to the ILO Declaration on Fundamental Principles and Rights at Work, Report I (B), International Labour Conference, 91th Session (Geneva, 2003), para 66. 
things.' ${ }^{62}$ Affirmative action is thus conceived as a tool to remedy the consequences of discrimination with the ultimate aim 'to put everyone on an equal footing, 63 and to increase the representation of discriminated groups in accessing employment, education and training. The Report, thus, seems to conceive of affirmative action as both a remedial instrument and a tool for redistributive justice. ${ }^{64}$

A further evolution has occurred with the 2007 Global Report, Equality at work: Tackling the challenges, ${ }^{65}$ which has emphasised that affirmative action is not due to limitations on the part of the beneficiary groups but rather to failures of labour market institutions to provide equal opportunities to all. This constitutes a change of perspective. The problem addressed by affirmative action does not lie at the level of the discriminated groups but, rather, it is entrenched in the structures and functioning of the labour market. This is not just a matter of how the rationale of affirmative action is presented. It also has implications for the objective of affirmative action. In fact, this Global Report focuses on those experiences of affirmative action that aim to change the behaviours of the actors on the demand side of the labour market. Notably, the Report describes affirmative action measures, which consist in asking employers to survey their workforce composition, identify causes for the under-representation of certain groups and formulate measures to address them by changing human resources policies and practices accordingly.

With the exception of the CEDAW and the Convention on the Rights of People with Disabilities, the human rights treaties and ILO Convention No. 111 have presented special measures as aimed at addressing the 'needs' of beneficial groups and as directed at their protection and 'advancement' or 'development'. This brief overview has shown how this approach has changed. To differing extents, special measures have lost the patronising and integrationist veneer they once had. The international supervisory bodies have interpreted them as tools to guarantee equality. Their views differ as to whether special measures help discriminated groups to enjoy the same rights and opportunities as others within existing structures, or by transforming them.

62 Ibid., para 198.

63 Ibid., para 207.

64 Conversely, according to Vosko, the ILO 2003 Global Report is based on a narrower view of equality as equality of treatment and opportunity. See LF Vosko, 'Gender, Precarious Work, and the International Labour Code: The Ghost in the ILO Closet' in Precarious Work, Women and the New Economy: The Challenge to Legal Norms, Onati International Series in Law and Society, eds. J Fudge \& R Owens (Oxford: Hart Publishing, 2006).

65 ILO, Equality at work: Tackling the challenges - Global report under the follow-up to the ILO Declaration on Fundamental Principles and Rights at Work, Report I (B), International Labour Conference, 96th Session (Geneva, 2007). 


\subsection{Are affirmative action measures mandatory?}

In a more or less explicit way, international human rights bodies have gradually expressed the view that special measures represent an obligation for member states, albeit not necessarily an absolute obligation but 'when the circumstances so warrant' or 'as long as necessary and appropriate'.

Article 2(2) of ICERD provides that special measures may be required in certain circumstances and all the State parties shall, when the circumstances so warrant, adopt them. CERD's General Recommendation No. 32 clearly conceives the adoption of these measures as an obligation for States party under the above article. The CERD states that states parties to the Convention 'should' include provisions on special measures in their legal systems through general legislation or legislation directed to specific sectors as well as though plans, programmes and other policies initiatives at national, regional and local levels. ${ }^{66}$

With General Recommendation No. 25, the CEDAW presents affirmative action measures as mandatory as long as these 'can be shown to be necessary and appropriate in order to accelerate the achievement of the overall, or a specific goal of, women's de facto or substantive equality' ${ }^{\prime} 7$ The General Recommendation derives the mandatory nature of special measures from a reading of article 4(1) of the Convention in conjunction with articles $1-5$ and article 24. This contributes to reducing the 'special' nature of these measures and to helping see them as an integral part of an equality strategy. State parties should be required to explain the lack of adoption of special measures by private actors in accordance with article 2 of the Convention (to be read in conjunction with all other articles), which 'imposes accountability on the States parties for action by these actors. ${ }^{68}$

In addition, the CESCR, in General Comment No. 5, does more than just suggest 'special treatment' for persons with disabilities. It says that State parties are 'required' to take appropriate measures 'when this is necessary' to 'enable such persons to seek to overcome disadvantages ensuing from the disability status and hindering the enjoyment of the rights envisaged in the Convention' 'to the maximum extent of their available resources'. ${ }^{69}$ The CESCR's view on affirmative action has evolved over time. While General Comment No. 16 only encouraged State parties to adopt special measures, General Comment No. 20 provided that in some cases there is an obligation

66 CERD, General Recommendation No. 32, para 13.

67 CEDAW, General Recommendation No. 25, para 24.

68 Ibid., para 29.

69 CESCR, General Comment No. 5: Persons with disabilities, 9 December 1994, E/1995/22, para 5 . 
to adopt special measures: 'In order to eliminate substantive discrimination, states parties may be, and in some cases, are, under an obligation to adopt special measures to attenuate or suppress conditions that perpetuate discrimination. ${ }^{70}$

The Human Rights Committee has consistently presented affirmative action as being required by articles 3, 2(1) and 26 of the Covenant. ${ }^{71}$

The UN Convention on the Rights of Persons with Disabilities is silent on the mandatory (or otherwise) nature of special measures. However, article 5(2) is explicit in stating that there can be situations in which they are 'necessary'. For the moment, the relevant monitoring body - that is, the Committee on the Rights of Persons with Disabilities (CRPD) - has confined itself to encouraging the adoption of affirmative action. In a statement of May 2013, it talked of affirmation action as one of the means to be used for the eradication of discrimination and has called upon the international community to:

$[\mathrm{T}]$ ake measures to ensure that persons with disabilities enjoy their right to development on equal basis with others [...] and that stigma and discrimination on the basis of discrimination are effectively eradicated, including through the adoption of affirmative action measures, so that inequalities faced by persons with disabilities are properly addressed and eliminated. ${ }^{72}$

Within the international labour standards system, there is no explicit statement on the mandatory nature of special measures. However, the ILO Committee of Experts seems to conceive of affirmative action as mandatory at least with respect to women who have suffered from career breaks. With the Special Survey of 1996, it says that:

In order to apply effectively the principle of equality in access to employment and occupation without discrimination on the basis of sex, special measures should be taken to promote the re-entry of unemployed women workers into the labour force, in particular those who have considerable family responsibilities. ${ }^{73}$ (italics added)

70 CESCR, General Comment No. 20: Non-discrimination in economic, social and cultural rights (art. 2, para 2, of the International Covenant on Economic, Social and Cultural Rights), 2 July 2009, E/C.12/GC/20, para 9.

71 See HRC, General Comment No. 4: Article 3 (Equal right of men and women to the enjoyment of all civil and political rights, (13th Session, 1981), para 2; HRC, General Comment No. 18: Non-discrimination, (37th Session, 1989), para 10.; and HRC, General Comment No. 28: Article 3 (The equality of rights between men and women), (68th Session, 2000), para 29.

72 Statement of the Committee on the Rights of Persons with Disabilities on including the rights of persons with disabilities in the post-2015 agenda on disability and development, May 2013, para 15.

73 ILO, Equality in employment and occupation: Special Survey, para 183. 
The same approach has been adopted by the Commission of Inquiry set up to examine the complaint presented against Romania for non-observance of Convention No. 111. ${ }^{74}$ The Commission of Inquiry gave this reminder:

$[\mathrm{T}]$ he Committee of Experts had previously pointed out that the obligation of formulating and applying a national policy in accordance with the objectives of the Convention has as its corollary the duty to repeal statutory provisions and modify administrative practices which are inconsistent with this policy. [...] While this absolute and universal obligation is a necessary condition for the application (of the Convention), it should be borne in mind that it is only one aspect of their implementation, which also implies the adoption of affirmative action measures to correct the de facto inequalities in all fields concerning employment and occupation, whether or not governed by law or by administrative action. ${ }^{75}$ (italics added)

The individual comments (direct requests and observations) addressed by the CEACR to member states often refer to affirmative action as part of the national policy 'to promote [...] equality of opportunity and treatment in respect of employment and occupation, with a view to eliminating any discrimination in respect thereof' and which member states having ratified the Convention have an obligation to adopt under article $2 .{ }^{76}$ Today this view has been spelled out in the General Survey 2012 (Fundamental Conventions) concerning rights at work, which states that affirmative action measures are 'an important component of the national equality policy, required under Article 2.' ${ }^{77}$

74 Complaint concerning the non-observance by Romania of the Discrimination (Employment and Occupation) Convention, 1958 (No. 111) made by delegates to the 76th (1989) Session of the Conference under article 26 of the Constitution (O.B., Vol. LXXIV, 1991, Series B, Suppl. 3).

75 Report of the Commission of Inquiry appointed under article 26 of the Constitution of the International Labour Organisation to examine the observance by Romania of the Discrimination (Employment and Occupation) Convention 1958 (No. 111), Official Bulletin, Vol. LXXIV, Series B, Suppl. 3, 1991, para 47.

76 This understanding of affirmative action as part of national policy is reflected in a survey of comments addressed by the CEACR under Convention No. 111 to African governments until 2010; see unpublished paper, 'An international perspective of affirmative action', which the author presented at an international workshop on affirmative action that took place at the Stellenbosch Institute of Advanced Study (STIAS) on 22 July 2011. See also CEACR, General Conclusions on the reports relating to the Convention (No. 111) and Recommendation (No. 111) concerning Discrimination in Respects of Employment and Occupation, 1958, Report III (Part IV), International Labour Conference, 47th Session (Geneva, 1963), para 39.

77 ILO, General Survey 2012 (Fundamental Conventions), para 862. 


\subsection{The content of affirmative action and areas concerned}

With regard to the content of special measures and the areas concerned, there is no uniformity of approach. As seen above, with the only exception of ILO Conventions Nos. 107, 169 and 181, international instruments do not provide any specific guidance on the content of special measures. Among the international supervisory bodies, only the CEDAW and the ILO CEACR have provided illustrations of the content of special measures. ${ }^{78}$

In General Recommendation No. 5, the CEDAW has indicated that special measures can be 'positive action, preferential treatment or quota systems. Drawing on the experience of state parties, General Recommendation No. 23 has provided for a broader list of illustrations, which includes:

$[\mathrm{R}]$ ecruiting, financially assisting and training women candidates, amending electoral procedures, developing campaigns directed at equal participation, setting numerical goals and quotas and targeting women for appointment to public positions such as the judiciary or other professional groups that play an essential part in the everyday life of all societies. ${ }^{79}$

Moreover, it has provided examples of measures taken by political parties such as:

$[S]$ etting aside for women a certain minimum number or percentage of positions on their executive bodies, ensuring that there is a balance between the number of male and female candidates nominated for election, and ensuring that women are not consistently assigned to less favourable constituencies or to the least advantageous positions on a party list. ${ }^{80}$

State parties should ensure that such temporary special measures, while capable of being a spontaneous initiative, have a legal basis and are specifically permitted under anti-discrimination legislation or other constitutional guarantees of equality. ${ }^{81}$

General Recommendation No. 25 has refined the scope of 'temporary special measures'. These measures can include 'outreach or support programmes; allocation and/or

78 Talking of the CESCR, Craven observed that ' $[\mathrm{M}]$ embers of the Committee have given little indication of what forms of positive measures they consider to be legitimate'. At least until 2000, the CESCR talked of training and fiscal measures and made no objection to quotas. According to CERD's General Recommendation No. 32, affirmative action measures include 'legislation, executive, administrative, budgetary and regulatory instruments, at every level in the State apparatus, as well as plans, policies, programmes and preferential regimes'. However, with the exception only of preferential regimes, the above list does not say anything on the content but rather focuses on the instruments that can provide for them.

79 CEDAW, General Recommendation No. 23, para 15.

80 Ibid., para 33.

81 Ibid. 
reallocation of resources; preferential treatment; targeted recruitment, hiring and promotion; numerical goals connected with time frames; and quota systems. ${ }^{82}$ The choice of the type of measure depends on the context and on the specific goal it aims to achieve. Special measures can be adopted through 'legislative, executive, administrative and other regulatory instruments' as well as 'policies and practices. ${ }^{83}$ They can be negotiated by social partners or applied on a voluntary basis by public or private enterprises, organisations, institutions and political parties. ${ }^{84}$ As in the preceding General Recommendation No. 23, here too the CEDAW recommends that temporary special measures by governmental or private actors be explicitly allowed in states parties' constitutions or in national legislation, which can also give guidance on the type of temporary special measures to be formulated. ${ }^{85}$

The CEACR is also of the view that affirmative action can take different forms and be implemented both in the private and in the public sector, at national level or that of the enterprise. By drawing on various national experiences, the CEACR has provided a broad list of possible measures. These range from preferential treatment, to quotas, numerical targets, tax and financial benefits for entrepreneurial initiatives taken by disadvantaged groups, wage subsidies, tax breaks and exemptions from contributions to social security schemes, targeted training and employment programmes, education, and promotional measures aimed at changing behaviours and attitudes. ${ }^{86}$

The CESCR has adopted a broad definition of special measures that also encompasses (reasonable) accommodation measures - for instance, for persons with sensory impairments. ${ }^{87} \mathrm{~A}$ different approach has been adopted by the Convention on the Rights of Persons with Disabilities. This distinguishes between the two categories and provides a definition of accommodation measures as:

$[\mathrm{N}]$ ecessary and appropriate modification and adjustments not imposing a disproportionate or undue burden, where needed in a particular case, to ensure to persons with disabilities the enjoyment or exercise on an equal basis with others of all human rights and fundamental freedoms. ${ }^{88}$

82 CEDAW, General Recommendation No. 25, para 22.

83 Ibid., para 22.

84 Ibid., para 32.

85 Ibid., para 31.

86 See CEACR, Equality in Employment and Occupation: General Survey 1988; CEACR, Equality in employment and occupation: Special Survey 1996; and CEACR, General Survey 2012 (Fundamental Conventions).

87 CESCR, General Comment No. 20, para 9.

88 Art. 2. 
The two measures are both based on a substantive conception of equality, where equality does not mean treating all the same. However, accommodation measures can be directed at specific individuals rather than an entire group of people, and can give rise to individual rights. ${ }^{89}$

The areas of life affected by affirmative action under international law are limited. CERD's General Recommendation No. 32 envisages employment, housing, education, culture, and participation in public life. General Recommendation No. 25 goes beyond thinking only of employment and education and, consistent with the approach of the Convention, indicates that special temporary measures can also concern other areas such as 'credit and loans, sports, culture and recreation, and legal awareness. ${ }^{90}$ An analysis of the CEACR's comments addressed to African countries up until 2010 reveals that the ILO Committee of Experts has tended to focus on access to employment and training. ${ }^{91}$ More rarely does it refer to other areas such as access to trade and credit.

The ILO's 2007 Global Report, while reaffirming the 'essential' nature of affirmative action in addressing discrimination at work, has also maintained that this is insufficient if not accompanied by action that addresses pre-labour market factors such as residential segregation. This statement is important because it underlines the fact that inequalities and discrimination in the world of work can have their roots outside it. Therefore, the promotion of equality at work requires action also in fields other than the world of work.

\subsection{From design to implementation and monitoring of affirmative action measures and conditions for their legitimacy}

Both the international human rights system and the ILS system have pronounced themselves on the process for the adoption, implementation and, to a lesser extent, monitoring of special measures. The human rights treaty bodies have spoken of prior consultation and active participation of affected communities in the design

89 See L Waddington \& M Bell, 'Exploring the boundaries of positive action under EU law: A search for conceptual clarity', Common Market Law Review 48, no. 5 (2011): 1518. According to Arnardóttir, the Convention on the Rights of Persons with Disabilities gives an individual right to accommodation measures. See OM Arnardóttir, 'A Future of Multidimensional Disadvantage Equality', in The UN Convention on the Rights of Persons with Disabilities: European and Scandinavian Perspectives, eds. OM Arnardóttir \& G Quinn (Leiden: Martinus Nijhoff Publishers, 2009), 60.

90 CEDAW, General Recommendation No. 25, para 263.

91 See Tzehainesh Teklè 'An international perspective of affirmative action', which the author presented at an international workshop on affirmative action that took place at the Stellenbosch Institute of Advanced Study (STIAS) on 22 July 2011. 
and implementation (General Comment No. 32 of CERD) or involvement of women in their design, implementation and evaluation (General Recommendation No. 25 of CEDAW) or participation of affected groups and individuals in their design (General Comment No. 16 of CESCR).

Article 5(2) of ILO Convention No. 111 provides for the prior consultation of social partners. The CEACR presents 'prior consultation and the consent of the stakeholders, including workers' and employers' organizations' as helping 'to ensure that the measures taken are broadly accepted, effective and in line with the principle of non-discrimination. ${ }^{\prime 2}$ The Committee of Experts has also taken the position that affirmative action measures 'should be re-examined periodically' with a view to assess whether they are still needed and remain effective. ${ }^{93}$ As seen above, ILO Convention No. 169 enshrines the principle of co-operation with indigenous peoples.

The 2007 Global Report has addressed some of the controversies that surround affirmative action measures and has recognised that these measures may trigger 'unintended backlash and the stigmatization of designated groups.94 For this reason, it advocates the prior consent and not just the consultation of designated groups. Moreover, it recommends the consultation of all stakeholders spelling out that these include the 'economically dominant groups', the beneficiaries, the State and the social partners. ${ }^{95}$

Both the human rights treaty bodies and the ILO Committee of Experts have also singled out a number of features that affirmative action should have. The first one is the temporary character that has been endorsed by all international supervisory bodies and which has even been expressly indicated in the text of the Convention on the Elimination of All Forms of Discrimination against Women. Affirmative action should last as long as target groups are not in a position to enjoy equality in practice. The ICERD has specified that the objective has to be achieved in a sustainable manner, and upon assessment of the impact that an interruption or cessation of affirmative action measures would have on achieving the objective. However, the CESCR in General Recommendation No. 20 envisages the possibility that special measures may 'exceptionally' be permanent. As seen above, this is possible because the CESCR has adopted a broad definition of special measures that encompasses not only measures favouring disadvantaged groups or individual members but also (reasonable) accommodation measures. ${ }^{96}$ The second characteristic is proportionality,

92 CEACR, General Survey, 2012 (Fundamental Conventions), para 862.

93 Ibid.

94 ILO, Global Report 2007, para 200.

95 Ibid., para 200.

96 CESCR, General Comment No. 20, para 9. 
which has been expressed in the comments of the CERD, the CESCR, the HRC and the CEACR. For example, the CEACR has explained that affirmative action measures 'must be proportional to the nature and scope of the protection or assistance needed or of the existing discrimination. ${ }^{\prime 97}$ The HRC in a communication adopted in response to an individual's complaint presented under the Optional Protocol ${ }^{98}$ talked of a reasonable proportionality between the purpose of the affirmative action, the means and modalities applied and the aim of having qualified people.

In a footnote to General Comment No. 16, the CESCR has introduced the principle of proportionality along lines that recall the jurisprudence of the European Court of Justice. ${ }^{99}$ In the name of the principle of proportionality, measures in favour of women should not be adopted when 'reasons specific to an individual male candidate may tilt the balance in his favour, which is to be assessed objectively, taking into account all criteria pertaining to the individual candidate.' ${ }^{100}$ The condition of proportionality is strictly linked to a remedial conception and use of affirmative action.

CESCR's General Comment No. 16 provides for a further condition for the legitimacy of special measures - namely, that they should be necessary to redress de facto discrimination. ${ }^{101}$ CESCR's General Comment No. 20 completes the list of conditions for the legitimacy of these measures. Besides proportionality to the objective pursued, these measures should be reasonable and objective: 'Such measures are legitimate to the extent that they represent reasonable, objective and proportional means to redress de facto discrimination and are discontinued when substantive equality has been sustainably achieved.'102

\subsection{The beneficiaries of affirmative action}

The complex issues surrounding the identification of the beneficiaries of affirmative action have received limited coverage. Affirmative action is presented as meant

97 CEACR, General Survey, 2012, para 862.

98 See HRC, Guido Jacobs v Belgium, Communication No. 943/2000.

99 In 1997, the European Court of Justice recognised that even when women are as qualified as men, they do not have equal chances. It ruled that 'a national rule which, in a case where there are fewer women than men" and candidates for the post are "equally qualified in terms of their suitability, competence and professional performance, requires that priority be given to the promotion of female candidates unless reasons specific to an individual male candidate tilt the balance in his favour is not precluded by Article 2(1) and (4) of Council Directive 76/207/EEC" (Helmut Marshall v Land Nord-Rhein-Westfalen, Case C-409/95 (1997)).

100 CESCR, General Comment No. 16, footnote 9.

101 Ibid., para 15.

102 CESCR, General Comment No. 20, para 9. 
to benefit groups that are identified on the basis of personal characteristics. ${ }^{103}$ However, who should determine group membership? Is it always possible to clearly determine to which group a person belongs? What about multiple identities? And how does one deal with the socio-economic differences existing within groups? How does one respond to the critiques that affirmative action may benefit some groups to the detriment of others?

Only the CERD, in General Recommendation No. 32, has addressed the first question indicating that the criterion to be used to identify the beneficiaries of affirmative action should be that of self-identification.

Only the CEDAW, in General Recommendation No. 25, provides that special measures should be adopted to address multiple discrimination (para 12). ${ }^{104}$ A multiplicity of identities (for example, gender and ethnicity) may not be adequately addressed by an affirmative action model that is based on rigid group membership boundaries. ${ }^{105}$

Only the ILO Global Report of 2007 raises the controversial issue of affirmative action benefiting the most well-off members of the beneficiary groups and echoes the position of the Special Rapporteur, Mark Bossuyt. He has suggested that socioeconomic status be taken into account together with group membership to determine who is entitled to the benefits deriving from affirmative action measures. ${ }^{106}$

A further merit of General Recommendation No. 25 is to address one of the most frequent objections against special measures - notably that they open the door to the possibility that less-qualified persons or groups in areas such as politics, education and employment are preferred, thus sacrificing the principle of merit. This objection is particularly powerful when so-called 'strong' preferential treatment is involved and less-qualified persons belonging to disadvantaged groups are given precedence over persons belonging to 'dominant' groups. However, the perception of unfairness may also arise in cases where the so-called 'weak' preferential treatment is in place and women receive the social good (for example, a job) for which they compete with men on the basis of equal qualifications. The General Recommendation does

103 Fredman observes that '[A]ffirmative action denotes the deliberate use of race- or genderconscious criteria for the specific purpose of benefiting a group which has previously been disadvantaged on grounds of race or gender' in S Fredman, 'Reversing discrimination', $L Q R$ 113 (1997): 575.

104 For a review of the concepts surrounding the multiplicities of identities, see T Makkonen, Multiple, Compound and Intersectional Discrimination: Bringing the Experiences of the Most Marginalized to the Fore, Institute for Human Rights, Åbo Akademi University, April 2002.

105 See also C Sheppard, 'Multiple Discrimination in the World of Work', Working Paper No. 66, ILO, Geneva, September 2011.

106 Bossuyt, Prevention of Discrimination, para 15. 
not enter into these distinctions and responds to the critiques with a reminder that qualifications and merit are 'normatively and culturally determined' and, therefore, that they 'need to be reviewed carefully for gender bias. ${ }^{107} \mathrm{In}$ sum, what is presented as objective in reality is not. Merit is also a social and legal construct not immune from bias ${ }^{108}$ since it was constructed by the dominant group according to its own characteristics.

\subsection{Conclusions}

The above overview has shown that affirmative action is an instrument that both the international human rights system and the international labour law system promote and consider as key in the elimination of discrimination and the promotion of equality. The perspective of both systems on affirmative action has evolved thanks to the relevant supervisory bodies. Some similarities exist between the two systems but differences persist both between and within them.

With regard to the relationship between affirmative action and the principle of non-discrimination, the ICERD, the Convention on the Elimination of All Forms of Discrimination against Women, the Convention on the Rights of Persons with Disabilities, and ILO Conventions Nos. 111, 159 and 181 all feature provisions whose main aim is to explain that these measures do not constitute discrimination. According to some scholars, this approach reveals a formal conception of equality. Thus, the differential treatment implied by affirmative action would be conceived by these instruments as a derogation from, or an exception to, the general principle of equality. This is why these measures are presented as special (with the exception of the Convention of the Rights of Persons with Disabilities) and as necessarily temporary. However, as Fredman has argued, these provisions can be reconceptualised as 'saving clauses' that simply explain the nature of these measures to avoid any doubt. ${ }^{109}$ As seen above, international supervisory bodies have interpreted special measures as being based on the principle of equality and non-discrimination and as being part and parcel of the positive measures that States have to take to achieve de facto equality.

The conceptualisation of the aims of special measures has also developed. One common evolution is the abandonment by the international supervisory bodies of the language used in many of the instruments examined, and which reveal an 'integrationist philosophy'. In these instruments, special measures were originally

107 CEDAW, General Recommendation No. 25, para 23.

108 On the issue of merit see C McCrudden, 'Merit Principles', Oxford J. Legal Stud. 18 (1998), 543; Fredman, 'Reversing Discrimination', 598-9.

109 Ibid. 
conceived as a means to assist the integration of certain groups in mainstream institutions and development processes, and neglected the fact that the lack of integration was due to the biases intrinsic in the way these institutions are shaped and function, and in the way that the development processes are designed. The deconstruction of the concept of merit by CEDAW in General Recommendation No. 25 epitomises this development.

However, the interpretation of the aims of affirmative action is not uniform. Within the human rights system, the CERD seems to conceive of affirmative action as a remedial tool. Other human rights treaty bodies have gradually attributed to affirmative action other roles, while maintaining the traditional remedial one. The CEDAW is the body that has gone most clearly in this direction. General Recommendation No. 25 combines three different approaches to affirmative action: (i) a remedial approach according to which the purpose of special measures is to provide women with compensation for past and current discrimination; (ii) a distributive justice or equality of results approach according to which the aim of these measures is 'to accelerate the improvement of the position of women to achieve their de facto or substantive equality with men'; ${ }^{110}$ and (iii) a wider transformative approach according to which these measures are aimed 'to effect the structural, social and cultural changes necessary to correct past and current forms and effects of discrimination against women.'111 The emphasis is placed on the second and third aim. The CESCR in its latest General Comment No. 16 also seems to embrace this wider perspective on affirmative action. The HRC has also opted for a transformative approach in the above-mentioned Communication to Belgium and in General Comment No. 18.

The ILO has tended to adopt a traditional notion of affirmative action as aimed at compensating for and redressing imbalances resulting from discrimination. This approach results from the pronouncements of the CEACR on Convention No. 111,112 but it is also contained in instruments and reports dealing with gender equality such as the Declaration on Equality of Opportunity and Treatment for Women Workers of 1975, the Resolution on Equal Opportunities and Equal Treatment for Men and Women in Employment adopted in 1985, and the Resolution concerning Gender Equality at the Heart of Decent Work of 2009. A broader approach has been adopted in the ILO with the 2003 and, above all, the 2007 ILO Global Reports, with the latter emphasising the role that affirmative action can play in changing policies and structures.

110 General Recommendation No. 25, para 15.

111 Ibid.

112 However, it is worthwhile noting that the CEACR has included promotional measures aimed at changing behaviours and attitudes among the special measures; see section 4.3 above. 
The remedial approach places the problem to be addressed at the level of the discriminated groups rather than at the level of the structures, institutions, policies and practices that limit the opportunities, choices and participation of members of certain social groups in the various social fields. However, a mere shift to an equality of results approach would not suffice. A mere quantitative increase in the participation of previously excluded groups is not per se conducive to raising the access of the overall group membership to social goods and opportunities traditionally outside their reach. The underlying causes of exclusion need to be tackled. Otherwise, affirmative action is confined to assisting discriminated groups adapt to the dominant structures and institutions of societies without necessarily integrating their concerns and views. Many who cannot adapt and assimilate to the dominant model would still be left outside. ${ }^{113}$ Thinking of equality in terms of recognising and accommodating diversity has repercussions on the design of affirmative action measures. Besides removing barriers and promoting the participation of discriminated groups in various areas, the measures should deal with the structures and functioning of society and its different institutions.

A related issue is the question whether affirmative action measures are mandatory in nature. In a more or less explicit way, all human rights treaty bodies have gradually expressed the view that these measures represent an obligation for member states, albeit not always in absolute terms. The ILO Committee of Experts has not spoken of an obligation. However, in its dialogue with member states, it has frequently drawn their attention to the fact that the national policy that they have an obligation to adopt under article 2 of Convention No. 111 also implies affirmative action. The same position has been taken by the Commission of Inquiry set up in 1989 to look at the complaint submitted against Romania for non-observance of Convention No. 111.114

Linked to the aims of affirmative action is its content. In this regard, there is also no uniformity of approach. With the exception of ILO Conventions Nos. 107, 169 and 181, international instruments do not provide any specific guidance. Among the international supervisory bodies, only CEDAW and the ILO CEACR have provided illustrations of various different measures.

Both the human rights treaty bodies and the ILO Committee of Experts have pronounced themselves on the conditions for the legitimacy of affirmative action measures. They all agree on their temporary character. The CESCR, though, envisages permanent special measures because it includes accommodation measures. Another recurrent condition is the necessary character of these measures and their

113 See also Fredman, 'Beyond the Dichotomy of Formal and Substantive Equality'.

114 See ILO, 'Complaint concerning non-observance by Romania 1989'. 
proportionality to the aim pursued and to the nature and scope of the protection needed. These conditions reveal a remedial conceptualisation of affirmative action, which implies forms of compensation for discriminated groups that may constitute limitations for the dominant groups.

Another fundamental issue is that of the design, implementation, enforcement and monitoring of affirmative action measures. The human rights treaty bodies speak of prior consultation, active participation or involvement of concerned groups and individuals in the design and implementation. The ILS system provides for the prior consultation and consent of stakeholders (social partners, in particular). ILO Convention No. 169 envisages co-operation with indigenous peoples. The ILO Global Report of 2007 expressly envisages not only consultation, but also prior consent. Moreover, it envisages the involvement not only of social partners but also both the beneficiary and the dominant groups. This seems the most inclusive proposal within the UN system, as it explicitly recognises that discriminated people may not be represented in employers' and workers' organisations or may have other forms of representation, and that dominant groups should also have a say in the adoption of measures that could affect them. A well thought-through process of adoption and follow-up seems crucial to provide affirmative action measures with the necessary legitimacy and adequacy for their context, and to attenuate the adverse effects that affirmative action could produce such as consolidating instead of overcoming prejudices.

Both the international human rights system and the international labour law system have considered the monitoring phases to a lesser degree. Supervisory bodies such as the CESCR and the ILO CEACR mention the latter. The ILO Committee of Experts explicitly calls for a periodic re-examination to assess the effectiveness of special measures. While supervisory bodies systematically ask governments for statistics relating to the situation of discriminated groups, nothing has been expressly said about the indicators for determining the sustainable achievement of the objectives of these measures.

The complexities in the identification of the beneficiaries of affirmative action have also received only limited coverage. Only the CERD has addressed the question of the identification of beneficiaries, indicating that the criterion to be used should be that of self-identification. Only the CEDAW provides that special measures should be adopted to address multiple discrimination. Finally, only the ILO Global Report of 2007 addresses the issue that affirmative action, while diminishing inter-group inequalities, may raise intra-group inequality, and echoes the position adopted by Special Rapporteur Mark Bossuyt, according to whom a person's socio-economic status should be taken into account together with group membership to determine entitlement to affirmative action measures. 
A limitation of the international perspective on affirmative action is that it is mainly confined to certain areas - in particular, education, employment in the formal economy and politics. ${ }^{115}$ However, considering the extent of the informal economy, it seems that international law cannot afford to maintain an approach to affirmative action that overlooks the fact that discrimination is not only found in wage employment in the formal economy. ${ }^{116}$ Furthermore, affirmative action in the above areas has to be combined with measures addressing unequal power relations and unbalanced distribution of responsibilities in the private sphere, which have an impact on the access to and conditions in these same areas.

In conclusion, it seems that the international perspective on affirmative action has evolved and is continuing to evolve, ${ }^{117}$ nurtured not only by national experiences but also by scholarly reflections. However, more coherence seems needed ${ }^{118}$ within and between the international human rights and the international labour law systems, and there is room for more reflection on how to face some overlooked issues on which the social acceptance, inclusiveness and effectiveness of affirmative action depend.

115 The ILO Committee of Experts has made explicit reference to the informal economy in the comments addressed to a few countries and has indirectly dealt with it when looking at national equality policies. See ILO, Transitioning from the informal to the formal economy, Report V(1), ILC, 103rd Session (Geneva, 2014), para 61. For a few examples of the CEACR's comments addressing discrimination in the informal economy and asking governments to provide information on measures taken to promote women's equal access to income-generating activities and to address pay discrimination in the informal economy though initiatives aimed at promoting girls' access to education and vocational training as well as sensitisation programmes to overcome the traditional stereotypes of the role of women in society, see ILO, Extending the scope of application of labour laws to workers in the informal economy: Digest of comments of the ILO supervisory bodies related to the informal economy (Geneva: 2010).

116 See ILO, Resolution concerning decent work and the informal economy, ILC, 90th Session, (Geneva: 2002).

117 In 1999, Jane Hodges expressed the view that the supervisory bodies of the UN system 'have been timid in coming forward with strong guidance, even if, when given the chance to do so in reports on ratified Conventions, they have commented favourably when examining measures for achieving equal employment opportunities'. See J Hodges, 'Affirmative Action in Employment: Recent Court Approaches to a Difficult Concept', International Labour Review 138, no. 3 (1999): 270. This timidity has been, to a good extent, overcome among UN treaty bodies in the last years.

118 The CERD has expressly recognised this need in General Recommendation No. 32. 


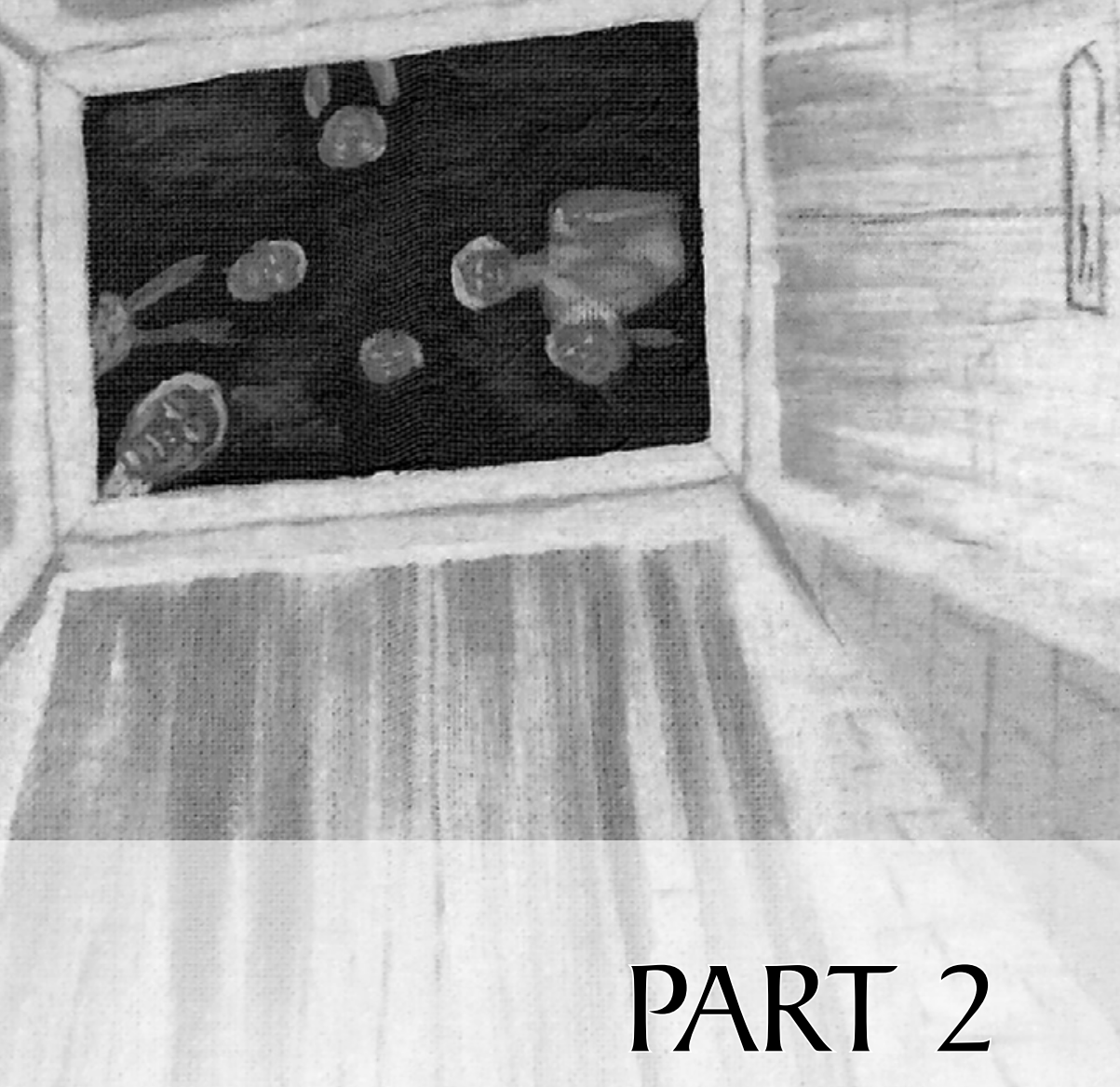

NATIONAL PERSPECTIVES 


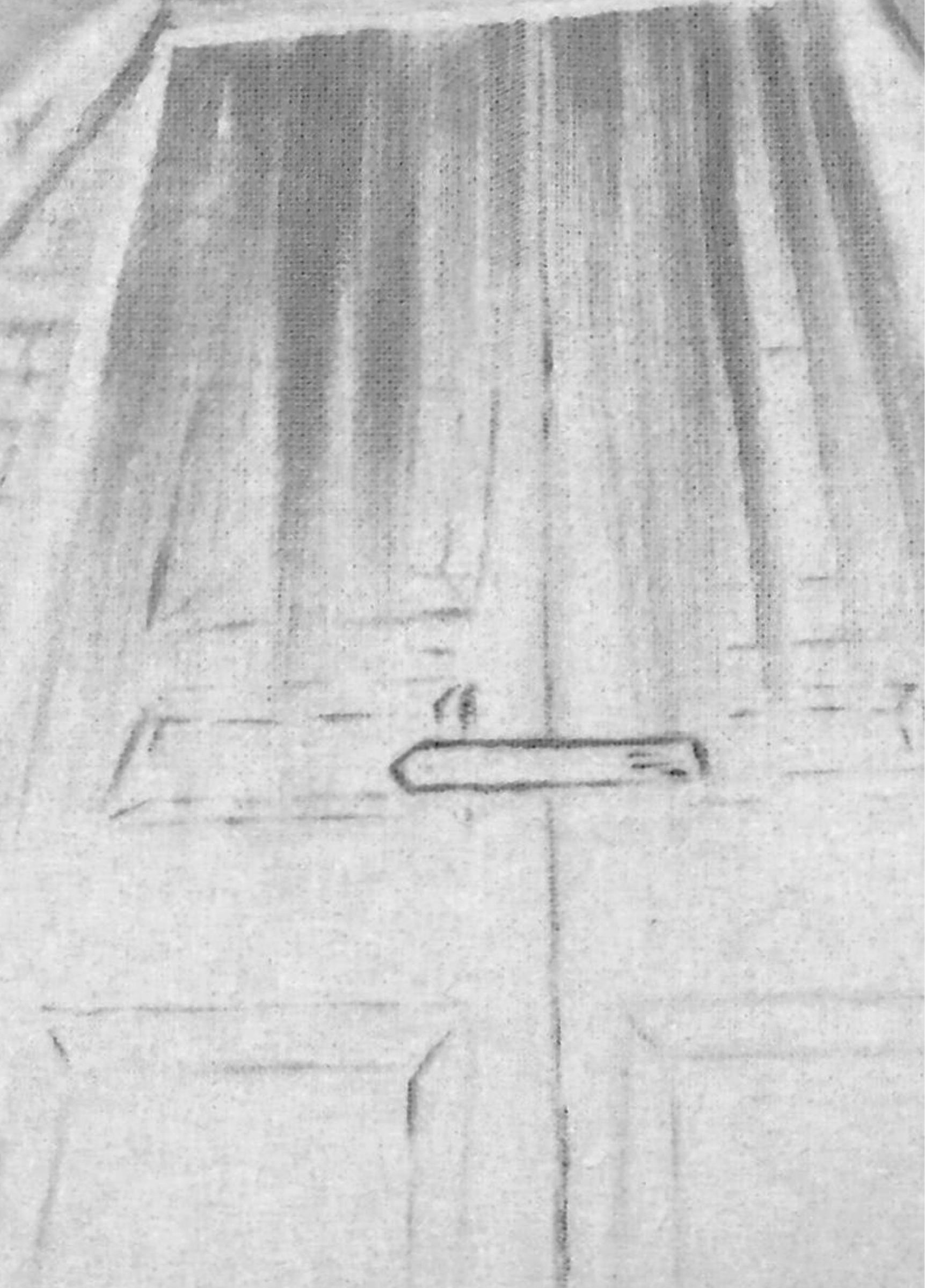




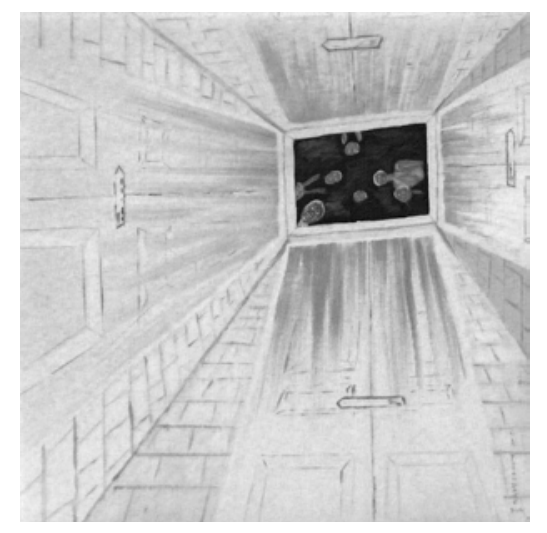

\section{NEGLIGENCE AND APPROPRIATE REPRESENTATION \\ The Israeli case}

Moshe Cohen-Eliya

\subsection{Introduction}

We normally think of affirmative action policies and the requirement to ensure 'appropriate representation' (AR) in progressive terms - as a results-oriented means of achieving substantive equality. Progressives, who support such policies, are criticised for adhering to quotas, imposing illegitimate strict liability (which contradicts liberal premises of responsibility), and undermining market efficiency. These accusations stem from different visions of the purpose of the anti-discrimination principle. While the progressive proponents of AR policies are portrayed as seeking results-oriented redistribution, their opponents follow a more classic understanding of the rationale of the anti-discrimination principle - namely, to prohibit decisions that are based on bias and irrational attitudes towards women and minorities. The main role of the courts, by the classic account, is to uncover and nullify such illicit motives and intentions - not to engage in redistribution. 
Building on the Israeli case law, I argue that the AR norm can be constructed in a way that is not oblivious to the notions of blame and responsibility and does not necessarily undermine efficiency. Rather, this norm can be conceived of as setting a duty of care - that is, requiring the agent to take a set of reasonable measures to ensure that women and minorities are not under-represented in various sectors of Israeli economic and public life. Refraining from taking such measures constitutes a negligent violation of the AR norm. Israeli jurisprudence on $\mathrm{AR}$ demonstrates that this norm can function within the framework of Pareto optimality; that is to say, under this norm, women and minorities are better off without undermining efficiency.

Part I starts by describing the ways in which the AR norm evolved in Israeli law and then documents its rapid spread (especially with regard to women) and spill-over to minorities (especially Arabs) in Israeli society. Part II proceeds to explain why a negligence-like theory is most suited to understanding and interpreting the AR norm and that such a theory is connected in many respects to the classic purpose of the anti-discrimination principle. Part III concludes by arguing that the Israeli case law on the AR norm can be best understood as setting a demanding standard of care, essentially requiring the decision-maker to aggressively search for more representative options.

\subsection{The norm}

Israel is a deeply divided society across ethnic, national, and religious lines. The Arab national minority constitutes roughly one-fifth of the general Israeli population; the self-segregated, ultra-orthodox Jewish minority comprises almost one-tenth of the population; and the entire Jewish population is almost equally divided between the hegemonic Ashkenazi Jews (Jews who emigrated from or are the descendents of immigrants from Europe and North America) and Mizrahi Jews (Jews who immigrated from or are the descendants of immigrants from North Africa and Asia). Deep ethnic and religious tensions are always fertile ground for stereotyping, prejudice, and discrimination against the other, and Israel is no exception in this respect. Ethnic groups in Israel such as Mizrahi Jews and, in particular, the Arab minority group suffer from stigmatising stereotypes and are under-represented in the upper echelons of Israeli economic and public life. ${ }^{1}$

1 See, for example, on racial attitudes towards Arabs, Daniel Bar-Tal \& Yona Teichman, Stereotypes and Prejudice in Conflict: Representations of Arabs in Israeli Jewish Society (Cambridge UK: Cambridge University Press, 2005). On racial attitudes towards Mizrahi Jews, see Sammy Smooha, 'Jewish Ethnicity in Israel: Symbolic or Real?' in Jews in Israel: Contemporary Social and Cultural Patterns, eds. Uzi Rebhun \& Chaim I Waxman (Hanover, NH: Brandies University Press, published by University Press of New England, 2004), 60. The case of attitudes towards ultra-orthodox Jews in Israel is more complex. While there 
By contrast, Israel has traditionally been regarded as the champion of women's rights. What is often labeled as 'the myth of gender equality' in Israel relates to the economic, social, and political achievements of Jewish women in the pre-state period and during the early years of the state. ${ }^{2}$ But as the years passed, women's status in Israel came to duplicate the typical standing of women in Western societies and the obstacles they encounter (the glass ceiling phenomenon in the marketplace and politics) and in more traditional societies (linked, for example, to the lack of separation between state and religion in Israel). ${ }^{3}$

In this light, one would expect the AR norm to evolve primarily so as to address the severe under-representation of Arabs in Israeli political and economic life. But this has not been the case in Israel. Both the anti-discrimination norm and the AR norm developed in Israel initially to contend with the problems that women face, and only later were they extended to the Arab minority. ${ }^{4}$ The NGOs lobbying for the enactment of the anti-discrimination and the AR norms realised - precisely because of the greater animosity towards Arabs in Israeli society - that it would be politically easier to establish these norms first with respect to women and then later build on the logic of the Dworkinian principle of the integrity of the law $w^{5}$ to extend the norms to Arabs.

In its original formulation, the Equal Opportunities in Employment Act, as adopted in 1988, banned discrimination only on grounds associated with women. ${ }^{6}$ So long as no anti-discrimination norms were set in respect of the private sector, such an avoidance could be grounded on public reason: on the principle of liberty and on

is, indeed, widespread prejudice against the members of this group and while its members are among the poorest in Israel, this group wields substantial political power and thus can protect its interests well in the political process. See Gila Stopler, 'Contextualizing Multiculturalism - A Three-Dimensional Examination of Multicultural Claims', Law \& Ethics Hum. Rts. 1 (2007): 309.

2 Dafna Izraeli, 'Gender Politics in Israel: The Case of Affirmative Action for Women Directors', Women's Studies Int'l Forum 26 (2003): 109, 113.

3 Anat Maor, The Rising Power: The Promotion of Women in the Workplace - Breaking the Glass Ceiling (Tel Aviv: Sifriat Ha' Poalim, 1997) (Hebrew).

4 Moshe Cohen-Eliya, 'Discrimination against Arabs in Israel in Public Accommodation', N.Y.U. J. Int'l. L. \& Pol. 36 (2004): 717.

5 This principle, as described by Ronald Dworkin, requires the legal system to act similarly in similar cases. The legal system should act consistently and in a manner coherent with the principles underlining the existing body of law. Because these institutions seek legitimacy, they must/should try to present their legal arrangements as emanating from these principles. See Ronald Dworkin, Law's Empire (Cambridge Mass: Harvard University Press, 1986), 225-75.

6 The original version of this law, from 1988, prohibited discrimination on the basis of gender, parentage, and marital status. 
the desire to enable the individual to exercise maximum liberty when acting in the private sphere. But once the Israeli legislature had recognised the need to limit the prerogative of private employers (in order to protect women), it would have been difficult to point to a public reason to justify the lack of similar protection for Arabs. And indeed, the integrity of the law principle, that is, the requirement to act similarly in similar cases, led the Israeli legislature to amend the Act in 1995 and to guarantee protection for the Arab minority as well. ${ }^{7}$ Failure to do so would have publicly revealed the bias and animosity of the legislature against Arabs.

The same logic applied to the evolvement of the AR norm in Israel. In response to the severe under-representation of women on the boards of directors of government corporations, ${ }^{8}$ two of Israel's biggest NGOs - the Israel Women's Network and the Association for Civil Rights in Israel - successfully lobbied for the 1993 amendment of the Government Corporations Law. Section 18A of the Law provides:

(a) The composition of the board of directors of a Government corporation shall give appropriate representation of both sexes.

(b) Until proper expression of such representation is achieved, ministers shall appoint, in so far as is possible under the circumstances of the case, directors of the sex that is not properly represented at that time on the board of directors of the corporation.

Subsequent to this amendment, in an impressive legislative move, the requirement for appropriate representation of women spread rapidly to a broad range of domains. ${ }^{9}$ Two of the major extensions of the norm were the 1995 amendment to the Civil Service (Nominations) Law, 1959, which requires the government to

7 Article 2(a) of the Equal Opportunities in Employment Act, 1988 has been amended several times and now prohibits discrimination on the following grounds: 'sex, sexual tendencies, personal status or because of their age, race, religion, nationality, country of origin, views, party or duration of reserve service'.

8 In 1993, only $7 \%$ of directors on government corporation boards were women. See Orly Almagor Lotan, Appropriate for Women: Legislation and Reality (Jerusalem: Knesset Research \& Information Center, 2011), available at <http://www.knesset.gov.il/mmm/data/ $\mathrm{pdf} / \mathrm{m} 02819 . \mathrm{pdf}>$.

9 The requirement for appropriate representation for women appears in the following laws, with the first two in fact preceding the enactment of section 18A of the 1993 Government Corporations Law: section 9A of the Sports Law, 1988; section 4(b) of the Veterans Law, 1989; section 49(b) of the National Health Insurance Law, 1994; section 8(b)(3) of the National Authority for the Authorization of Laboratories, 1977; section 11(c) of the National Fight against Car Accidents, 1977; section 9(e) of the Authority for the Advancement of the Status of Women Law, 1998; section 239(d) of the Corporations Law, 1999; and section 4(e) of the National Commission for Research and Civil Development, 2002. 
ensure appropriate representation for both sexes in all branches of the civil service, ${ }^{10}$ and the 2005 amendment to the Equal Rights for Women Law, 1951, requiring AR on public committees. ${ }^{11}$ The amount of legislation mandating AR for both sexes was so extensive by 1998 that the Israeli Supreme Court was led to rule that the requirement to seek appropriate representation constitutes a general doctrine of public law and is not contingent on the specific dictates of the relevant statutes. ${ }^{12}$

The emergence of the AR norm with respect to women has had a spill-over effect for Arabs and other under-represented groups. In 2000, the norm was extended to Arabs with regard to both government corporation boards of directors and the civil service. ${ }^{13}$ Currently, this norm applies also to people with disabilities and Jews of Ethiopian descent in these contexts. ${ }^{14}$ The dynamics that Jon Elster has termed 'the civilizing force of hypocrisy'15 - the fact that most politicians cannot afford to present themselves in public as bigots, even if they are - have emerged as a very powerful tool for extending the AR norm to the most vulnerable groups in Israel - those groups whose interests are typically not protected by the regular political processes.

There are a few limitations to the scope of the AR norm. First, it does not ordinarily apply to the private sector. The affirmative duty to implement the norm is borne primarily by public entities. ${ }^{16}$ One exception is set in section 9 of the 1998 Equal Rights for People with Disabilities Act, which requires employers to promote appropriate representation of people with disabilities. However, this provision, which constitutes an intrusive intervention into the employer's liberty (as it imposes

10 Section 15A of the Civil Service Law (Nomination), 1959.

11 Section 6C1 of the Equal Rights for Women Law, 1951.

12 HCJ 2671/98, Israel Women's Network v Minister of Work \& Welfare, 52(3) PD630 (1998). As a general doctrine of public law, it is often subject to balancing, and the concrete circumstances of each case.

13 Section 15A of the Civil Service Law (Nomination) (11th Amendment), 2000; section 18A of the Government Corporations Law (11th Amendment), 2000.

14 Section 15A of the Civil Service Law (Nomination) (13th Amendment), 2005; section 50A of the Government Corporations Law (29th Amendment), 2011.

15 Jon Elster, 'Deliberation and Constitution Making' in Deliberative Democracy, ed. Jon Elster (Cambridge, Mass: Cambridge University Press, 1998), 97, 111. ('The presence of a public makes it especially hard to appear motivated merely by self-interest. Even if one's fellow assembly members would not be shocked, the audience would be. In general, this civilizing force of hypocrisy is a desirable effect of publicity.')

16 While in Israel constitutional norms are generally indirectly applied to private entities, even in the absence of specific legislation, rarely is it the case that affirmative duties are imposed on private entities without a specific provision in a statute. 
positive rather than negative obligations), has not been enforced. ${ }^{17}$ Second, thus far, the AR laws have not been directed at legislative bodies or at access to land or education. In practice, however, some major political parties have voluntarily set some minimal quotas for the representation of women on their party lists. ${ }^{18}$ Similarly, a few of the public universities have adopted policies designed to increase the access of higher education to Arabs, Ethiopian Jews, and applicants from peripheral towns. ${ }^{19}$

Thus, the norm that has emerged in Israel in recent years is the requirement that the decision-maker ensure appropriate representation primarily for women and, later, for minorities as well, particularly in the public workforce. But what does this AR norm mean precisely? Does it impose strict liability on decision-makers whenever women and minorities are under-represented, or does it impose liability only when there is some evidence that the decision-maker intentionally violated the norm? The discussion now proceeds to the notion of responsibility and the AR norm.

\subsection{Negligent violation of the AR norm}

We normally think of appropriate representation policies as a results-oriented mechanism for achieving substantive equality. Proponents of substantive equality subscribe to the ideal of equal representation of women and minorities in all spheres of leadership in the public and economic life of society. In order to achieve equality in results, they advocate not only the taking of negative measures (for example, prohibiting facially neutral policies that in practice have a disparate impact on protected groups) but also the taking of positive measures in the form of reasonable accommodation and appropriate representation.

Results-oriented mechanisms are often contrasted with the more classic understanding of the anti-discrimination principle - namely, 'disparate treatment.' Under this latter, deontological approach, the purpose of the anti-discrimination principle is to nullify decisions and policies that rest on irrational bias and animosity towards discrete and insular minorities, and which result in severe psychological harm (stigma) and material damage to these groups. The evil that the disparate treatment

17 Interestingly, in Germany and other Continental states, private corporations are required to set some quotas for people with disabilities. In cases in which a corporation fails to meet this requirement, it is required to pay the government money that is allocated to the benefit of people with disabilities. See <http://www.justice.gov.il/NR/rdonlyres/B500014E-F4544BEE-91D0-4F9486948012/12219/idudmasikim.pdf >.

18 Galia Golan, 'Ensuring the Representation of Women in Politics' in Affirmative Actions and Equal Representation in Israel, ed. Anat Maor (Tel Aviv: Ramot Press, 2004), 315.

19 See Menachem Mautner, 'The Special Acceptance Program in the Law Faculty of Tel Aviv University' in Affirmative Actions and Equal Representation in Israel, ed. Maor, 457. 
approach seeks to remedy lies in the state of mind of decision-makers - their motives and intentions.

These two approaches diverge not only in the respective ideals they aspire to realise, but also in their understanding of the concept of responsibility. The disparate treatment approach, which dominates American case law, is based on the notion that only intentional action should be subject to moral judgement. Assigning responsibility, under this approach, requires proof that the behaviour of the defendant was wrong in the sense that he or she knew what he or she was doing and why. ${ }^{20}$ This approach is manifested doctrinally in the ways in which American courts approve affirmative action policies. Affirmative action is recognised as legitimate in the US only when there is at least some prima facie evidence of past intentional discrimination against the given minority. ${ }^{21}$ As Iris Young puts it, the concept of discrimination in American law is an agent-oriented, fault-oriented concept. Thus it tends to focus attention on perpetrator and a particular action or policy, rather than on victims and their situation. 22

Advocates of the disparate treatment approach maintain that a results-oriented approach will water down our moral, common-sense understanding of responsibility. Justice O'Connor pointed to the dangers of the disparate impact approach:

If quotas and preferential treatment become the only cost-effective means of avoiding expensive litigation and potentially catastrophic liability, such measures will be widely adopted. The prudent employer will be careful to ensure that its programs are discussed in euphemistic terms, but will be equally careful to ensure that the quotas are met. ${ }^{23}$

So, the claim is that enforcing quotas practically, and even logically, stems from a commitment to a results-oriented conception of equality and affirmative action. The accusation being made is that any results-oriented approach is, in the end, reduced to imposing strict liability on well-intentioned agents.

Building on the Israeli jurisprudential experience, I argue that, contrary to this claim, the AR norm does not necessarily entail strict liability. Rather, the norm can be conceived of as setting a duty of care - that is, requiring the agent to take a set of reasonable measures to ensure that women and minorities are not underrepresented in various sectors of the public workforce. Refraining from taking such measures may be viewed as constituting a negligent violation of the AR norm.

20 Iris Marion Young, Justice and the Politics of Justice (Princeton NY: Princeton University Press, 1990), 150. See McDonnell Douglas Corp. v Green, 411 US 792 (1973).

21 Johnson $v$ Transportation agency of Santa Clara County 480 US 616 (1987).

22 Young, Justice and the Politics of Justice, 194.

23 Watson v Fort Worth Bank \& Trust, 487 US 977, 993 (1988). 
David Oppenheimer has developed the concept of 'negligent discrimination' as best explaining the American civil rights jurisprudence in the field of accommodations, disparate impact, and sexual and ethnic harassment. ${ }^{24}$ Oppenheimer argues that the Supreme Court has devised a set of requirements that set a standard of care, including the following:

[A]n employer should be found liable when it fails to conform its conduct to the statutory established standard of care by making employment decisions that have a discriminatory effect, without first carefully examining its processes, searching for less discriminatory alternatives, and examining its own motives for evidence of stereotyping, the requirement that less discriminatory measures should be employed. ${ }^{25}$

Although explicitly avoiding the term, this set of requirements comes very close to adopting the doctrine of negligent discrimination.

There is something special about the anti-discrimination norm that makes the negligence approach more appealing here. Cognitive psychologists have repeatedly found that even when people are committed to equality on the cognitive level, most do not internalise the norm on the subconscious level. ${ }^{26}$ Since our brain functions efficiently, stereotyping is a very useful mechanism that enables us to function reasonably in a complex world with a vast amount of data to process. When our brain thinks in stereotypical terms, it is in fact in 'cruise control' mode. The negligence approach allows us to devise a set of rules reminding us of our commitment on the cognitive level to equality. When the courts require an agent to search for less discriminatory alternatives, it raises the agent's commitment to equality to the more conscious level; it directs him or her to exit 'cruise control' and take control of the decision-making process.

24 David B Oppenheimer, 'Negligent Discrimination', U. Pa. L. Rev. 141 (1993): 899.

Oppenheimer, however, did not regard affirmative action as a sphere in US law for implicitly adopting the negligence approach.

25 Ibid., 900.

26 See Irene V Blair \& Mahzarin R Banaji, 'Automatic and Controlled Processes in Stereotype Priming,'J. Personality \& Soc. Psychol. 70 (1996): 1142 (noting that numerous studies have demonstrated 'how stereotypes may influence responses without perceivers' awareness of that influence'); Mahzarin R Banaji \& Curtis D Hardin, 'Automatic Stereotyping', Psychol. Sci. 7(3) (1996): 136 ('Several recent experiments have demonstrated that stereotyping can occur implicitly, without subjects' conscious awareness of the source or use of stereotypic information in judgment.'); Brian A Nosek, Mahzarin R Banaji \& Anthony G Greenwald, 'Harvesting Implicit Group Attitudes and Beliefs from a Demonstration Website', Group Dynamics 6 (2002): 101 (discussing a study that demonstrates the operation of unconscious and implicit prejudicial attitudes with respect to race, age, and gender). 
There have been several tragic incidents in Israel in which infants were forgotten in locked cars in the hot Israeli summer, resulting in either death or severe brain damage. In most cases, these infants had been forgotten by their fathers, who did not usually bring them along on the specific route taken that day. As in the case of discrimination, when people function in cruise control mode, they are more prone to be negligent. In cases in which parents deviate from their routine course of action, they should heighten their level of awareness when they put their infants in their cars. The setting of a duty of care functions as a reminder of the possibility that an accident could occur.

In the typical case, the agent's intention is to make the most efficient decision. A side effect of this, however, could be the under-representation of women and minorities. As I will show in the next part, the Israeli courts hold an agent responsible for such side-effects when he or she acts negligently ('knew or should have known'). But can we understand the agent's state of mind, when he or she seeks efficiency and is indifferent to the AR norm, as intentionally violating this norm?

Experimental philosophers tell us, quite surprisingly, that our moral intuition ascribes intentionality in such instances. This is due to an interesting phenomenon known as the Knobe Effect (named after Joshua Knobe, who first detected the phenomenon): ${ }^{27}$

Consider an executive who, motivated entirely by the goal of maximizing profit, embarks on a policy that he knows will also cause environmental damage. Does he intentionally harm the environment? Most people hold that he does. In contrast, when considering an otherwise identical case in which the side effects would be beneficial to the environment, most people hold that the executive does not intentionally help the environment. A number of follow-up studies have found that the finding is robust, that it applies to children as young as four, and that it occurs in other languages and cultures. ${ }^{28}$

The ascription of intentionality in such instances can be regarded as a cognitive error, since moral considerations should not affect our determination of intentionality. But it is also possible to conceptually justify the asymmetry. Richard Holton argues that there is a conceptual difference between violating a norm and conforming to that norm. ${ }^{29}$ Because people are sensitive to the existence of norms and to whether these norms are being violated, they attribute intentionality when the agent has

27 Joshua Knobe, 'Intentional Action and Side Effects in Ordinary Language', Analysis 63 (2003): 190.

28 This concise summary is taken from Richard Holton, 'Norms and the Knobe Effect', Analysis 70 (2010): 417.

29 Ibid. 
knowingly violated a norm. By this account, when an agent gives lexical preference to efficiency and is totally indifferent to its side-effect (in our case, the AR norm), most people will view this as intentionally violating the norm.

\subsection{The norm, the courts, and negligence}

What would constitute a negligent violation of the AR norm? This part presents the jurisprudence of the Israeli Supreme Court as interpreting the AR norm as a rigorous standard of care.

The Israeli Supreme Court is sympathetic to the idea of substantive equality. It has repeatedly ruled that the plaintiff in discrimination cases is not required to prove the defendant's intentionality ('animus'). Since the 1990s, the court has developed three layers of substantive equality: (i) the doctrine of disparate impact (responding to facially neutral policies disproportionately disadvantaging a protected group); ${ }^{30}$ (ii) the requirement to reasonably accommodate the needs of women and people with disabilities; ${ }^{31}$ and (iii) affirmative action. What is common to all three is the court's willingness to impose some costs on the agent in order to achieve equality. In its landmark Miller case, for example, when the court obligated the Israeli Air Force to enrol women in its pilot training course, it referred to Chief Justice Barak's book, stating that ' $[\mathrm{t}]$ he protection of human rights costs money, and a society that respects human rights must be prepared to bear the financial burden. 32

While the development of the concept of affirmative action in Israeli constitutional law is part of a general shift in Israeli jurisprudence towards positive rights, the doctrine does not come close to imposing strict liability. Since the realisation of constitutional norms typically incurs some cost and could undermine efficiency, there is a structural, even logical, need for balancing. ${ }^{33}$ This is especially true in legal systems that reject the notion that $\mathrm{AR}$ requires quotas. The qualification to the AR norm - 'in so far as is possible in the circumstances of the case' - directs the courts to balance the benefits from realising the norm against the costs. As I will describe shortly, the Supreme Court has preferred applying a demanding necessity test, which functions as a requirement for Pareto optimality, rather than applying a simple cost-benefit analysis.

30 HCJ 953/87, Poraz v Mayor of Tel Aviv-Jaffa, 42(2) PD 309 (1988); HCJ 11163/03, Supreme Monitoring Committee for Arab Affairs in Israel v Prime Minister, [2006] (1) IsrLR 105.

31 HCJ 7081/93, Botzer v Macabim-Reut Local Council, 50(1) PD 19 (1996); HCJ 4541/94, Millerv Minister of Defense, 49(4) PD 94 (1995).

32 Miller, 49(4) PD at 113.

33 Mark Kelman, 'Market Discrimination and Groups', Stan. L.Rev. 53 (2002): 833, 842. 
The 1994 Israeli Women's Network case ${ }^{34}$ was the first to be litigated following the enactment of section 18A of the Government Corporations Law, 1993.35 The case related to the nomination of men to two boards of directors in government corporations on which there were no women directors. The Minister of Transport argued that the appointees were the best candidates for the position and that even if the court were to find that the ministers had acted wrongly, the appointments should not be nullified in this particular instance, as it was the first time the matter had come before the court.

The Supreme Court granted the petition and nullified the nominations. Justice Mazza, writing the majority opinion, invoked the rhetoric of substantive equality: "The idea of "affirmative action" derives from the principle of equality, and its essence lies in establishing a legal policy for achieving equality as a resultant social norm. ${ }^{36}$ In view of the qualification 'in so far as is possible in the circumstances of the case', the court ruled that the AR norm 'is not absolute but relative' and that, in the process of balancing, 'primary importance should be attached to the duty to prefer women., ${ }^{37}$ The court then proceeded to set what can be termed 'the standard of care' in AR cases:

$[T]$ he burden of proof that in the circumstances of a specific case it was not possible to appoint a woman rests with the appointing minister. This burden is not a light one. In order to discharge it, the appointing minister must show that he examined the possibility of appointing a suitable female candidate, but discovered that, in the circumstances of the case, this was impossible. Even his duty to make such an examination is not simple. In order to discharge it, the minister must adopt reasonable measures to locate a suitable female candidate. The scope of these measures depends on the type of appointment in question. When he must appoint a director from among the employees of his ministry, the examination must encompass all the female employees in his ministry who prima facie have the basic qualifications required. If he must choose the candidate from among the general public, his examination must encompass those sectors of the population where a suitable female candidate is likely to be found. This does not mean that the minister must seek, at any cost, to locate an unknown female candidate who has the necessary qualifications.

34 HCJ 2671/98, Israel Women's Network v Minister of Work \& Welfare, 52(3) PD 630 (1998).

35 This was not the first case in which the Israeli Supreme Court signalled its support for the concept of affirmative action. In HCJ 528/88, Avitan v Israel Lands Administration, PD 43(4) 297 (1988), the court ruled that leasing land cheaply for the housing requirements of Bedouins, which the state has an obvious interest in ensuring, does not contravene the principle of equality, and therefore it does not entitle someone who is not a Bedouin (like the petitioner) to claim that he too should be leased land for housing on the same terms.

36 Ibid., para 16.

37 Ibid., para 29. 
But he also will not have done his duty by making a 'formal' search for any female candidate. In order to do his duty properly, he must adopt reasonable measures designed to lead to the discovery and appointment of a suitable female candidate. For this purpose, it is not impossible that the Minister will seek assistance not only from his assistants and advisors, but also from external public bodies (such as business guilds, professional associations and societies, trade $[\mathrm{sic}]$ unions, the universities, women's organizations, etc.) and of professional authorities (such as the Adviser on the Status of Women in the Prime Minister's Office), who have in their possession the relevant information which he needs and who may recommend candidates with the qualifications required for the various appointment. ${ }^{38}$

The court then ruled that the standard had not been met in the particular case at hand and that the lack of intentionality of the respondents was no excuse:

Hence, there is no significance to the argument that the defective decisions were the result of an oversight. On the contrary, if further proof is required of the essentiality of enforcing this law, the alleged lack of awareness of the Ministers to act in accordance with its binding provision provides the necessary proof. Furthermore, the approach underlying the procedure laid down by the Minister of Finance following the passage of the Appointments Law, and the affidavits in reply that were submitted in these petitions merely strengthen the impression that the nature of the obligation imposed on the Ministers under section 18A(b) has not yet been properly understood. ${ }^{39}$

The standard of care set in this case was applied in subsequent cases ${ }^{40}$ and later incorporated into the directives of the Knesset Legal Advisor. ${ }^{41}$ More recently, the government issued a number of decisions that express an even greater commitment to the AR norm. ${ }^{42}$

38 Ibid., para 30.

39 Ibid., para 34.

40 HCJ 6924/98, Assoc. for Civil Rights in Israel v Gov't of Israel, 55(5) PD 15, 29 (2001); HCJ 2671/98, Israel Women's Network v Minister of Labor \& Social Affairs, 52(3) PD 630, 664-65 (1998); HCJ 2754/02, Israel Women's Network v Gov't of Israel (2002) (not yet published).

41 Guidelines of the Attorney General of Israel No. 1.1503, Appropriate Representation of Certain Sectors (March 2003).

42 Government Decision 1362 of March 2007 concerning 'appropriate representation of women in boards of directors of government corporations' stipulated that government ministers should appoint women to the directorates of government corporations until attaining 50\%, within two years of the decision's adoption. See also Government Decision 2506 of November 2010, concerning 'appropriate representation of members of the Ethiopian Jewish community in the civil service', Government Decision 4730 of March 2006, concerning 'appropriate representation among legal interns in the Ministry of Justice', 
The standard of care that emerged from Women's Network has been strictly applied in later cases. In a recent case, concerning the appointment of the Turkel Commission investigating the Gaza flotilla raid and blockade of Gaza, an attempt was made to find a female international law expert to serve on the Commission. ${ }^{43}$ The Commission chairperson approached three such well-known experts, but they all declined the appointment. A new list of ten highly ranked female candidates was then submitted to the chairperson, but he rejected them in the belief that their possible contribution to the Commission did not match the potential of the two male candidates who were eventually chosen. A petition was brought before the Supreme Court claiming that the failure to nominate a female member to the Commission constitutes a violation of the AR norm set in the Equal Rights for Women Law. The Supreme Court ruled that the chairperson's efforts did not meet the demanding standard set in the Women's Network case and that he should have approached at least some of the ten female candidates who had been recommended to him. The Court expressed its wonder: 'How could it be that in the entire territory of the state of Israel, with its vast range of activities and research, not even one suitable and capable female candidate could be found?'44 In the wake of this decision, the Minister of Justice and Commission chairperson approached five additional female candidates, but all rejected the offer to serve on the Commission.

Thus, even when the most demanding standard is applied by the Supreme Court, the Pareto optimality logic persists and the reasoning remains procedural administrative-law style. The court is not willing to undermine governmental and market efficiency; rather it operates within the analytical structure of a necessity test, asking whether there are any less discriminatory alternatives that achieve the governmental interest in full (or almost in full). This negligence-like approach does not necessarily mean that courts are oblivious to motives and intent. Although the Supreme Court typically assumes that the respondent acted in good faith, it is also aware of the possibility that illicit motives had a conscious or subconscious impact on the decision. When less discriminatory options are available, there should be good reason to suspect that the choice of the more discriminatory option was driven by an illicit motive.

The two rounds of litigation in the Yael Aran case capture nicely the two elements of the Israeli negligence approach to the AR norm: (i) the application of a demanding

Government Decision 2579 of November 2007, concerning 'appropriate representation of members of the Arab, Druze and Cherkassy population in the civil service'.

43 HCJ 5660/10, Women Lawyers for Social Change v Prime Minister (2010).

44 Ibid., para 16. 
standard of care aimed at heightening the decision-maker's level of consciousness regarding the norm, and (ii) a Pareto-optimality approach to the norm and abstention from cost-benefit horizontal balancing.

The first round of litigation concerned a professional search committee's recommendation of Yael Aran, a female candidate, for the position of CEO of the Israeli Anti-Drug Authority, determining her to have slightly better credentials than a male candidate with a military background. ${ }^{45}$ The CEO of the Prime Minister's Office rejected this recommendation, preferring instead the male candidate. While there are good reasons to suspect that the decision-making process was consciously or subconsciously influenced by an 'old boy's network' state of mind, the Supreme Court ruled in Aran's petition against the appointment, stating that 'there is no ground for the conclusion that the CEO of the Prime Minister's Office bore in mind irrelevant considerations. ${ }^{6}$ Instead, the Court granted the petition on the ground that 'the law, whose purpose is the fashioning of the decision makers' state of mind, was not sufficiently addressed in the decision making process'. ${ }^{47}$

After this petition was granted, the decision regarding the appointment was assigned to the CEO of the Ministry of Public Security, who, like the Prime Minister Office's CEO before him, chose the male candidate over Aran. The new petition brought by Aran against this second decision was dismissed by a panel of three female Supreme Court justices, who found that the decision-maker had been aware of the AR norm and had followed the court's procedural directive set in the first decision. The court thus allowed the decision-maker a wide margin of discretion and refrained from applying a balancing test.

The Itach case $\mathrm{e}^{48}$ is a good illustration of how the logic of negligence and the internalisation of the AR norm, in conjunction with the public reason principle, can facilitate the application of the norm to Israel's Arab minority. Following massive popular protests for social justice in the summer of 2011, the Israeli government set up the Trachtenberg Committee for Social and Economic Change. Of the committee's fourteen members, five were women, all of whom were Jewish. Itach, a not-for-profit organisation of female jurists for social justice, petitioned the Supreme Court regarding the composition of the committee. Relying on section $6 \mathrm{C}(1)$ of the Equal Rights for Women Act, which requires representation of 'women of all sectors of the population', the petitioners demanded the appointment of an Arab woman to the committee, in addition to the five Jewish female members. After the

45 HCJ 5755/08, Aranv Gov't of Israel (21 April 2009).

46 Ibid., para 16.

47 Ibid.

48 HCJ 5980/11, Itach $v$ Prime Minister (28 August 2011) (not yet published). 
petition was filed and granted by the Supreme Court, the government responded by appointing an Arab woman to the committee. The petition was subsequently withdrawn, as its demands had been met, but the court still awarded legal costs to the petitioners. Justice Rubinstein, in the court's ruling on the matter, reflected on the issue at the heart of the petition. He noted that 'the real difficulty is, of course, its internalization and implementation, so that it is constantly in the minds of those who appoint committees. 49

Justice Rubinstein referred to a Biblical passage to make his point:

Surely, this commandment that I am commanding you today is not too hard for you, nor is it too far away. It is not in heaven, that you should say, 'Who will go up to heaven for us, and get it for us so that we may hear it and observe it?' Neither is it beyond the sea, that you should say, 'Who will cross to the other side of the sea for us, and get it for us so that we may hear it and observe it?' No, the word is very near to you; it is in your mouth and in your heart for you to observe. ${ }^{50}$

What needed to be internalised in this case, of course, was not belief in God, but belief in the importance of the AR norm.

\subsection{Conclusion}

Women and minorities continue to suffer from under-representation at the upper levels of public and economic life in Israel. However, the test case of the implementation of the AR norm in the context of government corporation boards of directors is an impressive illustration of the great potential impact of this norm in facilitating social change. Since the enactment of section 18A of the Government Corporations Law in 1993, the number of women sitting on boards of directors of government corporations has risen sharply. While in 1993 only 7 per cent of the directors were female, this increased steadily to 44 per cent in 2010 . We are thus fast approaching equal representation for both sexes on government corporations' boards of directors. ${ }^{51}$

\section{Ibid., sec. 5.}

50 Deuteronomy 30, 11-14.

51 Nevertheless, according to the Israeli Securities Authority, despite section 239(d) of the Government Corporations Law (which requires that in a public company, if, at the time of the appointment of an outside director, all members of the company's board of directors are of the same sex, the outside director must be of the opposite sex), the proportion of women on the boards of public companies in 2010 stood at only about 17\%. Furthermore, the proportion of women at the senior management level of government companies in 2010 was only $15 \%$. See supra note 8 . 
What could account for this remarkable development? It seems to be a combination of three factors: (i) a vibrant civil society that lobbied for the enactment of the AR norms as a sophisticated repeat player in the courts; (ii) an activist Supreme Court that expressed great sympathy for this cause and whose decisions in this field enjoyed relatively large public support; and (iii) a political will that resulted in extensive legislation that extended the application of the AR norm for women (and later for other minorities) to many other sectors of Israeli public and economic life. In such circumstances, a negligence-like approach can be a highly effective mechanism for realising the AR norm.

What we can now hope for is that the successful realisation of the norm with respect to women will have a spill-over effect for other minorities, especially the Arab sector of Israeli society, by way of the Dworkinian principle of the integrity of the law. 

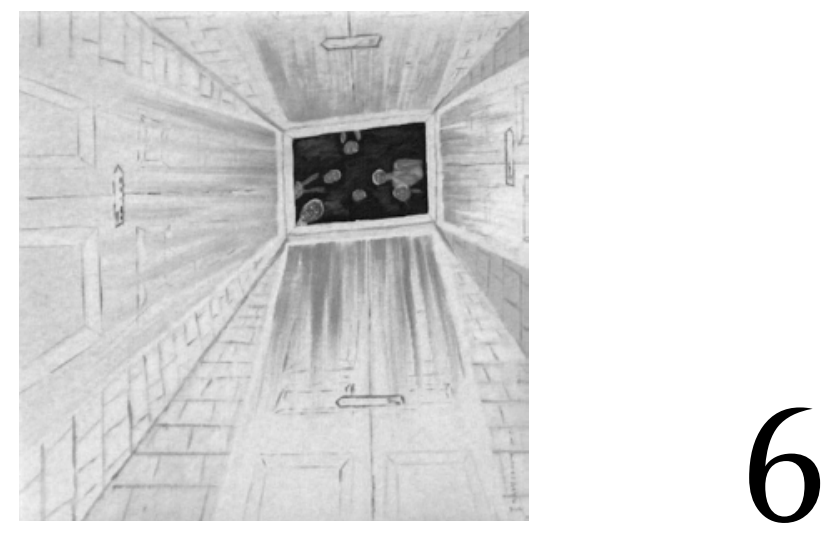

\title{
AFFIRMATIVE ACTION IN MALAYSIA \\ Solid ground, long arms, shallow roots
}

\author{
Hwok-Aun Lee
}

\section{I Introduction}

Malaysia marks an exceptional case of affirmative action. It is one of the few majorityfavouring regimes around the world. The political dominance of the beneficiary group, the Bumiputera, coupled with constitutional grounds for group preference and authoritarian modes of governance, and bolstered by the imperative of responding to racial tensions and social crisis, have laid conditions for preferential programmes of extensive scope and intensity.

When Malaya gained independence in 1957, it comprised Malay, Chinese, and Indians as major groups, with native communities at the margins. Malaysia was formed in 1963 with the merging of the Malayan Peninsula and the states of Sabah and Sarawak, whose native groups, constituting a large proportion of the population, were subsumed under the Bumiputera banner. ${ }^{1}$ The Bumiputera category encompasses predominantly Peninsula-domiciled Malays and non-Malay Bumiputeras of Sabah and Sarawak. By the 2010 census, Malaysia's population comprised 54.6 per cent Malay Bumiputera, 12.8 per cent non-Malay Bumiputera,

1 Singapore joined Malaysia as well, but parted soon after, in 1965. 
24.6 per cent Chinese, 7.3 per cent Indian, and 0.7 per cent other groups. Mixed marriages are exceptionally rare, and in the case of Malay-Muslims and others, typically involve the adoption by the non-Malay of Malay customs and religion.

Malaysia's constitution embeds provisions for affirmative action, and more distinctively, safeguards one group as beneficiaries on the basis of the group's status. Affirmative action has been implemented since Malaya's independence in 1957, but was expanded and consolidated in the wake of the racial riots of 13 May 1969. The ensuing New Economic Policy (NEP) from 1971 instituted a sweeping agenda, amid increasing race-based assertions and dominance of the executive branch of government. Developments since the NEP have transformed Malaysia.

This chapter surveys and discusses the basis and context of affirmative action, outlines Malaysia's policies, evaluates the outcomes and discusses implications. We focus on direct, primary objectives and empirically assessable outcomes, touching only briefly on more multi-faceted and far-reaching issues such as national unity, where affirmative action plays a more indirect and supplementary role. The case for affirmative action grows from solid constitutional, socio-economic and political grounds. The Malaysian Constitution explicitly provides for group preference in particular areas, while political dynamics and crisis moments compelled co-ordinated action to reduce inter-group inequalities. The magnitude of disparity across a range of socio-economic categories was wide, including household income, educational attainment, social mobility, representation in high-level occupations, and capital ownership. The political imperative of promoting the interests of the majority has been shaped by these realities, while political motivations have propelled the use of resources and preferential status for the distribution of largesse and patronage. The reach of state interventions is expansive, stemming from the gravity of real disparities and the vast extent of state resources that could be mustered for racebased programmes, given Malaysia's unique race-based coalition and authoritarian electoral political system.

For a time, these programmes made considerable gains, promoting Bumiputera attainments in higher education, upward occupational mobility and ownership. However, the momentum of progress waned over time, dependence on the public sector and preferential treatment have persisted, and the quality of public education - arguably, the most effective channel of affirmative action - has diminished. After over four decades of extensive and intensive policies, the prospects for scaling back group quotas and preferences are hardly brighter than at their inception; the inertia of the status quo holds strong. Programmes that ultimately should function as transitory instruments for promoting a group's advancement and self-reliance were shallowly planted, such that progress has not been sustained, and is in some cases encumbered by the existing state of affairs. 
The rhetoric of affirmative action reform has intensified in recent years, mostly rallying around misguided and incoherent notions of need-based affirmative action instead of recognising its intrinsic, unavoidable racial basis and dealing squarely with real and pressing problems, especially in the education system. For reforms to have meaningful and lasting impact, Malaysia will have to start by making current affirmative action mechanisms even more effective, while negotiating ways to wind down the regime.

\subsection{Foundations and motivations}

Affirmative action grew from solid grounds. Constitutional underpinnings provided a legal justification for group preference, political imperatives drove the intensity and reach of affirmative action policies, and the severity of inter-group disparities warranted state intervention. The following discussion locates Malaysia's policies in their historical, political and socio-economic context.

\subsubsection{Constitutional provisions and prevalent interpretations}

The foundations for affirmative action are laid in Malaysia's Constitution, which establishes the principle of equality as well as one group's special position and reservation policies in its favour. The 1957 Federal Constitution of Malaya set out these provisions favouring the Malays. With the formation of Malaysia in 1963, Sabah and Sarawak indigenous groups were incorporated into a broader category of beneficiaries. Article 8 provides for individual equality and the prohibition of discrimination, with a proviso: ' $[\mathrm{e}] \mathrm{xcept}$ as expressly authorized by this Constitution'. Article 153 articulates such authorisation, through provisions for the Yang Di-Pertuan Agong (the national king) to:

[E]xercise his functions under this Constitution and federal law in such manner as may be necessary to safeguard the special position of the Malays and natives of any of the States of Sabah and Sarawak [i.e. the Bumiputera] and the legitimate interests of other communities,

by reserving places for the designated group in public sector employment, scholarships, training programmes, permits and licences.

The language and prevailing interpretations of Article 153 warrant further discussion. First, the specification of the Bumiputera as holding a 'special position', on its own, allows for broad and permanent claims for preferential benefits, and renders it rather susceptible to be radicalised or utilised as a nationalistic rallying point. ${ }^{2}$ This constitutional provision of one group's special position, coupled with Malaysia's

2 Daniel Sabbagh, 'Affirmative Action Policies: An International Perspective', Human

Development Report Office Occasional Paper 2004/12 (Geneva: UNDP, 2004). 
predominant race-based political order, has allowed for hegemonic assertions to be consolidated, while also pre-empting broader interpretations. A fuller reading of the provision will take into account the clause stipulating that measures to safeguard Bumiputera special position can be taken 'as may be necessary'. In a clear but indirect sense, then, affirmative action in Malaysia is contingent on there being necessity for such extraordinary interventions.

Group preference in Article 153 emerged out of historical circumstances. The stipulation of the role of Malay rulers in safeguarding the special position of the Malays and the reservation of opportunities for Malays in designated areas was adopted into the 1957 Malaya Constitution from the 1948 Federation of Malaya Agreement. ${ }^{3}$ The presence of the monarchies, whose position and authority were then being asserted, provided conditions for the vesting of such powers, at a time when the Malay community's vast socio-economic disadvantages in a nascent capitalist economy were a source of concern. ${ }^{4}$ At the same time, the contentiousness of this institutionalisation of group preference encouraged caution. In drafting the Malayan Constitution, it was proposed that provisions in what would later be Article 153 should be reviewed after 15 years. ${ }^{5}$ However, this clause was not adopted in deference to political pressures, thus precluding the possibility of a parliamentary review of Article 153. The dominance of Malaysia's executive branch of government and its highly centralised state - albeit within a formal federation - have also forged a system of policy formulation and implementation by discretionary measures and a centralised structure with much power concentrated within the Prime Minister's office, rather than legislative institutions such as employment equity or antidiscrimination laws, or the devolution of responsibility to autonomous agencies.

Second, the concepts of discrimination, equity or fairness do not appear in these constitutional passages, and thus do not formally constrain the application of Bumiputera preference. While discrimination constitutes a premise for corrective action or historical redress in societies with records of political repression or labour subjugation of one group, the lack of such conditions in Malaysia precluded

3 Hock Guan Lee, 'Affirmative Action in Malaysia', Southeast Asian Affairs (2005): 211-28.

4 In 1948, a mere 11 per cent of the Malay population was urbanised, compared to 43 per cent of Chinese and 34 per cent of Indians. By 1957, Malay urbanisation had slightly increased to 19 per cent, while that of Chinese and Indians, respectively, reached 73 per cent and 41 per cent. Just eight per cent of Malays were employed in manufacturing and commerce, against 46 per cent of Chinese. See Boo Teik Khoo, 'Ethnic Structure, Inequality and Governance in the Public Sector: Malaysian Experiences', Democracy, Governance and Human Rights Programme Paper 20 (Geneva: UNRISD, 2005).

5 Joseph Fernando, The Making of the Malayan Constitution (Kuala Lumpur: Malayan Branch of the Royal Asiatic Society, 2002). 
preferential policies favouring Malays on the basis of past discrimination. Although Malay communities were evidently disadvantaged with regard to economic opportunity, participation and ownership, these resulted more from social exclusion than systematic subordination. Malay sultanates had established spheres of rule, and under British colonialism, monarchies and aristocratic elites were elevated through ostentatious ceremonies and prominence in the civil service, while land became reserved for Malays, specifically for rice cultivation by the Malay peasantry. ${ }^{6}$

Third, preferential treatment for the purpose of safeguarding the Bumiputera special position is constrained by a provision that 'legitimate interests of other communities' will also be safeguarded. As mentioned above, there are no explicit constitutional safeguards against affirmative action overreach - that is, against infringements of the principles of equity or fairness - although it is implied that reservations must be proportionally 'reasonable'. Over time, no legislation has been passed - in the form of a 'fair employment' Act, for instance - availing judicial recourse for affirmative action non-beneficiaries to take up cases of being unreasonably denied opportunity. ${ }^{7}$ The 'bargain' in Malaysia has in practice been mainly a matter of implementing Bumiputera preference in the public realm - that is, public sector employment, public education institutions, and public procurement - while limiting affirmative action requirements in the private sector.

Fourth, the form and scope of measures to safeguard the Bumiputera special position are specified. The measures take the form of a reservation of positions in the public sector employment, scholarships, training, permits and licences. The prevalence of race quotas as the means of affirmative action derives from the constitutional legitimation of reservation - and evidently also from its practical simplicity and the lack of policy alternatives, such as incentives and targets, at the time of the writing of the Constitution. The particular areas of intervention also evidently reflect the needs and economic structure of the time, and were the main areas of affirmative action from Malayan independence in 1957. Nonetheless, this has not prevented affirmative action measures in other areas, notably university admissions, government contracts, equity and property ownership. In practice, interventions ostensibly to safeguard the Bumiputera special position have not been sectorally constrained by specific constitutional stipulations. This is not surprising, given the political forces driving affirmative action.

6 Barbara Watson Andaya and Leonard Y Andaya, A History of Malaysia (Honolulu: University of Hawai'i Press, 2001).

7 Recently, the New Economic Model proposed setting up an Equal Opportunity Commission (NEAC 2010), but its inception was aborted owing to political resistance. Such an institution would be of at least symbolic importance, although its efficacy would be curtailed by the lack of equal opportunity legislation and political will, even if it were established. 


\subsubsection{Political imperatives and motivations}

Affirmative action is invariably political, and is all the more so in Malaysia. Persistent group disparities are unsustainable; crisis episodes such as the 13 May 1969 racial unrest further compel political action to redress the imbalances. Preferential policies also can be, and most likely will be, used for political patronage and power preservation. In Malaysia, the political dimension of affirmative action has distinctive roots and has followed particular trajectories. British colonial policies cast racial and ethnic identities and inter-group fissures. ${ }^{8}$ The governing coalition, which has dominated politics since Malaysia's independence, has been forged out of race-based entities. The Alliance, comprising three parties - the United Malays National Organisation (UMNO), the Malaysian Chinese Association (MCA), and the Malaysian Indian Congress (MIC) - governed Malaysia from its independence, and was expanded to the Barisan Nasional (BN), or National Front, which consists of the Alliance members and parties co-opted into a broader coalition in the early 1970s, amid political economic reconfigurations.

Throughout Malaysia's history, politics has largely been framed by representation of and compromise between racially constituted parties. UMNO carries the heaviest electoral weight and sustains hegemony within the coalition, yet depends on other members to preserve power. Thus, Bumiputera preference and concessions to non-Bumiputera communities have both become embedded in the development policy framework. The executive branch of government has also predominated over the legislature, and the bureaucracy has constantly reserved high positions for Bumiputera. These features were magnified and consolidated in the 1970s, alongside the New Economic Policy and the re-assertion of Malay primacy, and the passage of laws curbing freedoms and expanding executive power. ${ }^{9}$ Concomitantly, more overtly pro-Malay programmes were instituted under the NEP, and in an authoritarian, centralised and discretionary manner. While the non-Malay Bumiputeras of Sabah and Sarawak have been formally accorded the same status as Malays since the formation of Malaysia in 1963, political power has consistently centred on Peninsular Malaysia (formerly Malaya) and policy design and execution have disproportionately benefited Peninsular Malays. From the late

8 Colin Abraham, Divide and Rule: The Roots of Race Relations in Malaysia (Kuala Lumpur: Insan, 1997); Charles Hirschman, 'The Making of Race in Colonial Malaya: Political Economy and Racial Ideology', Sociological Forum 1, no. 2 (1986): 330-59.

9 For instance, the Official Secrets Act 1972, University and University Colleges Act (amendment) 1975, and Sedition Act (amendment) 1971 each introduced or amplified restrictions on thought, association and expression. The institutionalisation of strictures and controls would continue in the 1980s, in the form of legislation such as the Printing Presses and Publications Act 1984. 
1980s, political patronage grew in terms of the distribution of largesse, especially through privatisation of state assets, to politically connected persons and Malay corporate titans. ${ }^{10}$

Malaysia's political circumstances and dynamics have impacted on affirmative action in significant ways. First, the centralisation of race as a political platform has bolstered consciousness of Bumiputera preference, and allowed the permeation of entitlement rhetoric and mentality. In popular and political parlance, the constitutional safeguard of the Malay 'special position' has transmuted into Malay special 'rights' and 'privileges', which connote more basic, permanent and emotive claims on preferential treatment. Concomitantly, the question of duration dissipated over time, although the original NEP outlined two decades as the period of implementation (1971-1990). The twenty-year timeline has never been given heavy emphasis, nor have the consequences of attaining or falling short of targets been spelled out. Indeed, Malaysia's affirmative action regime persists as a basically permanent feature in education, public sector employment and procurement with alterations at the margins, while policies in equity distribution have been altered from time to time. The following section outlines key developments in the form and scale of programmes over the past few decades.

Second, we can also observe other departures from the original constitutional intent, which leaned toward productive, instead of acquisitive, opportunities. Thus, asset and wealth transfers, although not explicitly sanctioned in the Constitution, have featured prominently in Malaysia's affirmative action regime. Third, in line with the pursuit of wealth transfer and political patronage, and the policy objective of cultivating a Malay commercial and industrial class, priorities have been skewed towards the development of a capitalist class, while measures to promote advancement through education have been retained in form, but with little attention to substance and the quality of institutions.

\subsubsection{Socio-economic disparities}

While affirmative action in Malaysia was secured in the Constitution and driven by political imperatives, the socio-economic conditions out of which the provisions and policies emerged are inextricably interlinked. From independence in 1957 and through the 1960s, general patterns of social separation and labour market stratification persisted, which can be aptly termed a racial or ethnic division of labour. ${ }^{11}$ The vast majority of the Malay population lived in rural settings,

10 Edmund Terence Gomez \& KS Jomo, Malaysia’s Political Economy: Power, Profits, Patronage (Cambridge: Cambridge University Press, 1999).

11 Khoo, 'Ethnic Structure, Inequality and Governance in the Public Sector'. 
engaged in agrarian activities rice cultivation. They also occupied large sections of and high positions in the bureaucracy, police and security services. The Chinese population was mainly urbanised, and comprised a substantial working class and a nascent capitalist class, especially in distribution and retail sectors, with clan-based networks providing financial resources. The Indian population was more evenly distributed between the rural and urban economies, and were most conspicuous in two areas: labourers on rubber plantations and lower-rung administrators in government services. ${ }^{12}$

While there is little data for the period, various indicators capture the magnitude of inequality in a general sense. In 1957, the poverty rate among Malays was 70.5 per cent, compared to 27.4 per cent for Chinese and 35.7 per cent for Indians. The disparity persisted through to 1970, although by a decreased margin, as poverty remained considerably higher for Malays (64.8 per cent) than for Chinese (26.0 per cent), while it increased slightly among Indians (39.2 per cent). ${ }^{13}$ In Peninsular Malaysia in 1967, the Chinese: Malay household income ratio was recorded at 2.47, and the Indian: Malay household income ratio at $1.95 .{ }^{14}$

Similar divides prevailed in the spheres more directly pertinent to affirmative action: higher education, high-level occupations, and ownership. The racial composition in 1970 at the University of Malaya - Malaysia's then sole higher education institution - generally reflected the national population, with 40.2 per cent Malay, 48.9 per cent Chinese and 7.3 per cent Indian. However, Malay representation in some fields, especially technical and professional ones, was exceedingly low. Malay graduates numbered 22 out of a total 493 in science, 1 out of 67 in medicine, 1 out of 71 in engineering, and 15 out of 49 in agriculture. ${ }^{15}$ While Malays constituted 52.7 per cent of the Malaysian population in 1970, they occupied 22.4 per cent of management and administrative positions. In the top rungs of the civil service, Malays filled 39.3 per cent of positions. ${ }^{16}$ These figures capture both the low representation of Malays in upper level positions, and the fact that their upward mobility was heavily dependent on the public sector. With regard to equity ownership, in 1970, Malays accounted for 1.5 per cent of total share capital ownership of limited companies in

12 Andaya \& Andaya, A History of Malaysia; Gomez \& Jomo, Malaysia’s Political Economy.

13 Richard Leete, From Kampung to Twin Towers: 50 Years of Economic and Social Development. (Petaling Jaya: Oxford Fajar, 2007).

14 Sudhir Anand, Inequality and Poverty in Malaysia: Measurement and Decomposition (Oxford: Oxford University Press, 1981).

15 Viswanathan Selvaratnam, 'Ethnicity, Inequality and Higher Education in Malaysia, Comparative Education Review 32, no. 2 (1988): 180.

16 Malaysia, Third Malaysia Plan, 1976-1980 (Kuala Lumpur: Government Printer, 1976); Khoo, 'Ethnic Structure, Inequality and Governance in the Public Sector'. 
Peninsular Malaysia, while Chinese and Indians held 23.7 per cent, and 62.1 per cent was traced to foreign interests. ${ }^{17}$

The structure of socio-economic disparities impacted on the formation of Malaysia's affirmative action regime. First, given the paucity of higher education institutions in the country as a whole at that time, affirmative action in Malaysia emerged alongside the creation of numerous new educational institutions, which provided conducive conditions for university administrations to be centralised, for admissions quotas to be embedded from the onset, and for the establishment of Bumiputera-only institutions (at both tertiary and post-secondary levels). Second, as remarked above with regard to the Constitution, labour markets were characterised more by disadvantage or exclusion than by discrimination or repression. The absence of historical, systematic labour market discrimination against the Bumiputera, along with the Bumiputera preference in the public sector since Malaysian independence, partly set the stage for an implicit bargain of the public sector and public enterprises as channels for Bumiputera advancement, in exchange for relative restraint in policies overseeing group representation in private sector employment.

Third, the minority groups in Malaysia, especially the Chinese, had gained economic footholds in some sectors, but not comprehensive power, across economic sectors. Thus, the state was in a fairly strong position to extract concessions from domestic, predominantly Chinese, capital. Importantly, large foreign holdings in Malaysia, in key sectors such as plantations and tin mining, presented an external target for equity transfer to Bumiputera interests, thereby defusing domestic conflict to some extent. ${ }^{18}$ The presence of a Bumiputera bureaucratic elite had provided administrative experience that could be ushered into management positions in commercial and financial entities.

\subsection{Affirmative action programmes}

This section focuses on affirmative action since its extensive and intensive implementation under the New Economic Policy. It is important to note that the NEP was more of a visionary framework than a policy set. Accordingly, national unity was declared as the overarching purpose. Its breadth and complexity stretch beyond the scope of this chapter; myriad policies besides affirmative action fall under the umbrella of national unity.

17 Malaysia, Second Malaysia Plan, 1971-1975 (Kuala Lumpur: Government Printer, 1971), 40.

18 In the all-important agricultural sector, Malays owned 0.9 per cent, Chinese 22.4 per cent, Indian 0.1 per cent and foreigners 75.3 per cent; and similarly in mining, the distribution was mining 0.7 per cent Malay, 16.8 per cent Chinese, 0.4 per cent Indian, and 72.4 per cent foreign (Gomez \& Jomo, Malaysia’s Political Economy, 20). 
However, the NEP's development vision quite clearly places affirmative action within the entire transformative process. Two prongs were outlined as principal objectives: (i) to alleviate poverty irrespective of race; and (ii) to accelerate the restructuring of society to reduce and eventually eliminate the identification of race with economic function. ${ }^{19}$ The second prong broadly corresponds with the aims of affirmative action. The NEP cogently recognised poverty alleviation policies (based on need, for the purpose of helping the poor escape poverty) as distinct yet related to 'social restructuring' policies (based on group preference, addressing the problem of a disadvantaged group's under-representation in positions that confer social esteem or economic influence). ${ }^{20}$ The NEP implicitly, and correctly, understood the two prongs as complements, not substitutes. In other words, anti-poverty programmes can reinforce, but not replace, affirmative action. Poverty alleviation policies address problems related to poverty principally through provision of basic goods and services, such as primary and secondary schooling, public health services, infrastructure, and social transfers. Thus, in terms of both policy objectives and instruments, poverty alleviation, (or need-based socio-economic development in general) fundamentally differs from affirmative action. With reference to the NEP, this article focuses on the restructuring component, and on the key areas of higher education and occupational representation (in relation to which the policy targeted representation in proportion to the national population's composition), and on enterprise development and capital ownership (in respect of which the policy targeted Bumiputera ownership of 30 per cent of share capital).

\subsubsection{Higher education}

Malaysia established new school-level institutions for Bumiputera students and a quota system for university enrolment and scholarships. From the mid-1970s, the Ministry of Education established exclusively Bumiputera residential science colleges to address a growing need for science and engineering graduates. ${ }^{21}$ MARA (Majlis Amanah Rakyat, or the Council of Trust for the People) also founded junior residential colleges, which were held to higher teaching standards and allocated better facilities, especially in the sciences, which catered mainly for pupils from rural and underprivileged areas. ${ }^{22}$

19 Malaysia, Second Malaysia Plan, 1.

20 Hwok-Aun Lee, 'Affirmative Action in Malaysia: Education and Employment Outcomes Since the 1990s', Journal of Contemporary Asia 42, no. 2 (2012): 230-54.

21 Kiong Hock Lee, 'Human Resources and Skill Development' in Malaysian Development Experience: Changes and Challenges (Kuala Lumpur: INTAN, 1994), 819-52.

22 Between 1970 and 1990, MARA allocated RM700 million - 67 per cent of its total budget - toward education programmes (Jamaludin Faridah, 'Malaysia's New Economic Policy: Has it Been a Success?' in Boundaries of Clan and Color: Transnational Comparisons of 
At the tertiary level, government founded new public universities and a centralised admissions unit, which implemented de facto enrolment quotas. The number of public universities increased from one in 1971 to five by 1975. A policy of ensuring proportional representation was recommended in 1971, although university admission quotas have not been formally codified. ${ }^{23}$ In practice, 55 per cent of places were reportedly allocated to Bumiputeras from the late 1970s through to the early 2000s. ${ }^{24}$ Notwithstanding the expansion in facilities, tertiary education supply trailed a rapidly increasing demand. The share of applicants who were offered a place in university dropped from around half in the early 1970s to one-fifth by the mid1980s. Shortfalls in public tertiary education provision were covered to an extent by overseas and private institutions, especially for non-Bumiputeras. Many nonBumiputeras who did not gain entry to local universities pursued degree-level studies abroad or opted for local pre-university programmes. In 1985, there were more Chinese enrolled in tertiary institutions overseas than in Malaysia. ${ }^{25}$ Private tertiary education grew further, with the creation of colleges affiliated to foreign universities or accreditation bodies offering pre-university diploma programmes from which students could transition to full-degree programmes under a foreign university.

The mid-1990s witnessed a sea change in Malaysian tertiary education. Public tertiary education burgeoned, while private tertiary education proliferated upon the passage of the Private Higher Education Act of 1996, which allowed domestic private for-profit degree-granting universities. ${ }^{26}$ Private higher education has grown in tandem with Malaysia's continuing affirmative action programme,

Inter-Group Disparity, eds. William Darity \& Ashwin Deshpande (London and New York: Routledge, 2003), 152-74.) See also Leete, From Kampung to Twin Towers, 189.

23 Ting Hui Lee, Chinese Schools in Peninsular Malaysia: The Struggle for Survival (Singapore: Institute for Southeast Asian Studies, 2011), 122-3.

24 Faridah, 'Malaysia's New Economic Policy'; Akihito Aihara 'Paradoxes of Higher Education Reforms: Implications on the Malaysian Middle Class', International Journal of Asia-Pacific Studies 5, no. 1 (2009): 81-113.

25 Faridah (in 'Malaysia's New Economic Policy', 166), reports that in 1985, out of 22,684 students studying overseas, 73.4 per cent were non-Bumiputera who had failed to gain admission to local public universities or who were not offered places in their preferred discipline.

26 The proportion of tertiary students (degree, diploma and certificate) enrolled in overseas institutions declined from 40.2 per cent in 1985 to 13.8 per cent in 1995 , while the share of local private institutions increased from 8.9 per cent in 1985 to 34.7 per cent in 1995. The number of Malaysian university (degree-level) students studying abroad in the 2000s shrank from 103,700 in 2001 to 53,900 in 2006 (Chang Da Wan, 'Public and Private Higher Education Institutions in Malaysia: Competing, Complementary or Crossbreeds as Education Providers', Kajian Malaysia 25, no. 1 (2007): 1-14. 
compensating for the deficit of spaces in public universities, especially for nonBumiputera students. ${ }^{27}$ In the public system, Bumiputera-only matriculation colleges were expanded in the late 1990s. ${ }^{28}$ Compared to Form Six in the national schooling system, matriculation programmes have shorter duration and are widely considered as easier routes to public university. ${ }^{29}$ A 10 per cent non-Bumiputera quota was introduced in matriculation colleges in 2002. In recent years, some scholarship programmes have also become somewhat more inclusive in selection, and transparent in their operations. ${ }^{30}$ On the whole, however, quotas remain the preponderant mode of operation, with marginal alterations from time to time. ${ }^{31}$

\subsubsection{Representation in high-level positions}

The New Economic Policy resolved that 'employment patterns at all levels and in all sectors $[. .$.$] must reflect the racial composition of the population. { }^{32}$ The key affirmative action interventions in this regard comprised de facto quotas in public sector employment, with some limited controls on the private sector. Government and statutory bodies facilitated Malay urbanisation and entry into formal wage employment.

27 In 2000, an estimated 61 per cent of tertiary-educated workers obtained diplomas or degrees from local public institutions, 21 per cent from local private institutions, and 18 per cent from overseas institutions. Within the Bumiputera tertiary-educated working population, 81 per cent attended local public institutions, 8 per cent attended local private institutions, and 11 per cent studied overseas. For the Chinese population, the local public / local private / foreign breakdown was 36 per cent / 41 per cent / 23 per cent, and for Indians, 46 per cent / 35 per cent / 20 per cent (author's calculations from a 2 per cent tape of the 2000 Population Census).

28 Enrolment in the then Bumiputera-only matriculation colleges burgeoned from 15,470 in 1995 to 46,509 in 2000, at a growth rate of 24.6 per cent per year (author's calculations from Malaysia, Eighth Malaysia Plan, 2001-2005 (Kuala Lumpur: Government Printer, 2001).

29 Seng Piew Loo, 'Schooling in Malaysia' in Going to School in East Asia, eds. Gerald A Postigliane \& Jason Tan (Westport, CT: Greenwood, 2007), 223.

30 For instance, it was revealed that a quota has been implemented in awarding Public Service Department scholarships, which was formally raised from 10 per cent non-Bumiputera to 45 per cent non-Bumiputera around 2000. However, reports found that from 2000 to 2007 the proportion of non-Bumiputera scholars at overseas institutions averaged about 15 per cent, while that for local institutions averaged 20-25 per cent.

31 A quota of 10 per cent non-Bumiputera enrolment in the 40 MARA junior science colleges was introduced in 2000. The proportion of non-Bumiputera in these colleges was 11.8 per cent in 2008 ('More than 3,000 non-bumis in Mara colleges', The Star, no author attributed, 15 May 2008, available at <http://www.thestar.com.my/ story $/$ ?file $=\% 2 f 2008 \% 2 f 5 \% 2 \mathrm{f} 15 \% 2$ fparliament $\% 2 f 21255183 \&$ sec $=$ parliament $>$ accessed 12 September 2014.

32 Malaysia, Second Malaysia Plan, 42. 
Prior to the NEP, measures had been in place to sustain and augment Malay representation in the public sector, especially at senior levels. Under the NEP, the public sector burgeoned, especially in the 1970s until the mid-1980s, and its affirmative action role grew through absorption of graduates and scholars into its ranks. ${ }^{33}$ Mehmet and Yip's 1985 survey of a graduating cohort reported that 86.2 per cent of Malays planned to work for government and statutory bodies, compared to 61.9 per cent of Chinese and Indians. Public sector employment and promotion adhered to Malay-favouring preferential selection, although the processes were largely not formalised and generally operated in a discretionary manner, sanctioned by the resolution to attain racial proportionality across all spheres of employment.

Malaysia has for the most part not pursued affirmative action in private sector employment. Implicitly, affirmative action in higher education is to equip Bumiputeras for open labour market participation and upward occupational mobility. The Industrial Coordination Act (ICA) 1975 required large-scale manufacturing firms to have workforces that are representative of Malaysia's population. Compliance on the production line was easily attained, especially through employment of young Malay women from villages migrating to work in electronics and textile and clothing factories. Managerial and professional positions were harder to fill, and no substantive research has been conducted on this subject. Given the subsidiary importance of employment within the ICA's objectives, compared to equity ownership requirements (of which more later), and the lack of a monitoring mechanism, the effect of the ICA on increasing Malay representation was minimal and concentrated in less technical roles such as human resource management. Employment requirements were eventually dismantled in the late-1980s as the ICA was phased out amid investment liberalisation. ${ }^{34}$

On the whole, Malaysia has placed little emphasis on the racial composition of workers within private sector organisations. There is no general legislation on employment outcomes aside from manufacturing, although some sectors strive for racial representativeness for ad hoc, strategic purposes. For example, most banks employ a diverse workforce in tellers and service jobs, although management tends to correspond racially with the banks' ownership. ${ }^{35}$ In recent years, fragments

33 The public sector's share of total employment grew from 11.9 per cent in 1970 to 15.0 per cent in 1981, then dipped slightly to 14.2 per cent in 1987 (Rajah Rasiah and Shari Ishak 'Market, Government and Malaysia's New Economic Policy', Cambridge Journal of Economics 25 (2001): 57-78).

34 Author's interview with senior industry source.

35 Author's interview with National Union of Banking Employees (NUBE) officials. 
of affirmative action in employment have rolled out occasionally, and rather inconsequentially. ${ }^{36}$

\subsubsection{Equity ownership and enterprise development}

Equity ownership has been the most emphasised and politically consequential of the NEP's objectives. It is also the area of starkest Malay under-representation, according to official figures. ${ }^{37}$ From the mid-1970s, the state came under mounting pressure to intervene more forcefully. The Industrial Coordination Act 1975 introduced equity requirements that compelled share transfers to Bumiputeras. Large-scale firms were required to obtain a manufacturing licence, conditional upon 30 per cent or more equity being allocated to Bumiputera individuals. ${ }^{38}$ This enforced redistribution fused the dual goals of ownership and substantial (though not majority) control in manufacturing. More generally, initial public offerings are required to set aside 30 per cent for Bumiputeras and at a discount.

The government also aggressively acquired stakes in foreign-owned companies, directly or indirectly through investment agencies. State-operated Bumiputera trust funds, notably Permodalan Nasional Berhad (or 'National Trust, Ltd.'), were founded from the late 1970s and invested sizably in priority sectors. Rather fortuitously, Malaysia enjoyed the 'advantage' of a large presence of foreign firms, particularly in the then-lucrative resource-based fields of mining and plantations. State investment funds played a key role in taking over ownership, as well as management, of hitherto foreign establishments.

The equity redistribution regime took a drastic turn in the mid-1980s. The Promotion of Investments Act of 1986 exempted a broader range of companies, and the bulk of manufacturing entities, from having to divest equity to Bumiputera interests. Massive waves of privatisation swept across the economy from the late 1980s, through various modes, including public listing, contracts and licensing.

36 The 2007 Federal Budget urged publicly listed companies to practise 'corporate social responsibility' through awarding contracts to Bumiputera vendors, ensuring diversity in workplaces, and developing human resources. The 2008 Budget followed up with a requirement that companies 'disclose their employment composition by race and gender, as well as programmes undertaken to develop domestic and Bumiputera vendors. However, the purpose of such disclosures, and rewards for compliance or penalties for non-compliance, remain unspecified.

37 Ownership patterns in the then-dominant primary sectors are instructive. In agriculture, Malays owned 0.9 per cent, Chinese 22.4 per cent, Indian 0.1 per cent and foreigners 75.3 per cent; in mining, the distribution was 0.7 per cent Malay, 16.8 per cent Chinese, 0.4 per cent Indian, and 72.4 per cent foreign (Gomez \& Jomo, 1999: 20).

38 Export-oriented (more than 80 per cent of output exported) firms were exempted from these equity requirements. 
In contrast to the preceding weighting on institutional ownership, privatisation concentrated capital in a legion of politically connected, mostly Bumiputera, individuals. However, the 1997-1998 financial crisis struck privatised entities the hardest, and in the aftermath of a swathe of bailouts and re-nationalisation exercises, state-aligned institutional investment returned to prominence.

Enterprise development, another mainstay of Malaysia's affirmative action, overlaps with the objective of increasing Bumiputera representation in high-level occupations, but unlike public administration, is focused on commercially oriented production of goods and services. One of the starkest spheres of Bumiputera underrepresentation was among managers in private establishments. Throughout most of the NEP, the Malaysian approach to enterprise development has been state-centric, beginning with the commissioning of various agencies to support Malay business, particularly in the 1970s and 1980s. State-owned enterprises, including publicservices departments, statutory bodies, and government-owned private or public companies, numbered 22 in 1960 and 109 in 1970, then burgeoned to 656 in 1980 and 1149 in 1992, with the largest numbers in manufacturing, services, agriculture, finance and construction. ${ }^{39}$ State Economic Development Corporations (SEDCs) were designated to spearhead Malay business from the early 1970s and provided seed funds or government guarantees. Most ventures, however, were unsuccessful or unsustainable, beset by poor governance, inexperience, or corruption..$^{40}$ As described above, from the late 1970s, the Malaysian government acquired control of British-owned companies through its investment arms, and facilitated entry of Malay managers and professionals into new sectors. While these interventions have not been researched extensively, their outcomes, compared to other programmes that started in the 1970s, have been more effective and sustained.

The state-sponsored Bumiputera capitalist and entrepreneurial development agenda underwent major shifts in the 1980s. The heavy industries programme was launched in the early part of the decade, venturing into various sectors, most conspicuously automobiles, steel, and cement. The newly created large firms were governmentowned and Bumiputera-managed, supported financially and operationally by Japan. Malaysia’s heavy industries struggled to take off, partly due to the global recession of the mid-1980s, but also through excess capacity, lack of experience, and poor performance monitoring. Toward the late 1980s, the focus turned again to public procurement and privatisation of state entities, which would facilitate the development of individuals representing and championing the Bumiputera Commercial and Industrial Community (BCIC).

39 Gomez \& Jomo, Malaysia’s Political Economy, 29-31.

40 In 1981, out of 260 companies under the purview of the Ministry of Public Enterprises, a reported 94 were making losses and 21 had yet to operate (James V Jesudason, Ethnicity and the Economy (Singapore: Oxford University Press, 1989), 98-100). 
The ascendancy of the Bumiputera capitalist class and individual capital accumulation to the top of the policy agenda had wide ramifications. Entrepreneurial development came to comprise handing over previously state-owned entities to individuals, who were selected not through competitive bidding but political ties. Bumiputera advances in the corporate sector and private wealth across the 1988-1997 boom years generated a sense that affirmative action was advancing rapidly, perhaps reinforcing the primacy of promoting the $\mathrm{BCIC}$ at the expense of other affirmative action programmes, especially in education. This trajectory would be interrupted again; the 1997-1998 financial crisis brought down many state-sponsored Malay capitalists and conglomerates, resulting in a full reversal - renationalisation of privatised projects, which then became re-defined as government-linked corporations (GLCs), and a resurgence of state institutional investment.

The GLCs, as well as government-linked investment companies (GLICs) such as Permodalan Nasional and Khazanah Nasional, continue to play significant roles in advancing Bumiputera ownership and spearheading Bumiputera enterprise. Recent initiatives underscore the considerable political interests that continue to press for special programmes for Bumiputera business - alongside some liberalisation measures, such as the lifting of equity requirements in 27 service sectors in 2009 , thus permitting 100 per cent foreign ownership. In 2009 and 2011, respectively, Ekuinas (National Equity) and Teraju (acronym for a 'Bumiputera Agenda Advancement Unit') were formed to invest in preferred enterprises, to facilitate networks and provide general support. In principle, selection of beneficiaries, while remaining exclusively Bumiputera-owned companies, will be more merit-based.

The Malaysian government has also used licensing, contracting and public procurement as instruments for nurturing a Bumiputera capitalist and entrepreneurial class. Affirmative action in licensing has functioned mainly on a sectoral basis. ${ }^{41}$ Notably, licences for large - and politically expedient - projects have been distributed in transportation, telecommunications, and media. ${ }^{42}$ The public procurement system serves to fund Bumiputera commerce through reserving smaller contracts for Bumiputera contractors and conferring preferential conditions

41 For instance, the Petroleum Development Act (1974) required that management of petrol stations be reserved for Bumiputeras. The issuing of taxi licences has also been regulated by terms that preserve Bumiputera ownership - although this has been a conspicuous area of 'Ali-Baba' relationships, where a Bumiputera partner merely secures a licence, then subcontracts the work to another, often Chinese, operator. Other examples include the vendor system in the automobile sector for parts suppliers, and the distribution of 'Approved Permits', or quotas for importing motor vehicles.

42 Gomez \& Jomo, Malaysia’s Political Economy, 91-100. 
for larger contracts. ${ }^{43}$ Vendor and franchise development schemes and educational programmes have operated from the 1990s, although the overall support to small and medium-scale Bumiputera enterprise pales in comparison to the bounteous resources availed to large contracts and projects.

Table 6.1 summarises the main affirmative action programmes. A few notable features that have been outlined above or will be discussed in the next section.

TABLE 6.1 Summary of Affirmative Action Programmes and their Notable Features ${ }^{44}$

\begin{tabular}{|c|c|c|}
\hline AREA & PROGRAMMES & NOTABLE FEATURES \\
\hline Higher education & $\begin{array}{l}\text { - Residential colleges } \\
\text { - Matriculation colleges } \\
\text { - Expansion of tertiary institutions, } \\
\text { enrolment quotas } \\
\text { - University scholarships }\end{array}$ & $\begin{array}{l}\text { - Exclusively Bumiputera (until 2000) } \\
\text { - Exclusively Bumiputera (until 2002) } \\
\text { - Immense growth of Bumiputera in tertiary } \\
\text { education; systemic decline in quality of public } \\
\text { institutions } \\
\text { - Important in facilitating access to university } \\
\text { education; lack of systematic equitable } \\
\text { distribution }\end{array}$ \\
\hline $\begin{array}{l}\text { Representation in } \\
\text { high-level occupations }\end{array}$ & $\begin{array}{l}\text { - Public sector employment } \\
\text { - Industrial Coordination Act }\end{array}$ & $\begin{array}{l}\text { - De facto quota, but largely ad hoc in } \\
\text { implementation; major role in growth of } \\
\text { Malay administrators and professionals, } \\
\text { urban middle class } \\
\text { - Minimal impact at managerial/ professional } \\
\text { levels, no impact on SMEs }\end{array}$ \\
\hline
\end{tabular}

43 The 1973 Bumiputera Economic Seminar resolved to prioritise Bumiputera operators in government transportation, supplies and service contracts. A tiered procurement framework was introduced in 1974, in which 100 per cent of small projects and 30 per cent of the total value of other projects are reserved for Bumiputera contractors. The remaining 70 per cent is open for bidding among all companies, Bumiputera and non-Bumiputera. Bumiputera contractors also receive price handicaps, on a sliding scale, that place Bumiputera bids on par with lower priced non-Bumiputera competitors - except for the largest category of contracts. In 1982, a provision was introduced to grant preference to Malay Chamber of Commerce members. The parameters for classifying contracts and discounts were adjusted in 1995, but the basic framework has been retained (Treasury Circular Letters No. 7, 1974, No. 3, 1982, and No. 4, 1995).

44 Table 6.1 draws substantially from Hwok-Aun Lee, 'Affirmative Action and Ethnic Inequality' in Malaysian Economy: Unfolding Growth and Social Change, ed., Rajah Rasiah (Petaling Jaya: Oxford University Press, 2011). 


\begin{tabular}{|l|l|l|}
\hline \multicolumn{1}{|c|}{ AREA } & \multicolumn{1}{|c|}{ PROGRAMMES } & \multicolumn{1}{c|}{ NOTABLE FEATURES } \\
\hline $\begin{array}{l}\text { Enterprise and } \\
\text { managerial development }\end{array}$ & $\begin{array}{l}\text { - Public enterprises } \\
\text { - Takeover of foreign companies } \\
\text { - Licensing } \\
\text { - Public procurement }\end{array}$ & $\begin{array}{l}\text { - Wide scope, but largely underperforming or } \\
\text { failed; post-1997 crisis, GLCs and GLICs issued } \\
\text { mandate to spearhead BCIC growth } \\
\text { - Steady development and retained ownership, } \\
\text { though limited in scale }\end{array}$ \\
& $\begin{array}{l}\text { - Confined to fields with limited technological } \\
\text { growth; no incentive structure, particularly } \\
\text { for SMEs } \\
\text { - Scant effect on advancing Bumiputera business; } \\
\text { widely viewed as distribution network for } \\
\text { political patronage; minimal incentive structure, } \\
\text { particularly for SMEs }\end{array}$ \\
\hline Equity ownership & $\begin{array}{l}\text { - Modest effects, low retention of shares, little } \\
\text { effective control transferred } \\
\text { listing equity requirements } \\
\text { - Privatisation } \\
\text { - Unit trust funds }\end{array}$ & $\begin{array}{l}\text { Concentrated wealth accumulation; many } \\
\text { requiring rescue in } 1997 \text { crisis }\end{array}$ \\
& $\begin{array}{l}\text { Broad participation, but immense concentration } \\
\text { in ownership of units }\end{array}$ \\
\hline
\end{tabular}

\subsection{Affirmative action outcomes}

Maintaining our focus on direct objectives and programmes of affirmative action, we proceed to evaluate outcomes in the main areas of intervention. Overall, Malaysia's record is chequered. While increasing the quantity of Bumiputera access and participation in the designated areas, we observe systemic decline in the quality of institutions facilitating the change, continual dependence on the public sector, and question marks over the capacities of affirmative action beneficiaries. Malaysia's development plans have targeted and tracked progress in some areas of affirmative action, and thus serve as main references here, with a few other official publications and scholarly sources providing supplementary statistics.

\subsubsection{Higher education}

Available sources trace out a broad but informative picture of substantial quantitative progress toward the goals of affirmative action in tertiary education. By the mid1980s, 390 MARA junior science colleges, exclusively for Bumiputera, had been established, registering enrolment of 15,000 students in $1987 .{ }^{45}$ Affirmative action opened doors for Bumiputera educational advancement, evidenced by changes in the composition of student bodies. In 1970, the public university population consisted of 40.2 per cent Bumiputera, 48.9 per cent Chinese and 7.3 per cent Indian; by 1985 , the corresponding figures were 63.0 per cent Bumiputera, 29.7 per cent Chinese

45 Selvaratnam, 'Ethnicity, Inequality and Higher Education in Malaysia', 185. 
and 6.5 per cent Indian. ${ }^{46}$ The proportions stabilised over the following decades, at 62.6 per cent Bumiputera, 32.2 per cent Chinese and 5.2 per cent Indian in 2003. ${ }^{47}$

The educational profile of the labour force mirrors the growth in tertiary education and affirmative action outcomes. Fairly consistent data on racial distribution are available across time (Table 6.2). In 2010, the proportion of the labour force with a degree, diploma, or post-secondary certificate was 24.2 per cent in Malaysia, and highest among Bumiputeras, at 27.2 per cent. However, differences prevail across groups and within the Bumiputera category. The share of tertiary-level qualifications was highest in the Malay labour force (29.9 per cent), ahead of the Chinese (25.1 per cent) and Indians (23.1 per cent). However, this figure is consistently lower among non-Malay Bumiputeras (15.2 per cent). In sum, the gateway to tertiary education has widened, but remains persistently narrower for Indians, and to a greater extent for non-Malay Bumiputeras.

TABLE 6.2 Percentage of Labour Force with Tertiary Education by Race

\begin{tabular}{|l|c|c|c|}
\hline \multicolumn{1}{|c|}{ RACE } & $\mathbf{1 9 9 0}$ & $\mathbf{2 0 0 0}$ & $\mathbf{2 0 1 0}$ \\
\hline Bumiputera & 5.5 & 14.8 & 27.2 \\
Malay & n.a. & 16.7 & 29.9 \\
Non-Malay Bumiputera & n.a. & 7.3 & 15.2 \\
\hline Chinese & 5.6 & 16.6 & 25.1 \\
\hline Indian & 4.4 & 12.2 & 23.1 \\
\hline Malaysia & 8.8 & 13.9 & 24.2 \\
\hline
\end{tabular}

Source: Labor Force Survey Report, various years.

Undeniably, affirmative action programmes have facilitated educational attainment for the Bumiputera, especially Malay, population. However, priorities and challenges have shifted over time. At the early stages of the NEP, attention was fixed on increasing Bumiputera representation and establishing new institutions. Over time, the main locus of policy has shifted to maintaining broad access and cultivating

46 See Khoo, 'Ethnic Structure, Inequality and Governance in the Public Sector', 21. Student composition varies across institutions. The proportion of Bumiputera is higher at some universities, such as the National University (73.0 per cent), Agricultural University (81.0 per cent) and Technological University (76.0 per cent), while MARA Institute of Technology has been exclusively Bumiputera. Other tertiary institutes, however, have consistently been allocated higher proportions of non-Bumiputera, such University of Malaya (37.7 per cent Chinese) and Science University (35.0 per cent Chinese). 97.9 per cent of students in privately owned TAR College are Chinese.

47 Machi Sato, 'Education, Ethnicity and Economics: Higher Education Reforms in Malaysia, 1957-2003', Nagoya University of Commerce and Business Journal of Language, Culture and Communication 7, no. 1 (2005): 86. 
capable graduates, in tandem with the momentum toward mass higher education. Quality of education increasingly impacts graduates' job and income prospects, with Bumiputeras disadvantaged in some ways by a system that was meant to assist them. This issue involves both the dwindling exceptionality of holding tertiary-level qualification as it becomes more common, as well as the deterioration in educational institutions due to a complex of factors - which, in the case of Malaysia, includes affirmative action.

Major questions loom over the quality of education, especially with mounting concern over graduate unemployment in recent years and its disproportionately higher incidence among Bumiputera. A comparison of the unemployment rate between similarly qualified workforces suggests inter-group differences in the capacity of graduates to participate in the labour market. Table 6.3 shows higher unemployment rates for the tertiary-educated labour force within the Malay and Indian populations, relative to the Chinese. Non-Malay Bumiputera are, again, the worst affected at this level of aggregation.

TABLE 6.3 Unemployment Rate by Race and Education Level, 2010

\begin{tabular}{|l|c|c|c|c|}
\hline EDUCATION LEVEL & Malay & $\begin{array}{c}\text { Non-Malay } \\
\text { Bumiputera }\end{array}$ & Chinese & Indian \\
\hline Primary & 1.5 & 2.6 & 2.6 & 4.0 \\
\hline Secondary & 3.7 & 5.9 & 2.7 & 5.4 \\
\hline Tertiary & 3.7 & 7.6 & 2.6 & 3.5 \\
\hline All education levels & 3.4 & 5.1 & 2.7 & 4.8 \\
\hline
\end{tabular}

Source: Author's calculations from Labor Force Survey Report.

Recent research has found evidence of an adverse effect of affirmative action on tertiary education outcomes, consistent with the pattern of relative difficulty for Bumiputera in labour market participation. Studies point to a correspondence between Bumiputera-exclusive programmes or admissions quotas and poorer academic performance. ${ }^{48} \mathrm{Haliza}$ and others ${ }^{49}$ have investigated possible differences in academic performance of new university entrants, between those who graduated from matriculation colleges and those who were admitted through the national

48 Yao Sua Tan and Santhiram R Raman, 'The Transformation from Elitist to Mass Higher Education in Malaysia: Problems and Challenges', CenPRIS Working Paper 101/09 (Universiti Sains Malaysia, 2009).

49 Haliza Othman, Zulkifli Mohd Nopiah, Izamarlina Asshaari, Noorhelyna Razali, Mohd Haniff Osman \& Norhana Ramli, 'A comparative study of engineering students on their preuniversity results with their first-year performance at FKAB, UKM', paper presented the 2009 Teaching and Learning Congress, National University of Malaysia, Bangi. 
schooling system - that is, with STPM (Malaysian Higher Certificate) upon completion of Form Six. ${ }^{50}$ In their sample, Bumiputera constitute 76 per cent of matriculation students and 2 per cent of STPM holders. The study finds that, out of those who scored an A in matriculation mathematics, 13.6 per cent scored an A and 23.9 per cent obtained a $\mathrm{C}$ in the university course. In stark contrast, among students with an A in STPM mathematics, 61.6 per cent got an A and 2.7 per cent a $\mathrm{C}$ in the university course. Evidently, the preferential programme through which the vast majority of Bumiputera enter public universities equips them less capably and competitively than does the national schooling system.

Findings of firm-based surveys and Census data shed further light on the graduate unemployment dilemma, indicating that graduates of local public universities, where the vast majority of Bumiputera students are enrolled, experience greater difficulty securing jobs commensurate with their qualifications. In a major investment survey, conducted in 2003 across manufacturing zones in Peninsular Malaysia, about onethird considered Malaysians trained abroad more capable than Malaysians trained locally. ${ }^{51} \mathrm{~A}$ follow-up survey in 2007 found the corresponding figure to be about the same: almost 30 per cent of respondents perceive Malaysian workers with overseas qualifications abroad as more competent. ${ }^{52}$ In concurrence, Lee ${ }^{53}$ finds in an analysis of 2000 Census data that Bumiputera graduates of local public institutions are less likely than non-Bumiputera graduates of local public institutions or Bumiputera graduates of overseas institutions to attain managerial or professional positions in the private sector.

\subsubsection{Representation in high-level positions}

A few patterns stand out in Bumiputera representation in managerial, professional and technical occupations over the official NEP timeline (1971-1990), and across the subsequent period (Tables 6.4 and 6.5). Bumiputera entry into professional and technical positions progressed steadily in the 1970s and 1980s, but this momentum

50 Specifically, they survey 271 students in the first semester at the Faculty of Engineering and Built Environment and cross-tabulate grades from pre-university with grades obtained in the faculty's linear algebra course.

51 World Bank, 'Malaysia: Firm Competitiveness, Investment Climate, and Growth', Poverty Reduction, Economic Management and Financial Sector Unit (PREM), Report No. 26841-MA (East Asia and Pacific Region, 2005).

52 World Bank, 'Malaysia Productivity and Investment Climate: Assessment Update', Poverty Reduction and Economic Management Sector Unit, Report No. 49137-MY (East Asia and Pacific Region, 2009).

53 Lee, 'Affirmative Action in Malaysia: Education and Employment Outcomes Since the 1990 s', 230-54. 
waned in the 1990s and the 2000s. Whereas Bumiputera representation increased from 47.2 per cent in 1970 to 62.2 per cent in 1990, change was very slight between 1990 and 2000. Moreover, teachers and nurses contributed to a continuously high and marginally growing proportion of Bumiputera professionals and technicians (under which teachers and nurses are categorised). The subsequent period (2000-2005) continued to see only a marginal increase in the percentage of Bumiputera among professionals and technicians, as well as their concentration in the education sector. We should note that the job classification system was amended in 2000, which accounts for some of the discrepancies observed between Tables 6.4 and 6.5.

TABLE 6.4 Distribution of Occupation by Ethnic Group as a percentage of Malaysians, $1970-2000$

\begin{tabular}{|c|c|c|c|c|c|c|}
\hline \multirow{2}{*}{ OCCUPATION } & \multicolumn{3}{|c|}{1970 (Percentage) } & \multicolumn{3}{|c|}{1990 (Percentage) } \\
\hline & Bumiputera & Chinese & Indian & Bumiputera & Chinese & Indian \\
\hline Administration and managerial & 22.4 & 65.7 & 7.5 & 30.3 & 65.5 & 4.2 \\
\hline Professional and technical & 47.2 & 37.7 & 12.7 & 62.2 & 29.9 & 7.9 \\
\hline Excluding teachers and nurses & n.a. & n.a. & n.a. & 58.0 & 33.2 & 8.8 \\
\hline Teachers and nurses & n.a. & n.a. & n.a. & 68.8 & 24.7 & 6.4 \\
\hline Clerical workers & 33.4 & 51.0 & 14.3 & 52.6 & 38.8 & 8.6 \\
\hline Sales and service workers & n.a. & n.a. & n.a. & 46.4 & 45.0 & 8.6 \\
\hline Agricultural workers & 68.7 & 20.8 & 9.6 & 76.5 & 15.3 & 8.1 \\
\hline Production workers & 31.3 & 59.9 & 8.6 & 46.4 & 42.1 & 11.5 \\
\hline OVERALL & 51.4 & 37.0 & 10.7 & 56.3 & 34.6 & 9.1 \\
\hline OCCIPATINN & \multicolumn{3}{|c|}{1995 (Percentage) } & \multicolumn{3}{|c|}{2000 (Percentage) } \\
\hline UUUTAIIUN & Bumiputera & Chinese & Indian & Bumiputera & Chinese & Indian \\
\hline Administration and managerial & 36.8 & 52.5 & 4.8 & 37.0 & 52.3 & 5.5 \\
\hline Professional and technical & 64.4 & 25.7 & 7.0 & 63.9 & 25.8 & 7.6 \\
\hline Excluding teachers and nurses & 60.0 & 28.5 & 7.2 & 59.3 & 29.5 & 7.9 \\
\hline Teachers and nurses & 72.3 & 20.5 & 6.6 & 73.2 & 18.4 & 6.9 \\
\hline Clerical workers & 57.5 & 33.8 & 7.4 & 56.8 & 32.9 & 8.6 \\
\hline Sales and service workers & 47.0 & 35.8 & 7.2 & 47.9 & 35.3 & 7.7 \\
\hline Agricultural workers & 61.2 & 11.9 & 6.9 & 61.2 & 10.3 & 6.9 \\
\hline Production workers & 44.2 & 33.7 & 9.6 & 44.7 & 33.8 & 10.0 \\
\hline OVERALL & 51.4 & 29.6 & 7.9 & 51.5 & 29.7 & 8.3 \\
\hline
\end{tabular}

Notes: Rows do not total 100 due to the omitted category termed 'Others'; n.a. = not available.Sources: Third Malaysia Plan (cited in Jesudason, Ethnicity and the Economy), Seventh Malaysia Plan, Eighth Malaysia Plan. 
TABLE 6.5 Distribution of Occupation by Ethnic Group as a percentage of Malaysians, 2000 and 2005

\begin{tabular}{|l|c|c|c|c|c|c|}
\hline \multirow{2}{*}{ OCCUPATION } & \multicolumn{3}{c|}{2000 (Percentage) } & \multicolumn{3}{c|}{2005 (Percentage) } \\
\cline { 2 - 8 } & Bumiputera & Chinese & Indian & Bumiputera & Chinese & Indian \\
\hline Administration and managerial & 36.6 & 55.8 & 6.6 & 37.1 & 55.1 & 7.1 \\
\hline Professionals & 57.3 & 33.5 & 7.9 & 58.5 & 31.9 & 8.2 \\
\hline Excluding teachers and lecturers & 45.4 & 44.2 & 9.3 & 47.2 & 42.0 & 9.6 \\
\hline Teachers and lecturers & 74.4 & 18.2 & 5.8 & 74.9 & 17.4 & 6.2 \\
\hline Technicians and associated professionals & 59.5 & 30.3 & 9.5 & 59.5 & 29.7 & 10.0 \\
\hline Excluding teachers and nurses & 54.6 & 34.0 & 10.8 & 55.2 & 32.9 & 11.2 \\
\hline Teachers and nurses & 71.1 & 21.4 & 6.4 & 70.6 & 21.5 & 6.9 \\
\hline Clerical workers & 56.6 & 35.4 & 7.4 & 56.7 & 34.3 & 8.5 \\
\hline Sales and service workers & 51.2 & 40.6 & 7.3 & 51.5 & 39.6 & 8.0 \\
\hline Agricultural workers & 77.1 & 13.9 & 5.5 & 80.8 & 11.3 & 4.3 \\
\hline Production workers & 53.2 & 31.5 & 12.3 & 54.4 & 30.9 & 12.0 \\
\hline OVERALL & 56.4 & $\mathbf{3 2 . 5}$ & $\mathbf{9 . 1}$ & 56.5 & 32.4 & 9.3 \\
\hline
\end{tabular}

Notes: Rows do not total 100 due to the omitted 'Others' category

Source: Ninth Malaysia Plan.

The public sector has played an instrumental role in fostering upward mobility and building a Malay middle class. Studies have documented this dependence on government employment, particularly in the 1970s and $1980 \mathrm{~s}^{54}$ - and recent employment trends indicate that this dependence persists. Table 6.6 shows that more than half of Bumiputera professionals, compared to about 22 per cent of Chinese professionals and 30 per cent of Indian professionals, work as teachers and lecturers. Data compiled from the public sector employment register demonstrate that the importance of the public sector in the early 2000s did not merely persist, but in fact increased, especially in the upper echelons. ${ }^{55} \mathrm{~A}$ pattern of disparity parallel to the one in higher education attainment is found within the Bumiputera public sector workforce. Malay representation rises as we move up the ranks, but non-Malay Bumiputeras are considerably under-represented. In June 2005, Malays comprised

54 Takashi Torii, 'The Mechanism for State-Led Creation of Malaysia's Middle Classes', The Developing Economies 41, no. 2 (2003): 221-42; Abdul Rahman Embong, 'Social Transformation, the State and the Middle Classes in Post-Independence Malaysia', Southeast Asian Studies 34, no. 3 (1996): 56-79.

55 The share of the public sector in total managers and professionals in the labour market increased between 2000 and 2005 , from 11.3 per cent to 17.0 per cent - that is, by a higher margin than its share in overall employment, which rose from 10.4 per cent to 11.3 per cent (Author's calculations from Personnel List of Government Ministries and Departments and Annual Statistical Yearbook). 
83.9 per cent in top management, 81.6 per cent at management and professional level, and 75.8 per cent of support staff. Non-Malay Bumiputera occupy only 1.4 per cent of top management positions and 3.2 per cent of managers and professionals. ${ }^{56}$

TABLE 6.6 Teachers and Nurses as a percentage of Professionals and Technicians by Race, 2000 and 2005

\begin{tabular}{|l|c|c|c|c|}
\hline \multirow{2}{*}{ RACE } & $\begin{array}{r}\text { Lecturers and secondary school teachers per } \\
\text { total professionals }\end{array}$ & $\begin{array}{c}\text { Primary school teachers and nurses per total } \\
\text { technicans }\end{array}$ \\
\cline { 2 - 5 } & 2000 & 2005 & 2000 & 2005 \\
\hline Bumiputera & 53.2 & 52.5 & 35.6 & 33.6 \\
\hline Chinese & 22.2 & 22.4 & 21.0 & 20.5 \\
\hline Indian & 30.2 & 30.8 & 20.3 & 19.5 \\
\hline OVERALL & 41.0 & 41.0 & 29.8 & 28.3 \\
\hline
\end{tabular}

Source: Author's calculations from the Ninth Malaysia Plan.

The composition of membership in professional associations also reflects the changes in racial representation in high-level positions. Table 6.7 shows that the Bumiputera share of total registered professionals - mainly in the private sector increased from 4.9 per cent in 1970 to 29.0 per cent in 1990, 35.5 per cent in 2000, and 38.8 per cent in 2005 (the most recent available data). Similar to the pattern observed in labour market data above, these figures also show the momentum of rising Bumiputera representation in professional organisations dwindling from the 1990s, although in a few categories - specifically, architects, dentists and lawyers the proportion of Bumiputera have grown more substantially.

TABLE 6.7 Percentage of Registered Professionals ${ }^{a}$ by Race

\begin{tabular}{|c|c|c|c|c|}
\hline YEAR & Bumiputera & Chinese & Indian & Others \\
\hline $1970^{\mathrm{b}}$ & 4.9 & 61.0 & 23.3 & 10.8 \\
\hline 1980 & 14.9 & 63.5 & 17.4 & 1.2 \\
\hline 1990 & 29.0 & 55.9 & 13.2 & 1.6 \\
\hline 1995 & 33.1 & 52.4 & 12.9 & 1.3 \\
\hline 2000 & 35.5 & 51.2 & 12.0 & 1.9 \\
\hline 2005 & 38.8 & 48.7 & 10.6 & \\
\hline
\end{tabular}

${ }^{a}$ Architects, accountants, dentists, doctors, engineers, lawyers, surveyors, veterinarians

$\mathbf{b}_{\text {Excludes surveyors and lawyers }}$

Sources: KS Jomo, 'The New Economic Policy and Interethnic Relations in Malaysia', Identities, Conflict and Cohesion Programme Paper No. 7 (Geneva: UNRISD, 2004); Seventh Malaysia Plan; and Ninth Malaysia Plan.

56 Centre for Public Policy Analysis (CPPS), Towards a more representative and world class civil service (Kuala Lumpur: CPPS, 2006). 
The goal of developing an independent Bumiputera managerial and entrepreneurial class has been the most elusive. Bumiputera representation in management and administrative positions - encompassing public and private sectors - hovered at around 37 per cent over 1995-2005. The causes of these static figures are complex, but a few remarks can be made here. As noted above, a heavy percentage of Bumiputera in this occupational class are located in the public sector. Management of government-linked companies also account for a noteworthy portion, especially in the banking, plantations, utilities and telecommunications sectors, but the employment share is less than their economic and political significance. ${ }^{57}$ The preceding increase in Bumiputera participation in management, over 1990-1995, possibly captures the effects of privatisation exercises of the 1990s, in contrast to various shortfalls of SEDCs and heavy industry projects in the 1980s, which may account for the slow growth between 1970 and 1990 (Table 6.4).

However, privatisation also failed to sustain managerial and entrepreneurial capacity. ${ }^{58}$ Indeed, various privatised entities collapsed in the aftermath of the 1997-1998 Asian financial crisis, and were then rescued by government and reconfigured as government-linked companies - corporations with government, through its investment agencies such as Khazanah Nasional and Ministry of Finance, Inc., holding majority stakes and/or exercising control. Indeed, corporate control and enterprise development were the only spheres of Malaysia's extensive affirmative action regime that underwent significant change as a result of the crisis.

Growth and self-sufficiency of Bumiputera-owned and -operated small-and-mediumscale enterprises remains an area of pronounced shortcoming, particularly in manufacturing activities, where reliance on foreign investment persists. ${ }^{59}$ Potential gains from leveraging licensing and procurement toward affirmative action goals have been attenuated by weak implementation and inefficacy in spurring efficiency and growth. For instance, the vast majority of Malay contractors involved in the public procurement projects are in the small classes, ${ }^{60}$ and almost never scale up. While 22 per cent of non-Bumiputera contractors are in A Class, 90 per cent of Bumiputera contractors are classed from D to F. Only 0.2 per cent of nearly 29,000 F-Class contractors managed to upgrade to a higher class. ${ }^{61}$

57 GLCs employed 325,722 personnel in 2006, or about 3 per cent of the employed population (The Star, 8 September 2007).

58 Jeff Tan, Privatization in Malaysia: Regulation, Rent-seeking and Policy Failure (London and New York: Routledge, 2008).

59 Hwok-Aun Lee, 'Industrial Policy and Inter-ethnic Income Distribution in Malaysia: Industrial Development and Equity Ownership, 1975-97', in Industrial Policy in Malaysia, ed., KS Jomo (Singapore: Singapore University Press, 2007): 216-44.

60 Where the largest are classed $A$ and the smallest F.

61 REFSA (2011) calculations based on the Minister of Works' statement in Parliament, 7 April 2011. 


\subsubsection{Equity ownership}

The government has diligently tracked equity ownership, in line with the political supremacy of this arm of affirmative action. Likewise, as much as the policy has been highly contentious, the data have also been subject to more debate. Official sources maintain a data series of share capital distribution, based on par value, disaggregated by race and forms of holdings - individuals, trust agencies and nominees (Table 6.8). The Bumiputera share increased from 2.4 per cent in 1970 to 12.5 per cent in 1980, largely through taking over foreign holdings. By 1990, the Bumiputera portion had risen to 19.3 per cent, most of it held by individuals. The Chinese share also grew over this period, from 27.2 per cent in 1970 to 45.5 per cent in 1990. The 1990s, until the 1997-1998 financial crisis, saw Bumiputera and foreign proportions both rise slightly, while the Chinese share dropped. The impact of the crisis show up in the 1999 data, where we observe proportional declines in Bumiputera and Chinese ownership and a rise in foreign ownership. Between 1999 and 2006, the overall Bumiputera share stabilised, with trust agencies constituting an increasing portion, while the Chinese share grew. In sum, by official accounts, Bumiputera ownership of aggregate equity has remained virtually static over the past two decades.

TABLE 6.8 Share Capital Ownership (at par value) by Ethnic Group, 1970-2008

\begin{tabular}{|l|c|c|c|c|c|c|c|}
\hline \multicolumn{1}{|c|}{ ETHNIC GROUP } & 1970 & 1980 & 1990 & 1995 & 1999 & 2006 & 2008 \\
\hline Bumiputera & 2.4 & 12.5 & 19.3 & 20.6 & 19.1 & 19.4 & 21.9 \\
Individuals & 1.6 & 5.8 & 14.2 & 18.6 & 17.4 & 15.1 & n.a. \\
Trust agencies & 0.8 & 6.7 & 5.1 & 2.0 & 1.7 & 4.3 & n.a. \\
\hline Non-Bumiputera & 28.3 & 44.6 & 46.8 & 43.4 & 40.3 & 43.9 & 36.7 \\
Chinese & 27.2 & n.a. & 45.5 & 40.9 & 37.9 & 42.4 & n.a. \\
Indians & 1.1 & n.a. & 1.0 & 1.5 & 1.5 & 1.1 & n.a. \\
\hline Others & - & - & 0.3 & 1.0 & 0.9 & 0.4 & n.a. \\
\hline Nominees & 6.0 & - & 8.5 & 8.3 & 7.9 & 6.6 & n.a. \\
\hline Foreigners & 63.4 & 42.9 & 25.4 & 27.7 & 32.7 & 30.1 & 41.4 \\
\hline
\end{tabular}

Notes: Par value denotes the price at which the share was first issued; Government ownership is omitted. Sources: Jomo, 'The New Economic Policy and Interethnic Relations in Malaysia'; Malaysia, Mid-term Review of the Ninth Malaysia Plan (Kuala Lumpur: Government Printer, 2008).

These official figures are questionable, particularly in terms of usage of par value, inadequate accounting of holdings through nominees, and the omission of government ownership. ${ }^{62}$ By referring to par value, instead of market value or net tangible assets, the data omit changes in asset price that contribute to wealth

62 KS Jomo, 'The New Economic Policy and Interethnic Relations in Malaysia', Identities, Conflict and Cohesion Programme Paper No. 7 (Geneva: UNRISD, 2004); CPPS, Corporate equity distribution: past trends and future policy (Kuala Lumpur: CPPS, 2006). 
distribution, and understate holdings in large corporations, where Bumiputera ownership is known to be concentrated. The considerable incidence of indirect holdings through nominees or others - estimated to be as high as 21.2 per cent in $1988^{63}$ - also probably understates Bumiputera ownership. The omission of government ownership has been reasoned on the grounds that the government does not represent a particular race group. However, state policy unambiguously stipulates Bumiputera Commercial and Industrial Community development as a prime objective; executive and managerial positions in government-linked companies are predominantly Bumiputera. GLCs, largely excluded from official ownership statistics, comprised 37 per cent of market capitalisation in 2010.

Alternate estimates of ownership are difficult to obtain. Jomo ${ }^{64}$ references published statistics of publicly listed companies, indicating that in March 1989, the market value of shares held by Bumiputera was 34.5 per cent. ${ }^{65}$ Incorporating the criticisms above, CPPS ${ }^{66}$ estimates Bumiputera ownership to be 45 per cent in $2005 .{ }^{67}$ Specifically, the study applies market value to publicly listed shares, and includes government-linked companies, to which the authors assign a 70 per cent Bumiputera stake. The study notes that the Bumiputera presence has become substantial in some sectors, such as banking, plantations, and oil and gas. The study also found a minute fraction of firms listed on the Malaysian Bourse's Main Board - 18 out of 757, or 2.4 per cent - that can be said to meaningfully and independently forge inter-racial partnerships.

In sum, Bumiputera equity ownership undoubtedly grew over the 1970s and 1980s. The record since then, however, is a site of polarised debate, with official statistics suggesting minimal progress but other research indicating sizable Bumiputera holdings. Measurement methods applying market value and including government ownership stand up much better to critical scrutiny. In other words, Bumiputera wealth accumulation and empowerment in the corporate sector, reflected in substantial stakes through government-linked corporations or private holdings in major industries, have advanced substantially.

However, efforts to expand private individual equity ownership, such as Bumiputera quotas in the ICA and public listings, and to broaden participation in trust funds, have fallen short. Ownership through general mandated quotas -30 per cent under the ICA or public listing regulations - and special transfers to select individuals

63 Jomo, 'The New Economic Policy and Interethnic Relations in Malaysia', 12.

64 Jomo, 'The New Economic Policy and Interethnic Relations in Malaysia'.

65 Figures cited from the Kuala Lumpur Stock Exchange (KLSE) Annual Companies Handbook.

66 CPPS, Corporate equity distribution: past trends and future policy.

67 These findings derive from publicly listed companies, whereas the government figures draw on a publicly inaccessible database of 600,000 companies. However, publicly listed companies constitute a dominant share of total share capital. 
(chiefly, under privatisation) have dissipated through profiteering and low ownership retention. ${ }^{68}$ The distribution of ownership of trust fund units has been found to be highly skewed. Ownership of ASB remains highly concentrated, although perhaps less so than two decades ago. ${ }^{69}$ In the late 1980 s, 1.3 per cent of two million unit holders owned 75 per cent of ASB (then known as Amanah Saham Nasional) shares. ${ }^{70}$ At the end of 2008, 16 per cent of 6.5 million unit holders held 91 per cent of the total number of units. ${ }^{71}$ Evidently, multitudes of Bumiputeras respond to the outreach of these funds but lack the income to purchase and retain units.

\subsection{Conclusions and implications}

Constitutional mandates, political imperatives and socio-economic disparities converged to form solid grounds for affirmative action in Malaysia. These conditions gave rise to pro-Malay preferential programmes from the time of independence in 1957. Political crisis in 1969, ensuing assertions of Malay dominance and consolidation of executive power, ushered in extensive and intensive affirmative action under centralised authority and discretionary power. The New Economic Policy from 1971 has transformed Malaysia. Affirmative action programmes for the Malay, and more broadly Bumiputera, population have expanded access to higher education, upward occupational and social mobility, and ownership and enterprise. The results demonstrate the reliability of racially exclusive education institutions and university admissions quotas, preferential selection in public sector employment, licensing and contracting, and state-sanctioned equity transfers, toward delivering the quantitative outcomes.

68 The Malaysian Prime Minister revealed in March 2010 that, out of RM54 billion of publicly listed shares issued under affirmative action requirements, only 2 billion remained in Bumiputera hands. Case studies are illustrative - for instance, the privatisation of the national sewerage system, in which the effective controlling stake changed hands three times between 1991 and its debacle and renationalisation in 2000 (see Tan, Privatization in Malaysia: Regulation, Rent-seeking and Policy Failure, 98).

69 The Amanah Saham Malaysia funds managed by Permodalan Nasional and open to all Malaysians have faced difficulty attracting Bumiputera, as well as Indian, purchases. Most recently, the Amanah Saham 1Malaysia was launched at the end of July 2009 with an initial allocation of 50 per cent for Bumiputera, 30 per cent for Chinese and 15 per cent for Indians. By mid-November 2009, 78.5 per cent of the Chinese quota had been subscribed, compared to 19.7 of the Indian quota and just 3 per cent of the Bumiputera quota (Bernama, 12 November 2009). The availability of Amanah Saham Bumiputera, exclusively for Bumiputera, may partly account for the lack of participation, but the rate of undersubscription is still staggeringly low.

70 Jomo, 'The New Economic Policy and Interethnic Relations in Malaysia', 13-14.

71 Author's calculations from Amanah Saham Bumiputera Annual Report (2008). 
After over four decades, however, various shortfalls remain. Affirmative action has failed to plant roots deep enough for the Bumiputera community to withstand the policy's removal. The waning momentum of affirmative action has been documented, particularly in terms of a deterioration in public education (where preferential selection applies), and dependence on public sector employment (although education programmes were meant to nurture participation across all sectors). In ownership and enterprise, a plethora of policies discussed above have nurtured some pockets of productive enterprise and sustained ownership, but have largely been undermined by political patronage, skewed ownership, poor selection and monitoring of beneficiaries, and rampant acquisitive behaviour. The avenues and mechanisms for sustaining Bumiputera capability, confidence and self-reliance have dwindled in efficacy.

Has Malaysia become a more or less polarised, more or less unified? This nationally vital question spans a sea of factors, and is far from adequately answered with reference to the research surveyed above. We also simply do not know what would have transpired in the absence of affirmative action. But we can discern that crossracial interactions have increased, group stereotypes and stigmas have diminished alongside the policies. Thus, the claim that national unity has been fostered because of affirmative action cannot be denied. At the same time, the claim that national unity has prevailed in spite of affirmative action also rings true, as racial categories remain firmly entrenched and grievances surrounding unequal opportunity persist among non-beneficiary groups. These integrating and polarising elements are both reflected in the considerable scrutiny directed at affirmative action in recent years. The opportunity for such open and bold discourses is facilitated by the fact that the policy's achievements are significant enough that its contents can be questioned, but perhaps not momentous enough for a bold set of extensive and intensive reforms to be countenanced.

Affirmative action in its current incarnation has become unpopular, among nonBumiputera but also in some sections of the Bumiputera community, and has spurred talk of reform. Unfortunately, this situation is muddled by nebulous notions of need-based policies as a replacement for race-based policies, which both the federal government and opposition alliances have projected as political platforms - particularly since the watershed general elections of 2008 out of which a two-coalition system took shape. ${ }^{72}$ The government has carried out partial reforms, such as relaxing equity requirements, while misleadingly pitching such

72 Dasar Pakatan Rakyat (Pakatan Rakyat Policy, 2009), available at <http://www. keadilanrakyat.org/images/stories/webimg/docs/Dasar-PakatanRakyat.pdf $>$ accessed 20 September 2010; NEAC 2010). National Economic Advisory Council (NEAC), New Economic Model for Malaysia, Part 1 (Putrajaya: NEAC, 2010). 
modifications as systemic change. Tellingly, amid rhetoric of reform, preferential programmes in education and employment - the cornerstones of affirmative action remain untouched.

Clearly, systematic reform is needed in Malaysia's affirmative action regime. Beyond delivering quantitative outcomes, the onus on the policy is heavier than ever to broadly and sustainably cultivate capability and self-reliance, which are prerequisites for removing preferential treatment. This begins with an acknowledgment that affirmative action continues to find coherence and viability when based on race - although it can and must be reinforced by need-based considerations and stringent selection and monitoring. Distribution of benefits within the current framework also warrants consideration. Socio-economic progress of non-Malay Bumiputera is lagging, while considerable segments of the Indian community, despite facing disadvantages similar to the Bumiputera community's, are excluded from the system of preferential treatment. Measures to uplift these groups, especially to close educational achievement gaps, are vital.

Against prevailing currents of pseudo reform and avoidance of the most entrenched affirmative action programmes, Malaysia needs to grapple with race-based affirmative action head on and make the programmes more effective, particularly in education. The decline in public educational institutions in general, and in matriculation and other programmes specially serving Bumiputeras, must be reversed. Progressive distribution of benefits, and tougher selection and monitoring of Bumiputera beneficiaries, need to be incorporated more systematically into the policy framework. The earning capacity of the Bumiputera workforce warrants greater emphasis than financial holdings, in view of the highly skewed unit trust ownership.

The area of ownership and enterprise warrants some specific consideration, given its acute shortcomings and downright failures, and the proclivity for vested interests and avarice to subvert policy purposes and productive endeavours. Governmentlinked (production) companies and government-linked investment companies play paramount roles in spearheading Bumiputera interests, while equity allocation requirements have been relaxed. This mirrors the acute difficulty in cultivating an independent capitalist and entrepreneurial class, as well as the detachment of the masses from financial markets such that rollbacks of preferential treatment can pass without much resistance. However, profound questions remain, surrounding the benchmark for targets. In view of the outcomes and controversies of the past, the case for racial proportionality as a target - that is, 67 per cent Bumiputera ownership - is weaker than in the spheres of Bumiputera representation in higher education and employment, which are productively oriented, more attainable, and less susceptible to abuse and profligacy. 
Much greater resistance to change springs partly from the prospect of more challenging access and opportunity, most saliently in the face of eventual harder entry to public universities and public sector employment for the Bumiputera community. Given these widespread anxieties, a new set of negotiations and bargains will need to be explored. Instead of centrally administered quotas, a broader and decentralised university admissions system that balances diversity, need and merit can be formulated. To diversify both public and private workplaces, incentives for employing Bumiputera in companies awarded government contracts or licences can be maintained, in exchange for an increasing intake of non-Bumiputera and an assurance of merit-based promotion in the public sector.

Ultimately, the phasing out of preferential policies must be confronted and integrated into any meaningful reform programme. Presently, Malaysia has no timeline or achievement targets for a scheduled reduction or termination of affirmative action. This is not surprising, even appropriate, since any end date would be arbitrary and inchoate, given the dearth of plans to rejuvenate the efficacy of affirmative action, especially in education, and to negotiate compromises that can make its removal feasible. The magnitude of the challenge cannot be understated. Political will must galvanise honest public discourse on the unfinished work of affirmative action and stimulate critical appraisal of policy deficiencies. A national consensus must crystallise around an effective and equitable programme of action that maximises the viability of dismantling affirmative action. 

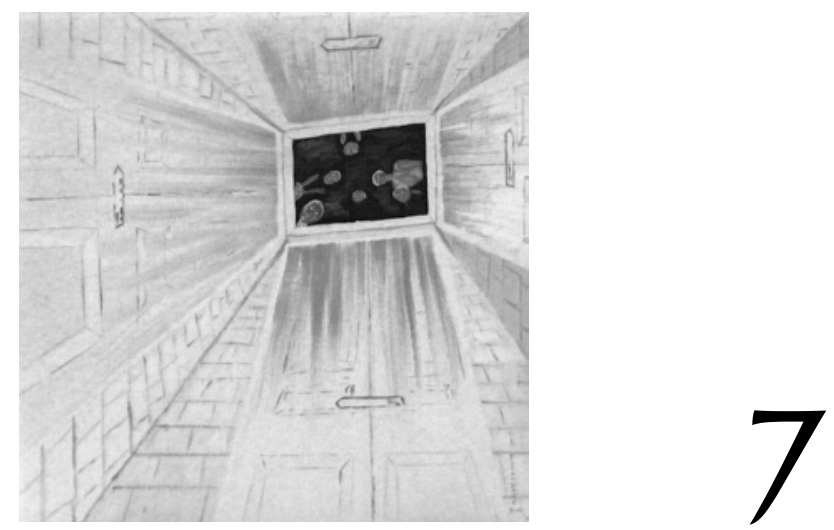

\title{
DIVERSITY AND INTERSECTIONALITY \\ Affirmative action in India
}

\author{
Kamala Sankaran ${ }^{1}$
}

Laws or policy measures that treat certain groups differently have been a commonplace for a long time now. Such measures have been used to discriminate against certain communities or groups, or alternatively, to enhance the privilege of elite groups or dominant communities. There have also been intermittent actions of charity, acts of welfare or ex-gratia grants of money to help individuals and groups overcome the effects of natural calamity or accidents or to celebrate and commemorate particular events considered important by those in power. The use of special measures as a form of social engineering in order to enhance the position or status of 'backward' or deprived groups appears to be of more recent origin. What appears to set the more recent measures apart is the recognition that any state that is committed to equality needs to draw up systematic plans to benefit groups that are perceived to be deprived. These special measures are often termed

1 Professor, Campus Law Centre, Faculty of Law, University of Delhi, India. Contact: kamala. sankaran@gmail.com. 
'affirmative action'. This term can be used to convey a variety of measures that can be put in place to 'benefit' a group. It is in this sense that I will use the term in this chapter, notwithstanding that the term is not current in South Asia. Special measures, reservations, concessions and relaxations are different terms used in this region to describe the slew of measures targeted at designated groups with a view to benefitting these groups and/or redressing past disadvantage. ${ }^{2}$

This chapter examines the constitutional mandate for affirmative action in public employment and education in India, and examines the design and operation of some of these programmes with a view to understanding how these affirmative action measures have dealt with the overlapping identities of designated groups.

\section{I Constitutional mandate for affirmative action}

Considering that South Asia was the first region in the world ${ }^{3}$ to introduce affirmative action programmes as a social engineering measure, it comes as no surprise that the constitutions of India (1950), Pakistan (1973), Sri Lanka (1978), Bangladesh (1972), and Nepal (Interim Constitution, 2007) have explicit provisions dealing with affirmative action.

The idea of devising a policy to selectively appoint certain groups to public office, the army or government service has an old pedigree under British colonialism. An informal quota system existed under colonial rule for recruitment to the Indian army. The British favoured the recruitment of 'martial' races ('ethno-religious groups' seen as suitable for recruitment to the army) and did not recruit from those religious and ethnic groups whose loyalty they mistrusted. ${ }^{4}$ Despite the shared regional history and the experience of colonial rule (barring Nepal, which remained an independent monarchy until recently), the scope and extent of affirmative action vary greatly across the region.

2 I am conscious of the politics of naming and the implicit hegemony of ideas in a book such as this that deals with a comparative project straddling counties in the North and the South. International law has continued to use the term special measures (cf. ILO, CEDAW). I will use the terms affirmative action and special measures interchangeably.

3 The Maharaja of Kolhapur reportedly introduced reservations in 1902 in his state. See Ashok Kumar Thakur $v$ Union of India (2008) 6 SCC 1.

4 While such a policy was dismantled after independence, commentators have noted: 'The Indian armed forces, as composed today, do not mirror the social diversity of the Indian population. Some groups are over-represented while some are nearly absent.' See Omar Khalidi, 'Ethnic Group Recruitment in the Indian Army: The Contrasting Cases of Sikhs, Muslims, Gurkhas and Others', Pacific Affairs 74, no. 4 (Winter, 2001-2002): 529-52. 
The connection between present-day affirmative action in public employment to increase the presence of certain designated groups in public service and the earlier colonial policy of selecting certain groups into the public service or the army (while discriminating against others) is a very close one in terms of design and logistics. What is different is the purpose and justification behind such partisan recruitment during colonial times and the logic of affirmative action measures and the choice of groups selected for these measures today.

The emergence of affirmative action as a specific policy measure to address issues of justice and equality is an important aspect of political developments in the past hundred years or so. It would appear that this specific form of 'public assistance' namely, affirmative action - has developed as a concomitant feature of the welfare state or democracy in some, but not all, countries. Why affirmative action has not been selected as a viable policy option in several countries is an important question, but one that is outside the scope of the present chapter. The constitutions of several countries, particularly those in South Asia, have placed great emphasis upon such special/affirmative action measures as an important vehicle to achieve the larger constitutional goals of social justice, equality and fraternity. The presence of constitutional provisions either permitting or mandating affirmative action foregrounds the instrumental role destined to be played by such measures in these countries. These provisions have often been explicitly included and adopted (as indicated by the proceedings of the constituent assemblies) as a means to achieving equality in societies that are both unequal and diverse. Questions as to whether affirmative action measures are expected to achieve diversity or achieve substantive equality or whether they have the implicit role of 'recognition' or a more 'transformative' role, have been a preoccupation for some time now in several jurisdictions. It comes as no surprise that this preoccupation has been most acute in the US; its Constitution is rather reflective of the times in which it was drafted and is conspicuous by the absence of any provision assigning a proactive role to the State in achieving substantive equality. The quest for the moral justification for affirmative action seems to have preoccupied a large measure of scholarship in that country in contrast to those countries with more recent constitutions drafted in the wake of an anti-colonial or pro-democracy struggle. The need for the new State to take a partisan position vis-à-vis inequality and to actively deal with past discrimination has been a predominant aspect reflected in the constitutions adopted in these countries. The moral justification for the proactive role that the State was to play was often settled in the political realm in the course of the anti-colonial struggle; consequently, in those countries with express constitutional provisions for affirmative action, moral justification was not dependent upon judicial elaboration. This is one reason that a five-judge bench of the Supreme Court of India has held that the test of strict scrutiny to determine the constitutionality of an affirmative 
action programme has no relevance in India. ${ }^{5}$ It is perhaps for this reason that the emphasis of both the courts and of academic writing in these jurisdictions has been devoted to the design of affirmative action policies and an evaluation of their results rather than their moral justification.

\subsection{Distinguishing between general welfare measures and affirmative action}

Constitutions of developing countries such as those in South Asia have provisions that permit the State to take special measures for specific groups of persons. For instance, the Indian Constitution (1950) permits the State to make special provisions for women and children ${ }^{6}$ and for socially and economically backward classes of citizens. ${ }^{7}$ Likewise, the special measures that target specific groups such as victims of natural disasters, the poverty alleviation schemes or other general schemes for the distribution of state largesse need to be distinguished from affirmative action programmes. I limit use of the term 'affirmative action' to those regular special measures targeted at specific groups identified on pre-determined criteria, as opposed to instances of social assistance, which I term 'general welfare measures', and which target differing groups that vary as circumstances warrant.

Affirmative action measures are aimed at providing greater access to education, employment or resources for constitutionally permitted groups/communities. In other words, these groups are specifically chosen for preferential treatment in contrast to general welfare measures, which may benefit them as members of the beneficiary group targeted on bases other than those used in affirmative action measures. ${ }^{8}$ The allocation of resources that forms part of general welfare measures is a policy prerogative of any government. There is, of course, considerable overlap between the two categories of measures. Victims of natural disasters or those requiring health care or public housing will often also be members of the communities/groups selected for affirmative action measures. The beneficiaries of socio-economic rights could also be those designated groups identified by the affirmative action programmes. The overlap between the two categories of governmental action is particularly great in India since (as noted below) some of the designated groups are selected for their social, educational and economic backwardness and are not merely based on a single criterion of race, ethnicity or gender. Nevertheless, even in India, a distinction can

5 Ashok Kumar Thakurv Union of India (2008) 6 SCC1.

6 Article 15(3).

7 Article 15(4).

8 See for instance Myron Weiner, 'The Political Consequences of Preferential Policies: A Comparative Perspective', Comparative Politics 16, no. 1 (October 1983): 35-52. 
be made between a beneficiary of a general welfare measure and a beneficiary of an affirmative action measure since the latter will not only be victim of a disaster, poverty or ill health (need-based) but will, in addition, belong to a pre-determined social/ethnic group that has been selected for affirmative action.

A feature of affirmative action programmes is that they regulate the access of certain enumerated groups to limited resources such as jobs or seats in educational institutions. In contrast, a general welfare measure or social assistance is usually available to any person fulfilling the eligibility requirements for such social assistance. For instance, access to a government job is regulated by a system of quotas in India, whereas access to the guaranteed 100-days-a-year jobs under the National Rural Employment Guarantee Act (NREGA), 2005 is available to anyone where the scheme is operational and who self-selects to avail themselves of the scheme. It would therefore appear that the logic and express intention of the programme would be critical in determining whether a governmental measure is an affirmative action measure or something else.

Speaking specifically of India, and of South Asia more generally, the model of constitutionalism and of separation of powers that is predominant in this region has meant that the oversight and control over budgetary spends for general welfare measures is through parliamentary approval of finance bills. Judicial challenges to budgets are almost never entertained because of a policy of judicial restraint that favours avoidance of conflict with other branches of government. On the other hand, judicial oversight over affirmative action programmes, their design and their functioning, is a very dominant feature of case law in this region.

Table 7.1 captures some of these distinctions.

TABLE 7.1 Distinctions between welfare measures and affirmative action measures

\begin{tabular}{|l|l|l|}
\hline & \multicolumn{1}{|c|}{ Welfare measures/social } & \multicolumn{1}{c|}{ Affirmative action measures } \\
\hline Access to benefits & Open-ended & Restricted \\
\hline Eligibility & Need-based & Largely status-based (except for the creamy layer) \\
\hline Selection criteria & Self selected & Targeted \\
\hline Nature of benefit & Welfare/policy-based & Right-based \\
\hline Oversight & Parliamentary control over budget allocation & Judicial review \\
\hline
\end{tabular}

These generalisations have necessarily been stated in overly broad terms; individual schemes and benefits may reflect features of both types of measures described in Table 7.1. For instance, the right to employment under the NREGA, 2005 provides for employment of anyone who seeks work in any rural district in India, but the provision is also a rights-based measure. Similarly, it is only recently that the quota-based reservation of seats in educational institutions in India has been 
transformed into a rights-based scheme guaranteed though law. For many decades, affirmative action schemes in education were created by government orders, which technically could be reversed at any time. Consequently, in the past, the courts were constrained to treat such measures as policy measures rather than as justiciable rights - notwithstanding that the Indian Constitution places the provisions for such special measures in the part dealing with fundamental rights. The Indian Supreme Court held, notwithstanding that the Constitution provided for affirmative action measures permitting reservation of seats in educational institutions or in government jobs, that these were merely enabling provisions. The court was of the view that, as they did not impose duties on the State to provide such measures, they were non-justiciable. ${ }^{9}$ The rights-based foundation for certain affirmative action measures, such as setting quotas for certain categories of students belonging to Scheduled Castes, Scheduled Tribes and Other Backward Classes, was placed on a firmer footing with the adoption of a law in Parliament mandating centrally funded educational institutions to make the necessary reservations for these groups. ${ }^{10}$

\subsubsection{Justiciability of affirmative action measures}

The two categories of measures described above overlap across another axis too - that of policy and rights. The constitutions of the countries in the South Asian region have a sharp distinction between justiciable rights and policy measures that seek to advance some policy goal of the State. The 1920s and 1930s were the years when early draft constitutions emerged in this region for India, Pakistan and Bangladesh on the one hand ${ }^{11}$ and Sri Lanka on the other. ${ }^{12}$ The freedom movements in the region had created a strong groundswell of opinion that the yetto-be finalised constitutions for undivided India and for Sri Lanka should have a comprehensive set of rights that would include not only negative political liberties but also the social rights that would be essential for a social transformation of the countries. Yet, through events that anticipated the subsequent division of human rights instruments during the Cold War, the drafts of the newly created Indian

9 Ajit Singh $v$ State of Punjab II AIR 1999 SC 3471. See also State Bank of India Scheduled Caste/Tribe Employees' Welfare Assn. v State Bank of India (1996) 4 SCC 119. See also M. Nagaraj v Union of India AIR 2007 SC 71.

10 Central Educational Institutions (Reservation in Admission) Act, 2006.

11 India, Pakistan and Bangladesh were one political entity in that period. Independence from British colonial rule saw the division of the sub-continent and the emergence of India and Pakistan as two political states. Pakistan split into two in 1971, which saw East Pakistan emerge as the present day Bangladesh.

12 Sri Lanka, which experienced Portuguese and, later, British colonial rule, saw constitutional developments unfold at the same time as in India and Pakistan. Sri Lanka's first Constitution was adopted in 1947. 
and Pakistan constitutions saw a cleavage of these rights into a set of justiciable fundamental rights on the one hand and directive principles of state policy on the other. ${ }^{13}$ The latter were to guide government policies but would not be cognisable in a court of law. ${ }^{14}$ Subsequent interpretations by the courts have 'read' such directive principles into the Constitution to broaden the idea of justiciable fundamental rights. Thus, the rights to education and to health, have, in a limited manner, been read into the right to life in the Indian Constitution.

The long tradition of public interest litigation in India has seen the transformation of many of these benefits into justiciable socio-economic rights. Where they have been made justiciable, erstwhile welfare provisions are accessible by the population as a whole. It is for this reason that there is a conceptual distinction between socio-economic claims as justiciable rights available to all citizens or persons and affirmative action measures that target specific groups. ${ }^{15}$

In contrast to justiciable socio-economic rights, affirmative action measures are often treated as 'enabling' provisions under the constitutional frameworks, and, in a few instances, as immediately justiciable rights. An example of the latter category is seen in the affirmative action measures on representation for certain groups/communities though the reservation of seats in parliamentary or state-level legislative bodies. However, affirmative action measures such as reservations in public employment or in education for designated categories are merely enabled by the constitutional provisions. ${ }^{16}$

13 For instance, as finally adopted, the provisions of the Indian Constitution dealing with nonjusticiable directive principles stated: '37. The provision contained in this Part shall not be enforceable in any Court, but the principles therein laid down are nevertheless fundamental in the governance of the country and it shall be duty of the State to apply these principles in making laws.' And: '38. The State shall strive to promote the welfare of the people by securing and protecting as effectively as it may a social order in which justice, social, economic, and political, shall inform all the institutions of the national life [...].'

14 For details of the division of these basic rights into two categories, see Granville Austin, The Indian Constitution: Cornerstone of a Nation (New Delhi: Oxford University Press, 1972); for its influence upon subsequent events in the United Nations, see Kamala Sankaran, 'Fundamental Principles and Rights at Work: India and the ILO', Economic \& Political Weekly, xlvi, no. 10 (5 March 2011). See also Radhika Coomarswamy, Sri Lanka: The Crisis of the Anglo-American Constitutional Traditions in a Developing Society (New Delhi: Vikas Publishing House, 1984).

15 For an elaboration of this distinction, see Kamala Sankaran, 'Special Provisions and Access to Socio-Economic Rights: Women and the Indian Constitution', South African Journal on Human Rights 23 (2007): 277-90.

16 See for instance art. 15(4) which states, 'Nothing in this article or in clause (2) of Article 29 shall prevent the State from making any special provision for the advancement of any socially and educationally backward classes of citizens or for the Scheduled Castes and the Scheduled Tribes'. 
Given the 'enabling' nature of the textual provisions, the affirmative action measures are discretionary policy choices available to the government (or legislatures) and they can determine the timing and scope of these measures. These measures have the quality of 'policy' measures and are not enforceable rights - this despite their presence in the constitutions, and in the chapter dealing with 'fundamental' rights. The location and formulation of the provisions has often led commentators (mistakenly) to assume that there is a 'right' to such affirmative action. ${ }^{17}$ They continue to remain rights in a rhetorical sense but lack the 'coherence' of a legal right since there is no explicit duty cast upon the State to formulate a corresponding affirmative action measure. ${ }^{18}$ However, these 'rights' are actualised upon the executive determining that such a reservation or a measure is required. Once a policy of reservation/quotas is in place, members of the designated group can move the courts if they are denied the right to avail themselves of such a scheme. Alternately, once legislation is enacted based on the competence to legislate granted by the Constitution, a derivative legal right can be created. ${ }^{19}$

In recent years, a shift has taken place and we notice that the decision to undertake special provisions in the form of reservation is no longer left to the discretion of the executive, but instead requires legislation by Parliament to bring them into force. Following the 93rd constitutional amendment carried out in India in 2005, the reservation of seats in unaided educational institutions is now required to be made through law. Earlier, such affirmative action measures could have been carried out by mere executive order since the constitutional permission for such measures was already in place.

The shift in the locus of power from the executive to the legislature in determining the extent and duration of affirmative measures in educational institutions is an interesting development. Does the explanation lie in a reworking of boundaries in the constitutional structures characterised by a separation of powers, and/or in the need for the legislature to take credit for putting the affirmative action programme in place in order to reap political dividends for such measures in the form of electoral advantage? In the Indian case, the explanation lies partly elsewhere too. For the first time, affirmative action measures in educational institutions were extended from government-financed institutions to unaided private educational bodies. The nature

17 See for instance Mahendra P Singh, 'Do Articles 15(4) and 16(4) confer Fundamental Rights?' 3 (1994) SCC (J) 33.

18 See for instance, Amartya Sen, 'Culture and Human Rights' in Development as Freedom (New Delhi: Oxford University Press, 2000), 227-48.

19 For instance, Persons with Disabilities (Equal Opportunities, Protection of Rights and Full Participation) Act, 1996 enacted in India gives an enforceable right for persons with disabilities to benefit from a $3 \%$ quota in all government jobs. 
of economic changes taking place in India over the last two decades has meant that private investment in the educational sector has greatly increased. The need for affirmative action in the privately funded institutions has been a strongly voiced demand for some time. Any affirmative action programme in their sphere would be seen as a restriction on the fundamental rights of these private bodies to carry out their activities, and one which constitutionally can only be imposed through law. ${ }^{20}$

\subsubsection{Reservation in public employment}

A striking feature in India is the absence of comprehensive anti-discrimination law. Discrimination in the form of 'untouchability' is constitutionally prohibited and is treated as an egregious offence. However, discriminating against a person on the basis of his or her caste or religion is prohibited only in public employment. The lack of 'horizontal effects' of fundamental rights has meant that these do not apply to the private employers. Specific legislation such as the Equal Remuneration Act, 1976 applies to all private employers and prohibits discrimination against women at the time of their recruitment, promotion or transfer and in wages payable for same or similar work as performed by a man. For the private employer however, there is no equivalent law that prohibits discrimination on grounds of caste, religion, language, ethnicity or other bases. The proposed Equal Opportunity Commission under discussion is expected to fill this gap. ${ }^{21}$

The Indian Constitution states that there shall be equality of opportunity for all citizens in matters relating to employment or appointment to any office under the State. ${ }^{22}$ Article 16(4) maintains that nothing in that article shall prevent the State from reserving seats in government jobs for backward classes of citizens which in the opinion of the State is not adequately represented in government services. The quantum of reservation across groups is determined by the subjective satisfaction of the executive. Judicial decisions have clarified that the category of backward classes of citizens includes the Scheduled Castes (SCs), Scheduled Tribes (STs) and other backward classes (OBCs) who are socially and educationally backward. They have also clarified that when recruitment is done on the basis of an entrance examination (a common feature for recruitment to government jobs in India), the minimum

20 The nine-judge bench decision in TMA Pai Foundation $v$ State of Karnataka AIR 2003 SC 355 declared that there was a fundamental right of private persons to set up educational institutions and identified it under the right to carry on an occupation under art. 19(1)(g) of the Constitution.

21 See Report of the Committee on the Equal Opportunity Commission set up by the Ministry of Minority Affairs, Government of India, What, Why and How?, available at <http:// minorityaffairs.gov.in/newsite/reports/eoc_wwh/eoc_wwh.pdf > .

22 Art. 16(1). 
eligibility marks could be relaxed for candidates from the backward classes. This has been explicitly permitted by article 335 . Further, judicial opinion has also held that in filling the quotas, members of the backward classes who obtain jobs that are part of the general (unreserved) posts because of their higher eligibility marks will not be counted towards the quotas, since the general posts are available to all. Into the Constitution (Eighty-second Amendment) Act, 2000, a proviso was inserted at the end of article 335 of the Constitution which now reads:

Provided that nothing in this article shall prevent in making of any provision in favour of the members of the Scheduled Castes and the Scheduled Tribes for relaxation in qualifying marks in any examination or lowering the standards of evaluation, for reservation in matters of promotion to any class or classes of services or posts in connection with the affairs of the Union or of a State.

The scope of the provisions in article 16(4) permitting reservation in public employment was initially understood to be restricted to reservation at the time of recruitment. Subsequent judgments of the Supreme Court held that the equality of opportunity in 'matters relating to employment or appointment' as indicated in article 16(1) of the Constitution would extend to reservations in promotions within government too. ${ }^{23}$ This was a hotly contested matter. A nine-judge bench of the Supreme Court in 1992 held that reservation of appointments or posts as permitted by article 16(4) related only to initial recruitment and did not extend to reservations at the time of promotions. ${ }^{24}$ In order to reverse the political fall-out caused by this judgment, Parliament stepped in with a constitutional amendment. The Constitution (Seventy-seventh) Amendment Act, 1995 inserted clause 16(4A) with effect from 17 June 1995. The clause (4A) (as it stood at that time) read:

(4A) Nothing in this article shall prevent the State from making any provision for reservation in matters of promotion to any class or classes of posts in the services under the State in favour of the Scheduled Castes and the Scheduled Tribes which, in the opinion of the State, are not adequately represented in the services under the State.

The amendment permitted reservations in matters of promotion. This required posts to be made available on the basis of quotas at the time of promotion too. Following litigation in the courts, government departments now follow a 'roster' system whereby all posts are pre-allotted on a quota basis and recruitment and promotions are done on this basis. ${ }^{25}$

23 General Manager, Southern Railway v Rangachari AIR 1962 SC 36.

24 Indra Sawhney $v$ Union of India AIR 1993 SC 477.

25 R.K. Sabharwal v State of Punjab (1995) 2 SCC 745. 
Another feature of the quota/reservation system is that when reserved posts are available but do not get filled up in any year for lack of eligible candidates, they are re-advertised in subsequent years. While filling these 'backlog' posts, a frequent ground for challenge was that the number of reserved seats in a particular year exceeded the ' 50 per cent' rule, a judicially recognised rule that the proportion of reserved posts to general posts in any cadre in a given year cannot exceed 50 per cent of all posts available. To get over this challenge, Parliament adopted the Constitution (Eighty-first Amendment) Act, 2000 adding article 16 (4B), which reiterates that 'backlog posts' of previous years cannot be counted towards determining the 50 per cent rule. ${ }^{26}$

Another consequence of the reservation of posts at the time of promotions has entailed questions regarding seniority subsequent to promotion. Normally the inter se seniority between general and reserved government employees is determined at the time of recruitment. If a reserved category employee who was junior to a general category employee at the time of initial recruitment gets promoted to a senior level because a 'reserved' post fell vacant before a 'general' post (under the roster system that designates all posts as general or reserved) fell vacant, would this affect 'consequential seniority'? Several court judgments held that the initial seniority would be maintained despite the prior promotion of a reserved category employee merely because that post fell vacant earlier. ${ }^{27}$ However, this view was reversed by the Constitution (Eighty-fifth) Amendment Act, 2001, which inserted the words 'in matter of promotion, with consequential seniority' in article 16(4A) to grant seniority to reserved category employees who got promoted earlier.

All these constitutional amendments relating to reservations were reviewed by a five-judge bench of the Supreme Court in the M. Nagaraj case. ${ }^{28}$ The court observed that once a separate reservation is permitted under article $16(4)$, this would extend to matters of promotion too. In the view of the court, articles 16(4), 16(4A) and 16(4B) form a part of the same scheme of egalitarian equality. The court took the position that these amendments were means to achieve equality and upheld the impugned constitutional amendments.

26 Article 16 (4-B) states: 'Nothing in this article shall prevent the State from considering any unfilled vacancies of a year which are reserved for being filled up in that year in accordance with any provision for reservation made under clause (4) or clause (4-A) as a separate class of vacancies to be filled up in any succeeding year or years and such class of vacancies shall not be considered together with the vacancies of the year in which they are being filled up for determining the ceiling of fifty per cent reservation on total number of vacancies of that year.'

27 Union of India $v$ Virpal Singh Chauhan (1995) 6 SCC 648. See also Ajit Singh Januja $v$ State of Punjab, (1996) 2 SCC 684 and Jagdish Lal v State of Haryana (1997) 6 SCC 538.

28 M. Nagaraj v Union of India (2006) 8 SCC 212. 
The court upheld all the other amendments pertaining to reservation, consequential seniority, and backlog cases. Commenting on the argument of efficiency in article 335 and the insertion of the proviso, the court held:

$[E]$ ven after insertion of this proviso, the limitation of overall efficiency in Article 335 is not obliterated. Reason is that 'efficiency' is a variable factor. It is for the concerned State to decide in a given case, whether the overall efficiency of the system is affected by such relaxation. If the relaxation is so excessive that it ceases to be qualifying marks then certainly in a given case, as in the past, the State is free not to relax such standards. In other cases, the State may evolve a mechanism under which efficiency, equity and justice, all three variables, could be accommodated. Moreover, Article 335 is to be read with Article 46 which provides that the State shall promote with special care the educational and economic interests of the weaker sections of the people and in particular of the scheduled tribes and shall protect them from social injustice. Therefore, where the State finds compelling interests of backwardness and inadequacy, it may relax the qualifying marks for SCs/ STs. These compelling interests, however, have to be identified by weighty and comparable data. ${ }^{29}$ (italics added)

The functioning of reservations in public employment has been a subject matter of numerous constitutional amendments and has contributed to a sizeable proportion of the docket of the Supreme Court. Not only have reservations been enabled by the Constitution, but government employees are also granted constitutional protection (Part XIV, Constitution of India). As a result, government employees are not covered by labour law but by service law, which is an extension of constitutional law. Though government employees are a minute proportion of the workforce in the country ( 13 million out of a workforce of over 400 million persons), it is this section alone that is the 'face' of affirmative action in India. Given that government jobs are eagerly sought after since they spell stability and status, the political significance of affirmative action measures for this group of employees is tremendous. This is one of the reasons that Parliament has stepped in so frequently to deal with judicial opinions that are perceived as whittling down the scope of affirmative action measures. The period of turbulence between the court and the legislature over matters of reservation in public employment in the 1990s has since settled down. There is a move now to extend reservations to the private sector. Already, the first step of extending reservation into private unaided educational institutions has taken place following the 93rd constitutional amendment. The need to build political consensus among private industry parties for the extension of reservation has yet to develop. In the meanwhile, private industry has started a voluntary diversity programme to achieve diversity in its workforce and has stated that it will achieve similar results voluntarily. A general anti-discrimination law and the extension of

29 Ibid. 
affirmative action measures to the private sector (whether voluntarily or otherwise) appear to be the next stage of legal and constitutional developments in India.

\subsubsection{Identification of 'beneficiaries'}

The design of affirmative action programmes has always been subject to great contest. There has been a robust, often acrimonious, debate over the design and duration of affirmative action programmes.

The Indian Constitution, in its provisions dealing with public employment, states that the State can make special provisions for backward classes of citizens. ${ }^{30}$ In the case of SCs, the status of a group, as perceived by the larger community, is an important criterion. Reservation for SCs is reparation based and therefore no proof of present-day deprivation is required to be proved. As a result, there is no 'creamylayer' criterion applicable. ${ }^{31}$ In the case of OBCs, there are a range of social, economic and educational factors that determine backwardness. ${ }^{32}$ The identification of socially

30 For details about these provisions, see Marc Galantar, Competing Equalities: Law and the Backward Classes in India (Delhi: Oxford University Press, 1991), and the court decision in Ashok Kumar Thakur $v$ Union of India (2008) 6 SCC 1.

31 The creamy layer comprises those individuals who due to their social and educational status no longer belong to the groups identified as 'backward'.

32 In the Commission appointed to carry out the survey, an elaborate 22-point system was used to determine the backwardness of any group. Social 'indicators' were given a weighting of 3 points each, educational 'indicators' a weighting of 2 points each and economic 'indicators' a weighting of one point each. Social backwardness was determined by: (i) castes/classes considered as socially backward by others; (ii) castes/classes that mainly depend on manual labour for their livelihood; (iii) castes/classes in which the marriage age of females is below 17 years in rural areas in at least $25 \%$ above the state average number of cases and $10 \%$ above average for males, and in urban areas at least $10 \%$ above average for females and $5 \%$ for males; (iv) castes/classes where the participation of females in work is at least $25 \%$ above the state average, the higher work participation for females being treated in this regard not as a marker of progress but of 'backwardness'; this peculiarity is due to the social context within which these criteria were developed. Educational backwardness was established by: (i) castes/ classes where the number of children in the age group 5-15 years who have never attended school is at least $25 \%$ above the state average; (ii) castes/classes where the rate of student drop-out in the age group 5-15 years is at least 25\% above the state average; and (iii) castes/ classes amongst whom the proportion of matriculants is at least $25 \%$ below the state average. Economic backwardness was measured by: (i) castes/classes where the average value of family assets is at least $25 \%$ below the state average; (ii) castes/classes where the number of families living in mud/thatch houses is at least $25 \%$ above the state average; (iii) castes/classes where the source of drinking water is beyond half a kilometre from the home for more than $50 \%$ of the households; and (iv) castes/classes where the number of households having taken consumption loan is at least $25 \%$ above the state average. Groups having more than 11 points are considered backward. 
and educationally backward classes is based upon an elaborate empirical exercise to determine the status of different groups. However, reservation for OBCs is justified on the principle of distributive justice and therefore present-day deprivation needs to be empirically assessed and periodically reviewed. It is here that the principle of creamy layer is applied. ${ }^{33}$

The courts have also examined the criteria developed by the executive to identify those socially and educationally backward groups (OBCs) eligible for affirmative action measures under the OBC quota. One of the early judgments from the Supreme Court indicated that caste could not be the sole basis for identification of backwardness. In later judgments, the court laid down that caste could be a starting point for locating a group that would then have to satisfy the multiple criteria of social and educational backwardness discussed above. ${ }^{34}$ Related to this is the question whether religion could be a constitutionally valid starting point for the identification of backwardness. States such as Kerala and Karnataka have identified all Muslims as members of the OBC because they as a group satisfy the other criteria of social and educational backwardness. However, the empirical basis on which Muslims are identified as socially and educationally backward is a contentious one. A five-judge bench of the Andhra Pradesh High Court struck down an ordinance that identified Muslims as 'backward' since the AP State Commission for Backward Classes could not demonstrate that it had employed sufficiently objective criteria to determine why Muslims as a group were to be identified as socially and educationally backward. The court stated that Muslims as a group were not homogenous and that the entire group could not be identified as socially and educationally backward. Yet the court seems to have ignored the ability of the creamy-layer test to filter out individuals who are no longer considered 'backward. 35

In the remaining part of the chapter, I examine how groups that have overlapping identities are selected for affirmative action programmes and the problems these pose for accurate selection.

33 For details, see Kamala Sankaran, 'Towards Inclusion and Diversity: India’s Experience with Affirmative Action' in Equality in the Workplace, eds. Ockert Dupper \& Christoph Garbers (Cape Town: Juta, 2010).

34 See for instance the contrast between M.R. Balaji v State of Mysore (1963), and A. Periakkarruppan $v$ State of Tamil Nadu (1971).

35 B Archana Reddy $v$ State of Andhra Pradesh (2005). For a critique of this and related judgments, see Kamala Sankaran, 'Issues before the Courts', Seminar no. 602 (Issue on India's Religious Minorities) (2009), available at <www.india-seminar.com/2009/602/602_ kamala_sankaran.htm>. 


\subsection{Intersectionality of caste, religion and gender}

Scheduled Castes, among, others have been provided with reservations in public employment and electoral seats under the Indian Constitution. The term 'Scheduled Castes' (SCs) was used for the first time in the Government of India Act, 1935. The term SCs is also defined along the same lines in the Constitution. ${ }^{36}$

Article 341 gives the President primacy in identifying SCs and Scheduled Tribes (STs) in the first instance, following which Parliament can make changes to the presidential order. The Constitution does not lay down any guidelines regarding the identification of SCs. As it originally stood, a person had to be a Hindu in order to be classified as SC under the 1950 Presidential Order. A person does not cease to be a member of a Scheduled Caste upon conversion from the Hindu faith to another religion that is understood to be included in the term 'Hindu', as broadly defined in these laws. The 1950 Presidential Order has been amended by Parliament to include conversion to other religions such as Sikhism and Buddhism. ${ }^{37}$ However SC converts to Christianity or Islam continue to be denied SC status. One of the reasons for this exclusion is that conversion puts an end to caste discrimination. For instance in the case of the converts to Christianity, the court has held:

The Christian religion does not recognise any caste classifications [...]. The tenets of Christianity militate against persons professing Christian faith being divided or discriminated on the basis of any such classification as the caste system. ${ }^{38}$

However, the Sachar Committee Report (2006) ${ }^{39}$ brought out the deprivation of the large number of Muslims who belonged to such 'lower castes' prior to conversion several generations back and whose condition is similar to the deprivation experienced by SCs and STs. However, the conversion to a religion by tribal persons does not affect their ST status, so long as they follows their tribal rituals and customs. ${ }^{40}$ The exclusion from the benefits of affirmative action programmes of SC converts to Christianity and Islam is currently under challenge before the courts.

36 'Scheduled Castes' means such castes, races or tribes or parts of or groups within such castes, races or tribes as are deemed under article 341 to be Scheduled Castes for the purposes of this Constitution. (The expression 'Dalit' is an expression born of the movement against caste oppression and atrocities, but is not recognised in legal discourse.)

37 See for instance Constitution (Scheduled Castes) Order (Amendment) Act, 1990.

38 S. Rajagopal v C.M. Arumugam AIR 1967 SC 101. See also S. Swvigaradoss v Zonal Manager, FCI (1996) 3 SCC 103.

39 A committee appointed by the government to examine the socio-economic conditions of Muslims in India.

40 State of Kerala $v$ Chandramohanan (2004) 3 SCC 429. 
The identification of an SC member is also inextricably linked with the question of patriarchy. The courts hold that a woman upon marriage becomes a member of the family of her husband and that she thereby becomes a member of his caste, provided there is recognition and acceptance of this by the community. ${ }^{41}$

When it comes to marriages between SC and non-SC persons, the position of the courts has been different. The courts hold that a person who is a high-caste Hindu cannot by reason of marriage alone become a member of an SC or ST and claim the benefits accorded to disadvantaged persons. ${ }^{42}$ The logic is to restrict the scheme of constitutional reservation to those who suffer from disabilities of caste discrimination from birth. In doing so, the courts have deviated from their earlier position and now hold that a wife does not acquire the caste status of her husband after marriage.

Women are often caught in the intersectionality of religion and caste and can lose on both counts. A recent case from Kerala where a Muslim woman married a man from an SC, and who converted herself to Hinduism highlights this aspect. As a Muslim woman marrying a Hindu man, she was expelled from the Muslim community and could therefore not apply under the OBC (Muslim) quota for a government job. ${ }^{43}$ Upon marriage to an SC man, she could not get the benefit of SC reservation. Clearly, the loser on all counts was the woman who could get advantage from neither her natal religion nor her caste upon marriage.

\subsection{Dealing with difference}

Diversity in India has meant that the identification of beneficiary groups for affirmative action has been beset with problems. Multiple identities such as caste, religion, tribe and sex intersect and these have implications for the design and impact of affirmative action programmes. One way to address the issue of intersectionality is to subject those who convert or who marry into a designated group to an empirical assessment on the same yardstick of backwardness used for assessing others in the same group. The need to have accurate assessments of 'backwardness' and the competitive politics to be so enumerated has led to calls for better empirical methods to assess and survey backwardness. Simultaneously, those opposed to seemingly endless affirmative action programmes have called for fresh

\footnotetext{
41 See N.E. Horo v Hajanara Jaipal Singh AIR 1972 SC 1840.

42 Meera Kanwaria v Sunita AIR 2006 SC 597.

43 Indian Council for Agricultural Research v Dr. Sudha Sukumaran WP(C).No. 7721 of 2008(S) Kerala HC decided on 29 January 2009, available at <http://judis.nic.in/judis_ kerala/qrydisp.aspx $?$ filename $=90518>$.
} 
assessments to ensure that those groups who have moved out of 'backwardness' are weeded out of such programmes; since the creamy-layer filters merely identify individuals who are ineligible, they are inadequate for the purpose of identifying groups that no longer need the support of affirmative action programmes. In fact, for political reasons, several states have refused to identify criteria for identifying the creamy layer, since the $\mathrm{OBC}$ population reportedly constitutes more than 50 per cent of the population. The courts too have asserted the need for regular monitoring of groups to assess their inclusion in such lists. ${ }^{44}$

This pressure to have a more evidence-based affirmative action programme has led to the government launching the first socio-economic and caste census in June 2011. Unlike previous methods that were based on sample surveys, this, when completed, will be a census of a population of 1.2 billion - a staggering task. It is also important for another reason. Caste censuses were stopped in 1931 since it was feared that it would exacerbate caste divisions. Whatever may be the justification and logic of these affirmative action measures, working out a viable design for these measures that is capable of achieving their stated goals has remained a challenge. Truly, the devil lies in the details.

44 The Ashok Kumar Thakur [(2008) 6 SCC 1] judgment has called for regular surveys of 'backward' groups. Judicial opinions were divided over whether these should be conducted every five or ten years. 

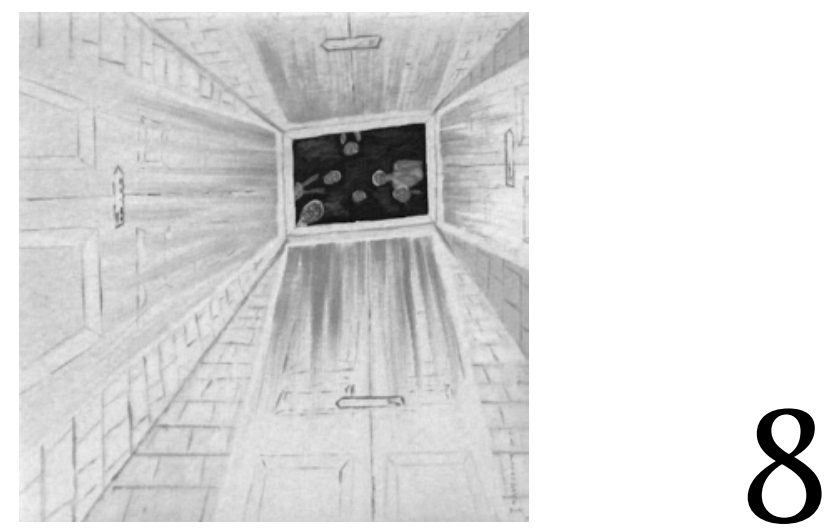

\title{
IUSTIFYING AFFIRMATVE ACTION IN MEXICO
}

\author{
Mario Santiago Juárez ${ }^{1}$
}

\subsection{The indigenous people in Mexico: a history of exclusion}

In 1521, after the arrival of the Spaniards in what today is Mexico, slavery of the indigenous people was common. These people were reduced to slavery in two main ways: war and rescue. During the first half of the sixteenth century, the Spaniards continued to seize land and then enslave the defeated. At the same time, those that were already slaves in the pre-Hispanic organisation could be 'rescued' by the Spaniards who thus became their new masters. Another initial way to enslave people was by tribute: when the indigenous chief could not pay the commander the sums imposed on him in gold or other assets, he would substitute them by delivering a certain number of slaves. ${ }^{2}$ The commission of a crime could also be a reason for a conviction to service that was similar to slavery - perpetually or for a period of several years.

1 Director of Research of the Museum of the Constitutions of the National Autonomous University of Mexico. This article has been translated from Spanish - eds.

2 See Alfonso Caso, Silvio Zavala, Jose Miranda, Moises Gonzale Navarro, Gonzalo Aguirre Beltran \& Ricardo Pozas Arciniega, La Politica indigenista en México: Métodos y resultados (Mexico City: T. I. Instituto Nacional Indigenista, 1954), 83 ff. 
The above notwithstanding, Spanish law started to protect indigenous people. A royal decree dated 2 August 1530 ordered that even in the 'just wars', indigenous people should not be made captive and that slaves should not be acquired by rescue. This was partially complied with and thus, when the New Laws of 1542 (and later ones that confirmed them) were issued, the slaves were gradually liberated in Mexico and the provinces. In 1680, the slavery of indigenous people, whether in peace or in war, was definitively prohibited. ${ }^{3}$ However, an exception was established for hostile indigenous peoples that were at permanent war with the Spaniards, like the 'barbaric' peoples of the North (the chichimecas). At the end of colonial times, slaves continued to be taken, tied with chains, from the North to the capital.

During the first stages of the conquest, the use of the 'encomienda' system, or commandeering, an institution very similar to the European feudal servitude, by which a group of indigenous persons was delivered to a person in order to profit from their work or from a tribute taxed by the authorities, and always with the commander's obligation to procure and pay for the Christian instruction of the indigenous people, was common. The encomienda, as a labour institution, ended with the issue of a royal decree on 22 February 1549.

This work relationship was replaced by the forced labour of indigenous manpower, especially for the development of cities, mines, buildings and fields when the 'laziness' of the worker impeded him from participating in a full freedom regime and when this work could be justified as serving the public interest. Finally, in 1632, the Viceroy Marquis of Cerralbo ordered the suspension of all the forced repartitions, except for in the mining industry. This paved the way for compulsion, based on an individual contract accompanied by debts. Several months of salary were given in advance, so that the workers could not abandon their work during the contractual period.

We may conclude that during the first half of the sixteenth century, slavery and commandeering ('encomienda') dominated, while between 1550 and 1632 forced labour became a way of exploitation of the indigenous manpower. Subsequently, the attachment due to debts was maintained until the beginning of the twentieth century. Although the Constitution of 1857 enshrines the freedom to work, the criminal law of the states typically included the crime of breaching work contracts when money had been received in advance.

On the other hand, the dispossession of indigenous land was common during viceroyalty times, notwithstanding the legal protection of the indigenous people's property rights. The truth is that the growth of the society of European origin was supported in their religious, political and economic aspects. At the same time,

3 Act 1, Tit. 2, Vol. VI and acts 12, 13, 14 and 16 of the same title and volume. 
racial segregation was one of the intentions at the beginning of the conquest. Only artisans and domestic workers ('criados'), as indigenous persons that lived with their masters, were allowed to reside within the cask of the Spanish city. At the end of the sixteenth century and beginning of the seventeenth century, a policy of settlements ('reducciones') started to be implemented, consisting of the forced concentration/ settlements of indigenous peoples. The purpose was to convert them to Christianity, and one result was the forced displacement of thousands of indigenous people, who lost their land.

After independence from Spain in 1821, the indigenous people's fortunes did not change radically and they were dispossessed of their land by way of legislation that ordered the partition of these lands in order to transform them into private property. During the second half of the nineteenth century, the dispossession of indigenous land continued and it is for this reason that at the beginning of the twentieth century indigenous people were in a situation of total exclusion and disadvantage compared to the rest of the population and they fought for their land and better conditions of life.

\subsection{The present situation of indigenous people in Mexico}

It is clear that the current situation of the indigenous peoples in Mexico is critical; a very high percentage of them live in significant poverty and exclusion. During 2005 , the part of the population of Mexico speaking the indigenous language was 6 million persons; of these, 4.7 million were 15 years or older and, and of these, 1.5 million (31.6 per cent of the total) could not read and write. ${ }^{4}$

Within the area of education there are big differences between the indigenous population and the rest of the population. The National Institute of Statistics and Geography has published that, among the members of non-indigenous homes, the rate of school attendance is 94.7 per cent, representing a 3.7 per cent higher attendance than from indigenous homes. The difference is higher with respect to the levels of literacy and school attendance average, because in the non-indigenous homes, 93.3 per cent of their members know how to read and write and register 8.2 years of approved school attendance. On the other hand, in the indigenous homes only 70.4 per cent of its members are not illiterate. ${ }^{5}$

4 For this group, the proportions of illiteracy are significant for both sexes, with men registering 23.2\% and women 39.6\%. See Instituto Nacional de Estadistica, Geografia e Informatica, 'Estadísticas a propósito del día internacional de la alfabetización: Datos nacionales', available at <http://www.inegi.gob.mx/inegi/contenidos/espanol/prensa/ Contenidos/estadisticas/2006/alfabetizacion06.pdf $>$.

$5 \quad$ Ibid., 4-5. 
The education situation is also not equal because the quality of education provided for indigenous people is generally lower. The details are more than disappointing; in the area of basic education, 13.4 per cent of the students at public schools reach a level of reading comprehension that fully corresponds to the curricular objectives, but in indigenous schools, only 2.5 per cent reach the desired level. ${ }^{6}$

It is clear that when they finish their primary education, indigenous pupils are disadvantaged with respect to those who are not, because they do not understand the basic tools. If they continue in junior school, 'they have serious learning difficulties' and when they reach the middle or higher level, they are confronted with admission exams that a very low percentage of them can pass when compared to those of nonindigenous people. In this way, indigenous persons are 'punished' when they are already the victims of a deficient educational system. ${ }^{7}$

The history of the indigenous peoples of Mexico, together with their current situation, represents an enormous challenge - namely, the need to change this reality of exclusion and inequality. Here it would be easy to ask: what are the mechanisms that we must implement to achieve change? I can say in advance that the answer to this question is not a simple one - because the truth is that infinite things could be done to try to change the situation. I believe that the bottom line for a solution is the implemention of policies that aim to end the marginalisation and poverty of, and the discrimination against, indigenous peoples. However, here I simply propose one mechanism within the myriad possible applicable ones. This instrument is affirmative action. Through affirmative action, I believe, the percentage of indigenous university students would increase, causing a lessening of the exclusion within the scope of higher education, which without doubt would reflect in less inequality and, finally, in the professional sphere. Besides, the indigenous university students would act as role models for other indigenous individuals, thus helping to end the prejudices and pernicious social structures.

\subsection{Affirmative action as an alternative}

In this book, what is meant by affirmative action has been precisely indicated. It is for this reason that I will only make a short distinction between positive actions and affirmative action (or inverse discrimination). In simple terms, positive actions are those that seek to improve the situation of a certain group of individuals by means

6 See Instituto Nacional Indigenista, 'La educación indígena en México', available at <http:// www.inee.edu.mx/images/stories/documentos_pdf/Publicaciones/Folletos/Los_Temas_de_ la_Evaluacion/folleto_01.pdf $>$.

7 Observatorio Ciudadano de la Educación. 'La educación indígena en México: inconsistencias y retos', Este Pais 210 (September 2008): 37-41. 
of direct support to the members of the group that are socially disadvantaged. A concrete example of this type of support is the 'Program of Basic Infrastructure for the Attention of Indigenous Peoples.' The intention of this programme is to contribute to the social and economic development of the peoples and communities, giving priority to indigenous regions.

I could quote endless similar programmes that intend to achieve a real equality of opportunities providing scarce goods to specific groups of individuals. These actions are needed because they are an effective way to guarantee the exercise of certain rights. Nevertheless, these types of programme cannot be considered to be affirmative action, because they do not represent measures that will affect people other than those belonging to the intended beneficiary group. Affirmative action refers to those actions that cause damage to members of society that do not belong to the universe of people that they intend to benefit. ${ }^{9}$

In order to clarify the above, it is advisable to study the real case of a programme of affirmative action implemented by the government of the Guanajuato State in 2008. The executive of the State, through its Secretary of Public Works, submitted to tender the building of a road that will link two towns within the entity. One of the clauses establishes that:

Should there be a technical draw between the bidders the work shall be granted, in equal conditions, to the company that has among its work force a five per cent of people with disabilities, whose registration at the Mexican Institute of Social Insurance has been made six months before the closure of the Public Tender. ${ }^{10}$

This clause rewards those entrepreneurs that have hired people with disabilities; thus, in equal circumstances, the award of the tender will be determined, not by a factor related to the capability of the company to offer better working conditions, but by the existence of a previous implementation by the company in hiring persons with disabilities. These are definitely affirmative action or inverse discrimination actions, because a company that had not hired the required five per cent of individuals with

8 The programme was implemented in 2007 by virtue of the 'Agreement of Coordination for the Execution of the Program of Basic Infrastructure for the Attention of the Indigenous Peoples', entered between the National Commission for the Development of the Indigenous Peoples and the Hidalgo State. The Agreement was published in the Official Gazette of the Federation on Monday, 3 December 2007.

9 This volume has termed actions and programmes that benefit a specific group as affirmative action irrespective of whether other groups who are excluded from such benefits face any disadvantage or not in being so excluded.

10 See <http://uaip.guanajuato.gob.mx/portalcs/docaart10/200811071928380.2008-016.pdf> accessed 17 March 2009. 
some disability beforehand will lose the tender; it will be affected by an issue other than one directly related to the company's possible performance regarding the building of the road.

Another typical case of affirmative action is the one used in Brazil within the area of public employment. The Brazilian state, through its Ministry of Agricultural Development, established a system of quotas for the directive posts in public contests. ${ }^{11}$ In systems like this, it is clear that there will be affected persons, because the quotas avoid the appointment of people that would have won if only meritbased criteria were used.

These two examples allow us to understand the definition of affirmative action or actions of inverse discrimination as follows: using the different characteristics of the groups that suffer exclusion or discrimination, affirmative action tries to benefit the members of the said groups by granting them scarce goods and, in doing so, prejudicing certain people who would have enjoyed the scarce goods if things had followed their normal course.

In order not to leave a margin for doubt, I will explain the elements that make up the proposed definition. In the first place, affirmative action plans may be used within the public sector (for example, by autonomous bodies, secretaries of state and public universities) or within the private sector (for example, by a company in which private shares are held). The advantages to which the definition refers should empower people who belong to groups that are in a situation of exclusion and who, as a consequence, do not have access to certain scarce goods. In this way, the characteristics that define the disadvantaged group (race, gender, ethnic origin or certain disabilities) are used. The scarce goods may be jobs, places at universities, tenders for public works and others that most probably would not have been granted to the members of certain unfavoured groups if a common criterion of distribution such as the meritocratic principle had been used. In using a non-traditional criterion of distribution, affirmative action excludes people who under normal circumstances would have acquired the scarce good. As a consequence, these persons see themselves as victims of affirmative action plans. In essence, these people may consider that they have been discriminated against because certain personal characteristics, or the lack thereof, have been determinant factors in denying them the scarce good.

The change in the criteria of distribution of scarce goods leads us to question if this is discriminatory. To answer this, it is obviously necessary to study the rules that enshrine the right to equality in Mexico, as well as the prohibition of discrimination.

11 The foundation of this programme is Decree number 202 of 4 September 2001. On this matter, see Shigeru Suzuki, 'Brasil en la época del multiculturalismo: Una polémica en torno a las acciones afirmativas', Humania del sur. Revista de estudios latinoamericanos, africanos y asiáticos, Merida, Universidad de los Andes, 2, no. 3 (July-December 2007): 73-85. 


\subsection{Equality as a constitutional principle in Mexico}

The Constitution is the body of law that determines the minimum rights of individuals within the Mexican territory. It is for this reason that every legal study about equality should depart from its provisions. In this paragraph, we will analyse the right to equality as enshrined in the Constitution.

The original text of the Constitution of 1927 used the term 'equality' on only one occasion. Paradoxically, it used it to establish an inequality:

The Mexicans should be preferred over the foreigners, under equal circumstances, for every type of concessions and for all the jobs, positions or commissions of the Government in which the quality of being a citizen is not indispensable.

In article 123, however, the Constitution already expressly established a principle derived from the equality right: 'The same pay must be paid for doing the same work, regardless of sex or nationality'. In no other place of the original text is the word 'equality' or any similar term used. However, many passages remind us that the founders sought equality in different areas.

Since its original version, article 1 has established the notion of the universality of rights or equality in the enjoyment of fundamental rights:

In the Mexican United States all individuals will enjoy the human rights acknowledged by this Constitution and by the international treaties of which the Mexican State is a part, as well as the guarantees for their protection, the exercise of which may not be restricted or suspended, except in the cases and under the conditions established by this Constitution itself.

This refers not only to the content of the Constitution itself but to all those legal provisions that are a 'Supreme Act of the Union as a whole'; that is, the content of the constitutional text and the international treaties ratified by the Mexican state. ${ }^{12}$

Besides, article 5 of the Constitution implicitly establishes the guarantee of work equality: 'No one should be prevented from performing the profession, industrial work or commercial work that suits him/her provided it is a lawful one [...]'. On this subject, a ruling in 2000 of the Supreme Court of Justice of the Nation firmly establishes that article 5 of the Constitution should be understood as an equality right - that it substantially provides for this fundamental principle of equality, for its purpose is to place all governed people under equal conditions, whatever their category or social condition. ${ }^{13}$

12 Miguel Carbonell, Los derechos fundamentales en México (México: Comisión Nacional de los Derechos Humanos-IIJ UNAM, 2004), 175.

13 Ruling: PXC. 2000, isolated ruling. Semanario Judicial de la Federación y su Gaceta, XC, Novena Época, June 2000, at 470, Garantía de igualdad. It is implicitly contained in article 5 
On the other hand, the reform to constitutional article 4 of 1974 introduces the principle of equality before the law for men and women: that men and women are equal before the law. The law shall protect family organisation and development. ${ }^{14}$ In 2001, a new constitutional reform added a second paragraph to article 1 stating that slavery is expressly prohibited. ${ }^{15}$ A last paragraph was introduced in December 2006, which we may consider as the most important constitutional reform in relation to our issue because it prohibits discrimination:

Discrimination based on ethnic or national origin as well as discrimination based on gender, age, disabilities of any kind, social status, health conditions, religious opinions, preferences of any kind, civil status or any other reason that attempts to undermine human dignity and which is directed to either cancel or restrain the individuals' privileges and immunities, shall be prohibited.

But, how should the prohibition of discrimination as established in the transcribed paragraph be understood? To answer this, it is first necessary to define what the term 'to discriminate' means. The Dictionary of the Royal Academy, in its second meaning of the term, points out that discrimination is: 'to treat in an inferior manner a person or collective group of persons due to racial, religious, political and other reasons. It is obvious that the constitutional prohibition refers specifically to this second meaning and not to the first one contained in the dictionary, which defines discrimination as: 'to select by exclusion'.

Accordingly, the Constitution prohibits treating other people as inferior on the basis of the abovementioned prohibited criteria. This paragraph is a clause of formal equality that implies, in the first instance, a mandate to the public powers, which are constrained to respect the prohibition of discrimination. At this point, we must respond to a question of enormous transcendence: who are those obliged by this constitutional norm? The classic answer to the first question within our juridical tradition would be that only the State is restricted to respect such a mandate. This is so because in Mexico the idea that human rights are only to be claimed against the State has prevailed - that is, they can only be executed and respected against public powers.

I believe that through history the principle that differentiates between the responsibilities of the State and those of individuals has been changing drastically.

of the Constitution. Appeal for Constitutional Protection being revised No. 2352/97.

United International Pictures, S. De RL.

14 On this article, see Carbonell, Los derechos fundamentales, $208 \mathrm{ff}$.

15 'Slavery shall be forbidden in the United States of Mexico. Every individual that is considered as a slave in a foreign country shall be freed and protected under the law by just entering the national territory.' This paragraph was added by means of a decree published in the Official Gazette (Diario Oficial de la Federación - DOF) on 14 August 2001. 
For example, we must remember that, for a long time, labour laws were considered as rules of private law governed by the principle of autonomous will. If a work contract is the combination of the wills of two subjects with full power of execution, it would appear obvious to think that this cannot be limited. The truth is that in a typical work relationship the will is not full, because it is restricted by the worker's need to obtain financial resources translatable for his or her personal or familiar sustenance; for this reason, the principles of law were modified, 'limiting' the freedom of work contracts, which have since needed to adhere to new principles of justice. ${ }^{16} \mathrm{With}$ the establishment of a maximum legal working day, for example, a right that had to be respected both by public and private employers was acknowledged.

In the understanding that work relationships were seen as part of the private sector, discriminatory actions were defended as expressions of freedom. However, discrimination at work has been slowly prohibited. In particular, the right to nondiscrimination was introduced in Mexico for the first time in labour matters in 1970, with the Federal Labour Act, article 56 of which prohibits differences in working conditions 'by reason of race, nationality, sex, age, religious beliefs or political doctrine [...]. ${ }^{\prime 7}$ The proscription of discrimination in salaries was introduced in the Constitution in 1986 with the reform to article 123: 'Equal work shall be remunerated with equal salary, regardless of sex or nationality.' ${ }^{18}$

These principles of labour law are translated into rights that can be claimed against both State and private individuals, although the State is certainly the first one to be obliged to respect the prohibition of discrimination, as well as to enforce it within the private sector.

Having clarified that the prohibition to discriminate is general, because it is addressed to both public and private actors, we have to ask which type of actions should be prohibited: When should a certain act be considered as discrimination? The answer to this seems complicated if we consider that, in our lives as human beings, we do discriminate against different people or groups of people. In many situations, we do

16 For example, the right to a maximum legal working day, which protects employees against possible abuse committed under the contractual freedom banner by employers. Labour rights, such as the maximum working hours, are applicable against the State as employer, but mainly against private employers. The same has happened with other rights that are enforceable against private subjects.

17 Article 56 of the LFT (for its acronym in Spanish) provides: 'The working conditions shall not in any case be inferior to those provided for in this Act and shall be proportional to the importance of the services and equal for equal work, without differences by reason of race, nationality, sex, age, religious beliefs or political doctrine, except for the modalities expressly provided for by this Act.'

18 Paragraph A, fraction VII. 
so in a subconscious manner and as a consequence of prejudices transmitted from generation to generation; we continue lines of learnt behaviour that reflect prejudice for what we consider inferior or simply different. The above notwithstanding, we can measure to what extent members of certain social groups are discriminated against within certain areas. We know, for example, that in Mexico, as pointed out by the First National Survey on Discrimination, the most discriminated persons are homosexuals and indigenous people. A clear example of the discrimination against indigenous people in our country is evident when considering that 40 per cent of surveyed persons were prepared to organise themselves to prevent indigenous people from establishing themselves near their community.

This type of discrimination within the private sphere is one of many manifestations of prejudice against certain social groups. There is no doubt that the State is obliged to implement public policies addressed to eliminate the roots of discrimination. Education is the most certain way to reverse the discrimination phenomenon. However, the modification of social structures is achieved in the long term and thus it is necessary to work with other tools in parallel to end discrimination against certain categories of people. It is true that we cannot force people to establish friendships with homosexual people, nor can we force them to live in the vicinity of indigenous people. However, we may punish those who refuse to hire a person only because she is a woman. We can prohibit the actions destined to limit access to certain scarce goods by indigenous people.

It must be pointed out that the third paragraph of the constitutional article being studied prohibits any discrimination that infringes against a person's dignity. It is clear that this implies that the list of prohibited criteria is not limited; every distinction that appears to infringe against the principle of equality by intending to 'nullify rights and liberties' - that is, to create obstacles for their effective exercise - should be considered as being against the Constitution. Thus, 'prohibited discrimination' is based on the criteria that have been expressly listed and 'the purpose of which is to nullify or undermine the rights and liberties of people'. It is for this reason that those differences that are the cause of treating certain people as inferiors and that limit the effective exercise of their rights and liberties, should be considered to be against the Constitution.

After eight years of the application of this constitutional paragraph, we have some important interpretations from the supreme body of constitutional control. For the National Supreme Court of Justice (SCJN - its acronym in Spanish), the guarantee of equality implies an identical treatment of all the peoples situated under the same circumstances. ${ }^{\prime}$ The highest court in Mexico considers that:

19 Ruling: 2a. VI/2009, isolated ruling, Semanario Judicial de la Federación y su Gaceta, XXIX, Novena Época, February 2009, at 470. The matter concerned constitutional and labour law 
$[\mathrm{N}]$ on-discrimination is a true individual guarantee, consisting in the public subjective right of the governed person to be treated in the same manner as all the others and it is the authorities' correlated legal duty to guarantee identical treatment to all the people under the same circumstances. ${ }^{20}$

This ruling of the SCJN warns that the right not to be discriminated against must be claimed from the State. In particular, it has been pointed out that it is a mandate for the legislator, because this is prohibited from:

discriminating on the basis of a series of listed reasons during the general performance of its duties [...] without this implying that a legislator is absolutely prohibited from using the said categories during the performance of its legislating duties but it must be particularly careful when doing so. In these cases, the constitutional Judge should submit the legislators' work to particularly careful scrutiny with the respect to the guarantee of equality. ${ }^{21}$

With this ruling, the SCJN has introduced into Mexico what in the North American doctrine is known as strict scrutiny. This scrutiny was designed by the Supreme Court of the United States in order to analyse the classifications made by the legislator using racial or national criteria. For the highest court of that country, it was clear that they must be careful, overall, with the racial classifications, because these had traditionally been used to discriminate. Every legislative classification of this type would be seen as potentially unconstitutional. The Supreme Court will demand evidence that the classification is designed with the purpose of attaining an absolutely crucial objective or that it obeys an urgent interest, and that the said classification is related to the attainment of this objective. ${ }^{22}$ The SCJN has used these criteria, pointing out what a constitutional judge must do in those cases involving an analysis of the use of the reasons for discrimination that are expressly prohibited:

In all the cases where the Constitution compels the constitutional judge to do a more thorough scrutiny of equality, the application of the criteria that have been listed above should pass the relevant modulation. Thus, the constitutional

issues over claims to a widower's pension. The court found that the second paragraph of the social insurance act, which made the granting of a pension to the widower conditional upon proof of financial dependence on the diseased insured female worker, violates the guarantees of equality and non-discrimination.

20 Ruling: 2a. CXVI/2007, isolated ruling, Semanario Judicial de la Federación y su Gaceta, XXVI, Novena Época, August 2007, at 639. The matter concerned the constitutional guarantee of non-discrimination and the constitutional protection it affords.

21 Ruling: 1a. / J. 37/2008, jurisprudence, Semanario Judicial de la Federación y su Gaceta, XXVII, Novena Época, April 2008, at 175. This constitutional case concerned the right to equality and the cases in which the constitutional judge must do a strict scrutiny of the legislative classifications (interpretation of Article 1 of the Political Constitution of the Mexican United States).

22 On this subject see Mario Santiago Juárez, Igualdad y acciones afirmativas (Mexico: IIJ UNAM-CONAPRED, 1997), $142 \mathrm{ff}$. 
judge must ensure, for example, that the legislative measures being examined may be seen as measures oriented towards reaching, not only a constitutionally admissible purpose - that is, an end that is not openly contradictory with the constitutional provisions - but a purpose with clear constitutional support that is, an objective that is constitutionally important. ${ }^{23}$

Thus it must be concluded that the Constitution prohibits the use of certain classification criteria in order to exclude people from the enjoyment of certain goods, rights or liberties. The constitutional prohibition, however, and as clarified by the SCJN, is not a hindrance to the legislator, provided that its use of reasons listed in article 1 does not imply an inferior treatment of the persons that are the object of the norm. The SCJN already had the opportunity to declare as unconstitutional subsection 45, second category of article 226 of the Act of Social Security for the Armed Forces. Article 226 provides:

In order to determine the categories and degrees of accidents or diseases that cause retirement due to disability the following tables will apply: Second Category 45. Being seropositive to the antibodies against the human immunodeficiency virus as confirmed by supplementary tests. ${ }^{24}$

Precisely the SCJN uses its strict constitutionality test in order to analyse the constitutionality of this norm. In this case, the juridical norms analysed are declared unconstitutional for the following reasons:

The legislator, through the said legal cause of retirement intends, as a constitutionally valid objective, the efficiency of the armed forces, as well as the protection of the integrity of its members and third parties; however, the said regulation implies a legal distinction among the members of the Mexican Armed Forces that violates the guarantees of equality and non-discrimination by reason of health as contained in Article 1 of the Political Constitution of the Mexican United States, which lacks juridical proportionality and reasonability, because: 1) it is inadequate to reach the said purpose due to the fact that medical science, as reflected in several national and international directives, has shown the inaccuracy of stating that those that have the virus are - per se - agents of direct transmission and, as a consequence, individuals that are inept to perform the duties required within the Army; 2) it is disproportional because the legislator, in order to reach the said objective, had less grave alternatives for the affected soldier, considering that military legislation makes it possible to transfer him to a different area, according to his physical aptitude as it develops during his illness, as it happens with various curable diseases $\left[\ldots . . .^{25}\right.$

23 Direct appeal in revision 988/2004. Engrose at 39.

24 This subsection was derogated by a reform published in the Official Gazette on 20 November 2008.

25 Ruling: P./J. 131/2007, Jurisprudence, Semanario Judicial de la Federación y su Gaceta, XXVI, Novena Época, December 2007, at 12. This constitutional and administrative law matter concerned social security for the Mexican armed forces, and a finding that article 226, 
These criteria created by the SCJN have been used in order to determine if the analysed norms should be considered as discriminatory and, therefore, unconstitutional. The first thing that the constitutional judge must do is determine whether the object that the legislator (and the State in general) is trying to achieve has been provided for by the Constitution. These 'constitutional objectives' are in fact very wide; let us think, for example, that every public policy that intends to comply with every fundamental right (individual guarantees) should be considered as an important constitutional objective. The second requirement that the highest court has imposed with its constitutionality test is the link that should exist between the abovementioned objectives and the means established to achieve them. This requirement is attempting to determine if the classification to be analysed will result in the achievement of the desired objective. Lastly, the consequences of the means implemented in order to achieve the constitutional ends should be analysed. For the SCJN, there must be proportionality between the implemented measures and the benefits that they are trying to achieve. Finally, the damage caused by a legislative classification that discriminates on the basis of the criteria mentioned in the Constitution should never translate into a violation of the fundamental rights. I would add, it should never be a cause for exclusion of certain minorities.

Once the current interpretation of the right of equality has been pointed out, one should ask if affirmative action, while damaging certain people because they do not belong to a certain ethnic group, contradicts the prohibition to discriminate as contained in the third paragraph of the Constitution. Before answering this question, we must point out that this type of interrogation has been posed before jurisdictional bodies in other countries and has been answered by their constitutional courts. In Mexico, on the contrary, there has been no case of affirmative action in favour of indigenous persons submitted before the SCJN. ${ }^{26}$ This is undoubtedly due to a lack of implementation of these actions, a paradoxical question if we consider the fact that large sectors of the Mexican population have been uninterruptedly discriminated against and that the actions implemented in order to avoid this situation have had little success.

second category, subsection 45 , of the act of the relative institution, which provides the legal basis for retirement due to disability based on the seropositive condition of the antibodies against the human immunodeficiency virus (HIV), violates article 1 of the Constitution.

26 The only case of affirmative action to have been submitted to the SCJN related to a system of 'maximum percentage' of participation in the registry of candidates of only one gender for positions in a popular election. In this ruling, it is pointed out that articles 20, second paragraph, 21, paragraphs four and five, and 26, fractions VII y VIII, of the Act of Political Institutions and Electoral Procedures of the State of Coahuila of Zaragoza, when establishing a maximum percentage of participation in the registry of candidates of only one gender in positions of popular election does not contravene the principle of equality. Ruling: P./J. 58/2005, jurisprudence, Semanario Judicial de la Federación y su Gaceta, XXII, Novena Época, July 2005, at 786. 


\subsection{Conclusions}

In the preceding sections, I have maintained that the use of affirmative action is founded on the right to equality as acknowledged in the Constitution. I have pointed out, as well, that the reasons, both historical and social, clarify the real inequality in which the Mexican indigenous people live. Accordingly, the use of affirmative action in different areas appears to be urgent. Affirmative action would undoubtedly be an efficient mechanism to end some of the consequences of hundreds of years of exclusion and discrimination experienced by the indigenous people of Mexico. 

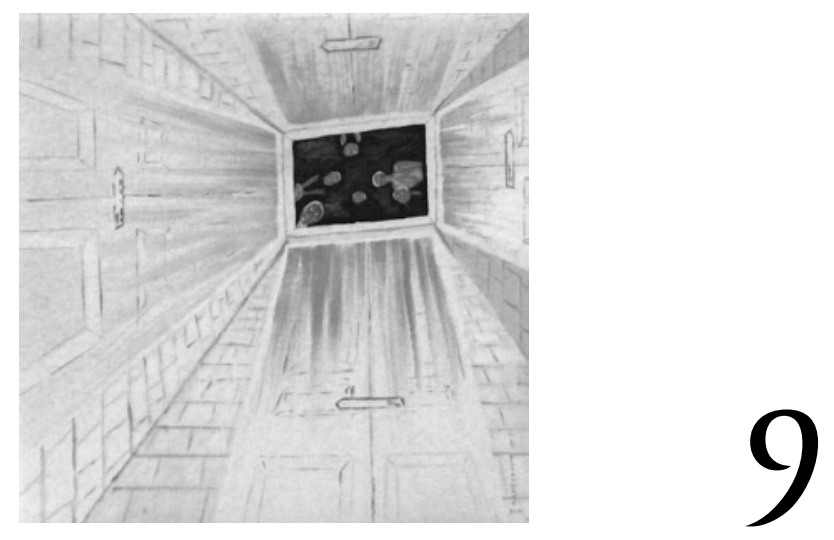

\title{
AFFIRMATIVE ACTION AND THE FIGHT AGAINST INEQUALITIES IN BRAZIL \\ The case of race and equal access to higher education ${ }^{1}$
}

\author{
Ingo Wolfgang Sarlet 2,3
}

\subsection{Introductory remarks}

Even considering its remarkable economic growth (Brazil is one of the biggest economies in the World $)^{4}$ and taking into account its GDP of $\mathrm{R} \$ 4.403$ trillion

1 I am grateful to STIAS for the financial and institutional support that enabled me to participate in the workshop and the research project coordinated by Professors Dupper and Sankaran, and to reside and conduct the research for this contribution.

2 Professor for Constitutional Law at Pontifical Catholic University Rio Grande do Sul (Pontifícia Universidade Católica do Rio Grande do Sul, <www.pucrs.br >) and State Judge in Porto Alegre, Brazil.

3 I thank Professor Carlos Alberto Molinaro, my colleague at PUCRS, for his help in the research and for some suggestions.

4 Phillip Inman, 'Brazil overtakes UK as sixth-largest economy' The Guardian (26 December 2011), available at <http://www.guardian.co.uk/business/2011/dec/26/brazil-overtakes-ukeconomy $>$ accessed 17 May 2012. 
(USD 2,223 trillion) in 2012,5 economic inequality is still a huge problem facing the Brazilian government and society. This is in spite of successful equality policies and rapid economic growth, which has led to a considerable reduction of poverty. According to official information, ${ }^{6} 8.5$ per cent of the Brazilian population currently still lives in a situation of extreme poverty; 4.8 million people have a monthly nominal income equal to zero, and 11.43 million have an income ranging from $\mathrm{R} \$ 1.00$ to $\mathrm{R} \$ 70.00$ (approximately 0.70 to $40.00 \mathrm{USD}$ ). ${ }^{7}$ This is one (but not the only) important reason explaining why equality-oriented policies are still of major importance to Brazilian society and also for the Brazilian legal order. Among these kinds of policies, affirmative action measures are being specially considered and several of such policies have been implemented by the federal government but also at the state and municipal level.

The first part of this chapter, while focusing on race and access to higher education, will offer an overview of the constitutional, legal and institutional framework order relating to equality, anti-discrimination and affirmative action policies in general. The monitoring and control of the implementation of affirmative action programmes will be explored in the second section, which will analyse the importance of judicial review in the light of recent decisions of the Brazilian Supreme Court. In view of some data about the performance of major affirmative action programmes, the final section attempts an evaluation and discussion of some of the challenges in achieving further goals related to the implementation of affirmative action policies that focus on affording access to higher education in Brazil.

\subsection{Equality-oriented policies and affirmative action as a duty of the state and society in the Brazilian constitutional order}

In light of the huge and enduring inequalities experienced since colonialism, the Brazilian Federal Constitution specifically contains a wide array of norms imposing goals, programmes and tasks in the field of equality policies. These norms form a complex and heterogeneous system of state and even non-state obligations that seek to tackle inequality, promote equality and prohibit discriminatory practices, as well as to impose a duty to implement affirmative action policies.

5 In the second quarter of 2013, the GDP (data released on $01 / 12 / 2013$ ) had an increase of $2.5 \%$. Also, the review of the 2012 GDP (which will be released on 12/03/2013) shows an increase of $1.5 \%$. See <http://www.ibge.gov.br/home/presidencia/noticias/imprensa/ppts/0 $0000014495008132013502830816470 . p d f>$.

6 Brazil Without Misery, the Ministry of Social Development And Fight Against Hunger, 'The profile of extreme poverty in Brazil on the basis of the 2010 Census', available at <http:// www.brasilsemmiseria.gov.br/wp-content/themes/bsm2nd/perfil_extrema_pobreza.pdf> accessed 17 May 2012.

7 Exchange rate US Dollar to Brazilian Real (29 November 2013): 1 USD = 2,337 BRL. 
According to Article 3 of the Brazilian Federal Constitution:

The fundamental objectives of the Federative Republic of Brazil are: I - to build a free, just and solidarian society; II - to guarantee national development; III - to eradicate poverty and sub-standard living conditions and to reduce social and regional inequalities; IV - to promote the well-being of all, without prejudice as to origin, race, sex, colour, age and any other forms of discrimination.

Regarding Social Policies and the Social Order (Title VIII), the Federal Constitution embraces the right to health and expresses the principle of universal and equal access to health services, which has established the Unified Health System (SUS). It is mandated that the right to health be guaranteed by means of social and economic policies. Article 205 establishes that all persons have the right to education, and that education is the duty of both the State and the family, while Article 206 expresses the principle of equal conditions of access in school. All this demonstrates how much the Brazilian constitutional framework is committed to achieving equality.

Of increasing importance are the express and implicit constitutional mandates (complemented by a series of laws and administrative acts) that refer to the implementation of affirmative action policies and even quota systems regarding access to social goods and to work positions in the public and private sectors. ${ }^{8}$ The

8 In the public sector, President Dilma Rousseff sent to Congress (6 November 2013), the Draft Law Nr. 6738/13, of the Executive Branch, which reserves for the black population (blacks and browns) 20\% of the positions offered in the public sector. At least four states and 28 cities in the country have already adopted racial quotas in public tenders, according to a survey by the Institute for Applied Economic Research (IPEA) and the Secretariat for Policies to Promote Racial Equality. In another ten municipalities the reservation of vacancies was approved, but the laws have been overturned in the courts. In most of the initiatives listed in the study, the quota is equal to or less than $20 \%$. The largest reservation is $44 \%$ in the City of Viamão, Province (State) of Rio Grande do Sul (RS). However, the map of the Spatial Distribution of Population, published by the Brazilian Institute of Geography and Statistics (IBGE) and also in partnership with the Secretariat, shows that only $24.3 \%$ of the population of the city is declared 'black' or 'brown' (terms used by the institute which together represent blacks). Moreover, the study found no initiative in Para State, which has the highest proportion of blacks (76.8\%). In Bahia (in second with 76.3\%), only Salvador reserves vacancies, but the standard has not been regulated. One common aspect is that there is little monitoring or disclosure of the results of affirmative action. In Paraná, the perception is that more objective criteria are needed to define which candidates are of African descent as they are entitled to $10 \%$ of the vacancies. The State also reported that all quotas are not always filled. Of 2,859 places reserved for the last 20 tenders, 2,456 were taken up. According to the survey, the edicts tend to accept self-declaration of skin colour. In some States special committees provide verification of race, such as Rio Grande do Sul. In two states, Rio de Janeiro and Mato Grosso do Sul, and at least two cities - Porto Feliz (SP) and Nova Iguaçu (RJ) - quotas for public service include indigenous people. South Mato Grosso state administrators showed more diversity in the public service because the law guarantees 
Constitution reserves a percentage of public offices and positions for persons with disabilities (Article 37, VIII, CF), and federal legislation has also allocated quotas in political parties for female candidates running for office. ${ }^{9}$ Further legislation establishes that both government ${ }^{10}$ and private companies ${ }^{11}$ must hire a certain percentage of employees with disabilities, and quotas are set in public universities, amongst other policies that could be mentioned.

In addition to the above-mentioned examples, and parallel to the general equality clause and the clauses prohibiting discrimination (referring to bases such as gender, spouses, children and parties in work relations), ${ }^{12}$ the Federal Constitution embodies a significant catalogue of social rights and classifies them as fundamental rights (rights to health, food, education, housing, leisure, employment and social security, among others). ${ }^{13}$ That equal access to these rights is one of the major problems faced by the Brazilian constitutional order and the role played by affirmative action will be addressed later.

Seen in this light, the vast majority of equality-oriented policies can be understood as programmes and actions that seek the realisation of constitutional mandates and can be qualified as state policies. It is even possible to conclude, considering the vast extent of the objectives listed under Article 3 of the Brazilian Federal Constitution, that all equality-oriented policies have this quality. On the other hand, the fact that the constitutional and legal orders warrant the right to formal and material equality does not guarantee that these rights will be pursued and realised in an effective manner. For this reason, the control over public policies (including equality-oriented

$10 \%$ of vacancies to blacks and $3 \%$ to indigenous people. In Rio Grande do Sul, state law and six municipal standards also set quotas for blacks granting them the right to participate in advertising (marketing material).

9 Brazilian Federal Law No. 9504, 30 September 1997.

101988 Brazilian Federal Constitution, Article 37, s VIII. Federal Law No. 8112, Article 5, s 20, 11 December 1990. Federal Decree No. 3298, 20 December 1999.

11 Federal Law No. 8213, Article 93, 24 July 1991. Federal Decree No. 3298, 20 December 1999.

12 See, for example, Article 5, caput ('All persons are equal before the law, without any distinction whatsoever, Brazilians and foreigners residing in the country being ensured of inviolability of the right to life, liberty, equality, security and property [...]'); Article 50, I ('men and women have equal rights and duties under the terms of this Constitution'); Article 226, s 50 ('The rights and the duties of marital society shall be exercised equally by the man and the woman'); Article 227, s 60 ('Children born inside or outside wedlock or adopted shall have the same rights and qualifications, any discriminatory designation of their filiations being forbidden').

13 In the original text of the 1988 Constitution, the Rights of Housing and Food are not included; they were incorporated by constitutional amendments in 2000 and 2010, respectively. 
policies in general and affirmative action in particular) is often carried out by the judiciary through judicial review, a point that will be taken up later in this chapter.

As in other countries, there is a broad set of public policies to fight inequalities and discrimination. In this sense, the programmes contemplated in this study represent strategies to achieve both formal and substantial equality. If it is through the constitutional equality clauses that the country seeks to guarantee equality before the law, they also intend to achieve equality of conditions and opportunities in the fields of education, access to goods and services in the economic and social orders and determine that equal treatment shall be given to diversity. In this sense, equalityoriented policies are policies of identity recognition, as well as policies of social, political, economic, and cultural integration. Among the different policies that fall into this category, we find the complex and diverse network of anti-discrimination measures, as well as the so-called affirmative action policies based on a series of criteria, such as gender, sexual orientation, physical and mental disabilities.

Since it is impossible to present, even briefly, all major policies implemented in the field of equality promotion through affirmative action, we are going to focus on the racial case and the problem of access to higher education, which is by far the most controversial.

Racial discrimination concerning in particular Brazil's Afro-descendant population has raised the most sensitive issues on egalitarian-oriented public policy debates. Although the concept of race cannot be discussed in physiological (biological) terms anymore (according to current opinion shared also by the Brazilian Supreme Court), ${ }^{14}$ it is plainly possible to identify racism in political, social, economic, cultural and legal fields dealing with all kinds of prejudice and discrimination issues based on race, colour or ethnicity. In this sense, Brazil has been sadly recognised as the last country to abolish slavery (practised in the Brazil in an extreme manner for more than three centuries), ${ }^{15}$ but fortunately the racial issues, and particularly

14 The leading case decided by the Brazilian Supreme Court was not an affirmative action case but a criminal case in which a publisher of German descent was convicted for his publications that denied the Holocaust. The state prosecutor charged him with racism, interpreting this crime in a broad sense. The court decided that although we cannot speak of race in a biological sense, racism is a normative concept. See the so-called 'Ellwanger' case of 17 September 2003. Habeas Corpus 82424 Siegfried Ellwanger $v$ Superior Tribunal de Justiça (Brazilian Supreme Court, published in DJ 19 March 2004).

15 The first African slaves (not considering former slavery by indigenous people) were brought to Brazil in the sixteenth century to be used as a workforce for the sugar cane plantations and sugar industry. See Rafael de Bivar Marquese, 'A Dinâmica da Escravidão no Brasil: Resistência, tráfico negreiro e alforrias, séculos XVII a XIX', Novos Estudos 74 (2006): 107, 110-11, available at <http://dx.doi.org/10.1590/S0101-33002006000100007> accessed 18 May 2012. Despite some legislation starting to reduce slavery in the early nineteenth 
the situation of Afro-descendant people, have been receiving a special and sensitive attention in the political and legal order, mainly after the enactment of the current Federal Constitution (1988) and by the Federal Governments under Fernando Henrique Cardoso and Luiz Inácio (Lula) da Silva, ${ }^{16}$ and in particular with the recent significant developments under the Government of President Dilma Roussef. ${ }^{17}$

As in other countries, it is of particular importance to make a distinction between direct and indirect discrimination when the matter of racial discrimination is in debate; the former is expressed in public practices and private conducts grounded on prejudice against a race resulting in unequal, unfavourable and, often excluding treatment of certain people and which is conducted in a conscious and deliberate manner; the latter unleashes, even if not intentionally in most cases, an unfavourable

century (for instance, the formal prohibition of the importation of slaves from Africa), only in May 1888 was slavery definitively abolished at the twilight of the Brazilian monarchy (the Republic was declared in November 1889).

16 On the evolution from anti-discrimination to affirmative action in Brazil, see, for instance, Mala Htun, 'From "Racial Democracy" to Affirmative Action: Changing State Policy on Race in Brazil', Latin American Research Review 39, no. 1 (2004): 60. It should be added, that the major affirmative action programmes were introduced from around 2003-2004.

17 President Dilma Rousseff has ensured that affirmative action, and more specifically quotas, are a central element in the struggle for equality in Brazil. Among other measures, specific agendas for discussion between some ministries and organisations of the black movement and the National Council for the Promotion of Racial Equality will also be imposed. The Secretariat for Policies to Promote Racial Equality (Seppir, acronym in Portuguese) pledged to deliver by the end of 2013, for the Presidency, a proposal for a presidential decree to regulate quotas for blacks in federal public tenders, according to that foreseen in the Statute of Racial Equality. The president reaffirmed the position that affirmative action, and, more specifically, quotas, are a central element of the struggle for equality in Brazil. Indeed, on 29 August 2012, the President Dilma Rousseff signed Law No. 12,711, which provides for the admission into federal universities and federal institutions of technical education high school. On 11 October 2012, Decree No. 7,824 was published, regulating Law No. 12,711. According to the text, the federal public universities and federal technical institutes should reserve at least $50 \%$ of places for students who have attended high school at public schools, with proportional distribution of vacancies among blacks, mulattos and Indians. The decree details the rules and schedule for implementing the new system for the distribution of vacancies in the federal system of higher education. Universities and federal institutes will have four years to gradually deploy the percentage of quotas established by law, even those that have adopted some sort of system to select students. Federal institutions that offer vacancies for technical schools should make reservations for each entry in the competition for selective secondary courses by course and shift at least $50 \%$ of their seats for students who have fully attended elementary school in public schools. The legislation also creates mechanisms (such as tutoring) to compensate for any differences between students who entered in the quotas and the other graduates of the universal system. 
treatment (therefore, with a disproportional impact) on specific groups of people, such as Afro-descendants, with measures, rather impartial in their abstract form, taking into account a race-based point of view, being implemented in a way that causes inequality. Indirect discrimination, on the other hand, cannot be compared with direct discrimination, since the latter situation occurs when a valid norm is systematically and continuously enforced by rightful authorities in an unfavourable and unequal way against a specific group. ${ }^{18}$

On the other hand, discrimination based on colour or race (here taken as the same criterion according to the current practice in Brazil) assumes a particular significance in Brazil, because it represents a problem afflicting the majority of the Brazilian people, which is not surprising since Brazil is the second largest black nation after Nigeria. ${ }^{19}$ It should be reinforced that the group affected by (direct and indirect) discriminatory conducts is composed of both black and brown people - that is, people who are considered Afro-descendants - and who are entitled to affirmative action policies, as we shall see. It should be underlined that the brown population represent the great majority amongst Afro-Brazilians since they are the result of an intense miscegenation among the Brazilian people developed over centuries. This becomes an argument for those who sustain that affirmative action based on race is not the best path to be followed, but this is discussed later, when major reasons in favour and contrary to affirmative action are presented.

In addition to the fact that the touchstone to many affirmative action policies is founded on 'race' or colour (blacks and browns), the colour criterion has been feverishly discussed in Brazil. I will address the relevant discussion in judicial venues later in this work. But before starting the presentation of major affirmative action programmes and their implementation, some data is presented about the racial mix (colour) of the Brazilian population as well as some data stating the significant existence of inequalities, particularly between whites and blacks (including browns).

18 See, among others in Brazilian literature, Daniel Sarmento, Livres e Iguais: Estudos de Direito Constitucional (Rio de Janeiro: Lumen Juris Editora, 2006), 147 ff.

19 'As a result of three and a half centuries of a slavery-based economy, Brazil has the second largest population of African descent after Nigeria. They account for almost one-half of all Brazilians: there were 11.6 million blacks and 79.6 million browns (persons of mixed resulting from miscegenation among whites, blacks and Indians) in a total population of 184.4 million in 2005. Despite the absence of legally-sanctioned racism since slavery was abolished in 1888, this system has left a legacy of social discrimination against AfroBrazilians, who are more likely to be members of socially disadvantaged groups.' Carlos Gradín, 'Why is Poverty So High Among Afro-Brazilians? A Decomposition Analysis of the Racial Poverty Gap', Journal of Development Studies 45, no. 9 (2009): 1426. 
According to the National Household census 2010, out of a total population of $190,755,799$, up to 51 per cent is considered to be black, which includes both blacks ( 7 per cent) and browns ( 44 per cent). The data relies on people who have declared themselves to be part of each group. Yellow and aboriginal people represent 1 per cent of the total and white people make up to 48 per cent. Comparing these figures with the results drawn in 2000, it is clear that there was a slight increase in the percentage of people who declared themselves as black (blacks or browns); according to the 2000 survey, 45 per cent declared themselves as black, of which 5 per cent were black and 40 per cent brown out of a total population of 171 million inhabitants at that time. ${ }^{20}$

A few further examples are worth mentioning. With regard to attendance time at school (people from 10 years old onwards), whites have attended school for an average of 9.2 years, while for blacks, it is 7.4 years and browns 7.2 years. Considering the national average monthly income per capita (people from 10 years old onwards and considering labour activities altogether), whites have earned the equivalent of 3.2 times the minimum wage, while blacks and browns have earned 1.8 times the minimum wage each. However, in this area we can see that the situation is changing and the difference between the races has been reduced; in 2005, a black worker had an income of 53.3 per cent of what corresponded to the income of a white one considering the national average. ${ }^{21}$

Further data has shown that functional illiteracy rate among people equal or older than 15 years old is divided as follows: 15 per cent of whites, 25.4 per cent of blacks and 25.7 per cent of browns. Data has also shown that the rate of people from 18 to 25 years old attending higher education in 2010 was as follows: 20.6 per cent were whites, while the rate for blacks and browns was, respectively, 7.4 per cent and 8.4 per cent. As it has been shown in the data above, in comparison with the year 2000 , when the percentage of blacks (here, blacks and browns) who have attended higher education reached just 2 per cent, an advancement in the inclusion process (not only in terms of access to higher education) is evident and this means that affirmative action policies have been quite effective. This is discussed later after presenting the major affirmative action programmes implemented in Brazil.

20 Official data published from the latest census in 2010. See IBGE / DPE / COPIS Department of Population and Social Indicators, available at <http://biblioteca.ibge.gov. br/d_detalhes.php?id=264529> accessed 29 November 2013.

21 See Sergei Suarez Dillon Soares and Natália de Oliveira Fontoura and Luana Pinheiro, 'Tendências Recentes na Escolaridade e no Rendimento de Negros e de Brancos', in Ricardo Paes de Barros, Miguel Nathan Foguel \& Gabriel Ulyssea, eds., Desigualdade de Renda no Brasil: uma análise da queda recente Vol. II (IPEA, 2007), 401, 408-11, available at <http:// www.ipea.gov.br/igualdaderacial/images/stories/pdf/cap29.pdf> accessed 28 March 2012. 
Besides important measures against direct discrimination, a broad network of affirmative action programmes has been implemented through public and even private actors. These programmes are mostly directed towards the inclusion of Afro-descendant people (blacks and browns), both in the labour market (especially in the public sector) and in the higher education system, where it includes quota policies in universities, which have already been implemented at various levels. The most comprehensive and important of these policies is the recently enacted Statute of Racial Equality, which includes a series of different topics that go well beyond access to higher education and the labour market. Enacted through Federal Law 12.288 of 20 July 2010, the Statute of Racial Equality has the following objectives: to guarantee that the Afro-descendant population will have the right to equal opportunities, to protect ethnic rights of an individual, collective and diffuse nature and to tackle discrimination and different forms of racial intolerance (Federal Law 12.288, article 1). The statute defines some basic concepts (such as racial discrimination, racial inequality, gender inequality, black population, public policy and affirmative action). It mandates that the state and society have a duty to foster equal conditions and promote social, economic, cultural and political inclusion. In the chapter on fundamental rights, the creation and structuring of a national system for the promotion of racial equality is of major importance, and is mandatory for all public powers.

One can already see the comprehensive character of the statute from these first articles. As examples of measures and actions that are assigned in the chapters mentioned above, it is worth stating what the compulsory public policies are:

(a) the production of scientific knowledge and technological know-how regarding the health of the black population;

(b) the implementation of affirmative action policies in the field of education;

(c) the provision of religious assistance to followers of Afro-descendant religions who are checked into hospitals or other institutions, including prison inmates;

(d) the promotion of education and professional orientation for black workers and black rural communities;

(e) actions to be taken by financial institutions in order to provide access to financing for housing to the black population; and

(f) the responsibility to implement policies oriented towards the inclusion of the black population in the labour market.

In spite of the relevance of the Racial Equality Statute, as mentioned above, several affirmative action policies had previously been implemented, including quotas 
to ensure access to higher education. ${ }^{22}$ Here we can distinguish between general programmes, created by the federal government, and more specific policies implemented by other organs and institutions, such as public and even private universities, even without direct legal authorisation. These policies sometimes differ in terms of how to promote equality and sometimes combine different criteria. As an illustration, we now offer a short overview of the most important and effective general federal policy (the so-called University For All Programme) implemented in the field of access to higher education, and which includes affirmative action measures. This programme, along with other specific policies implemented by several public universities - which also include or even focus on race (colour) as a criterion - was submitted to judicial scrutiny and reached the Brazilian Federal Supreme Court decision.

The University for All Programme (ProUni) assumes a relevant position amongst the many strategic instruments aimed at guaranteeing the fundamental right to education. The programme is especially significant in view of article 206, I of the Brazilian Federal Constitution, which determines that education shall be provided to citizens based on the principle of equal conditions of access and permanence in school. Originally, the 'ProUni' programme was established by Provisional Measure 213 on 10 September 2004, and was regulated by Presidential Decree 5.245/2004. It was later enacted by Congress through Federal Law 11.096/2005, and regulated by Presidential Decree 5.493/2005.

The purpose of the ProUni programme is to grant full or partial scholarships to students attending undergraduate education or other higher education programmes in private universities. Full scholarships are granted to Brazilians who do not have a degree yet and whose monthly per capita family income does not exceed oneand-a-half times the minimum wage. Partial scholarships, accounting for 50 per cent or 25 per cent of the tuition, are granted to Brazilians who have no previous undergraduate degree and whose monthly per capita family income does not exceed three times the minimum wage. The ProUni scholarship system seeks to provide access to higher education to students in two situations: those who have graduated

22 Such as, for example, the affirmative action programme at the Federal University of Santa Catarina, whose implementation was in 2008 and the programme created by UNICAMP (University of Campinas, São Paulo) in 2005. See Marcelo Tragtenberg, 'Universidade Federal de Santa Catarina' (Public hearing on the Constitutionality of Affirmative Action Policies in Higher Education Access, Federal Supreme Court 2010) 416, available at < http://www.stf. jus.br/arquivo/cms/processoAudienciaPublicaAcaoAfirmativa/anexo/Notas_Taquigraficas_ Audiencia_Publica.pdf> accessed 30 March 2012. See also Renato Hyuda de Luna Pedrosa, 'Ação Afirmativa na Unicamp' (Public hearing on the Constitutionality of Affirmative Action) 5 , available at <http://www.stf.jus.br/arquivo/cms/processoAudienciaPublicaAcaoAfirmativa/ anexo/TextoUnicampSTFAPcotas.pdf $>$ accessed 30 March 2012. 
from public high schools and those who have graduated from private institutions, but had been granted full scholarships during their studies. Students with disabilities and teachers from the public education system can also be beneficiaries of the ProUni programme. In granting scholarships to teachers, the programme seeks to qualify teachers for the basic education system and, in this case, the financial aid is not conditioned by income conditions.

The ProUni programme was also conceived as an anti-discrimination policy, and includes affirmative action measures amongst its policy instruments. According to Article 7 of Federal Law 11.096/2005, a certain fraction of the total available scholarships must be granted to persons with disabilities or to students who declare themselves to be indigenous or black. This fraction must be at least equal to the percentage of citizens, who declare themselves to be indigenous, brown (pardo) ${ }^{23}$ or black (preto) in the state where it is applicable. This norm is meant to establish a system that respects the different demographic characteristics of the Brazilian states.

There has been much controversy surrounding the University for All Programme. The debates and criticisms have focused on two aspects of ProUni: (a) its affirmative action dimensions - namely, the quota system established by the programme, and (b) its reliance on the private education system, which is said to reaffirm a 'privatisation' of the Brazilian education system. Many critics argue that 'ProUni' carries within it a highly problematic notion of democratisation, for it establishes a distinction between students coming from different social backgrounds and thus entails a notion of social stratification. Beyond this, it is said that the programme unduly favours the private education system, since it offers tax benefits to schools that integrate the programme, even though these schools do not always operate in a sufficiently transparent manner in their granting of scholarships. Furthermore, it is argued that, instead of implementing a programme that benefits the private school system, the government should invest in the public education system and in the democratisation of higher education. Still others argue that, in order to achieve one of the goals established in the National Education Plan (Plano Nacional de EducaçãoPNE), which determines that the rate of enrolment in the higher education system amongst the population aged 18 to 24 must increase from 9 per cent to 30 per cent, the Ministry of Education and Culture (MEC) has simply decided to grant benefits instead of promoting rights. ${ }^{24}$

23 'Pardo' is an official term in Brazil formally used to describe someone of multiracial origin. In other countries where Portuguese is spoken, it is used with the same meaning as the terms 'mulatto' or 'mestizo'. According to the Brazilian Institute of Geography and Statistics, the brown group is one of five groups of 'colour or race' that make up the population, along with white, black, yellow and indigenous. See <http://www.ibge.gov.br/home>.

24 On this polemic, see Afrânio M Catani and Renato de S P Gilioli, 'The "ProUni" at a Crossroads: between citizenship and privatization', Linhas criticas 11, no. 20 (2005): 55-65. 
According to data provided by the Ministry of Education and Culture, since the year of its creation until the first school semester of 2013, ProUni has already benefited one million students, 70 per cent of whom were granted full scholarships. During the first semester of 2013, the programme granted a total of 162,329 scholarships, 82,680 of which are full scholarships and 79,649 partial. During the same period, the distribution of scholarships according to race was as follows: 47.9 per cent white; 34.9 per cent brown; 12.5 per cent black; 1.8 per cent Asian; 0.2 per cent indigenous; and 1.8 per cent unknown. Besides this, it is also noteworthy that, of the 858,172 scholarships, only 5,599 were granted to students with disabilities, which represents 1 per cent of the scholarships. ${ }^{25}$ Furthermore, from 2005 until 2013, 427,540 scholarships (or 49 per cent) were granted to men and 436,231 (51 per cent) were granted to women. ${ }^{26}$

Beside ProUni, another important public policy can be found in the Law of Quotas. The approval of the Law of Quotas is an important achievement. After thirteen years of debate in Congress, the Law Project 180/2008 establishing a policy of affirmative action in federal educational institutions, was approved and sanctioned by the President of the Republic, Dilma Rousseff, in August 2012, in the form of law $12.711 / 2012$, which states that by August 2016 all institutions of federal education shall (i) allocate at least 50 per cent of places for students who attended high school in public schools; (ii) ensure that half of these seats (or 25 per cent of the total) should be reserved for students whose families have incomes of less than one-anda-half the minimum wage; and (iii) reserve 50 per cent of vacancies for blacks, mulattos and Indians in numbers at least equal to the proportion of blacks, mulattos and self-declared Indians identified by IBGE in the federal unit in which they are located. In summary, 50 per cent of seats will be divided among public school students, the poor, blacks, browns or Indians and 50 per cent will be allocated to broad competition.

This Law of Quotas establishes the obligation to reserve places at universities and federal institutions, often combining the public school origin, income and colour (ethnicity) as qualifying criteria. The new quota law establishes that 50 per cent of vacancies of the federal universities are clearly intended for students from public schools. The same reservation must be made by the federal institutions of education, science and technology (IFES, by the Portuguese acronym). Institutions have four years to adapt to the new rule, which is already applicable this year, as at least 12.5 per cent of the vacancies for quota holders will be reserved this year. The

25 See statistical data of 'ProUni', available at <http://prouniportal.mec.gov.br/images/ arquivos/pdf/Representacoes_graficas/bolsistas_pessoas_deficiencia.pdf $>$.

26 See <http://prouniportal.mec.gov.br/images/arquivos/pdf/Representacoes_graficas/ bolsistas_por_sexo.pdf $>$. 
filling of vacancies for public school students must also comply with the other two criteria: income and ethnicity. Half of the vacancies reserved for the quota holders shall be filled by young people with a family income of no more than 1.5 times the minimum wage per person. This means that when quotas are fully adopted, 25 per cent of vacancies in a particular course will be filled by applicants from low-income (coming from the public school system). For the second criterion, self-identified black candidates, mulattos and Indians will be guaranteed a number of seats (out of all the vacancies for the quota holders) that is proportional to the participation of these populations in each Brazilian state. To determine this percentage, the demographics published by IBGE will be observed.

It should be noted that in the south, the federal universities surpassed the goal aimed at black, brown and indigenous population, with 17.7 per cent of the vacancies reserved compared to 10.5 per cent expected by the full implementation of the law. Other regions have approached the target, but not yet reached it. In the southeast, reservation of 18 per cent was achieved against a target of 22 per cent and, in the mid-west, the share of racial quotas was 24.3 per cent, four points behind the 28.5 per cent expected. In the north and north-east, where the black or brown and indigenous population is higher, the goals are still far from being fulfilled. While in the first region, it is still necessary to move from 17 per cent to 37.8 per cent, in the second, the rate needs to grow from 21.6 to 34.8 per cent. Nevertheless, the racial quotas expected for this year, with the gradual implementation of the law, were surpassed in all regions.

Reserved quotas in federal universities that have obtained a grade 3, within the General Index of Courses (IGC - Índice Geral de Cursos), ${ }^{27}$ increased from 9.1 to 25.3 per cent, from 2012 to 2013. Institutions with grade 5 showed the next largest increase with a jump from 18.3 to 27 per cent of total vacancies allocated by quota. Most institutions with grade 4 jumped from 24.5 to 32.2 per cent. With regard to the vacancies meant for blacks, mulattos and Indians, from 2012 to 2013 the percentage achieved rose from 8.8 to 13.9 per cent of total vacancies at universities with grade 5, the lowest increase recorded. Quota vacancies at universities with grade 4 jumped from 10.2 to 20.3 per cent. The courses with grade 3 were the most increased: from 6.7 to 20.5 per cent. Universities with grade 5 were the most resistant to introducing any kind of affirmative action, while universities with grade 4 started from higher levels of affirmative action and created even more vacancies in their quota systems.

27 This Index refers to the grades obtained by Universities (encompassing undergraduation and graduation) in evaluations based on the results of exams published from time to time by the Ministry of Education and Culture (MEC - Ministério da Educação e Cultura). The Grades awarded range from 1 to 5, 1 and 2 meaning 'unsatisfactory', 3 meaning 'regular (satisfatory)', 4 meaning 'good' and 5 'very good'. 
The situation almost reverses when analysing quotas for public school students and students from low-income backgrounds: universities with grade 3 increased the percentage from 2.3 to 4 per cent, while those with grade 4 reduced participation from 14.1 to 11.4 per cent. On the other hand, universities with grade 5 in this case were those that showed the biggest increase in the number of vacancies reserved for blacks, mulattos and Indians, from 9.6 to 13 per cent.

\subsection{The policies of affirmative action in court: analysis of the Brazilian Supreme Court decisions}

\subsubsection{Some general remarks: the public hearing and the major arguments for and against affirmative action}

As in other countries, in Brazil the affirmative action programmes implemented have been subject to judicial scrutiny. In view of its position as the guardian of the Federal Constitution, it is relevant to present and discuss the principal decisions of the Brazilian Federal Supreme Court (Supremo Tribunal Federal). In particular, we look at the decision on the constitutional consistency of the University for All (ProUni) programme and the decision on the quota system to access higher education that has been implemented, among others, in two Brazilian public universities - namely, the University of Brasilia (UNB) and the Federal University of Rio Grande do Sul (UFRGS).

As in other cases of high impact in Brazil, the judgments in the Supreme Court questioning the affirmative action programmes and policies were preceded by a public hearing called by the rapporteur of the case. The hearing took place from 3 to 5 March 2010 and a total of 38 specialists, representing public organs and organised civil society participated. ${ }^{28}$ In the public hearings, positive and opposing arguments were presented on the constitutionality of affirmative action policies based on race. These focused mainly on the legitimacy of using race (skin colour) as a criterion to determine the beneficiaries of quotas.

Amongst the arguments favouring the quota system, of particular significance is the need to repair historical damage caused by centuries of slavery, which affected blacks brought from the African continent and their descendants, as well as the process of exclusion that followed the end of that regime. Nevertheless, it is pointed out that for practical and ethical reasons, the direct identification of Afro-descendants should not happen. Instead, it is reasonable to use the categories 'black and brown',

28 Federal Supreme Court, 'Chronogram' (Public hearing on the Constitutionality of Affirmative Action), available at <http://www.stf.jus.br/portal/cms/verTexto. asp?servico=processoAudienciaPublicaAcaoAfirmativa $>$ accessed 30 March 2012. 
given the great probability that people who identify themselves as belonging to these groups are Afro-descendants. This criterion also accords with the social economic indices, since black and brown people are amongst the poorest and most excluded in the general population. In this sense, it has been stated that the basis of affirmative action is positive (reverse) discrimination, which represents the unequal application of resources to achieve general welfare. If positive discrimination were equated to negative discrimination (deprivation of the discriminated), then other similar policies (such as those from the BNDS) ${ }^{29}$ would be equally unconstitutional. ${ }^{30}$

In compliance with another line of argument, if we aim to live in harmony in the presence of diversity, we may also mingle universal policies with differential ones. ${ }^{31}$ This argument, however, is in opposition to the usual statement that 'nobody should be considered guilty by alleged crimes committed by their ancestors. ${ }^{32}$ In the context of race and segregation, one is talking of a blood debt, in which guilt and right to reparation are passed on through generations. ${ }^{33}$ On the other hand, from another point of view, justifying racial quotas using the 'guilty past' argument could make sense in the USA context. There has been a long tradition in the US of universities not admitting blacks and using other elements, besides performance in their studies, in the selection process - such as ethnic origin, gender, the fact of having parents as ex-students and talent in sports, which does not occur in the Brazilian entrance exam (vestibular). ${ }^{34}$

29 Brazilian Development Bank, <www.bndes.gov.br>.

30 João Feres Júnior, 'Instituto Universitário de Pesquisas do Rio de Janeiro - IUPERJ' (Public hearing on the Constitutionality of Affirmative Action) 2-3, 5-6, available at <http://www. stf.jus.br/arquivo/cms/processoAudienciaPublicaAcaoAfirmativa/anexo/Apresentacao_ STF_Joao_Feres_Junior.pdf $>$ accessed 30 March 2012.

31 Kabengele Munanga, 'Constitucionalidade das políticas de ação afirmativa nas Universidades Públicas brasileiras na modalidade de cotas' (Public hearing on the Constitutionality of Affirmative Action) 5, available at <http://www.stf.jus.br/arquivo/cms/ processoAudienciaPublicaAcaoAfirmativa/anexo/Kabengele_Munanga_AUDIENCIA_ PUBLICA.doc > accessed 29 March 2012. It addresses two approaches that have led to a debate and suggests they be combined.

32 See George de Cerqueira Leite Zarur, 'A Tragédia Étnica' (Public hearing on the Constitutionality of Affirmative Action) 4, available at <http://www.stf.jus.br/arquivo/cms/ processoAudienciaPublicaAcaoAfirmativa/anexo/Zarur_A_TRAGEDIA_ETNICA.doc $>$ accessed 29 March 2012.

33 Ibid., 2, 4-5.

34 Eunice R Durham, 'Desigualdade Educacional e Quotas para Negros nas Universidades' (Public hearing on the Constitutionality of Affirmative Action) 3, available at <http:// www.stf.jus.br/arquivo/cms/processoAudienciaPublicaAcaoAfirmativa/anexo/Durham Desigualdade_educacional_e_quotas_para_negros_nas_universidadestexo_brasilia.doc> accessed 29 March 2012. 
In opposition to quota systems is the argument that access to higher education must be guided by merit - that is, by each candidate's personal performance - and that only the best must be contemplated for the available vacancies. The conventional answer to this argument is that the best are those who end up having the best tools, coming generally from the private school system; those who have not had the opportunities to get their elementary and/or high school formation in private schools (which in general have better quality education) tend to be excluded or have reduced chances of admission to higher education. ${ }^{35}$

Returning to the use of the race criterion, it was also argued at the hearing that individuals should not be discriminated against on the basis of either their colour or appearance or their race, since everybody is equal. Only in the case of women or disabled people, would it be possible to establish compensatory advantages through quotas. ${ }^{36}$ Besides this, according to another argument, democratisation in the field of higher education would be reached by social quotas and not by racism camouflaged as public policy. Another argument says that governmental statistics are manipulated when dealing with the classification of the black population into black and brown, when in reality, these latter are mixed-race people, in such a way that the right to diversity would not be the base for the racial quotas. ${ }^{37}$

In this sense, it is expedient to present two other key arguments in support of affirmative action. The argument of the need to address social injustice is based on the premise that certain 'people are systematically marginalized and excluded from more prestigious and affluent positions', although all people are ostensibly equal an injustice per se. ${ }^{38}$ On the other hand, the argument in favour of diversity is based on the premise that all the social segments should be represented in the institutions of prestige and power in a democratic society; the lack of representation of a group is in itself an injustice, but added to this, diversity in representation contributes to the quality of the institutions - justifications that are not mutually exclusive. ${ }^{39}$ From

35 Munanga, 'Constitucionalidade das políticas', 3.

36 A similar paradox appears when the lawyer from the party that proposed the action points out this argument attacks only the quotas for blacks and racial quotas and not the preview of quotas for indigenous people, whereas at the same time there are innumerable other minority groups and that discrimination will not necessarily be combated through quotas.

See Roberta Fragoso Menezes Kaufmann, 'A lawyer from the arguing party' (Shorthand Notes, Public hearing on the Constitutionality of Affirmative Action) 76-8, available at <http://www.stf.jus.br/arquivo/cms/processoAudienciaPublicaAcaoAfirmativa/anexo/ Notas_Taquigraficas_Audiencia_Publica.pdf> accessed 30 March 2012.

37 Zarur, 'A Tragédia Étnica' 2, 4-5.

38 Júnior, 'Instituto Universitário de Pesquisas do Rio de Janeiro', 3.

39 Ibid., 3, 5. See also Flavia Piovesan, 'Ações Afirmativas da Perspectiva dos Direitos Humanos', 
the same perspective, it is suggested (following Ronald Dworkin) that ensuring diversity by means of racial quotas (or counterparts) is the only way to make white and black sometimes live together, a statement that is also correct for Brazil, although the context of segregation is not the same as in North America. ${ }^{40}$ From this perspective, reference is made to the low percentage of blacks in universities, but especially in managerial positions in the private sector and in higher ranking positions in the public sector, a reality that in Brazil continues to the present day, as it does in countries that have lived with intense racist practices, such as the United States and South Africa. ${ }^{41}$

In argument against quotas, it is still claimed that quotas themselves are responsible for ongoing racial discrimination and educational inequality. It is argued that they do not solve the problems as such and, in addition, sustain inequalities that were present in the previous school process, as well as generate a division amongst the students who entered better prepared and the ones who enter on worse grounds. Besides also depreciating the importance of a good basic formation, to these problems is added the inferiorisation of even those who could obtain good schooling, but who take advantage of the quotas. ${ }^{42}$

Considering the common objection against affirmative action that it promotes racialisation and racial conflict, ${ }^{43}$ the counter argument is that there has already been affirmative action in Brazil for over six years and that there has been no confirmed increase in racial conflict. With regard to racialisation, the census categories used by IBGE are not in themselves a racialisation practice and without them it would not be possible to identify racial inequality. Beyond this, it is stated that affirmative action appears in different countries in moments of democratic rebuilding, as was

Cadernos de Pesquisa 35, no. 124 (2000): 43, available at <http://www.scielo.br/pdf/cp/ v35n124/a0435124.pdf> accessed 22 May 2012.

40 See Kaufmann, 'A lawyer from the arguing party', 80.

41 See Munanga, 'Constitucionalidade das políticas', 1.

42 Durham, 'Desigualdade Educacional', 1, 3, 6-7.

43 For a synthesis of the elements of the arguments of racialisation, see Bernardo Lewgoy, 'Cotas raciais na UnB: as lições de um equívoco', Horiz. Antropol., 11, no. 23 (2005), available at <http://www.scielo.br/scielo. php?script=sci_arttext\&pid=S0104$71832005000100013 \& \operatorname{lng}=$ en\&nrm=iso $>$ accessed 22 May 2012.

This article provides insight into the criticism that quotas promote racialisation. It deals with the polemics of the programme of quotas at $\mathrm{UnB}$, which centres on the existence of a committee responsible for approving or rejecting registrations in the system of quotas. The committee takes into account the applicants' self-declaration as black and the photo taken at the moment of registration, as well as discussions about the 'racial expert services' from the perspective of anthropology. According to reports, the term 'racial tribunal' was used in the case, demonstrating the weight of the polemics. 
the case in India in its fight for independence and freedom from British imperialism; and in the USA, despite a very different context, in the Civil Rights Movements from the 60s; and in South Africa with the end of apartheid. In Brazil, the fight against military dictatorship and the re-democratisation process evolved into a fight for rights and the search for equality. ${ }^{44}$

With regard to the division into black (blacks and browns) and white required by affirmative action policies, it is argued that such a distinction lacks a scientific basis and contradicts the evidence of existing racial diversity in Brazil. This may be illustrated with reference to the different shades of 'black' and 'white' apparent and the difficulty generated when this difference exists between siblings and one of them can benefit from the quotas, but the other cannot - as happened in the heated episode created at the University of Brasilia. ${ }^{45}$ On the other hand, it is argued that blindness to colour is a flawed strategy and means ignoring clear discrimination and corresponding social and economic exclusion, as witnessed in Brazil over many years. ${ }^{46}$

\subsubsection{Brief presentation of the Supreme Court decisions and the most important opinions of the different Judges}

\subsubsection{The ProUni decision}

The arguments put forward throughout the public hearing and summarised above, with some support from literature, are reflected in several judgments that followed and which ended in May 2011. Three proposed applications against the University for All programme began in 2008. Whereas one of the cases, the Direct Action on Unconstitutionality (ADI-Ação Direta de Inconstitucionalidade) 3319,47 was dismissed for an absence of locus standi, the other two cases, the ADI 3330, proposed by National Confederation of Teaching Establishments (Confenen), and

See Marcos Chor Maio and Ricardo Ventura Santos, 'Política de cotas raciais, os "olhos da sociedade” e os usos da antropologia: o caso do vestibular da Universidade de Brasília (UnB), Horiz. Antropol. 11, no. 23 (2005), available at <http://www.scielo.br/scielo.php?script=sci_ arttext\&pid=S0104-71832005000100011\&lng=en\&nrm=iso $>$ accessed 25 May 2012.

44 Júnior, 'Instituto Universitário de Pesquisas do Rio de Janeiro', 6-7.

45 Durham, 'Desigualdade Educacional', 4, 6.

46 See Munanga, 'Constitucionalidade das políticas', 5.

47 In Brazil, as in Germany and other countries, the judiciary has the power to declare a legal statute to be unconstitutional in order to strike down the whole legislation or part of it. At the federal level, this is the role (besides other competencies) from the Federal Supreme Court, but also at the state level, legislation enacted by the municipalities and by the State can be submitted to abstract and concentrated control under the state constitution through the State Appeal Courts. 
ADI 3314, proposed by the DEM party, were joined in order to be dealt with as one matter. The application was finally decided on 3 May 2011; by a majority of votes, the rapporteur's opinion (Minister Carlos Britto) was confirmed, the cases were dismissed and the constitutional legitimacy of the programme granted, with a single dissenting vote. The Ministers Joaquim Barbosa, Luiz Fux, Gilmar Mendes and Rosa Weber followed the rapporteur, whereas Minister Marco Aurélio dissented. ${ }^{48}$

The content of the ministers' votes are presented here in a tight synthesis. ${ }^{49}$ Minister Ayres Britto understood that the programme does not harm the Constitution because it aims to compensate for a factual and historical asset and income inferiority, and that in this context, it is typical for the legislation to make distinctions in pursuit of social balance. Minister Joaquim Barbosa argued that ProUni was congruent with several constitutional values promoting the reduction of social inequalities, and that considering the unfilled vacancies at private universities, the distribution of scholarships to low-income students, according to the levels foreseen in the programme, would be an important factor for advancing social inclusion. Another element considered is the increase in the percentage of students, according to official research, who find work after receiving the scholarship, in comparison with the number employed at the time of entry into the programme. Moreover, he considered that the cost of a scholarship is lower than the price paid by the State to support a student at the public universities. The minister challenged the allegation that university autonomy was threatened, arguing that participation in the programme is not mandatory. He also considered that participation brings tax benefits and also that providers of private sector education were in any event not free to do as they pleased since the exploration of education by the private sector is governed by article 209 of the Constitution. Both Minister Luiz Fux and Minister Rosa Weber argued that to oppose quotas would be damaging to the principle of equality, pointing out that it is fundamental to attend to the demands of equality, treating in an equal way the equal and the unequal, unequally. ${ }^{50}$ In addition, they considered the paradox of public school students not being able to enter public universities, which are the best in the country, owing to the poor public school system. The dissension of Minister Marco Aurélio was in the sense that the provisional Act (called Medida Provisória in Portuguese) providing for the programme of quotas had several shortcomings - in

48 Federal Supreme Court, 'Supremo declara constitucionalidade do Pro Uni' (Notícias STF, 3 May 2012), available at <http://www.stf.jus.br/portal/cms/verNoticiaDetalhe. asp?idConteudo=206553\&tip=UN $>$ accessed 22 May 2012.

49 Federal Supreme Court, 'Ministro Carlos Ayres Britto vota pela constitucionalidade do ProUni' (Notícias STF, 2 April 2008), available at <http://www.stf.jus.br/portal/cms/ verNoticiaDetalhe.asp?idConteudo=85986\&caixaBusca=N > accessed 22 May 2012; Federal Supreme Court, 'Supremo declara constitucionalidade do Pro Uni'.

That maxim is also highlighted in Minister Ayres Britto's vote. 
that it did not respect the requirements of urgency and of relevance previewed in the Constitution and because it regulated tax matters (providing for tax exemptions to universities that join the programme), which could just be done by a special statute. Besides this, the Minister saw in the sanctions foreseen in case of non-compliance on the part of the institutions, a violation of university autonomy.

\subsubsection{The University of Brasilia case}

The other case decided by the Supreme Court was filed in 2009, by the Democrat Party (DEM), through the ADPF (Argüição de Descumprimento de Preceito Fundamental) action $186 . .^{51}$ The applicant was against the policy of ethnic-racial quotas for the student selection at the University of Brasilia (UnB). The ministers unanimously found the action to lack grounds..$^{52}$ Indeed, a synthesis of the request discloses that among the main arguments used by the author of the action were that quotas constituted: a violation of the precepts against discrimination and racism; a violation of equality and of the equality in teaching opportunities; a violation of the meritocratic criterion, which assures access to higher teaching levels according to the capacity of each one; and in addition, a violation of the universal right to education. Besides, it was claimed by the Ministers that the university had exceeded its competence in regulating such issues and had violated the principle of legality, for the quota policy was introduced by means of an internal decision of the university and not created by a legal statute, which is relevant because the adoption of affirmative action results in limiting third party rights. ${ }^{53}$

From this brief synthesis, we can conclude that arguments contrary to the quota system of the University of Brasilia do not entirely agree with the ones used in an attempt to demonstrate the unconstitutionality of The University for All Programme, which is why the votes of the Supreme Court Ministers also present a partially distinct content, being hereinafter addressed in a summarised way. ${ }^{54}$

51 The ADPF is a kind of special action created by the Constitution and regulated by Federal Law (Law 9882/1999) to allow certain state and social actors to bring a complaint directly to the Supreme Court in cases involving the violation (besides public actors) of fundamental dispositions of the Federal Constitution.

52 Federal Supreme Court, 'STF julga constitucional política de cotas na UnB' (Notícias STF, 26 April 2012), available at <http://www.stf.jus.br/portal/cms/verNoticiaDetalhe. asp?idConteudo=206042\&tip $=\mathrm{UN}>$ accessed 22 May 2012.

53 Democratas, 'Democrats Initial Petition of ADPF 186, filed in the Federal Supreme Court' (2009) 3, available at <http://www.stf.jus.br/portal/processo/pesquisarProcesso.asp> accessed 29 May 2012.

54 Federal Supreme Court, 'STF julga constitucional política de cotas na UnB' (n 49), available at <http://www.stf.jus.br/portal/cms/verNoticiaDetalhe. asp?idConteudo $=206042 \&$ tip $=U N>$ accessed 22 May 2012. Federal Supreme Court 
The first to vote was the reporting judge in the case, Minister Ricardo Lewandowski, for whom the implemented policies represented the means to attain a plural and diversified environment to overcome social distortions that had been historically consolidated. Minister Luiz Fux emphasised that the Constitution imposes the duty to repair previous damage in relation to blacks, ${ }^{55}$ by virtue of the fundamental objective of building a free, fair and cohesive society (article 3, I of the Constitution), and that the quota policy fulfils the constitutional duty of the State towards education, ensuring 'access to higher levels of education, research and the artistic creation, taking into account each one's capability'. Minister Rosa Weber, in turn, signaled that the quotas have three tasks:

(a) access to higher education of the representative group not found in a meaningful way;

(b) better understanding of the Brazilian reality and of its conditions to changes; and

(c) transformation of the social means in which the universities are included, in order to provide more chances to whom this reality had been denied.

She also states that it falls to the State to correct situations of concrete inequality so that formal equality may revive its beneficial role. Minister Cármen Lúcia Antunes Rocha indicated that affirmative action is a stage and that other measures should be implemented together with the goal so as not to reinforce prejudice. Minister Joaquim Barbosa emphasised that there is no example of a nation that was able to overcome its peripheral condition without fighting social exclusion. Minister Cezar Peluso pointed out that the educational and cultural deficit is due to the institutional barriers to access sources of education. He also cited the fundamental objectives foreseen in the Constitution supporting a legal right to equality. Minister Gilmar Mendes highlighted that using an exclusively racial criterion may allow for blacks with good social economic conditions to benefit from the quotas. Minister Marco Aurélio emphasised that the system must be terminated when the inequalities are overcome.

\subsubsection{The Federal University of Rio Grande do Sul decision}

The third programme of affirmative action analysed and decided by the Supreme Court and that deserves to be pointed out here is the programme of quotas from the

(Informativo 663, 23 a 27 de abril de 2012), available at <http://www.stf.jus.br/arquivo/ informativo/documento/informativo663.htm> accessed 29 May 2012.

55 In the same sense of these two arguments, Minister Gilmar Mendes points out the reduced number of blacks results from a historical process, arising from a slave-based model and the low quality of public schools. 
Federal University of Rio Grande do Sul (UFRGS). In the trial, the Extraordinary Appeal (Recurso Extraordinário 597285) ${ }^{56}$ was brought by a student who questioned the quota system from UFRGS in which the university:

allocates $30 \%$ of 160 vacancies to candidates coming from public schools and to the blacks who have also studied in public schools (being $15 \%$ to each), besides the 10 vacancies to the indigenous. ${ }^{57}$

The system of quotas was applied for the first time in 2008. As to the arguments of the plaintiff, a student who felt harmed by the system of quotas complained of an absence of formal law authorising the affirmative action, since it was devised by an internal act from the university. Besides, it was alleged to be an offence to the principle of equality, for the system of quotas represents inverted discrimination. As in the other cases decided, quotas were asserted to be a transgression of the democratic and republican principle of merit, which must guide access to higher education. It also was claimed that the quota system violates the principle of proportionality. ${ }^{58}$

The rapporteur, Minister Ricardo Lewandowski, decided that the system adopted by the university was constitutional. Besides referring to the elements of the adjudication related to the system of quotas taken by the University of Brasilia, UnB, (ADPF 186), he refuted the argument that there was a need for formal law, stating that the Law of Directives and Bases of Education (Lei de Diretrizes e Bases da Educação - LDB) leaves to the universities the establishment of the selection criteria as well as the adoption of affirmative action by the universities which is according to the didactic and scientific autonomy granted by the Constitution. Ministers Rosa Weber, Luiz Fux, Joaquim Barbosa, Gilmar Mendes, Celso de Mello, Ayres Britto, Dias Toffoli, Cezar Peluso and Carmem Lúcia Antunes Rocha concurred with the rapporteur. Minister Marco Aurélio dissented. ${ }^{59}$

Minister Rosa Weber claimed that the affirmative action programme was in absolute accordance with the Constitution, which values the dignity of the human being

56 The so-called Extraordinary Appeal (Recurso Extraordinário) is the regular way to access the Supreme Court in the domain of judicial review from decisions taken by ordinary courts at both federal and state level and by other Superior Federal Courts in cases in which the Constitution is at stake.

57 Federal Supreme Court, 'STF confirma validade de sistema de cotas em universidade pública' (Notícias STF, 9 May 2012), available at <http://www.stf.jus.br/portal/cms/ verNoticiaDetalhe.asp?idConteudo=207003\&tip=UN $>$ accessed 22 May 2012.

58 Petição do RE 597285 Gionave Pasqualito Fialho v Universidade Federal do Rio Grande do Sul [2008], available at <http://www.stf.jus.br/portal/processo/pesquisarProcesso.asp> accessed 29 May 2012.

59 Federal Supreme Court, 'STF confirma validade de sistema de cotas em universidade pública'. 
and has as a fundamental objective the eradication of poverty and the reduction of social and regional inequalities. Minister Luiz Fux considered the criterion adopted by UFRGS to be superior to the ethnic-racial quotas and pointed out that public school students and Afro-descendants have difficulty entering a public university. Minister Gilmar Mendes, on the other hand, pointed out that the system may be discriminatory in some units of the federation; and cited the example of the 'Colégio de Aplicação' and of the 'Colégio Militar', which although being public schools, could be more selective than the private schools - a reason for defending a re-evaluation of the system. Minister Celso de Mello pointed out the objective to build a fair, free, fraternal and supportive society, envisaged not only in the Constitution, but also in international instruments, aimed to reach equality in the future, despite seeming to create inequalities in the present. Minister Ayres Britto argued that it is the State's duty to 'fight poverty and marginalisation, promoting the social integration of the disadvantaged sectors'. Minister Marco Aurélio, dissenting, believes there are no reasons for quotas in favour of students coming from public schools. He maintains that there is a difference between seeking equality taking into account race and gender and the creation of distinction according to the school of origin. He argues that one must not presume that public schools do not ensure access to the university and that it would not be just the less fortunate the ones that studied in such schools. ${ }^{60}$

The three decisions presented reveal that the Supreme Court, in general terms and with minor internal differences, have recognised the constitutionality of the policies of affirmative action and have endorsed the system of quotas practised, but these cases also demonstrate that there are questions that remain unanswered. Permanent monitoring and a differentiation of cases, when necessary, may ensure more safety in terms of an adequate analysis. In the next and last section, we will refer to data about the performance of some of the principal programmes of affirmative action in an attempt to come to some (partial) conclusions.

\subsection{Evaluation of affirmative action policies and programmes: challenges and perspectives}

The two questions raised by Ronald Dworkin about affirmative action (does it work and is it fair? $)^{61}$ are also valid for the Brazilian case. As in the US, at least according to Dworkin's evaluation, the answer to both questions is likely to be positive, especially considering that affirmative action measures are very recent

60 Ibid.

61 See Ronald Dworkin, The Sovereign Virtue: The Theory and Practice of Equality (Cambridge: Harvard University Press, 2000), 386 ff, 409 ff. 
and still being implemented, and taking into account their evolution in this first decade in which affirmative action programmes in higher education were created and implemented throughout Brazil. This positive evaluation is not only because the Supreme Court gave support to major affirmative action programmes, but also because the Brazilian Federal Constitution and the social, economic and cultural inequalities presented, indicate that such policies (in spite of some controversy related to certain aspects - for example, the quota system and the use of race as a criterion) are in general mandatory and represent an important instrument to ensure social justice and integration.

Even though it is not possible to obtain information about all existing programmes (there are still experiments being created and submitted to evaluation) and taking into account that the programmes already implemented are to a certain extent different from each other, our purpose in this third and final part of the chapter is to profile some of the results of affirmative action policies in Brazil.

The University for All Programme (ProUni), by far the most important affirmative action policy created in Brazil, focuses on equal access to higher education. As already shown above, it has been a success, considering the number of full and partial scholarships distributed. Without such a policy, hundreds of thousands of students, including a significant number of Afro-descendants, would never have the opportunity to gain a university degree.

Research involving students from the Pontifical Catholic University of Rio Grande do Sul (PUCRS) (the first ProUni group who started a course in 2005) showed that in 878 courses taken by ProUni students, only 13.4 per cent of the students did not pass. If we consider the grades obtained by the ProUni students, 44 per cent reached coefficients above 7.0, and of this percentage, 59 per cent presented a coefficient between 7.0 and 8.0. Considering only the courses offered in the engineering school (245 disciplines), ${ }^{62}$ the conclusion was that the majority of the ProUni students got better grades than they had achieved in the disciplines in which they matriculated. Only 40 of the 245 grades evaluated were lower than the class average - namely, 16.3 per cent. ${ }^{63}$

62 Claudio Luis Crescente Frankenberg and Helena Sporleder Côrtes, 'O impacto do PROUNI sobre a universidade - levantamento e diagnóstico preliminar do rendimento de alunos da primeira turma a ingressar sob essa modalidade de seleção, nos cursos de engenharia da PUCRS' (Anais do XXXIV Congresso Brasileiro de Ensino de Engenharia, Passo Fundo, September 2006) 8.42, 8.46, available at <http://www.dee.ufma.br/ fsouza/anais/ arquivos/8_251_291.pdf> accessed 29 May 2012.

63 Ibid., 8.49. 
The State University of Rio de Janeiro (UERJ - Universidade Estadual do Rio de Janeiro) also implemented an important affirmative action programme. Among 1,558 students who entered through the quota system in 2003 (the first year of the programme), 38.7 per cent came from public schools, while 61.3 per cent were self-declared black and brown students. ${ }^{64}$ In terms of the academic results, the percentage of quota students approved in at least one discipline in the period from the first semester 2003 to the first semester 2005 was 97 per cent, while among the 'regular' (non-quota) students, the percentage was slightly lower - about 96.5 per cent. Insofar as students who failed in at least one discipline are concerned, the quota students followed the general tendency from the whole university, reducing from 29.1 per cent in 2003/1 to 23 per cent in 2005/1.65

The Federal University of Bahia (UFBA - Universidade Federal da Bahia) implemented an affirmative action programme only in 2005. According to this programme, 45 per cent of vacancies are reserved for students who have had three years of schooling at high school and one year at primary school in the public educational system. A second level of the policy requires that between 43 and 85 per cent of the places be reserved for/ self-declared black and brown students and 15 per cent for self-declared white people, while 2 per cent should be reserved for indigenous people. ${ }^{66}$ Research shows that the participation of students coming from public schools has increased from 38 per cent before the creation of the quota system to 51 per cent in $2005 .{ }^{67}$ The university also registered the increase in the numbers of black and brown students (about 43 per cent in 1997, 61.1 per cent in 2004 and 74.6 per cent after the creation of the quota system), with a reduction of the percentage of white students from 40.9 per cent in 2003 to 21.6 per cent in 2005. Since the black population in the state of Bahia represents about 80 per cent, the research indicates that the ideal representivity has not yet been reached. ${ }^{68}$ The difference in academic results obtained by students at the Federal University of

64 Universidade do Estado do Rio de Janeiro (UERJ), 'Retrato do perfil acadêmico dos alunos oriundos de ações afirmativas da UERJ: vestibular 2003 - $1^{\circ}$ semestre’ (Anexo 4, Comissão Própria de Avaliação, Rio de Janeiro 2006) 5-9, available at <http://www.cpa.uerj.br/pdf/ PerfilAlunosCotistasUERJ.pdf> accessed 29 May 2012.

65 Ibid., 10-13.

66 Jocélio Teles dos Santos and Delcele Mascarenhas Queiroz, 'Vestibular com cotas: análise em uma instituição pública federal' Revista USP 68 (2005-2006): 58-9, available at <http:// www.usp.br/revistausp/68/06-jocelio-delcele.pdf> accessed 29 May 2012.

67 Delcele Mascarenhas Queiroz and Jocélio Teles dos Santos, 'Sistema de cotas: um debate. Dos dados à manutenção de privilégios e de poder', Educ. Soc. 27, no. 96 (2006): 717, 727, available at <http://www.scielo.br/pdf/\%0D/es/v27n96/a05v2796.pdf> accessed 29 May 2012.

68 Dos Santos and Queiroz, 'Vestibular com cotas', 68. 
Bahia with and without access through the quota system, as at other universities, is also almost irrelevant - less than one point. In eleven of the eighteen courses with more competition, the quota students got the same or even superior average results. ${ }^{69}$ The programme adopted by the University of Brasilia (UnB) has also followed this tendency and it has been proved that in general there have been no relevant differences between the academic results of quota students and students who entered through the general system respectively. ${ }^{70}$

The experience of the University of Brasilia (UnB) is another example of affirmative action that has been studied and evaluated. A study published in 2009 showed that in spite of the fact that disparities between white and black quota students are lower than those found in society in general (since both black and white students have a similar social, economic and cultural background) the difference still exists and is not irrelevant. ${ }^{71}$ This circumstance and the evidence that race and socio-economic development are closely related was considered an acceptable justification for this kind of race-based policy, even if the conclusion of the study pointed out that there was a (small) difference between quota students and non-quota students in terms of academic performance. ${ }^{72}$

Even taking into account the lack of precise and actualised information about all the dozens of affirmative action programmes created and implemented throughout Brazil in the last decade, the data about the evolution and impact of the ProUni programme is powerful evidence of the success of this broad policy. This programme focuses on students from the lower class in economic terms and in this sense reduces possible side-effects of using racial criteria and does not affect the number of places offered in the public system. It creates a kind of public-private partnership and combines race (Afro-descendancy) with other criteria (poor students from public schools, students with disabilities, indigenous, public school teachers). The proportional impact of the ProUni system and its wide acceptance and positive results are also very important in supporting the opinion that this kind of policy can, in the long term, be even more effective than affirmative action that focuses only on race. Without excluding the quota system, it suggests that this kind of programme could be reshaped by adding variables other than race or skin colour

69 Queiroz and Dos Santos, 'Sistema de cotas', 733.

70 See Claudete Batista Cardoso, 'Efeitos da Política de Cotas na Universidade de Brasília' (Dissertação de Mestrado, Universidade de Brasília 2008) 119-21, available at <http://hdl. handle.net/10482/1891> accessed 22 May 2012.

71 Andrew M Francis and Maria Tannuri-Pianto, 'Using Brazil's Racial Continuum to Examine the Short-Term Effects of Affirmative Action in Higher Education' originally published in Journal of Human Resources 47, no. 3 (2012): 754-84.

72 Ibid. 
and improved by creating better general conditions for quota students after their admission in order to reduce the still-existing (at least according to some of the studies presented) disparities in academic performance when compared with nonquota students, when this is clearly the case.

The fact that the recently enacted Federal Race Statute does not impose a quota system based on race should be taken seriously at least as a guideline for the future. On the other hand, in light of the recent decisions of the Brazilian Supreme Court, it should be underlined that this legislative option cannot be used as an (exclusive) effective argument to strike down former quota programmes. Such a development might only be legitimate if and when other more effective compensatory measures are implemented. That this alternative (focusing on race and other criteria together, and not only race) seems to be the path to be followed, can be shown in light of the recent legislation approved by the Brazilian Federal Congress. ${ }^{73}$ The new federal statute envisages that 50 per cent of vacancies at federal universities should be reserved and must be distributed according to diverse criteria: 50 per cent of the quota should be for students coming from families with a per capita income of 1.5 times the minimum wage; and self-declared black, brown and indigenous people will be included (among the 50 per cent of all vacancies) according to the proportion of their presence in the population of each state where the university is located. The latter measure is very important to ensure the proportional impact of affirmative action in both directions - namely, the proportional representation of black, brown and indigenous people and to avoid an excessive (and disproportional) effect on rights and interests of third parties.

Considering the relatively recent and very diverse practice of affirmative action in Brazil and the new developments (mainly the implementation of the new federal legislation for federal universities), there is a need for further studies monitoring the different affirmative action programmes implemented. The creation of a national data base that allows a systematic and effective analysis and evaluation would also be an important step enabling the formulation of coherent and more effective policies in order to reach the fundamental goals established by the federal constitution namely, a fair and unified society in which racial democracy will not be an unrealistic myth, but something experienced at all levels of Brazilian society. That a race-based quota system should be complemented by other kinds of equality-oriented policies and affirmative action programmes has already been widely perceived and was even mentioned in the Supreme Court judgment. Such policies and programmes would fight the different causes of social, economic and cultural disparities between whites and blacks, and would aim to improve integration in the labour market and in the public sector, promote equal access to qualified primary and high school education,

737 August 2012. 
adequate housing and a fair and effective health system. Affirmative action should not be a goal in itself, but one important and powerful instrument that gives us hope that some day a race-based quota system may belong to the past and be no longer necessary to ensure adequate levels of social justice.

It should also be understood that 'quota policies' and affirmative action propose using a the criterion of 'necessity' - a far more suitable criterion than merit. The main argument for this is that 'merit is an illusion' according to which understanding the role of social and natural lotteries in merit is so persuasive that merit as an absolute criterion becomes unacceptable. The proposal of 'quota policies' is not to abolish meritocracy, but to use 'necessity' (measured by family income, enrolment in public school or self-declaration of skin colour or ethnic origin) as a mechanism to correct biases. Quotas, however, do not eliminate merit, since it is necessary to have merit in the competition between the quota holders. Merit is still the index used for the distribution of vacancies, but 'necessity' is imposed as the correction factor. It is comparable to giving preference to elderly, pregnant women and people with disabilities on waiting lists, where merit is first-come, first-served. And consider also the quota for the disabled in the public service. In these cases, it is also not considered immoral to choose less than the best, since the disabled candidate has more need than other candidates and better grades than those who have similar needs. ${ }^{74}$

All these aspects, although presented very briefly, support the general conclusion that in Brazil affirmative action policies belong to the most important political decisions in the field of equality-oriented policies and are gaining in practical importance. However, to be able to get a broad and clear enough concept about such policies and their effectiveness will take some time, because affirmative action is a very recent development demanding implementation, monitoring and proper evaluation after some experience. For the moment, it might be said that affirmative action in Brazil is responsible for the inclusion of millions in the system of social security, but mainly in the system of higher education, and keeps alive the promise of a more equal society and more social justice.

74 Lincoln Frias, 'As cotas raciais e sociais em universidades públicas são injustas?', in Direito, Estado e Sociedade, no. 41 (jul/dez 2012): 130-56. 

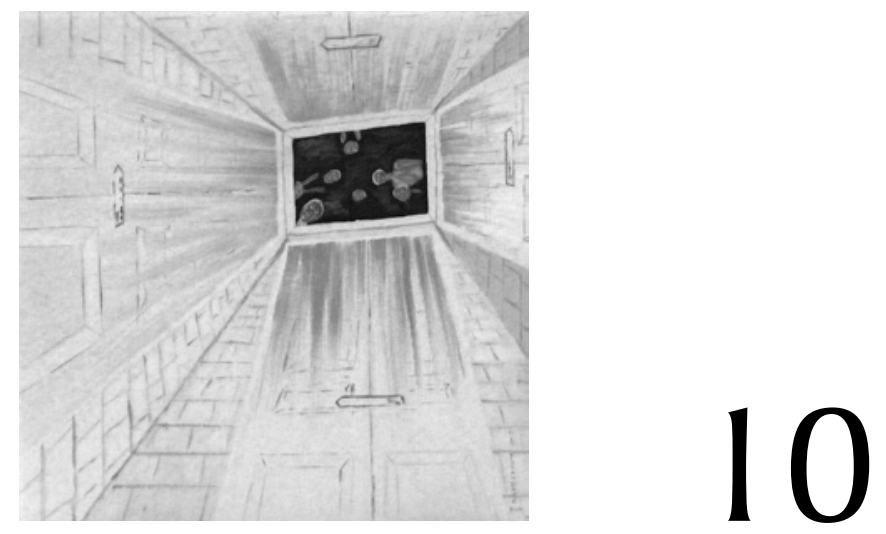

\title{
AFFIRMATIVE ACTION IN NIGERIA
}

\author{
Chioma Kanu Agomo ${ }^{1}$
}

\subsection{Introduction}

This chapter examines the use of the quota system called the Federal Character Principle (FCP) as a form of affirmative action in Nigeria. The rationale for the FCP is to address issues arising from the multi-ethnic structure of Nigerian society. It is argued that although the FCP has to some extent addressed some ethnic, tribal and geopolitical concerns, it has left a critical group, namely women, out of the process. This omission is being filled by legislative and policy frameworks outside the FCP. It is further argued that aside from the constitutional framework, the bulk of the efforts by government to address the gender imbalance through enactment of laws and policies are in direct response to its obligations under international and regional treaties and conventions. It is intended to show further that the journey towards equal access to resources, education, employment and others by all citizens or indigenes, ${ }^{2}$

1 Professor of Law, Faculty of Law, University of Lagos, Lagos, Nigeria.

2 'Indigenes' as used here refer to the different ethnic or tribal groups that make up the Nigerian Nation. 
has been uneven, long and tedious. The conclusion is that women as a distinct group ought to be accommodated in the FCP. This will require political will coupled with a change in thinking patterns to move the issue of equality and affirmative action from the theoretical stage to the practical, result-oriented and measurable stage. This fundamental shift can only happen with a sustained constructive engagement between government and the various stakeholders.

In this chapter, section 10.2 examines the general background relating to Nigeria and includes information on population and ethnic diversity. Section 10.3 examines the legal framework for affirmative action in Nigeria. Section 10.4 examines the genderspecific legal and policy provisions on affirmative action, highlighting the gaps in the application of these provisions. Section 10.5 provides the summary and conclusion.

\subsection{General background}

Nigeria is a multi-ethnic society comprising between 250 and 470 ethnicities. These groups had, before the advent of British colonial adventurers, existed as autonomous groups with different systems of administration and different levels of economic, educational and political development. Nigeria became one country in 1914 as a result of the amalgamation of what the British colonial government referred to as the northern and southern protectorates. Before that date, each protectorate was administered separately, while Lagos, which had been made a protectorate in 1852, was formally annexed and declared a crown colony and protectorate in $1861 .{ }^{3}$ Trade was the focal point and reason for colonisation, ${ }^{4}$ which meant that the complex make-up of the society was not directly in issue until the trading activities of the Royal Niger Company necessitated the opening up of the hinterland. ${ }^{5}$

Nigeria was granted independence from Great Britain on 1 October 1960. At independence, there were three regions, ${ }^{6}$ each with its own government headed by a premier. Nigeria became a Republic in 1963. ${ }^{7}$ In 1967, following the outbreak of the Nigerian Civil War, the regional institutional framework was abolished and replaced with twelve states.

3 The colony of Lagos was initially governed together with the Gold Coast colony (Ghana).

4 Initially, it was trade in human cargo and subsequently trade in palm produce and other commodities.

5 Udo Udoma, History and the Law of the Constitution of Nigeria (Lagos: Malthouse Press Ltd, 1994), 2.

6 Eastern Region, Northern Region and Western Region.

7 The fourth region, Mid-Western Region, was carved out of Western Region in 1964. 
This 'forced union' of unequal partners created right from the outset, tension and fear of domination by the more advanced tribe(s) over the others. The search for solutions during the run-up to independence had culminated in the creation of a federal structure under the 1954 Littleton Constitution. The country was divided into three autonomous regions - Northern Region, Western Region and Eastern Region - with their respective premiers and structures. To a large extent, it allowed each region to chart its own path to economic growth. The North had its groundnut pyramids, the West its cocoa plantations and the East its palm produce. This was the structure until the outbreak of the Civil War in 1967.

The Federal Character Commission summed up the position as follows, and it is worth quoting in full:

Firstly, it was observed that within the Nigerian nation, there were differences in culture, stages of social and economic development and levels of political awareness of the citizens. Secondly, it was observed that disparities existed in the educational development of different sections of the country and this resulted in some sections of the country having recognizable advantage in the employment of their indigenes in the public services. Therefore, in 1954 when Nigeria opted for a federal form of Government, the concept of QUOTA SYSTEM as a policy was adopted in the recruitment of persons into the officers' corps of the Armed Forces and the police as well as in admissions into educational institutions. ${ }^{8}$

The complex ethnic configuration of the country created the need for a deliberate policy aimed at the balancing of the various interests through specific actions. The adoption of a federal system of government was one such action, while the adoption of a quota system within the armed forces and the police was another. However, the need for the equitable distribution of resources, and equitable access to economic, educational and social services remained critical after independence in 1960. The quota system was reviewed in 1967 to include the filling of vacancies in federal schools and institutions, but without a specific body or agency charged with responsibility for its administration.

By 1975, the issue of 'federal character' had become a serious political issue. Thus, as part of its proposals, the Constitution Drafting Committee adopted the term 'federal character' 9 in discussing issues of marginalisation. This was entrenched in the 1979 Constitution. However, this bold step did not eliminate the deep-seated fears and concerns of the minorities and the less developed sections. The Constitutional

8 See <www.federalcharacter.gov.ng/establishment.htm> accessed 4 October 2013.

9 The federal character principle can best be described as a principle which aims at ensuring equitable distribution of public offices and resources equitably along ethnic, geopolitical and sectional groupings to avoid domination by one group or section. See s 318 (1) of the 1999 Constitution. 
Conference constituted by General Sanni Abacha in 1995 recommended the setting up of a Federal Character Commission as the vehicle that would drive the attainment of an equitable and fair distribution of economic resources and posts. ${ }^{10}$

This is the background to the adoption of the quota system known as 'federal character' and which is Nigeria's brand of affirmative action.

Today, there are 36 states and the federal capital territory, Abuja. The predominant tribes or ethnic groups in Nigeria are the Hausa-Fulani in the north, the Igbos in the South East, and the Yorubas in the South West. There are also significant minorities such as the Ijaws, Itshekiris, and the Urhobos in the Niger Delta, and the Efiks and Ibibios in the South. There are majority and minority interests within each ethnic group, thus presenting a web of intricate and delicate interests, each demanding attention. It is therefore not too difficult to see, at a glance, why affirmative action in Nigeria should not be seen as a theoretical and academic issue, but more as a practical and vibrant issue to be addressed functionally and effectively. ${ }^{11}$

The official census conducted in 2006 put the total population of Nigeria at $140,003,542$. The National Bureau of Statistics (NBS) estimates that the population grew from 159.3 million in 2010 to 164.4 million in 2011. The 2006 gender breakdown of the population headcount showed the composition to be 51 per cent male and 49 per cent female, with raw figures of $71,709,859$ and $68,293,683$ respectively. We are not concerned here with the controversies generated by the figures assigned to each state, especially Lagos. However, within the context of affirmative action, we must bear in mind the ratio of male to female and consider whether in law or policy considerations it can be said that affirmative action is in place to redress perceived imbalances between men and women within the Nigerian nation. This is the focus of section 10.4 below.

10 See <www.federalcharacter.gov.ng $>$.

11 Lagos state is an example of one of the states created in 1967 by the States (Creation and Transitional Provisions) Decree No.14 of 1967. It is the smallest state in Nigeria in terms of land mass, but it has the highest urban population (UN-Habitat). Ethnically, it is a Yoruba state, but there are within the Yoruba ethnic group, the Aworis, the Ogus, the Edos, Saros, Brazilians, Kannike/Tapa (collectively known as Ekos or Lagosians, Lagos State Government Official Diary 2012); among others. It is the same in other states of the federation. There is no homogeneous group in Nigeria. Bauchi state is another example. It is one of the northern states, carved out of the old North-Eastern State. It has a total of 55 tribal groups, among which are Hausa, Fulani, Gerawa, Sayawa, Jarawa, Bolewa, Karekare, Kanuri, Fa’awa, Butawa, Warjawa, Zulawa and Badawa (Sunday Punch, Nigeria, 25 March 2012, 54). This explains the fundamental importance of affirmative action in Nigeria. 


\subsection{The legal framework for affirmative action in Nigeria}

Affirmative action represents the various 'public policies and initiatives designed to help eliminate past and present discrimination based on race, color, religion, sex or national origin. ${ }^{12}$ It is seen as a tool or mechanism for tackling inequality in society. Fundamental as it is, affirmative action has never been free from controversy, even in the United States, which is often considered to be the 'land of its birth'. There are voices for and against it from both sides of the racial divide clamouring for attention. ${ }^{13}$ The Nigerian society, which is similar to the American society in composition, faces similar challenges. ${ }^{14}$

\subsubsection{Rationale for affirmative action}

The first and basic question we need to address is: is there such a policy as affirmative action in Nigeria? The simple answer is: yes, Nigeria has affirmative action policies and programmes aimed at bridging the gaps and inequalities between different groups within the polity. ${ }^{15}$ This is has already been established in section 10.1 . The

12 Marquita Sykes, 'Origins of Affirmative Action', National NOW Times, August 1995, available at <http://www.nor.org/nnt/08-95/affirmhs.htm> accessed 26 March 2012).

According to Sykes, initially civil rights programmes were used to assist African Americans to become full citizens of the United States - in other words to integrate them into American society. Although the Thirteenth Amendment to the Constitution made slavery illegal; the Fourteenth Amendment guaranteed equal protection under the law and the Fifteenth Amendment outlawed racial discrimination in access to voting.

13 See, for example, Charles V Dale, 'Federal Affirmative Action Law: A Brief History', CRS Report for Congress Order Code RS22256, 13 September 2005, available at <http://fpc. state.gov/documents/organization/53577.pdf> accessed 26 March 2012.

14 For example, Federal Ministry of Justice, Abuja, The 4th Periodic Country Report: 2008-2010 on the Implementation of the African Charter on Human and People's Rights in Nigeria, August 2011; UN Women: United Nations Entity for Gender Equality and Empowerment of Women, In Pursuit of Justice: Progress of the World's Women 2011-2012; United Nations Development Programme: Nigeria, Report of the Northern Zone Women's Consultation on the Electoral Reform, 2007; National Gender Policy 2007; The Nigeria CEDAW NGO Coalition Report submitted to the 41 st Session of the United Nations Committee on the Elimination of All Forms of Discrimination against Women Holding at the United Nations Plaza New York, 30 June-18 July 2008; Nigerian NGO Coalition on CEDAW Report for the Forty First (41st) Session of the Committee on the Elimination of All Forms of Discrimination Against Women, CEDAW and Accountability to Gender Equality in Nigeria: A Shadow Report, (Lagos, Nigeria: WomenAid Collective (WACOL) with the support of Heinrich Boll Foundation, 2008).

15 Abdul Raufu Mustapha, 'Institutionalising Ethnic Representation: How Effective is the Federal Character Commission in Nigeria?, CRISE Working Paper No. 43 June 2007, Centre for Research on Inequality, Human Security and Ethnicity, Department of International Development, University of Oxford. 
need and justification for affirmative action has also been touched upon briefly. However, it is worth restating:

Nigeria is inhabited by 470 ethnic groups, which are distinguished by language, customs and religious beliefs and vary in size, power and influence. Groups in the southern region of the country have traditionally had much higher levels of education and employment in the public sector than groups in the northern region. Much of the country's politics revolves around methods of preventing or resisting fears of domination of one region or ethnic group over others. To cope with the problems created by its multi-ethnic society, and to encourate (sic) a spirit of 'unity in diversity', successive constitutions of Nigeria have included specific provisions to promote power sharing, and to protect groups considered to be relatively disadvantaged. ${ }^{16}$

The various ethnic groups that were brought together to form one political entity were and still are at different levels of development, economically, educationally, politically and socially. Affirmative action is needed to address these inequalities. Thus the dismantling of the regional structure of governance can be said to have been a form of affirmative action designed to offset past discrimination. ${ }^{17}$ It is arguable whether this was indeed the case and whether it can be said that policies put in place between 1967 and 1979 did indeed compensate marginalised groups for past discriminatory actions. ${ }^{18}$

However, in the eyes of many, 1979 is considered to be a watershed year in the history of affirmative action in Nigeria because affirmative action as a policy and concept first became entrenched in the vocabulary of federalism and power and resource sharing in the 1979 Constitution. ${ }^{19}$ Babawale pointed out that the phrase 'federal character' entered into Nigerian political vocabulary for the first time in 1978 when it was mooted by the Constitution Drafting Committee as a means of promoting 'national loyalty in a multi-ethnic society. ${ }^{20}$ The constitutional provisions specifically provided for respect for federal character in the allocation of posts within the public service including employment. In 1996, the Abacha

\section{Ibid.}

17 Ibid., 8.

18 The events culminating in the Nigerian civil war of 1967-70 are traceable to allegations and counter-allegations of marginalisation, unequal access to national resources and facilities. The division of the regions into states was intended to assuage the grievances of the affected groups, and to bring development nearer to the people. Continued agitation led to further fragmentation and creation of more states.

19 See section 14(3), sections 135, 157, 197(2) and 199.

20 See TA Babawale, 'Federal Character Commission: An Evaluation', available at <http:// www.academia.edu/3682579/FEDERAL_CHARACTER_COMMISSION_AN_ EVALUATION $>$ accessed 4 January 2014. 
government promulgated the Federal Character Commission as an institution charged with responsibility for ensuring that federal character is observed in all relevant areas of public service.

\subsubsection{The Federal Character Commission}

It is not intended here to go into a detailed examination of the Federal Character Commission. Its functions and powers are highlighted to show that while successive governments have taken some concrete steps aimed at bridging the gap between the ethnic groups in the areas of education, economic and social development and appointment into strategic positions in the public service at all tiers, there is a glaring omission of a vulnerable group, namely women. It is obvious that the need to redress gender inequality was not in the agenda of the Federal Character Commission. The issue of gender equality and affirmative action will be addressed in section 10.4.

The Federal Character Commission was established by Act 34 of 1996:

to implement and enforce the Federal Character Principle of fairness and equity in the distribution of public-posts, socio-economic amenities and infrastructural facilities among the federating units of the Federal Republic of Nigeria.21

The stakeholders are said to be ' $\mathrm{t}]$ he Nigerian public, federal, state, FCT, local government, area council, authorities, government establishments, civil society, and indigenous communities'. Paragraph $8(1)$ (a) of section C, Part 1 of the Third Schedule to the Constitution of the Federal Republic of Nigeria enjoins the Federal Character Commission to:

work out an equitable formula, subject to the approval of the National Assembly, for distribution of all cadres of posts in the Public Service of the Federation and of the States, the Armed Forces of the Federation, the Nigerian Police Force and other Governmental Security Agencies, Governmentowned Companies/Parastatals of the States,

and to 'promote, monitor and enforce the compliance with the principles of proportional sharing of all bureaucratic, economic, media and political posts at all levels of Government.'

It is understandable that there is no specific mention of women or gender-specific group since the equality of the sexes is taken as given under the Constitution of the Federal Republic of Nigeria.

21 The Presidency Federal Character Handbook, ii. 
The Commission's brand of affirmative action is the quota system. ${ }^{22}$ Section 4 of the Federal Character Commission (Establishment, ETC) Act ${ }^{23}$ states that the functions of the Commission are:

(a) to work out an equitable formula, subject to the approval of the President, for the distribution of all cadres of posts in the civil and the public services of the Federation and of the States, the armed forces, the Nigeria Police Force and other security agencies, bodies corporate owned by the Federal or a State Government and Extra-Ministerial Departments and parastatals of the Federation and States;

(b) to promote, monitor and enforce compliance with the principles of proportional sharing of all bureaucratic, economic, media and political posts at all levels of government;

(c) to take such legal measures including the prosecution of the heads or staff of any Ministry, Extra-Ministerial Department or agency which fails to comply with any federal character principle or formula prescribed or adopted by the Commission;

(d) to work out (i) an equitable formula, subject to the approval of the President, for distribution of socio-economic services, amenities and infrastructural facilities; (ii) modalities and schemes, subject to the approval of the President, for redressing the problems of imbalances and reducing the fear of relative deprivation and marginalisation in the Nigerian system of federalism as it obtains in the public and private sectors;

(e) to intervene in the operation of any agency of the Federal Government, subject to the approval of the President, where in the opinion of the Commission the function of the agency concerned is relevant to the functions of the Commission and the Commission is of the opinion that it is not being effectively implemented;

(f) to advise the Federal, State, and local governments to intervene and influence providers of services, goods and socio-economic amenities to extend such services, goods and socio-economic amenities to deprived areas of the country; to work out an equitable formula, subject to the approval of the President, for the distribution of all cadres of posts in the civil and the public services of the Federation and of the States, the armed forces, the Nigeria Police Force and other;

(g) to ensure that all Ministries and Extra-Ministerial Departments, agencies and other bodies affected by this Act have a clear criteria indicating conditions to be fulfilled and comprehensive guidelines on the procedure for(i) determining eligibility and the procedure for employment in the public

22 Ibid., iii. It was pointed out here that the use of the quota system in Nigeria was introduced by the colonial administration for recruitment into the Nigerian Armed Forces. It was said to be used to prevent one section from dominating the others.

23 Act 34 of 1996. 
and private sectors of the economy; (ii) the provision of social services, goods and socio-economic amenities in Nigeria;

(h) to ensure that public officers shall, in the performance of their functions, adhere strictly to rules and regulations made pursuant to this Act;

(i) to advise the Federal Government of Nigeria on the structure and rationalisation of any Ministry, Extra-Ministerial Department or agency; and

(j) carry out such other functions as the President shall, from time to time, assign to it.

Section 4(2) spells out the posts that must be strictly filled by quota under the Federal Character Act in these words:

(2) For the avoidance of doubt- (a) the posts mentioned in paragraphs (a) and (b) of subsection (1) of this section shall include those of the Permanent Secretary in the Civil Service of the Federation or the State Civil Service, Directors-General in Extra-Ministerial Departments and Parastatals, Directors in Ministries and Extra-Ministerial Departments, Senior Military Officers, Senior Diplomatic Posts, Managerial Cadres in the Federal and State Parastatals, bodies corporate, Agencies and Institutions; and (b) socioeconomic services, amenities and facilities mentioned in paragraph (d) of subsection (1) of this section include those in the sectors of education, electricity, health, commerce and industry, telecommunications, transport and youth development. ${ }^{24}$

\subsubsection{Powers of the Commission and guiding principles}

The powers of the Federal Character Commission are enormous and far-reaching. It has powers to 'formulate and provide guidelines for Government agencies and other employers and provider of services and socio-economic amenities', among others. ${ }^{25}$ The guidelines formulated for the distribution of all cadres of posts are detailed. ${ }^{26}$ In the distribution of posts, services and amenities, the Commission advocates equitable representation of all states in all national institutions and in public enterprises and organisations. It also provides that the best and most competent persons shall be recruited from each State of the Federation to fill posts reserved for the indigenes of that State or the Federal Capital Territory'.

There is no doubt that the scope of functions and powers of the Commission are pervasive. As can be easily deduced from the various provisions, it embraces all tiers of government institutions, redistribution of social services, allocation of infrastructural development agenda and specifics, job redistribution and application of the principle

24 Section $4(2)(b)$.

25 See section 5(1)(a)-(h).

26 See 'Guiding Principles and Formulae for the distribution of all cadres of Posts', in the Federal Character Commission Handbook, 14. 
of proportionality or quota in Federal Civil Service Appointments. ${ }^{27}$ It is equally not in doubt that the FCP has achieved a measure of success in the redistribution of jobs, educational placements, and socio-economic services. Obiyan and Akindele are of the view that:

Regardless of the nature and extent of defects that may characterise the federal character principle in theory and practice in Nigeria, it has, for quite sometime, come to represent an important element in the country's policies and politics. ${ }^{28}$

One of the criticisms against the continued application of the FCP in its present form is that it has sacrificed merit on the altar of so-called quotas. Admission into federal colleges and institutions of higher learning is one area where the continued relevance of the quota system has been called into question. The quota application in the admission of candidates into federal universities, polytechnics and colleges of education, among others, operates by admitting 45 per cent on merit, 35 per cent by catchment and 20 per cent from the educationally least developed states (ELDS). All the states within the Northern Region fall within the ELDS, while only Ebonyi State in the South East, and Rivers and Baylesa and Cross River in South-South are counted as part of the ELDS. The effect of this principle is that many candidates with high scores who should come in on merit are denied admission based on quota.

In a recent publication, a commentator decried the application of the FCP in the admission process for the 104 federal government colleges, whereby candidates from 'educationally advanced' states such as Anambra, Imo, Delta Lagos and Plateau among others, must score between 139 and 97 to gain admission, while those from Bauchi, Jigawa, Yobe, and Zamfara needed to score between 9 and 2 respectively for the male, and between 27 and 11 for the female. ${ }^{29}$

27 Mustapha, 'Institutionalising Ethnic Representation'.

28 A Sat Obiyan and ST Akindele, 'The Federal Character Principle and Gender Representation in Nigeria, J. Soc. Sci. 6, no. 4 (2002): 241-6, available at <www.krepublishers.com/02Journals/JSS/JSS-06-0-000-000-2002-Web/JSS-06-04-237-02Abst-PDF> accessed 12 March 2012.

29 See <http://www.ngrguardiannews.com/education/125609-sonaiya-decries-use-of-federalcharacter $>$ accessed 11 October 2013. See also Segun Olugbile, 21 June 2013, available at <http://www.Punchng.com/education/unity schools-stakeholders-seek-abolition-offederal-character/> accessed 14 September 2014; Ahmed Babatunde Adeoaun, 'Federal Character Principle and National Integration: A Critical Appraisal', International Journal of Politics and Good Governance, 2, no. 2.4, Quarter IV (2011), available at <online research journals.com/ijo/pagg/art.89.pdf> accessed 14 September 2014. I recall that my younger son was affected by this principle when he scored $78 \%$ in the national common entrance examination into federal schools, but he was not invited for the next stage of the selection process on the ground that he did not meet the cut-off for his state of origin, Abia State, 


\subsubsection{Federal appointments and zoning}

Appointments into federal government ministries and agencies, and recruitments into the public service are based on federal character. For this purpose, the federation is divided into six geopolitical zones. They are: North-East, North-West, North-Central, South-West, South-East and South-South. The three northern zones represent the old Northern Nigeria under the pre-1967 regional system of government. The southern zones represent the old Western and Eastern states. There are nineteen states within the three northern zones, and seventeen states within the southern zones. The guiding principle applied by the Commission in the staffing of offices at the national level is that indigenes of a state

shall not constitute less than 2.5 per cent or more than 3 per cent of officers and staff at the head office of any national institution, public enterprise or organisation. In the case of branches or local offices not less than 75 per cent [...] shall be indigenes of the catchment area. ${ }^{30}$

There will not always be enough vacancies to accommodate every state of the federation. The guiding principle to deal with such shortfalls, is to share the vacancies among the zones. An indigene of a zone is to constitute not less than 15 per cent or more than 18 per cent of the total. Similar guidelines apply within a zone. The rationale is to ensure a just, fair and equitable distribution of resources, offices and jobs across the ethnic groups and zones. However, the reality is that there is agitation over alleged marginalisation even by the major ethnic groups. It is argued that in the quest to satisfy the ethnically diverse interests, merit has been sacrificed.

Zoning has also not ensured equitable representation of the various interest groups. ${ }^{31}$ Policy Brief 15 of the Inter-Regional Inequality Facility, ${ }^{32}$ while acknowledging the presence of 'a strong ideological commitment in Nigeria to the country's form of affirmative action, in the form of its Federal Character Principle', nevertheless highlighted the absence of a strong political will as an obstacle to its implementation, which

reflects the politics of patronage that is practiced, and the lack of transparency and accountability mechanisms. In addition, positive discrimination for one group is often read as negative discrimination by others. ${ }^{33}$

although he was born and raised in Lagos. His classmate and friend from Cross River State who scored $65 \%$ was invited. My son could not understand why he had to be sidelined. He felt cheated. Many still feel that way today.

30 See <http://federalcharacter.gov.ng/server_article.php/GUIDING-PRINCIPLES> accessed 12 October 2013.

31 Babawale, supra.

32 Jibrin Ibrahim, 'Affirmative Action: Nigeria', Policy Brief 15, February 2006 (London: Overseas Development Institute, 2005).

33 Ibid. 
Sonaiya while acknowledging that the FCP as enshrined in the Constitution is intended 'to ensure that in the running of the affairs of the nation, no group of people from a particular locality would feel excluded, due to lack of representation', is of the opinion that it 'is wrongheaded and flawed in its presumed justification. ${ }^{34}$ It is particularly flawed in its exclusion of gender. The focus of the next section is therefore on gender and affirmative action. It is important to explore briefly why Obiyan and Akindele pointed out that the FCP is not intended to reverse the existing gender imbalance in Nigeria ${ }^{35}$ before going on to examine the legislative and policy framework for gender and affirmative action.

\subsection{Gender and affirmative action}

In this section, the different legislative and policy measures taken by government are highlighted and thereafter the impact or lack of impact of some of these laws and policies on women's needs are examined. ${ }^{36}$ The mandate of the Commission is 'to ensure a strong, virile and indivisible Nation, based on fairness, equity and justice;'37 through equitable sharing of posts in the public service without sacrificing merit. The Commission's only provision specific to women is the opposite of affirmative action. Indeed, it discriminates against women by providing that a married woman can only claim her state of origin for the purpose of implementation of the FCP on appointments at the national level. ${ }^{38}$ There is no provision requiring a certain percentage of appointments or vacancies to be reserved exclusively for women. One may argue that there is no need for specific affirmative action since women are indigenes of one state or another. But that view cannot stand against the general

34 The procedure for recruitment into the federal public service by the Commission is detailed. For example, it provides that 'only candidates who have met the minimum requirements for each position shall be short-listed for written tests/oral interview or any other selection process. However, it goes further to state that under no circumstances should an unqualified candidate be short-listed purportedly on the basis of Federal Character consideration. This sounds unassailable but it is qualified by the provision that 'a candidate who has met the basic minimum requirement shall be eligible to compete for posts reserved for his state and/ or Zone, and shall not be penalized or disadvantaged in favour of a candidate from another State or Zone who may possess higher qualifications.'

35 Obiyan \& Akindele, 'The Federal Character Principle and Gender Representation in Nigeria', 242.

36 It is not feasible to cover every aspect of gender- and equality-related issues within the framework of this chapter. We have therefore selected employment, health, gender-based violence, education and political representation. Even in these areas, discussion cannot be in any detail..

37 Stated Vision of the Federal Character Commission, see The Presidency, Federal Character Commission Handbook, ii.

38 Ibid., 17. 
international human rights advocacy on mainstreaming of gender concerns in appointment and decision-making processes.

\subsubsection{Legal and policy framework for gender equality}

Section 14(1) of the Constitution of the Federal Republic of Nigeria 1999 states that the Federal Republic of Nigeria shall be based on democracy and social justice. According to section 14(3):

[t] he composition of the Government of the Federation or any of its agencies and the conduct of its affairs shall be carried out in such a manner as to reflect the federal character of Nigeria and the need to promote national unity, and also to command national loyalty, thereby ensuring that there shall be no predominance of persons from few States or from a few ethnic or other sectional groups in that Government or in any of its agencies.

Why was there no mention of the need to redress gender imbalance at all levels and in all sectors of the Nigerian society as envisaged by the FCP? The answer is not hard to find. Atsenuwa puts it succinctly in these words:

To the extent that constitutional rests on what the Constitution states, it is understandable that there should be a lot of interest in ascertaining the inclusivity of any process that leads to the making of the constitution. This is necessary because it helps to determine the balance of opportunities made available to the various interests (which often times are conflicting) in society to negotiate the final outcome. [...] Ensuring the women's participation in the process of making the constitution does not only assure that women's voices are heard and women's interests are negotiated towards inclusion in the constitution, it means also that should constitutionalists identify a need to have recourse to constitutional history in order to propound the intention of the constitution's framers, these 'other' voices and these 'other' interests will be documented as part of history. In other words, constitutional history will be as much her story as it is his-story. ${ }^{39}$

The various Constitutions of Nigeria - from the Independence Constitution of 1963 to the current one, the 1999 Constitution - have been 'his-story' and not 'her story'. What therefore appears on the surface to be gender neutral ${ }^{40}$ is biased against

39 Ayo Atsenuwa, 'Constitutionalism and Feminism: Stepping Stones or Implements on the Long Road to Freedom for Nigerian Women?', Jadesola Akande Memorial Lectures Series (Nigerian Institute of Advanced Legal Studies, 2011), 25, 29.

40 Section 17 (among others), provides that the state social order is founded on ideals of freedom, equality and justice. Every citizen shall have equality of rights, obligations and opportunities before the law. Sanctity of the human person shall be recognised and human dignity shall be maintained and enhanced. Chapter IV on fundamental rights enshrines the right to life (s 33), the right to dignity of the human person (s 34), and the right to freedom from discrimination (s 42), among others but the reality is at variance with the law. 
women. ${ }^{41}$ Women have never been given an equal opportunity to play tangible roles in any of the constitution-making debates ${ }^{42}$ that determine the majority of the laws and policies affecting their lives. There is an obvious gap between what the Constitution provides and reality. It is submitted that the exclusion of gender from alongside ethnicity in the search for fair, just and equitable distribution of resources and appointments at the national level cannot now be justified.

\subsubsection{Some legal and policy measures on affirmative action}

It is important to stress that even though the FCP does not include genderspecific provisions as an attempt to redress the existing gender imbalance, there are instruments that exist to promote gender equality/equity concerns in Nigeria.

The following instruments have been put in place to implement the provisions of the African Charter: ${ }^{43}$ the Constitution of the Federal Republic of Nigeria, 1999; National Agency for the Control of HIV/AIDS (Establishment) Act 2007; Child

41 Ayodele Atsenuwa, 'Gender \& Law: Engaging Custom and Customary Law Towards A New Feminist Legal Agenda In Nigeria', Legal Research and Resource Development Centre (2009); section 29 of the Constitution, which provides for the right of renunciation of citizenship from the age of majority, states, 'any woman who is married shall be deemed to be of full age.' Without any functional affirmative action making the age of 18 the minimum age for marriage, section 29 connotes that a child bride regardless of age is deemed to be of full age. Section 29(1) of the Constitution gives every citizen of Nigeria who is of 'full age', the right to renounce his or her Nigerian citizenship through a declaration. The point being made here is that whereas 'full age' means 18 years and above according to s 29(4)(a), s 29(4)(b) states 'any woman who is married shall be deemed to be of full age'. This provision is considered discriminatory. In the northern part of the country, girls far below the age of 18 years are sometimes given away in marriage. The qualifying age should apply to all citizens, male and female.

42 In the Memorandum submitted to the Senate Committee on the Independent National Electoral Commission (INEC) by the Citizen's Forum for Constitutional Reforms (CFCR), compiled by Ikubaje John, with the support of Jide Ojo, Sam Egwu, and Olola Bamidele in July 2005, it was pointed out on page 3, that 'although committees and commissions have always been established, unpopular governments usually handpicked the members of these bodies, with their mandates defined in such a way that precludes the consultation, mobilization and education of critical constituencies, whilst nation-wide dialogues and debates were never on the agenda' (quoting Julius Ihonvbere, 'Constitutionalism in Africa: Issues, Challenges and Opportunities', paper presented at CDHR Conference on Constitutionalism and State Reconstruction in West Africa, 2000). Women constitute a visible part of this disadvantaged critical mass.

43 Nigeria signed the Charter on 31 August 1982, and ratified it on 22 June 1983. It has also been domesticated. See African Charter on Human and People's Rights (Ratification and Enforcement) Cap A9 Laws of the Federation of Nigeria, 2004 (it is also the same as Cap 10 Laws of the Federation of Nigeria, 1990). The list of laws and policies is not exhaustive. 
Rights Act 2007; Trafficking in Persons (Prohibition) Law and Administration Acts, 2003 as amended (2005); National Human Rights Commission (Amendment) Act, 2011; Universal Basic Education (UBE) Act, 2003; National Health Policy 2004; National Gender Policy on Education, 2008; National Gender Policy, 2007; National Policy on the Elimination of Female Genital Mutilation, 2002; National Policy on HIV/AIDS, 2003; and the National Policy on Poverty Eradication, 2001. ${ }^{44}$

There are also gender-specific state laws. They include: the Malpractices Against Widows and Widowers (Prohibition) Law, 2005; 45 the Law to Prohibit Domestic Violence against Women and Maltreatment; ${ }^{46}$ the Inhuman Treatment of Widows (Prohibition) Law, 2004; ; $^{47}$ the Law Prohibiting Domestic Violence in Lagos State and Ekiti State, 2007;4 the Laws Prohibiting Withdrawal of the Girl Child from School for Marriage; ${ }^{49}$ and the Women's Reproductive Rights Law, 2005. ${ }^{50}$

These laws and policies together with others too numerous to be accommodated here, do show, as the Attorney-General of the Federation and Minister of Justice put it in his preface to the 2008-2010 Report, that the

Federal Republic of Nigeria is committed to the progressive realization of the basic rights and freedoms of individuals and groups as well as their duties enshrined in the African Charter on Human and People' Rights through legislative, policy, [among other measures].

In relation to CEDAW, the NGO Coalition Shadow Report, whilst acknowledging that Nigeria has domesticated the African Charter, nevertheless pointed out that

Despite spirited efforts of women's organizations in some states to domesticate CEDAW, the process of passing the Abolition of all forms of Discrimination Against Women in Nigeria and Other Related Matters Bill, 2006 (CEDAW Bill), drafted from the provisions of CEDAW, into law in Nigeria to make it enforceable was stalled at the National Assembly because of the misinterpretation of Articles 12 and 16.

44 See Nigeria’s 4th Periodic Country Report: 2008-2010 (August 2011), 15, 16, 27.

45 Enacted by Enugu, Imo, Ebonyi and Anambra States.

46 Law No. 10 of 2004 by Cross River State Government.

47 Edo State.

48 Passed by the State House of Assembly but not signed into law. See International Federation for Human Rights, The Nigeria NGO coalition shadow report to the CEDAW committee, 31 July 2008, 6, available at <http://www.refworld.org/docid/48a0007a2.html> accessed 3 September 2014.

49 Kano, Niger, Gombe, Bauchi, and Borno States.

50 Anambra State. 


\subsubsection{CEDAW and affirmative action}

The Convention on the Elimination of all forms of Discrimination Against Women (CEDAW) was adopted on 18 December 1979 by the United Nations General Assembly to protect and promote the rights of women and came into force on 3 September 1981. Nigeria ratified CEDAW in 1985 without reservations. However, the Constitution provides that treaties to which Nigeria is a party must be domesticated under section 12 of the 1999 Constitution. Without domestication, CEDAW cannot be applied in Nigeria. And, 31 years after ratification, Nigeria is yet to domesticate it despite assurance by relevant ministries.

The basic thrust of the Convention is the promotion of equality between men and women. It recognises that women all over the world have been discriminated against in both the past and the present. Article 1 of the Convention defines 'discrimination against women' for the purposes of the Convention to mean

any distinction, exclusion or restriction mode on the basis of sex which has the effect or purpose of nullifying the recognition, enjoyment or exercise by women, irrespective of their marital status, on a basis of equality of men and women, of human rights and fundamental freedoms in the political, economic, social, cultural, civil or any other field.

It advocates institutional measures by way of legislation and policies - including, where necessary, reverse discriminatory measures to provide a level playing field for men and women. It has rightly been described as the central and most comprehensive human rights treaty on the elimination of discrimination against women and the leading modern instrument on women's rights. ${ }^{51}$ Any country that is serious about gender equality needs to make CEDAW an integral part of its domestic laws. Article 11 expressly provides

States Parties shall take all appropriate measures to eliminate discrimination against women in the field of employment in order to secure, on a basis of equality of men and women, the same rights, in particular: (a) the right to work as an inalienable right of all human beings; (b), the right to the same employment opportunities, including the application of the same criteria for selection in matters of employment.

Some specific issues, namely employment, health and political participation, will now be examined briefly to highlight the gap between law/policy and practice.

51 Oby Nwankwo, Civil Resource Development and Documentation Centre (CIRDDOC), 'Briefing on the Domestication of the Convention on the Elimination of all forms of Discrimination against Women (CEDAW)', 1, available at < http://www.aacoalition.org/ domistic_cedaw.htm> accessed 14 March 2012. 


\subsubsection{Gender and employment}

Section 17(3)(a)-(e) of the Nigerian Constitution, 1999 obliges the State to direct its policy towards ensuring that all citizens, without discrimination on any ground whatsoever, have the opportunity of securing adequate means of livelihood as well as adequate opportunity to secure suitable employment. ${ }^{52}$ This is not a guarantee of a right to work. However, article 15 of the African Charter on Human and Peoples' Rights recognises the right to work. Section 42 of the Nigerian Constitution guarantees freedom from discrimination on various grounds, including sex and state of origin. The practice is different. Women are discriminated against. Specific provisions that discriminate against women in relation to employment are still extant in some specific laws - for example, those regulating employment of women in the police force - despite section 42 of the Constitution. ${ }^{53}$

As stated earlier, the Federal Character Commission has elaborate guidelines on recruitment and appointment based on state of origin or geopolitical zone.

Each State shall produce 2.75 per cent of the total work force in any Federal establishment while the Federal Capital Territory shall produce 1 per cent for the indigenes of the Federal Capital Territory provided that the Commission may adopt a range so that the indigenes of any State of the Federation shall not constitute less than the lower limit or more than the upper limit of the range. ${ }^{54}$

It goes further to specify the guidelines for distribution on a zonal basis so that a particular zone does not constitute less than the lower limit or more than the upper limit of the range that governs distribution by zone. Nigeria is divided into six zones, ${ }^{55}$ namely North-Central, North-East, North-West, South-East, South-South and South-West. As the names indicate, three of the zones comprise all the northern states where the Hausa-Fulani predominate, while the southern zones are made up of the majority Igbo and Yoruba ethnic groups, together with numerous vocal and large minority groups. All the zoning arrangements are attempts at streamlining the affirmative action principle.

The glaring absence of guidelines or specific formula within the FCP says much for the lack of political will to mainstream gender issues into the workings of the Commission. This deliberate omission supports the assertion of Fatile and

52 This is one of the non-justiciable provisions under Part II of the Constitution titled 'Fundamental Objectives and Directive Principles of State Policy'.

53 Sections 55 and 56 of the Labour Act prohibit the employment of women at night and underground respectively. See also Chioma Kanu Agomo, 'The Working Woman in a Changing World of Work', Inaugural Lecture Series (Lagos: University of Lagos Press, 2004).

54 Paragraph 6 of the Commission's 'Guiding Principles and Formulae’.

55 Ibid., para 8. 
Adejuwon that although gender as an academic discipline has been publicised, the political content has taken for granted the issue of gender discrimination as it relates to recruitment, training and promotion in the public sector, ${ }^{56}$ and one would add, in the private sector as well. The disadvantaged position of women is reiterated by the Nigeria CEDAW NGO Coalition report. ${ }^{57}$

That report pointed out:

educated females face a lot of discrimination in employment as there is internally constructed gender discrimination in almost all private industries [...] The uneducated females suffer worse fate as their field of specialization, mainly the informal sector, is unregulated by government's policies. ${ }^{58}$

It confirms that discrimination in employment and wages still remain rampant in both the government and private sector despite the fact that Nigeria is a signatory to the International Labour Organisation Convention 111, which deals with discrimination in respect of employment and occupation.

Government's response to the African Commission's concern about the poor level of female representation in all levels of government is that:

Though nationwide statistical data for $2008-2010$ is not yet available, yet efforts have been, and are still being made by all the three tiers of government consistent with the Gender Policy Strategic Framework. The federal Government is implementing affirmative action principle contained in the above policy. ${ }^{59}$

The National Gender Policy is one such step, but it still needs to scratch where the itch is.

56 Jacob Olufemi Fatile, O Adejuwon and Kehinde David, 'Gender Issues in human resource management in Nigerian Public service', African Journal of Political Science and International Relations 5, no. 3 (March 2011): 112-19, available at <http://www.academicjournals.org/ ajpsir $>$. Figures on page 115 of the paper show the gender disparity in appointments at various cadres within the Federal Civil Service.

57 Supra. The Report articulates the position of women article by article, highlighting the gaps and the challenges, and makes detailed recommendations on the way forward. This is a very good example of a private-public partnership. Agitation for affirmative action is being driven by a coalition of NGOs in constructive engagement with government. That is the only way forward. One such NGO is the National Coalition on Affirmative Action (NCAA). This group, through the executive director of the Civil Resource Development and Documentation Centre (CIRDDOC), has been working closely with the National Assembly Committees on Women, the Federal Ministry of Justice and the Federal Ministry of Women Affairs to muster support for the domestication of CEDAW. This is yet to yield the desired result. See <http://www.aacoalition.org/domistic_cedaw.htm> accessed 14 March 2012.

58 Ibid., xii.

59 Nigeria's 4th Periodic Country Report: 2008-2010, 7. 


\subsubsection{Discriminatory practices in the public service}

The Gender Policy 2007, an affirmative action policy, as earlier pointed out, provides for a strategic framework and monitoring measures to enhance women's participation in national development, and in access to employment, justice and information, among others. It can be said that the National Gender Policy is one that was produced with the active and constructive engagement of NGOs. The strategies and expected outcomes are laudable and impressive on paper. ${ }^{60}$ The reality is different. The 4th Country Report on the Implementation of the African Charter on Human and Peoples' Rights in Nigeria confirms this. ${ }^{61}$

The reality is that there are unequal playing fields for men and women. Women do not face the same selection process as men - for example, in selection for jobs in banks and the police. ${ }^{62}$ There are restrictions on unmarried women as to when to marry if employed. Married women also face restrictions on when to get pregnant. Men do not have such restrictions. Women are denied basic rights because of their sex. ${ }^{63}$

Regulation No. 6 of the Public Service Rules Corrected Version 2008, applicable to married foreign service officers, provides that 'Female officers shall enjoy children's benefits when they are divorced and have custody of the children or when widowed'. The implication and indeed the practice is that married women do not as of right enjoy a child benefit. Evidence is often required to show that the woman is maintaining the child in question. There is no corresponding restriction on a male officer. Similarly, regulation No. 120307 provides:

A female officer who is to undertake a course of training of not more than six months duration shall be called upon to enter into an agreement to refund the whole or part of the cost of the course in the event of her course being interrupted on grounds of pregnancy.

This is a complete negation of section 42 of the Constitution, of ILO Convention 111 , and of CEDAW.

There has however been an improvement in maternity rights. ${ }^{64}$ Women in public sector employment now enjoy fourteen weeks' maternity leave instead of the twelve provided for in section 54 of the Labour Act. Similarly, Regulation No. 100219 of the Public Service Rules provides that any female officer who is nursing a child shall be granted two hours off-duty every day for up to a maximum period of six months

60 See pages 46-8 of the government's report taken from the National Gender Policy, 2007, 23.

61 Supra.

62 See the NGO Coalition Shadow Report, supra.

63 Ibid., 41, 42.

64 Ibid., 41, para 5. 
from the date of resumption from maternity leave. This again constitutes a great improvement on the Labour Act provision of two 30-minute breaks per day for the purpose of nursing a baby. ${ }^{65}$ The snag is that these provisions do not extend to the private sector.

The unemployment data provided in Nigeria's 4th Country Report on the Implementation of the African Charter is not disaggregated. Rather it is set out by age group and sector between 1999 and 2008. It is not possible to know the number or percentage of unemployed women ${ }^{66}$ embedded within the general figures.

Nigeria it is yet to domesticate CEDAW, 24 years after ratification. This represents clear evidence of a lack of political will to take concrete steps to redress through affirmative action the disadvantaged position of women.

\subsubsection{Gender and access to health care}

The various laws and policies enumerated in this section together with other key treaties that recognise the right to health (such as the International Covenant on Economic, Social and Cultural Rights (ICESCR), CEDAW, and the Convention on the Rights of the Child (CRC), among others) and to which Nigeria is party, should provide solid springboards for the take-off of a robust health care system for all in Nigeria. But is this the case? The answer is no. It has already been pointed out that the non-domestication of CEDAW is a serious drawback to the effective implementation of affirmative action in Nigeria. The health sector has not fared better than the employment sector. Nnamuchi posits that

Nigeria recognizes the right to health and has committed itself to its protection by assuming obligations under international treaties and domestic legislations mandating specific conduct with respect to the health of individuals within its jurisdiction. ${ }^{67}$

She however also recognises that the robust health sector of the mid-1980s has given way to severe deficiencies. ${ }^{68}$ In specific health and gender-related areas, there have been intervention measures to address such issues as female genital mutilation (FGM), and according to Nigeria's country report, the prevalence of FGM is on a declining trend in Nigeria due to the measures taken so far. The checklist provided

65 See Agomo, 'The Working Woman in a Changing World of Work', 17-20.

66 See Table 6, 'Unemployment Rates by Age Group and Sector', 54.

67 Obiajulu Nnamuchi, 'The right to health in Nigeria, draft report of the Right to Health a Multi-Country Study Project (Law School, University of Aberdeen, December 2007), available at <http://www.abdn.ac.uk/law/hhr/shtml> accessed 27 March 2012.

Ibid. 
by the NGO Coalition Report reminds us that the constitutional health provisions fall within chapter II and its non-justiciable provisions. It goes further to state that despite the various reform efforts within the sector, reproductive health care delivery services for women have not benefitted many women because available facilities are inadequate and poorly maintained. Maternal and infant mortality in Nigeria is still very high. Pregnancy-related deaths account for about 52 per cent of deaths among Nigerian women, and for 10 per cent of global deaths. ${ }^{69}$ There are no laws on family planning in Nigeria except for a policy framework on population that is more concerned with the maximum number of children a woman can have. Seventy-four per cent of contraceptives in Nigeria are being distributed by the Society for Family Health and other NGO and international bodies. ${ }^{70}$

In relation to the control of communicable diseases such as HIV/AIDS, the efforts of government to stem the tide are acknowledged. This is contained in the NGO Coalition report:

$[G]$ overnment's efforts to combat the disease include setting up institutional arrangements such as the Presidential Committee on AIDS (PCA) and the National Agency on the Control of AIDS [...] These institutions also serve as an avenue through which the HIV/AIDS National Strategic Framework for Action 2005-2009 is being implemented. A 3-year HIV/AIDS Emergency Action Plan (HEAP) was also formulated in 2001 and is being implemented. The Nigerian Aid Response Fund/Gender Equality Strategies (NARFEGES) to ensure gender mainstreaming components into HIV/AIDS interaction at all levels in different societal settings were also formulated. Despite these interventions, the HIV/AIDS prevalence in Nigeria is still $4.4 \%{ }^{71}$

Ezeilo's shadow report ${ }^{72}$ also points out that full achievement of the global targets for reduction in maternal and child mortality has not materialised due to continued harmful cultural practices, early marriage and teen pregnancy among others. There is no doubt that steps are being taken at both national and state levels to tackle the myriad health issues that affect the population in general and women and children in particular. Access to health care is a human rights issue and the journey to quality health care and equal access to facilities is still very far from over.

69 NGO Coalition Report, 49. See <http://www.aacoalition.org/domestic.htm>

70 Ibid., 48.

71 Ibid.

72 Ibid. 


\subsubsection{Gender, political representation and participation in governance}

The Federal Character Commission provides that appointment to various categories of political office must be done on the basis of equitable representation of the state of the federation, or zones as the case my be, using the relevant formula. The offices are listed as ministers of cabinet rank; ministers of state; special adviser to the President; chairmen and members of statutory federal agencies. The same principle applies at state and local government level. There is no general provision for women except that married women are to continue to lay claim to their states of origin for purposes of implementation of the FCP. This provision, as already indicated, is grossly inadequate and indeed directly discriminatory. Women should be allowed to choose whether their state is their state of origin or the state of their marriage that is, their husband's state of origin.

Representation of women in politics remains too low. While the National Gender Policy seeks to promote 35 per cent affirmative action for women in politics, the reality is different. In 1999, at the dawn of the return to democracy, participation of women in politics was about 2 per cent. In 2003, it stood at 4 per cent, increasing to 7 per cent in 2007 and 8 per cent in 2011. Of over 10,000 candidates of all political parties, only about 9.1 per cent (909) were women. ${ }^{73}$ The central reason for the continued poor showing and low level of representation is an entrenched cultural attitude. ${ }^{74}$ It is submitted that the application of affirmative action under the FCP will go some way towards redressing the imbalance. One of the principles enshrined in the Protocol to the African Charter on Human and Peoples' Rights on the Rights of Women in Africa is the right to participate in the political and decision-making process. ${ }^{75}$ The Nigerian government is obliged to enact appropriate legislation to combat all forms of discrimination, and among many others, to take positive action to promote the participation of women in politics and decision-making. Some of the measures put in place by government have been highlighted.

\subsection{Conclusion}

This chapter has tried to establish that affirmative action operates in Nigeria through the Federal Character Principle enshrined in the Constitution of the Federal Republic of Nigeria and the Federal Character Act. Its application to address

73 See <http://www.un.org/womenwatch/daw/csw/csw52/statements_mission/nigeria.pdf >.

74 Atsenuwa, 'Gender and the Law: Engaging Custom and Customary Law towards a new Feminist Agenda in Nigeria', 45.

75 The Protocol guarantees Nigerian women the right to dignity, the right to life, integrity and security of persons, and the right to education and training, among others. 
inequalities in development, education and employment among the various ethnic groups and zones has been highlighted. Furthermore, it has been argued that the FCP is defective in its impact and practical application in that it fails to address the fundamental issue of gender imbalance. This gap, as has been pointed out, is currently being filled mainly in direct response to international and regional pressures, outside the federal character framework.

As Mustapha points out:

How we evaluate the performance of the FCC depends on our expectations of its role. Many expect the organisation to promote 'equal representation' within the federal bureaucracy. The arithmetic quota adopted by the Commission encourages this perception. ${ }^{76}$

Both friends and foes vilify the Federal Character Commission. While some measure of success has been achieved, the Commission faces enormous challenges. It is submitted that one of the major shortcomings is the total exclusion of gender mainstreaming as a measuring paradigm for affirmative action. Unless this is addressed, affirmative action measures will fail to address the disadvantages faced by women in Nigerian society.

76 Abdul Raufu Mustapha, 'Institutionalising ethnic representation: How effective is the Federal Character Commission in Nigeria?', CRISE Working Paper No. 43 (June 2007), 20. 

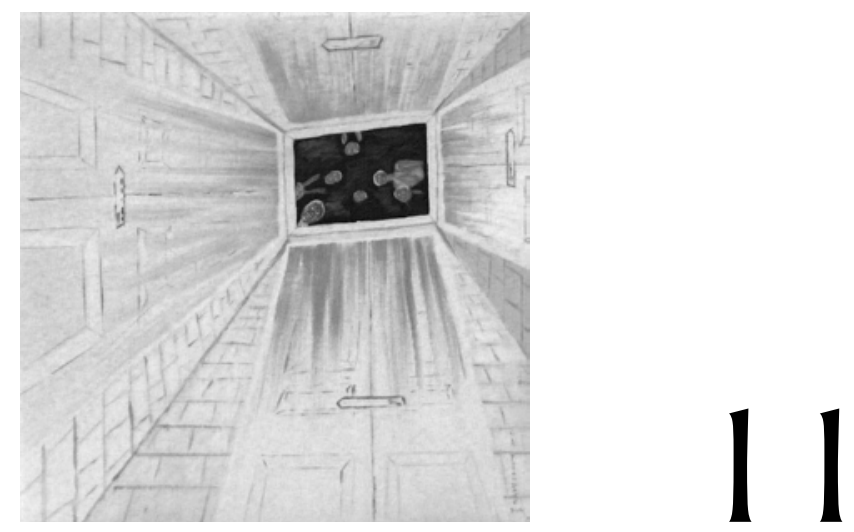

\title{
RESTRAINT, DEFERENCE AND REASONABLENESS
}

\section{Affirmative action in South Africa}

\author{
Ockert Dupper ${ }^{1}$
}

\subsection{Introduction}

Like the constitutions of many other countries, the South African Constitution confers the right to equal protection and benefit of the law, and the right to nondiscrimination. ${ }^{2}$ However, what separates the South African Constitution from most of its counterparts around the world is the explicit endorsement of affirmative action. Section 9(2) of the Constitution provides that in order to 'promote the achievement of equality, legislative and other measures designed to protect or advance persons, or categories of persons, disadvantaged by unfair discrimination may be taken'. The Employment Equity Act (EEA) ${ }^{3}$ gives effect to this constitutional provision, and regulates affirmative action measures in employment. One of the stated purposes of

\footnotetext{
1 Stellenbosch University.

2 Section 9 of the Constitution.

3 Act 55 of 1998.
} 
the EEA is to implement 'affirmative action measures to redress the disadvantages in employment experienced by designated groups, in order to ensure their equitable representation in all occupational categories and levels in the workforce.' ${ }^{4}$

In giving effect to this goal, the EEA spells out: who should be responsible for the protection and advancement of employees (primarily medium and large employers, including all levels of the public service); who should benefit from protection and advancement (black people, women and persons with disabilities); what 'protection' and 'advancement' mean (in essence preferential appointment and promotion); and, what may happen to employers if, in the view of the DirectorGeneral of the Department of Labour, they fail in that task (steps range from administrative compliance orders to judicially imposed fines to possible loss of government contracts).

Despite affirmative action's noble objectives, it is a controversial and emotive policy. This is largely because it departs from the ideal that people should be judged as far as possible on the basis of individual characteristics that are relevant to the situation, rather than involuntary group membership, especially when based on arbitrary grounds such as skin colour or sex. As a result, South African courts have been confronted with numerous legal challenges involving affirmative action over the past several years. As have courts elsewhere, the South African courts have had to confront the now familiar tension between the equal treatment principle and more distributive or substantive conceptions of equality. ${ }^{5}$ This means that courts have to resolve the tension between, on the one hand, the aim of ensuring equal treatment of all citizens regardless of arbitrary characteristics such as race or sex, and on the other hand, the aim of achieving a more equal distribution of welfare or resources among citizens that may require, in some instances, different treatment on the grounds of those very same characteristics. The predominant method of resolving this tension in Europe is to use a test of 'proportionality', whereas in the United States courts apply the equivalent test of 'strict scrutiny'. The essence of these tests is that specific measures designed to achieve substantive equality (such as affirmative

4 Section 2(b).

5 See Hugh Collins, 'Discrimination, Equality and Social Inclusion', Modern Law Review 66 (2003): 17. What precisely is meant by the notion of 'substantive equality' will not be explored in any detail in this contribution, save to say that it is acknowledged that equality is an elusive notion (see Nicholas Bamforth, 'Conceptions of Anti-Discrimination Law', Oxford Journal of Legal Studies 24 (2004): 693 at 703), and that our numerous appeals to (substantive) equality is often an appeal to some deeper normative value (such as human dignity, redistribution, participative democracy, etc.) rather than to the value of equality (in this regard, see, for example, J Raz, The Morality of Freedom (Oxford: Clarendon Press, 1986), 235; and E Holmes, 'Anti-Discrimination Rights Without Equality', The Modern Law Review 68 (March 2005): 175). 
action) must not be disproportionate violations of the equal treatment principle. ${ }^{6}$ How have the South African courts resolved this tension? This question will be the focus of this chapter.

\subsection{Affirmative action and the approach of the Constitutional Court}

In general, the Constitutional Court has held that given the South African constitutional design, history and social context, courts must adopt an approach to equality that goes beyond equal treatment (that is, beyond 'formal' equality) to some understanding of social and economic equality between individuals or groups (that is, 'substantive', 'remedial' or 'restitutionary' equality). ${ }^{7}$ Cathi Albertyn writes that the call for 'substantive equality' in South Africa emerges from the view that inequality is not the result of arbitrary or irrational action on the part of some (for example, employers), but is rooted in 'political, social and economic cleavages between groups.8

A constitutional commitment to substantive equality entails a commitment to the eradication of such systemic inequalities. As the court in Minister of Finance and Another v Van Heerden ${ }^{9}$ notes:

The Constitution enjoins us to dismantle (existing patterns of disadvantage) and to prevent the creation of new patterns of disadvantage. It is therefore incumbent on courts to scrutinise in each equality claim the situation of the complainants in society; their history and vulnerability; the history, nature and purpose of the discriminatory practice and whether it ameliorates or adds to group disadvantage in real life context, in order to determine its fairness or otherwise in the light of the values of our Constitution. In the assessment of fairness or otherwise a flexible but 'situation-sensitive' approach is indispensable because of shifting patterns of hurtful discrimination and stereotypical response in our evolving democratic society. ${ }^{10}$

One result of this 'context-sensitive' approach is to view affirmative action as an extension of, rather than an exception to, the right to equality. ${ }^{11}$ One way of understanding this is to think in terms of Amartya Sen's idea of the diversity

6 See Collins, 'Discrimination, Equality and Social Inclusion', 16, 18.

7 See, for example, National Coalition for Gay and Lesbian Equality v Minister of Justice (1999) 1 SA 6 (CC) at para 61.

8 Cathi Albertyn, 'Substantive Equality and Transformation in South Africa', South African Journal on Human Rights 23 (2007): 253, 254.

92004 (6) SA 121 (CC).

10 At paras 26-7.

11 C Albertyn, 'Equality', in South African Constitutional Law: The Bill of Rights, eds. H Cheadle, D Davis \& N Haysom (Durban: Butterworths, 2004), 4-23. 
of spaces in which equality may be demanded and pursued. Any proposal that addresses problems in the social sphere, must, to avoid a charge of being arbitrarily discriminatory, demand equality of something. But, to borrow Sen's now classic question, equality of what? ${ }^{12} \mathrm{~A}$ choice has to be made (based on acceptable reasons, of course) and this choice will inevitably lead to people being treated unequally in other respects. To quote Sen: 'Equality in what is seen as the "base" is invoked for a reasoned defence of the resulting inequalities in the far-flung "peripheries."'13 What is base and what is peripheral, and how to justify the choice made are questions that naturally raise difficult issues, which with limited space I am unable to explore here. However, one advantage of taking this approach, and an important one, is that it draws attention to the fact that certain measures in the pursuit of equality involve treating people unequally. This much the Constitutional Court has acknowledged in Van Heerden, noting that the achievement of equality may often come at a price for those who were previously advantaged. ${ }^{14}$

A consequence of adopting this approach, according to the court in Van Heerden, is that affirmative action measures that fall properly within the ambit of section 9(2) of the Constitution do not attract a presumption of unfairness, ${ }^{15}$ which is the usual fate of a measure differentiating on one of the prohibited grounds of discrimination. ${ }^{16}$ As Justice Moseneke explains: 'I cannot accept that our Constitution at once authorises measures aimed at redress of past inequality and disadvantage but also labels them as presumptively unfair. ${ }^{17}$ In other words, it would be wrong to see them as 'presumptively unfair' if they are integral to our understanding of equality. ${ }^{18}$ This means that section 9(2) provides a complete defence to a claim that positive measures constitute unfair discrimination. All that is required to succeed in this defence is to demonstrate compliance with the internal conditions established in section 9(2). It is to these internal criteria that I now turn.

\footnotetext{
12 A Sen, Inequality Reexamined (Cambridge: Harvard University Press, 1992), 19.

13 Ibid.

14 Van Heerden supra, at para 44 (per Moseneke J).

15 An onus that at least one court noted 'cannot be easy to discharge'. See Van Heerden supra at para 32 (referring to the High Court decision in the same matter). See also PSA v Minister of Justice 1997 (3) SA 925 (T).

16 See Harksen $v$ Lane NO \& Others 1998 (1) SA 300 (CC) at 325A, where it was held that differentiation on one of the sixteen specified grounds contained in the Constitution is presumed to amount to unfair discrimination. See also Albertyn, 'Equality', 4-25 n 162 and the cases cited there.

17 Van Heerden supra at para 33.

18 Albertyn, 'Equality', 4-26.
} 


\subsection{Section 9(2): internal criteria}

This part considers the general approach adopted by the Constitutional Court in determining whether a measure is covered by section 9(2) of the Constitution. The approach adopted by the court establishes a template for the consideration of all future affirmative action claims, including claims under the Employment Equity Act. ${ }^{19}$ The general approach can be described as one of restraint and deference, in recognition of the need to redress past social injustices:

Courts must be reluctant to interfere with such measures, and exercise due restraint when tempted to interpose themselves as arbiters as to whether the measure could have been proceeded with in a better or less onerous way [...] Given our historical circumstances and the massive inequalities that plague our society, the balance when determining whether a measure that promotes equality is fair will be heavily weighted in favour of opening up opportunities for the disadvantaged. ${ }^{20}$

The level of scrutiny of positive measures is therefore lower than that which applies to unfair discrimination. In particular, there is less emphasis on the negative impact of the measure, which would generally be on an advantaged group, and more emphasis on the group that is to be advanced. ${ }^{21}$ Despite this more 'hands off' approach, the courts have a duty to interfere in extreme cases where members of the previously advantaged group are ignored or excessively burdened. Justice Sachs put it as follows in Van Heerden:

[I]f the measure at issue is manifestly overbalanced in ignoring or trampling on the interests of members of the advantaged section of the community, and gratuitously and flagrantly imposes disproportionate burdens on them, the courts have a duty to interfere. ${ }^{22}$

19 Even though affirmative action measures in the workplace (both public and private) is regulated by the EEA, and the principle of 'avoidance' states that litigants may not litigate under the Constitution if secondary legislation on the point exists, there is no doubt that the Labour Courts will interpret the EEA in a way that coheres with, rather than contradicts, the decision of the Constitutional Court in Van Heerden.

20 Van Heerden supra, para 152 (per Sachs J). The Labour Court recently confirmed and followed this approach: 'Judicial restraint and deference is called for in recognition of the need for state action to redress past social injustices.' Alexandre $v$ Provincial Administration of the Western Cape (2005) 26 ILJ 765 (LC) at para 6.

21 Albertyn, 'Equality', 4-26.

22 Van Heerden supra at para 152, emphasis added. In the most recent Constitutional Court decision on affirmative action, some members of the Court argued that the applicable standard to determine whether the implementation of a remedial measure has adequately balanced substantive equality with the dignity of the person negatively affected by the measure is not mere 'rationality', because all exercises of power must at least be rational. 
In Van Heerden, the Constitutional Court established a three-fold enquiry to determine whether a measure falls properly within the ambit of section 9(2) of the Constitution. ${ }^{23}$

\subsubsection{Stage ONE: Does the measure target persons or categories of persons who have been disadvantaged by unfair discrimination?}

Section 9(2) of the Constitution leaves the identity of the potential beneficiaries of affirmative action deliberately vague and open-ended, referring to 'persons or categories of persons disadvantaged by unfair discrimination'. In this way, the Constitution recognises that disadvantage and inequality take on particularly complex forms in South Africa and that affirmative action measures may be tailored to a variety of groups, provided of course that they have been disadvantaged by unfair discrimination. In other words, there is an acknowledgement that disadvantage follows not only the axis of race, but that " $[\mathrm{r}]$ acial cleavages are cross-cut with rural-urban, gender, class, regional and cultural divides which complicate the nature of disadvantage and discrimination. ${ }^{24}$ The complex nature of disadvantage was acknowledged by the Constitutional Court when it noted that the purpose of section 9(2) is to redress disadvantages based not only on race, but also on the basis of gender and class and 'other levels and forms of social differentiation and systemic under-privilege which still persist.'25

The Employment Equity Act 55 of 1998 (EEA), however, is less circumspect in its approach, and identifies three very distinct categories of disadvantage that warrant redress - race, gender and disability. ${ }^{26}$ The Act therefore recognises black people, women of all races, and people with disabilities as the potential beneficiaries of affirmative action in the workplace. The category 'black' is intended to encompass all those previously classified as 'African', 'Coloured' and 'Indian', meaning that it

It is, as the court points out, the 'bare minimum requirement' (South African Police Service $v$ Solidarity obo Barnard [2014] ZACC 23, para 36 - separate concurring decision by Cameron J, Froneman J, and Majiedt AJ). A heightened level of scrutiny is required (para 96). The three judges proposed the standard of fairness (para 98), which the Justices determined the Police Commissioner had met in this case when deciding not to promote Barnard (at para 123).

23 This approach was endorsed in Barnard (see South African Police Service v Solidarity obo Barnard [2014] ZACC 23, para 36).

24 See Report of the Presidential Commission to Investigate Labour Market Policy (June 1996) (dissenting opinion of Commissioner Nicoli Nattrass).

25 Van Heerden supra at para 27.

26 Section 11.1. 
reproduces the very racial categories and divisions that underpinned apartheid. ${ }^{27} \mathrm{It}$ has fittingly been called 'one of the great paradoxes of South Africa's constitutional transition.' ${ }^{28}$ In Chinese Association of South Africa $v$ Minister of Labour and others, ${ }^{29}$ the Pretoria High Court determined that people of Chinese descent, who were classified as 'Coloured' in terms of the Population Registration Act, must also be included under the definition of 'black people' in the EEA and the BroadBased Black Economic Empowerment Act 53 of 2003. While three divergent categories of disadvantage are recognised in the EEA, it has been suggested that actual implementation favours 'race' over 'gender' and 'disability', and 'African' over 'Coloured' and 'Indian. ${ }^{30}$ According to those who hold this view, affirmative action in South Africa is a race-based strategy, mainly benefiting South Africans of African descent.

Those who defend the use of racial identification in the project of transformation point to the fact that after decades of formal racial classifications, on the basis of which some of South Africa's most fundamental social goods such as employment, land, housing and education were distributed, it is only to be expected that racial categories (African, Coloured, Indian and White) will continue to be used in South African society for some time to come. These racial groups were in effect created by the original unjust practice of racial discrimination, and to deny that fact (by pursuing a policy of colour blindness) would be to deny a social reality - a reality that cannot morally be ignored as long as the wrongs that created them have not yet been rectified. ${ }^{31}$

However, some have alluded to the dangers inherent in replicating apartheid's racial grid in the pursuit of affirmative action. ${ }^{32}$ One of the consequences of making these racial categories salient is that it gives them, to borrow Melissa Nobles's phrase, an

27 See the now repealed Population Registration Act 30 of 1950, s 1(xv), (x) and (iii). See also D Posel, 'What's in a name? Racial categorizations under apartheid and their afterlife,' Transformation 47 (2001): 50, 56.

28 H Botha, 'Equality, Plurality, and Structural Power', inaugural lecture, Faculty of Law, Stellenbosch University, 8 March 2008.

29 Case No: 59251/2007; 18 June 2008.

30 See K Bentley \& A Habib, 'Racial Redress, National Identity \& Citizenship in PostApartheid South Africa' in Racial Redress and Citizenship in South Africa, eds. K Bentley \& A Habib (Pretoria: HSRC Press, 2008), 21. See also M MacDonald, Why Race Matters in South Africa (Cambridge: Harvard University Press, 2006), 174.

31 See O Dupper, 'In Defence of Affirmative Action in South Africa', South African Law Journal 121 (2004): 187 at 213.

32 See, for example: O Dupper, 'Affirmative Action: Who, How, and How Long?', South African Journal on Human Rights 24 (2008): 425-44; N Alexander, 'Affirmative Action and 
'illusion of ordinariness', which prevents a critical and reflective consideration of the socially meaningful existence of races. ${ }^{33}$ It leads to a situation in which there is no need to question apartheid's race allocations. Race - especially the idea that South African society is comprised of four distinct races - becomes simply a given in the manner in which we think of society. It becomes a habit of thought and experience. In addition, it gives legitimacy to thoroughly discredited bioculturalist categorisations of race, which may be one of the more disturbing ironies of postapartheid redress. ${ }^{34}$ Race classification rears its head South Africa on a regular basis: from meeting the requirements of the EEA, to gaining or being refused admission to universities, to registering births, to completing a census form - all require the specification of 'race' or 'population group' or 'ethnic group' (where these all mean exactly the same thing). ${ }^{35}$

There have been calls for a more nuanced approach to affirmative action - one that takes account of the complexity of disadvantage and of the continuous shifts taking place in our social and economic relations. ${ }^{36}$ This approach recognises that inequalities follow many axes, of which race is only one. Current redress strategy, by placing society into two (or four) simplified camps, denies the complexity of causal relationships and of corrective action. In addition, it perpetuates race consciousness, which has implications for the goal of creating a non-racial society. Although the various specific alternatives to using race as the primary means of bringing about redress are not directly of interest here, it is worth pointing out that they involve not only a class-based approach, but are supplemented by more specific race-based initiatives; one based on the urban-rural divide; one based on language, among

the Perpetuation of Racial Identities in Post-Apartheid South Africa', lecture delivered at the East London Campus of the University of Fort Hare, 25 March 2006, 19; Posel, 'What's in a name?', 50; G Maré, 'Race Counts in Contemporary South Africa', Transformation 47 (2001): 75; K Bentley 'Rethinking the ultimate goal of affirmative action: who and what is it for', paper prepared for the 61st Harold Wolpe Memorial Trust Open Dialogue, 19 July 2007.

33 M Nobles, Shades of Citizenship: Race and the Census in Modern Politics (Stanford: Stanford University Press, 2000), 180.

34 See Posel, 'What's in a name?', 56. Studies also indicate that people still overwhelmingly claim a racialised identity as their primary means of describing themselves (see A Zegeye, I Liebenberg \& G Houston, 'Resisting Ethnicities from Above: Social Identities and Democracy in South Africa' in Democracy and Governance Review: Mandela's Legacy 1994-1999, eds. Y Muthien et al. (Pretoria: HSRC Press, 2000), 164).

35 See Maré, 'Race Counts', 87.

36 See Dupper, 'Affirmative Action: Who, How, and How Long?'; See also K Bentley \& A Habib, 'An alternative framework for redress and citizenship', in Racial Redress and Citizenship in South Africa, eds. Bentley \& Habib, 348. 
others. ${ }^{37}$ These approaches all share the same premise - namely, that the root causes of inequality are complex, and consequently require innovative, nuanced and context-specific solutions.

To return to the current emphasis on race-based redress: official definitions of the different racial groups no longer exist in South African law. How then does the EEA approach the issue of classification for purposes of affirmative action? In contrast to apartheid's notorious tests for racial identification, the EEA envisages that the authority to define membership of one of the designated racial groups should rest with the individual concerned. The Code of Good Practice on the Integration of Employment Equity into Human Resource Policies and Practices ${ }^{38}$ states the following:

It is preferable for employees to define themselves to enable the employer to allocate them to a designated group. Only in the absence of an employee's self-identification, can an employer rely on existing or historical data to determine the employee's designated group status. ${ }^{39}$

Presumably, in order for the affirmative action policy to function effectively, it must preclude those previously advantaged from defining themselves as African, Coloured or Indian (or Chinese) for convenience. In the unlikely event of this happening, it would place the employer in the difficult position of having to determine the particular individual's racial category on the basis of 'existing or historical data'.

How precisely should the group targeted for redress by means of affirmative action measures be defined? In keeping with the deferential standard referred to above, the Constitutional Court held that the degree of precision required when delineating the group of beneficiaries should not be too exacting. The court held that it was often 'difficult, impractical or undesirable to devise an affirmative action scheme with "pure" differentiation demarcating precisely the targeted classes.' 40 The court posited that within each scheme of redress, there may be exceptional or hard cases, or windfall beneficiaries. In the context of a section 9(2) measure, the court held, the legal efficacy of the remedial scheme should be judged by whether an overwhelming majority of members of the favoured class are persons designated as disadvantaged by unfair discrimination. ${ }^{41}$ There is thus no requirement that each and every member of the targeted group be 'disadvantaged by unfair discrimination'.

37 See Maré, 'Race Counts', 90; Alexander, 'Affirmative Action and the Perpetuation of Racial Identities', 11;

38 Published under GN 1358 in $G G 27866$ of 4 August 2005.

39 Item 5.3.10.

$40 \quad$ Para 39.

41 Para 40. 
However, those not falling into this category should be a small minority, with the vast majority meeting the requirement of being 'disadvantaged by unfair discrimination'.

In addition to raising the matter of the identity of those who should benefit from affirmative action measures, this requirement raises at least two more important questions. These are: (i) once the category or categories of the disadvantaged have been identified, does a person have to show actual disadvantage, or is membership of the affected class sufficient in order to benefit from affirmative action measures? and (ii) may affirmative action measures legitimately differentiate between persons within the broad category of the disadvantaged? Each of these issues will now be discussed in more detail.

\subsubsection{Must a person show actual disadvantage, or is membership of the affected class sufficient to benefit from affirmative action measures?}

Affirmative action, in facilitating substantive equality, specifically attaches socioeconomic benefits such as jobs or government contracts to those disadvantaged by status (such as race and gender). This arguably places affirmative action in the realm of redistributive - rather than regulatory policy measures. However, in order for affirmative action policies to have more than a 'remote distributive effect', ${ }^{42}$ a tight fit between status and disadvantage is required. If not, it invites the familiar objection that affirmative action is both over- and under-inclusive. To put it succinctly: if the aim of affirmative action measures is to address socio-economic disadvantage, then a group demarcated by status, such as race or gender, might be over-inclusive in including wealthier blacks or women, and under-inclusive, in excluding poor white men. ${ }^{43}$

Of the two objections, it is arguable that the critique of over-inclusiveness is the more persuasive. By focusing attention on groups rather than individuals, some individuals who are not needy will in fact receive benefits at the expense of those who have been handicapped most by the effects of discrimination and thus are most in need of advancement under such a policy. As affirmative action has tended to work in practice, those who have suffered most under discrimination are seldom those who benefit from these policies. As one opponent of affirmative action notes:

[Those who are most disadvantaged by injustice] are so disadvantaged that they often cannot even begin to compete for the positions that beneficiaries of racial affirmative action obtain. Those most likely to benefit are those

42 A Graser, 'Equality Oriented Policies: A New Concept in Public Policy?' (18 February 2013), 19, available at SSRN: <http://ssrn.com/abstract=2220289> accessed 14 September 2014.

43 S Fredman, 'Facing the Future: Substantive Equality Under the Spotlight', in Equality in the Workplace: Reflections from South Africa and Beyond, eds. O Dupper \& C Garbers (Cape Town: Juta, 2009), 29. 
who were either minimally disadvantaged or not disadvantaged at all (in the relevant ways) or those who, although once disadvantaged, have already been compensated. ${ }^{44}$

Critics point out that if what we want is to truly advance those who have been disadvantaged then the emphasis should be on the disadvantaged individuals of a deprived group, not the deprived group as a whole. But, they go on to say, the policy of affirmative action does not mandate or even recommend finding out whether individuals who benefit have actually been the victims of any injustice that could warrant redress. There are a number of potential replies to the above argument. ${ }^{45}$ One of the more convincing arguments for not engaging in such individual inquiries is that since almost all members of the disadvantaged groups have in fact been disadvantaged by discrimination, it is surely not unjustifiable to design and institute programmes to confer special benefits to the groups as such. ${ }^{46}$ The argument presupposes that there is in fact a very high correlation between being a black person or a woman or a member of a disadvantaged caste and being a victim of discriminatory and harmful treatment.

This argument underlies the approach adopted by the South African courts towards the demarcation of beneficiaries of affirmative action. Although the majority judgment of the Constitutional Court in the Van Heerden decision emphasises that 'the beneficiaries must be shown to be disadvantaged', this requirement relates to the identified group and not to each individual member of the group. The court made it clear that a measure will not fail because it benefits individual persons who have not, in fact, been disadvantaged. It is sufficient, the court said, that 'an overwhelming majority' have been so disadvantaged. ${ }^{47}$

In her minority judgment, Justice Mokgoro provided the rationale for the groupbased approach in instances where the targeted groups are defined with reference to the unfair discrimination suffered specifically under the policy of apartheid:

The approach of apartheid was to categorise people and attach consequences to those categories. No relevance was attached to the circumstances of individuals. Advantages or disadvantages were metered (sic) out according to one's membership of a group.

44 D Benetar, 'Justice, diversity and racial preference: A critique of affirmative action', South African Law Journal 125 (2008): 274.

45 For a more detailed discussion of these arguments see Dupper, 'In Defence of Affirmative Action'.

46 See James W Nickel, 'Should Reparations be to Individuals or to Groups?, Analysis 34 (1974): 155.

47 At para 40 . 
The significance of this, she points out, 'is that it is unnecessary for the state to show that each individual member of a group that was targeted by unfair discrimination was in fact individually discriminated against when enacting a measure under s 9(2)'.48 This view has also found support in the High Court. In Stoman v Minister of Safety and Security and Others the court confirmed that the intention of the legislature 'could not have been to make [affirmative action] measures dependent on the individual circumstances of each particular case. 49

\subsubsection{May affirmative action measures legitimately differentiate between persons within a particular disadvantaged group?}

The final question when considering the issue of who must benefit under affirmative action is whether it is permissible to distinguish between persons within a particular disadvantaged group. In other words,may those implementing affirmative action measures classify members of the designated groups into categories of relative disadvantage vis-à-vis each other? Although the Constitutional Court has not yet answered this question, it flagged it as 'a more difficult problem' for future consideration. $^{50}$ Lower courts and arbitration forums, however, have been confronted with the issue on a number of occasions. In each of these cases, the measures in question differentiated between Africans on the one hand and members of the other designated groups on the other.

The issue was first raised in a case falling outside the employment context. In Motala \& another $v$ University of Natal, ${ }^{51}$ the applicant, a female of Indian descent, was refused admission to the Medical School of the University of Natal. The reason given was that the university had decided that only 40 Indian students would be admitted annually, and that the requisite number had already been admitted. The university had adopted a policy to admit more African students to the faculty in order to redress the educational disadvantages they suffered under apartheid. The faculty acknowledged that in most instances the school results of the admitted African students were lower than those of other admitted applicants, and lower than those of other applicants (like Ms Motala) who were not accepted. ${ }^{52}$ The applicant contended that this 'affirmative action' policy amounted to unfair discrimination. The court rejected this contention:

The contention by counsel for the applicants appears to be based upon the premise that there were no degrees of 'disadvantage'. While there is no doubt whatsoever that the Indian group was decidedly disadvantaged by the

48 At para 85.

492002 (3) SA 468, 483J-484A.

50 Van Heerden supra at para 149.

511995 (3) BCLR 374 (D).

52 At $379 \mathrm{H}$. 
apartheid system, the evidence before me establishes clearly that the degree of disadvantage to which African pupils were subjected under the [apartheid] system of education was significantly greater than that suffered by their Indian counterparts. I do not consider that a selection system which compensates for this discrepancy runs counter to the provisions of [the equality provision of the Interim Constitution].53

This view has also found favour with the Labour Court, ${ }^{54}$ the CCMA, ${ }^{55}$ and a private arbitrator. $^{56}$

As mentioned above, even though the Constitutional Court has not yet confronted the issue, Justice Sachs indicated in Van Heerden that the resolution of the question of whether one should distinguish between persons in a particular disadvantaged group would require not only legal, but also historical and social evidence. ${ }^{57}$ This means that should a measure be specifically targeted, for example, at black women rather than all women, or at Africans rather than all black people, such a measure may be lawful, provided that 'the definition of the group is justified with reference to the actual historic and current unfair discrimination suffered by the majority of that group in a particular context. ${ }^{58}$ It may be that in cases of relative disadvantage, the level of scrutiny of the group would need to be higher than the relatively relaxed standard for identifying disadvantaged groups established by the Constitutional Court in Van Heerden. Mere assertions of relative disadvantage should not be allowed to survive judicial scrutiny. In Motala, for instance, the claim of the actual relative privilege of the majority of Indian over African scholars was supported with statistics, hence the court's reluctance to interfere with the measure.

53 At 383C-E.

54 See McInnes v Technikon Natal (2000) 21 ILJ 1138 (LC) at 1148D-E: 'The technikon defines affirmative action as the upliftment and advancement of all previously disadvantaged communities by seeking to redress the imbalances of the past. The first disadvantaged community to be considered at Technikon Natal is the African community (indigenous people who were here before European colonisation)'; Fourie v Provincial Commissioner of the SA Police Service (North West Province) \& another (2004) 25 ILJ 1716 (LC) at 1735H-I: 'I accept that white women were discriminated against under apartheid but not to the same extent as Black people and in particular African people.'; see also Henn $v$ SA Technical (Pty) Ltd (2006) 27 ILJ 2617 (LC).

55 Public Service Association - Gerhard Koorts v Free State Provincial Administration CCMA FS3915 21 May 1998 (unreported). The commissioner accepted the argument of the employer that white women did not suffer discrimination 'nearly to the same extent' as that experienced by blacks.

56 Solidarity obo Christiaans and Eskom Holdings Ltd (2006) 27 ILJ 1291 (ARB) at 1036. 'The EEA also, in my view, mandates an employer to distinguish between the different groups within the "designated groups".

57 Paragraph 149.

58 See Albertyn, "Equality', 4-28. 
Further, in cases where the relative disadvantage of Africans vis-à-vis other disadvantaged groups is asserted, there may be an additional reason for requiring some evidence to support the claim. The perception already exists among the other disadvantaged groups that even though affirmative action is officially directed at all black people, it mainly benefits those of African descent. Allowing these assertions of relative disadvantage in each and every case to go through unverified will not only solidify these perceptions but may arguably also lead to tensions between the different designated groups. ${ }^{59}$

Finally, it is submitted that while cases that fall outside of the ambit of the EEA may very well countenance 'degrees of disadvantage' arguments along the lines suggested above, the EEA in fact provides no basis for using 'relative disadvantage' as a criterion for differentiation among sections of the black population. The EEA expressly adopts the criterion of 'equitable representation' as the cornerstone for distinguishing between members of the designated groups, meaning that the degree to which persons from particular racial or gender groups are underrepresented in a particular occupational category or level within a workplace should guide the actual implementation of affirmative action measures, and not whether one group has been relatively more disadvantaged than another. ${ }^{60}$ The proper way of dealing with the question of 'relative disadvantage' therefore is to look at the goal of affirmative action under the EEA, which is 'the equitable representation [of designated groups] in all occupational categories and levels in the workforce. ${ }^{61}$ Because the notion of 'equitable representation' of persons from designated groups is integral to the concept of affirmative action under the EEA, the degree to which persons from particular racial or gender groups are underrepresented in a particular occupational category or level within a workplace should determine the appropriateness of affirmative action. For example, if the facts show that African women are most severely underrepresented in a job category of an employer operating in the Western Cape, the employer will be justified in giving preference to female African applicants who are suitably qualified. Similarly, if Coloured men are underrepresented in certain job categories of an employer in the Limpopo Province, suitably qualified candidates from this group may receive preferential treatment over African men, who may already be sufficiently represented in that job category. This approach, based on 'representivity' rather than one based on 'degrees of disadvantage' is directly aligned with the purpose of the EEA and is more sensitive to regional and industry contexts.

59 See K Naff, 'Passive Representation in the South African Bureaucracy: A Lot Has Happened, but it's a Lot More Complicated [...], 17 (unpublished paper), whch refers to significant tensions between Africans and Coloureds in the Western Cape government.

60 In this regard, see Baxter $v$ National Commissioner, Correctional Services \& another (2006) 27 ILJ 1833 (LC), [2006] 9 BLLR 844 (LC).

61 See s 2(b). 


\subsubsection{Stage TWO: Is the measure designed to protect or advance such persons or categories of persons?}

Section 9(2) of the Constitution places a further condition on affirmative action measures: they should be 'designed to protect or advance' certain persons or groups. The phrase 'designed to achieve' has both a substantive and a procedural element. As far as the substance of the measure is concerned, it must be clear from the policy that substantive equality both 'is intended and may be expected' if the measure is applied. ${ }^{62}$ This implies something between a guarantee of success and pure guesswork. According to the Constitutional Court, the measures 'must be reasonably capable of attaining the desired outcome.' ${ }^{63}$ There is no need to establish a 'precise prediction' that the measures will yield the stated objectives, as long as there is a 'reasonable likelihood' that this is possible. To require the promoter of positive measures to establish 'a precise prediction of a future outcome' would render the measure 'stillborn. ${ }^{4}$ The meaning of what is 'reasonably possible' is open-ended and the courts will develop this over time. It is however clear that measures that are 'arbitrary, capricious or display naked preferences' and those that are taken for improper corrupt motives, will not pass the test. For example, in Stoman v Minister of Safety and Security, ${ }^{65}$ the court noted that 'a policy or practice which can be regarded as haphazard, random and over-hasty $[. .$.$] could hardly be described as measures$ designed to achieve something. ${ }^{\prime 6}$

As far as the procedures that underlie affirmative action measures are concerned, what can be concluded from the case law is that a degree of consideration and planning must have preceded the imposition of such measures. The courts have made it clear that an employer's mere assertion that a measure amounts to an affirmative action measure will not be seen as sufficient. ${ }^{67}$ Evidence should be led that it is indeed consistent with the 'purpose' of the EEA. The relevant 'purpose' of the EEA is 'to redress the disadvantages in employment suffered by designated groups in order to ensure their equitable representation in all occupational categories and levels in the workforce' ${ }^{68}$ This purpose, it is submitted, is served primarily by employment

62 See N Smith, 'Affirmative Action under the New Constitution', South African Journal on Human Rights 2 (1995): 84 at 94.

63 Van Heerden at para 42.

64 Ibid.

$652002(3)$ SA $468(\mathrm{~T})$.

66 At 480A-B.

67 See, for example, Public Servants Association of SA and Others $v$ The Minister of Justice and Others 1997 (3) SA 925 (T).

68 Section 2(b). Although the EEA expressly links affirmative action measures to the objective of ensuring 'that suitably qualified people from designated groups [...] are equitably 
equity plans drawn up and implemented by designated employers in terms of Chapter III of the EEA. Measures forming part of such statutory plans should be regarded as being prima facie 'consistent with the purpose' of the EEA and therefore not unfair. ${ }^{69}$

However, this does not mean that in order for an affirmative action measure to be legitimate it must form part of an employment equity plan that complies with the provisions of the EEA. The reason is straightforward. Affirmative action measures by non-designated employers fall beyond the framework of statutory employment equity plans. Because non-designated employers do not have to comply with the requirements of the EEA, they will have to establish, on a balance of probabilities, that they are taking affirmative action measures that are consistent with the purpose of section 9(2) of the Constitution - namely, the achievement of equality through the protection or advancement of those disadvantaged by unfair discrimination. The test, in other words, is whether a measure is rationally connected to this objective. The fact that a measure is (a) intended to contribute to the objective of the achievement of equality; and (b) capable of doing so (for example, by reducing the underrepresentation of categories of persons disadvantaged by unfair discrimination), should be sufficient. Despite the fact that there is no obligation on non-designated employers to develop employment equity plans in line with the requirements of the EEA, the court has made it clear that 'properly formulated programmes go a long way to satisfying the [Constitutional] requirement of rationality. ${ }^{30}$ The reason for this is straightforward: the presence of such a programme or policy is to provide a basis for determining whether it meets the constitutional objective. ${ }^{71}$ Non-designated employers would therefore be well advised to develop plans or programmes in line with the requirements set out above. It is further submitted that the more closely such plans or programmes mirror those required by the EEA, the more likely they will be to pass constitutional muster. ${ }^{72}$

represented in all occupational categories and levels in the workforce of a designated employer (section 15(1); emphasis added), the right to implement affirmative action measures applies to all employers. Since it would be incongruous to give 'affirmative action' a different meaning in the case of non-designated employers, it is submitted that the above definition applies to all employers.

69 See Ockert Dupper 'Affirmative Action and Substantive Equality: The South African Experience', South African Mercantile Law Journal 14 (2002): 275.

70 Gordon v Department of Health: KwaZulu Natal 2008 (6) SA 522 (SCA), [2008] 11 BLLR 1023 (SCA) para 22.

71 Ibid.

72 This is because one of mechanisms that the EEA employs to ensure rationality is to provide for a procedure through which 'employment equity plans' have to be prepared, submitted, and implemented in the workplace (see sections $16-26$ of the EEA). 
Finally in this regard, the courts have also established the following two guidelines regarding the procedural elements that underlie affirmative action measures. First, where a policy document or collective agreement dealing with affirmative action requires detailed affirmative action plans to be developed in an organisation or in some of its divisions, failure to develop such plans could invalidate appointments or promotions made in terms of mere generalised policy statements. ${ }^{73}$ Second, where a formal affirmative action plan exists in an organisation, it must be adhered to. For example, in McInnes $v$ Technikon Natal, ${ }^{74}$ the court had to decide whether the appointment of a black applicant rather than a white female applicant (who had been recommended for the position) was in accordance with the Technikon's affirmative action policy. The court found that the Technikon had breached its own policy by appointing a candidate without lecturing experience when 'extensive lecturing experience' had been stated as a job requirement. The court added that while it is reluctant to 'second guess' an employer's operational decisions, a different situation arises 'where it is found that the policy, read properly, was not applied at all. 75 The importance of the decision is that it underlines the role of the court in scrutinising not only the content of an employer's professed affirmative action policy in order to determine whether it satisfies statutory ${ }^{76}$ or constitutional ${ }^{77}$ requirements, but also whether it is properly applied. Conduct not sanctioned by an affirmative action policy, when the policy itself is valid, cannot provide a defence to a claim of unfair discrimination.

\subsubsection{Stage THREE: Does the measure promote the achievement of equality?}

Finally, the purpose of the measure must fall within the overall purpose of achieving equality through protecting or advancing disadvantaged persons or groups. The long-term goal is a diverse non-racial, non-sexist society in which every person will be recognised and treated as a human being of equal worth and respect. In assessing, therefore, whether a measure will promote equality in the long term, this constitutional vision must be borne in mind. The court recognised that the achievement of this goal may often come at a price for those who were previously

73 See, for example, IMAWUv Greater Louis Trichardt Transitional Local Council (2000) 21 ILJ 1119 (LC) at 1125-6 and Coetzer \& others $v$ Minister of Safety and Security \& another (2003) 24 ILJ 163 (LC) at 176.

74 (2000) 21 ILJ 1138 (LC).

75 At $1150 \mathrm{H}$.

76 In the case of designated employers under the EEA.

77 In the case of non-designated employers, or other entities not covered by the EEA (such as Pension Funds - see Minister of Finance $v$ Van Heerden 2004). 
advantaged. ${ }^{78}$ Nonetheless, courts must ensure that the measure does not amount to 'an abuse of power' and that it does not impose 'substantial and undue harm' or 'disproportionate burdens' on those excluded from the measure. ${ }^{79}$ As the Constitutional Court recently noted:

Remedial measures must be implemented in a way that advances the position of people who have suffered past discrimination. Equally, they must not unduly invade the human dignity of those affected by them, if we are truly to achieve a non-racial, non-sexist and socially inclusive society. ${ }^{80}$ (italics added)

The interests of the previously advantaged often loom particularly large in the employment context, where persons belonging to this group are often passed over for appointment or promotion in the pursuit of an affirmative action policy. This raises the following question: under which circumstances would courts consider the failure to be appointed or promoted to be a disproportionate burden and worthy of intervention? The question really goes to the magnitude of the preference afforded to members of the disadvantaged groups in the pursuit of an affirmative action policy. In other words, when competing claims for scarce resources, such as jobs, are weighed, 'how heavy is the thumb that affirmative action actually places on the scales?' 81 This question is important because the larger the preference, the

78 Van Heerden supra at para 44 (per Moseneke J). I will unfortunately not be able to discuss the highly interesting question of why those who have benefited in the past should now bear the costs of affirmative action. Suffice it to state that my views correspond largely with those of Amy Gutmann, who writes: 'Those of us who have unfairly benefited in the past [...] have special obligations [...] to help others. We have these special obligations not because we asked to be unfairly advantaged, but because we have been and are unfairly advantaged. Because being white and affluent has been a source of unfair benefits in this country, fairness generates special obligations that are color- and class-conscious.' Amy Gutmann, 'Responding to Racial Injustice', in Color Conscious: The Political Morality of Race by K Anthony Appiah and Amy Gutmann (Princeton: Princeton University Press, 1996), 342, (emphasis in original). See also Ross, who criticises the invocation of the 'rhetoric of innocence' by those belonging to the previously advantaged sector of the society in order to place limits on affirmative action: ' $[\mathrm{T}]$ he rhetoric of innocence avoids the argument that white people generally have benefited from the oppression of [black people], that white people have been advantaged by this oppression in a myriad of obvious and less obvious ways. Thus, the rhetoric of innocence obscures this question: What white person is "innocent", if innocence is defined as the absence of advantage at the expense of others?' See T Ross, 'Innocence and Affirmative Action', Vanderbilt LR 43 (1990): 297, 301. See also K Sullivan, 'Sins of Discrimination: Last Term's Affirmative Cases', Harvard LR 100 (1986): 78, 97 (also criticising the rhetoric of innocence and its search for perpetrators and victims).

79 At para 152.

80 South African Police Servicev Solidarity obo Barnard [2014] ZACC 23, para 32.

81 See PH Schuck, 'Affirmative Action: Past, Present, and Future', Yale Law and Policy Review 20 (2002): 1, 17. 
greater its tension with the merit principle (and it is worth pointing out that this is so however one conceives of merit) ${ }^{82}$ and the greater the disruption to the interests of the non-preferred.

The least disruptive effect on their interests would occur when the preference merely serves as a tie-breaking factor between two 'equally qualified' candidates for a position. ${ }^{83}$ This would cause marginal harm to those excluded, and in terms of the Van Heerden analysis, not fall foul of section 9(2). However, as one court made clear, to argue that affirmative action considerations should only play a role where the candidates have the same qualifications and merits would not advance the achievement of equality in a situation where a society emerges from a history of unfair discrimination. ${ }^{84}$ The most disruptive of the interests of the non-preferred

82 Affirmative action preferences have, in many ways, diverted our attention from the biases inherent in the construction of merit. The familiar argument that all appointments not made purely on merit constitute an unacceptable lowering of standards derives some of its force from the erroneous notion that we would have a meritocracy were it not for affirmative action. See RA Wasserstrom, 'Racism, Sexism, and Preferential Treatment: An Approach to the Topics', UCLA Law Review 24 (1976-1977): 619. It is based on an assumption that 'merit' is verifiable, determined by objective, pre-existing standards. However, for the most part, employers who allocate a job on the basis of merit properly define it in their own ways. Merit's content is wholly contextual; it derives meaning only from one's particular conditions and purposes. See PH Schuck, 'Affirmative Action: Past, Present, and Future', Yale Law and Policy Review 20 (2002): 7. Therefore, as Stanley Fish points out, the ' $[\mathrm{m}]$ erit is not one thing but many things, and even when it becomes a disputed thing, the dispute is between different versions of merit and not between merit and something base and indefensible.' See S Fish, 'The Nifty Nine Arguments Against Affirmative Action in Higher Education', The Journal of Blacks in Higher Education (Spring 2000): 79, 80.

83 This essentially represents the approach adopted by the European Court of Justice in respect of affirmative action. See O Dupper, 'Affirmative Action in South Africa: (M)any Lessons for Europe?', Verfassung und Recht in Übersee (Law and Politics in Africa, Asia and Latin America) 39 (2006): 135, 161, and the cases referred to there. Whether it is possible to determine when two candidates possess 'equal qualifications', is of course open to debate.

84 Stoman $v$ Minister of Safety and Security and others 2002 (3) SA 468, 482. This raises an interesting question, namely whether initiators of affirmative action who implement affirmative action on this limited and 'weak' basis can be compelled to adopt a more robust approach to affirmative action. The court in Stoman characterised the implementation of affirmative action on this basis as 'too restrictive to give meaningful effect to the constitutional provision for such measures and the ideal of achieving equality' (see Stoman at 482). In other words, does section 9(2) of the Constitution (or Chapter 3 of the EEA) provide a sword to those who want to compel, for example, an employer to implement affirmative action measures or, if already being implemented, to implement it in a manner more in keeping with the constitutional vision of equality? The prevailing opinion (both under the Constitution and the EEA) militates against such a view (see Albertyn, 'Equality', 4-31; Dudley v City of Cape Town [2004] 5 BLLR 413 (LC); Cupido v Glaxosmithkline SA (Pty) 
would be the appointment of someone wholly unqualified for the position and incapable of doing the job required of him or her. This would cause 'substantial and undue harm' to those excluded from the measure and no doubt fall foul of section $9(2) .85$

We see then that the two extreme positions set out above yield relatively easy answers. Requiring equal qualifications would impose marginal harm on those excluded, but would have limited effect. ${ }^{86}$ Using race as the only criterion for appointment would not only be irrational, but impose undue burdens on those excluded. ${ }^{87}$ The more difficult situations arise between these two extremes. It would be myopic to deny that immense weight is given to race in situations where certain positions or places are expressly set aside on that basis. However, when would the point be reached

$L t d$ (2005) 26 ILJ 868 (LC)). However, it is submitted that the last word has not been spoken in this regard. When the Dudley decision reached the Constitutional Court, the court refused to hear the matter, citing lack of jurisdiction. See Dudley $v$ City of Cape Town 2005 (5) SA 429 (CC) and also Harmse $v$ City of Cape Town [2003] BLLR 557 (LC).

85 See Stoman supra at 482 . The more general point is that tokenism, that is to say appointing a black person or woman solely on the basis of race or sex, would be irrational.

86 As one commentator in Europe notes: 'While their validity by E.C. standards is beyond question, the effectiveness of positive action plans is a different matter. Where these schemes have been applied, the proportion of women in the workplace has remained static rather than having improved. One reason for this may lie in the plans' most debatable feature - the need to demonstrate equivalent qualifications of male and female candidates before any preferential criterion is triggered.' D Caruso, 'Limits of the Classic Method: Positive Action in the European Union after the New Equality Directives', Harvard Int LJ 44 (2003): 331, 341-2.

87 In Biggs $v$ Rand Water (2003) 24 ILJ 1957 (LC), for example, the court held that the appointment of someone solely on the basis of name and race, without considering the applications properly, and without conducting interviews, constitutes an absolute barrier for those belonging to the disfavoured race. As the court said in this case, the employer may as well have said that 'whites and Indians need not apply for the position' (at 1961). This amounts to a situation that Justice Sachs in Van Heerden refers to as 'hand-outs given simply on the basis of race' (para 156). It bears pointing out that the EEA does not preclude the use of quotas (see $s$ 15(3)), nor does it preclude the employer from adopting a policy that places a moratorium on the employment of members of the non-designated group, namely white males. Section 15(4) of the EEA provides that 'subject to section 42, nothing [...] requires a designated employer to take any decision concerning an employment policy or practice that would establish an absolute barrier to the prospective or continued employment or advancement of people who are not from designated groups. This section, in effect, provides that an employer cannot be forced to establish policies or practices that eliminate non-designated groups from prospective employment or continued employment. This is not to say an employer is precluded from doing so. It would be permissible when justified, and could even be 'required' to achieve the demographic targets referred to in s 42 . In fact, establishing a fixed quota for members of designated groups in effect means that those set-aside positions operate as an absolute barrier for members from the non-designated group. This is the way quotas normally work in practice. 
when, in the words of Denise Meyerson, 'any further sacrifices of the principle of merit would make not only whites but also blacks worse off?'88

The EEA gives us at least one indication. In terms of the EEA, candidates from designated groups will have to meet two criteria before being considered for appointment or promotion under an employment equity plan. The first is membership of the designated group; the second is proof that they are 'suitably qualified'. 89 The definition of 'suitably qualified' in the Act indicates that membership in a 'designated group' is not only a tie-breaking factor when two candidates are equally qualified, but is a consideration that may even outweigh other qualifications, provided the person in question has, in the view of the employer, the potential to 'grow' into the job within what is seen to be a reasonable period of time. ${ }^{90} \mathrm{I}$ have argued elsewhere that despite the broad and seemingly open-ended definition of 'suitably qualified', employers should nevertheless employ the idea of a 'threshold of performance' that candidates for a certain position must attain..${ }^{91} \mathrm{~A}$ strategy in which it is enough simply to be a member of a group with some qualification in order to be appointed may lead to a level of performance below this threshold, and surely reinforce rather than change stereotypical and prejudicial views towards members of disadvantaged groups.

Indications are that the failure to take a 'threshold of performance' into consideration has occurred with some regularity in the public service. The transformation of the public service from one that was overwhelmingly white and male in 1994 to one that is today broadly reflective of national racial demographics is nothing short of remarkable, ${ }^{92}$ and has far surpassed that of the private sector..$^{93}$ However, many

88 See D Meyerson, 'How Useful is the Concept of Racial Discrimination?', South African Law Journal 110 (1993): 575, 579.

89 Section 15;20(3) EEA.

90 A 'suitably qualified person' is defined as a person who may be qualified for a job as a result of any one of, or any combination of, that person's formal qualifications, prior learning, relevant experience, or capacity to acquire, within a reasonable time, the ability to do the job. See s 20(3) EEA.

91 Dupper, 'In Defence of Affirmative Action', 207-9.

92 In $1994,94 \%$ of the management echelon of the public service was white and $97 \%$ was male. The current racial composition of the population is $77.9 \%$ African, $8.5 \%$ Coloured, 2.5\% Indian, and $11.1 \%$ White; while the racial composition of the public service at national level is 74\% African, 10.0\% Coloured, 4.0\% Indian, and 12\% White. The same holds true for the public service at provincial level. See Naff, 'Passive Representation in The South African Bureaucracy', 7, 12. See also V Naidoo, 'Assessing Racial Redress in the Public Service' in Racial Redress and Citizenship in South Africa, eds. Bentley \& Habib, 99.

93 See Naidoo, 'Assessing Racial Redress in the Public Service', 112-3. The difference between the implementation of affirmative action in the public and private sectors is an interesting 
have argued that the accelerated drive to transform the public service has often led to the appointment of people who did not have the qualifications, experience, commitment or culture of service needed to be productive and loyal public servants. ${ }^{94}$ In short, it has led in certain instances to the appointment of people who were not 'suitably qualified'. By 2003, even the State admitted that the shakeout of the public service had been severe and even counter-productive. ${ }^{95}$ It led to a skills exodus and, most importantly, has impeded the State's ability to spend revenue and deliver effective services, something that impacts most adversely on the poorest and most marginalised of the citizenry. ${ }^{96}$

As a general rule, courts will be reluctant to interfere with the manner in which employers define 'suitably qualified. However, when these criteria amount to 'insurmountable obstacles' for members of the disfavoured group, they have not survived judicial scrutiny. For example, in a decision regarding the appointment of regional magistrates, the High Court held that a formula allocating marks to applicants based on race and gender, and resulting in the automatic exclusion of any white male in competition for a position with a black female, irrespective of qualifications, experience or skills, amounts to an unacceptable barrier. ${ }^{97}$ In addition, courts have also been willing to investigate whether the criteria that comprise suitable qualifications have been applied properly. For example, in the case of Greater Louis Trichardt Transitional Local Council, the Labour Court overturned the appointment of a person to the position of town treasurer, in part because the employer failed to demonstrate that any of the criteria for the position were considered in making the appointment, including the potential to develop the ability to perform the work. ${ }^{98}$

Efficiency considerations in the private sector are largely self-enforcing, with financial incentives compelling employers to define 'merit' in a manner that advances their

topic, and worthy of separate analysis. Suffice it to say that the goals of transformation in the two sectors differ significantly, and impacts on the manner in which transformation is pursued. See M Ndletyana, 'Affirmative Action in the Public Service' in Racial Redress and Citizenship in South Africa, eds. K Bentley \& A Habib (Pretoria: HSRC Press, 2008), 80.

94 See, for example, S Terreblanche, The History of Inequality in South Africa: 1652-2002 (Durban: University of KwaZulu-Natal Press, 2002), 447-8; Alexander, 'Affirmative Action and the Perpetuation of Racial Identities in Post-Apartheid South Africa', 5.

95 See G Ruiters, 'Public Services: Transformation or Stasis' in Public Services Yearbook 2005/6, 129.

96 Ibid., 129. See also Bentley \& Habib, 'An alternative framework for redress and citizenship', 342. Naidoo, however, warns that it is difficult to make a causal connection between redress and efficiency in the public service in light of the massive increase in the mandate of the postapartheid public service. See Naidoo, 'Assessing Racial Redress in the Public Service', 117.

97 See Du Preez v Minister of Justice and Constitutional Development and others [2006] 8 BLLR 767 (SE).

98 See IMAWUv Greater Louis Trichardt Transitional Local Council (2000) ILJ 1119 (LC). 
own interests. Private employers will therefore, as a matter of self interest, favour staying quite close to merit principles despite the relatively open-ended definition of 'suitably qualified' contained in the EEA. However, because this mechanism is less obvious in the public service, legislation has to step in to fill the void. In South Africa, the need to balance equality with efficiency considerations finds expression in the Constitution. The Constitution states that the public service must be both 'broadly representative' and 'efficient', and the police service must discharge its responsibilities 'effectively'.99 To be sure, these two objectives (promotion of equality and efficiency) need not necessarily be in conflict. As the court pointed out in Stoman, a police service 'could hardly be efficient if its composition is not [...] representative of the population or community it is supposed to serve.' 100 The argument is simple: only a police force representative of the community it serves will enjoy the trust, co-operation and support of that community that is needed to perform its functions effectively. This means that the appointment of a suitably qualified African male over a white female to the position of captain in a police station variously described as 'an old apartheid style police station' and a 'bastion of white privilege', can be justified on efficiency grounds. ${ }^{101}$

However, there may be situations in which the goal of the achievement of equality will yield to efficiency considerations. For example, in Coetzerv Minister of Safety and Security, ${ }^{102}$ the employer decided to keep positions in its explosives unit open rather than filling them with suitably qualified members of the non-designated group. The court held that the balance between the imperatives of representivity and efficiency should be a rational one. ${ }^{103}$ In this case, however, the employer had failed to embark on this balancing exercise, thereby ignoring the constitutional imperative that the police service should maintain its efficiency. ${ }^{104}$

99 See s 195(1) and s 205(2).

100 Stoman supra, 482.

101 See Fourie $v$ SAPS (2004) 25 ILJ 1716 (LC) at 1732 and 1735, where the court upheld the contention of the respondent that the appointment of a white women in an overwhelmingly white police station would not have promoted efficiency, while the appointment of an African male would because it would increase the legitimacy of the police in the eyes of the community that it was meant to serve.

102 (2003) 24 ILJ 163 (LC).

103 Ibid., 173.

104 Ibid., 176-7. It is interesting to note that in American law, it is an established principle that goals must be waived if qualified members of the targeted group cannot be found. See E Anderson, 'Integration, Affirmative Action, and Strict Scrutiny', New York University LR 77 (2002): 1195, 1248 and the cases referred to there. 
In a recent decision of the Labour Court in the case of Solidarity on behalf of Barnard $v$ SAPS, ${ }^{105}$ the court specifically considered the interests of the "previously advantaged' in the pursuit of affirmative action and did so without exclusive reference to competing (exogenous) interests such as 'efficiency' (as was the case in Coetzer). Barnard concerned the decision of the SAPS not to appoint a white woman (Barnard) to the position of superintendent despite the fact that she received the highest assessment score of all the shortlisted candidates and despite being recommended for the post by the selection panel. The post was advertised twice, and on both occasions the national police commissioner decided not to fill it. In finding that Barnard had been unfairly discriminated against, the Labour Court in this instance did not balance the competing interests of representivity and efficiency (as was the case in Coetzer), but indicated that the need for representivity must be weighed up against the affected individual's right to equality and dignity. ${ }^{106}$ The court held that there was no evidence that the commissioner had taken Barnard's right to equality or her personal work history and circumstances into account in deciding not to appoint her. ${ }^{107}$ In addition, while acknowledging that affirmative action will adversely affect some employees, the court highlighted a number of procedural lapses that impacted negatively on the dignity of the applicant such as the failure of the respondent to engage effectively in the mediation and conciliation procedures provided for within the SAPS and also provided for by the provisions of the Employment Equity Act. ${ }^{108}$ It ordered the SAPS to promote Barnard.

On appeal, the Labour Appeal Court (LAC) reversed the Labour Court's decision. ${ }^{109}$ The LAC disagreed with the central premise of the Labour Court - namely, rendering the implementation of restitutionary measures subject to the right of an individual's right to equality. This approach, the LAC noted, would defeat the very purpose of having restitutionary measures in the first place, 'as such implementation will always fall short, due to the reality that there will always be adverse effects on persons from non designated groups.' ${ }^{\prime 10}$ The LAC continued:

This is more so as this approach promotes the interests of persons from nondesignated categories to continue enjoying an unfair advantage which they had enjoyed under apartheid. Treating restitutionary measures in this manner is surely bound to stifle legitimate constitutional objectives and result in the perpetuation of inequitable representation in the workplace. ${ }^{111}$

105 (2010) 31 ILJ 742 (LC).

106 Para 25.3.

107 Para 36.

108 Para 38.

109 (2013) 34 ILJ 590 (LAC).

110 Para 26.

111 Para 30. 
Barnard appealed to the Supreme Court of Appeal (SCA). In its decision, the SCA concluded that Barnard had been discriminated against, ${ }^{112}$ and concentrated on the question whether the discrimination was fair. In concluding that the discrimination against Barnard was unfair, the SCA returned to the seemingly incompatible constitutional imperatives of 'efficiency' and 'representivity.'. ${ }^{113}$ It held that the SAPS had failed to advance convincing arguments that service delivery would not have been affected by failing to appoint Barnard:

Whilst it is true that [...] the National Commissioner [of SAPS] is not obliged to fill a vacancy, the most obvious instance being where there is no suitable person capable of fulfilling the requirements of the position, it does not follow that where the only suitable person is from a non-designated group in relation to representivity, that person should not be appointed. ${ }^{114}$

The Constitutional Court disagreed. ${ }^{115}$ In an important passage, it reiterated the importance of a threshold of qualifications, and the centrality of efficiency considerations in the implementation of affirmative action measures:

I pause to underline the requirement that beneficiaries of affirmative action must be equal to the task at hand. They must be suitably qualified people in order not to sacrifice efficiency and competence at the altar of remedial employment. The Act sets itself against the hurtful insinuation that affirmative action measures are a refuge for the mediocre or incompetent. Plainly, a core object of equity at the workplace is to employ and retain people who not only enhance diversity but who are also competent and effective in delivering goods and services to the public. ${ }^{116}$

In casu, however, the court determined that the current set of facts could be distinguished from those in Coetzer. ${ }^{17}$ While the explosives unit was fundamental to SAPS's core mandate and required highly trained and specialised candidates, meaning that the division could not have functioned effectively without filling these positions, the position that Barnard applied for did not meet these criteria. While the court was at pains to point out that courts should be careful to draw conclusions

112 As the court pointed out, ' $\mathrm{i}] \mathrm{f}$ a senior African female or male police officer had all of Barnard's skills and had achieved the same interviewing score, that person would most surely have been appointted (sic) to post 4701. It can "hardly be contested" that in the present case Barnard was not appointed because she was a white female.' Para 52.

113 Paras 70-79.

114 Para 78.

115 South African Police Service v Solidarity obo Barnard [2014] ZACC 23.

116 At para 41 (per Moseneke, ACJ). In another passage, the court reiterated these sentiments, stating that ' $[\mathrm{i}] \mathrm{t}$ would be unacceptable if an affirmative measure were implemented by appointing a wholly unqualified or incapable candidate [...]' (at para 186 - per Van der Westhuizen J).

117 Para 188. 
about the precise impact a policy, an appointment, or even a vacancy will have on service delivery without proper evidence or specialised institutional knowledge, it was satisfied in this case that 'it was [not] disproportionate for the National Commissioner [of Police] to rank representivity higher than the possible impact on service delivery [...]: ${ }^{\prime 18}$ The balance between efficiency and representivity must therefore be struck on a case-by-case basis, and requires consideration of a number of factors, including the nature of the duties of the job, the needs of the workplace and the employer and the under- or over-representation of the group seeking to be advanced by the affirmative measure. ${ }^{119}$

Nevertheless, the general approach of the courts has cast doubt on the lawfulness of what some studies indicate has become common practice in the public service - namely, the refusal to fill positions even though qualified members of the nonfavoured groups are available. ${ }^{120}$ If one takes into consideration the fact that the public service is experiencing an alarmingly high rate of vacancies, especially at senior management level, these judgments take on additional significance. ${ }^{121}$

In conclusion: it is clear that achievement of equality must be the goal of the measure - not, for example, to harm or punish the excluded groups. Ultimately, transformation must be carried out responsibly and its adverse impact minimised. If not, the courts have a duty to intervene. ${ }^{122}$

\subsection{Concluding remarks}

In this chapter, I have considered the general approach adopted by the Constitutional Court to determine whether an affirmative action measure is covered by section 9(2) of the Constitution, which explicitly authorises such measures. I have indicated that the general approach can be described as one of restraint and deference, in recognition of the need to redress past social injustices. This approach can usefully be contrasted with the standard of scrutiny applied by the European Court of Justice and the US Supreme Court, which both continue to regard affirmative action as a derogation from the principle of equality, and therefore to be construed strictly.

118 Para 189.

119 Para 186.

120 Bentley \& Habib, 'An alternative framework for redress and citizenship', 343.

121 Vacancies at especially senior management level have taken on alarming proportions, ranging between 44 and 48 per cent in departments such as Justice and Constitutional Development, Home Affairs and Trade and Industry. The average vacancy rate at senior management level is slightly more than 25 per cent. See Naidoo, 'Assessing Racial Redress in the Public Service', 122-3.

122 Van Heerden, para 152 (per Sachs J). 
However, despite the 'hands-off' approach, South African courts have nevertheless retained a role for themselves that draws a careful line between deference to the judgment of the executive (or, in the employment context, the employer) and appropriate judicial supervision.

This approach requires an affirmative action measure to meet the standard of reasonableness. The Constitutional Court stated that the remedial measures must be 'reasonably capable of attaining the desired outcome', namely to protect or advance individuals or categories of persons who have been disadvantaged by unfair discrimination. This excludes measures that are arbitrary, capricious or display naked preference, or are not reasonably likely to achieve the end of advancing or benefiting the interests of those who have been disadvantaged by unfair discrimination. ${ }^{123}$

123 Minister of Justice v Van Heerden [38]-[40]. 


\section{INDEX}

A

AAPs

conditions for legitimacy 109-111

defined 67

design of 109-111

evaluation $223-228$

features 110

Malaysia, AA 145-154

and other EOPS, broader context $64-66$

prior consultation with all stakeholders 108

proportionality 111

see also names of countries; unfairness of AAPs

affected groups, democratic participation in making \& enforcing AA schemes 44

anti-discrimination laws 66

appropriate representation in Israel

see Israel, appropriate representation

Ashkenazi Jews 122

asymmetry of substantive equality 10-11, 13

attitude-changing argument $28-30$

autopoiesis analogy 48

B

backward- and forward-looking arguments for justification and termination $34-40$

backward classes $25-26$

beneficiaries

actual disadvantage vs membership of affected class 262-264

Canadian courts on demarcation of 23-24

demarcation of 13-14, 21-27

demarcation of in Indian AA 25-26

demarcation of in United States 26-27

differentiation among members of groups 264-266

identification in Indian AA 181-182

measure designed to protect/advance test 267-269

South Africa AA 258-266

unqualified, perceptions $20-21$

see also demarcation of beneficiaries
Brazil, AA 17-19

Afro-descendants 207, 214-215

EOPs and AA as constitutional duty 202-214

evaluation of AAPs 223-228

Federal Constitution 202-205

Federal University of Bahia programme 225-226

Federal University of Rio Grande do Sul decision 221-223

functional illiteracy 208

judges' opinions 218-223

Law of Quotas and education 212-214

major arguments for and against AA 214-218

ProUni decision 218-220

ProUni programme 210-212

race $205-208$

State University of Rio de Janeiro programme 225

supreme court decisions $214-223$

University of Brasilia case 220-221

Bumiputera 139-141

burdened individuals, two categories of $69-70$

C

Canadian courts on demarcation of beneficiaries 23-24

caste $19,183-184$

CEACR 101-102

CESCR 9-10, 100-101

command-and-control

example 55

failure of $50-58$

conditions for legitimacy of AAPs 109-111

Convention on Elimination of All Forms of

Discrimination against Women 34, 91, 98 , 100, 243-244

Convention on the Rights of Persons with Disabilities 92, 98

cosmetic change 41

creamy layer $25-26,27,185$ 
D

demarcation of beneficiaries

courts 22-24

creamy layer $25-27$

groups vs individuals $22-24$

status combined with socio-economic disadvantage 25-27

see also beneficiaries

democratic participation in making and enforcing AA schemes

affected groups 44

command and control, failure of 50-58

equality of capabilities 44

introduction 43-45

participation and accountability $58-60$

reflexive regulation $45-50$

restorative justice $44-45,60-61$

transformative equality 44

diversity model 31-33

duration of affirmative action programmes 14 see also justification and termination of measures

duty of care 122,127

see also rigorous standard of care

E

Employment Equity Act, South Africa

categorical thinking 15-16

command-and-control 50-58

labour inspectors $56-57$

limited impact, reasons for $55-58$

trade unions 55-56

Equality Acts of 2006 and 2010 (UK) 52-54

Equality and Human Rights Commission

(UK) $52-54$

equality as a constitutional principle, Mexico 193-199

equality of capabilities, democratic participation in making and enforcing AA schemes 44

equal treatment principle 254-255

equity ownership and enterprise development 150-154, 162-164

Ethiopian Jews 122

F

Federal Constitution of Malaya 139-141

foundations and motivations 139-145
Fraser, Nancy

affirmative vs transformative redistribution 27

and effects of redistributive strategies 20

and status 14

underlying mechanisms of maldistribution 39

Fredman, Sandra, on substantive equality 13

functional illiteracy and Brazilian AA 208

G

group identity

see social identity

H

higher education AAPs

outcomes 154-157

programmes $146-148$

high-level positions, representation in 148-150, 157-161

\section{I}

ILO Global Reports

Equality at Work: Tackling the Challenges 103

Time for Equality at Work 101-102

impact assessment of AAPs 27-33

India, AA

beneficiaries, identification 181-182

caste $19-20$

constitutional mandate $170-172$

creamy layer 185

demarcation of beneficiaries $25-26$

diversity, administration of 184-185

general welfare measures vs AA, distinguishing 172-174

intersectionality of caste, religion and gender 183-184

justiciability of AA measures $174-177$

Other Backward Classes 19-20, 25, 35, 174,177

individual burdens, perceived unfairness 69

inequality 65

integrative argument 30-31

intentionality 129-130, 132

International Covenant on Civil and Political

Rights 91-92 
International Covenant on Economic, Social \& Cultural Rights 9, 91-92

International Covenant on Elimination of All Forms of Racial Discrimination 91

international perspective/s on AA beneficiaries of AA 111-113

content of AA and areas concerned 107-109

Convention on Elimination of All Forms of Discrimination against Women 91

Convention on the Rights of Persons with Disabilities 92

International Covenant on Civil and Political Rights 91-92

International Covenant on Economic, Social \& Cultural Rights 91-92

International Covenant on Elimination of All Forms of Racial Discrimination 91 international human rights law 90-93 international labour law 93-97

legitimacy of AAs, conditions for 109-111

objectives of AA and principle of non-discrimination 104-106

special measures $90-93$

UN Declaration on Elimination of All Forms of Racial Discrimination 90-91

UNESCO Declaration on Race and Racial Prejudice 92-93

intra-racial inequality $24-25$

Israel, appropriate representation

Arabs 123-124, 125

Ashkenazi 122

demographics 122

duty of care 122, 127

Equal Opportunities in Employment Act 123-124

Ethiopian Jews 122

Government Corporations Law 124

intentionality 129-130, 132

Knobe Effect 129

Mizrahi Jews 122

negligence $128-130,133,134$

negligent violation of AR norms 126-130

norms $122-126$

Orthodox minority Jews in Israel 122

Pareto optimality 133-134

quotas 127,130 rigorous standard of care $130-135$

stereotyping 128

substantive equality 130,131

J

justification and termination of measures

backward- and forward-looking arguments $34-40$

court rulings $37-40$

$\mathbf{K}$

Knobe Effect 129

L

law as instrument of social change, failure of 47

legitimacy of AAs, conditions 109-111

life experiences of people 31-32

living- vs abstract law 47

M

Malaysia, AA

AAP outcomes 154-164

AAPs 145-154

Bumiputera 139-141

constitutional provisions and prevalent interpretations 139-141

equity ownership and enterprise development 150-154

mandatory obligation of AA 104-106

CEACR 101-102

CEDAW General Recommendation No 25 98-100

CERD's General Recommendation No 2 98

CESCR 100-101

ILO Global Report Equality at Work: Tackling the Challenges 103

ILO Global Report Time for Equality at Work 101-102

Mexico, AA

AA as alternative 190-192

equality as a constitutional principle 193-199

indigenous people, history 187-189

indigenous people, present situation 189-190

meritocratic principle 192-193 
Mexico, AA (continued)

National Supreme Court of Justice 196

proportionality 198, 199

slavery $187-188$

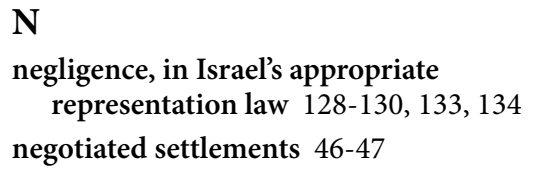

New Economic Policy, Malaysia 138, 145, 148

Nigeria, AA

CEDAW 243-244

discriminatory practices in the public services $247-248$

ethnic complexity 230-232

federal appointments and zoning 239-240

Federal Character Commission 231-232, 235-240

federal structure 230-232

gender and AA 240-250

gender and access to health care 248-249

gender and employment 245-246

gender, political representation \& participation in governance 250

HIV/AIDS 249

legal and policy framework for gender equality 241-242

legal and policy measures on AA 242-243

legal framework for AA 233-240

quota system 231-232, 236-238

rationale for AA 233-235

zoning and federal appointments 239-240

non-discrimination principle and AA

see objectives of AA and principle of non-discrimination

non-distributive justification 31-33

non-Malay Bumiputera 155-156

Northern Ireland, voluntary agreements 53-54

\section{O}

objections to AA and responses

AAPs and other EOPS, broader context 64-66 unfairness of AAPs, defences 70-86

unfairness of AAPs, objection 66-70

unfairness of AAPs, response 70-86

objectives of AA and principle of

non-discrimination 97-103

Orthodox minority Jews in Israel 122

Other Backward Classes 19-20, 25, 35, 174, 177

over- and underinclusiveness $22,24,41$

$\mathbf{P}$

participation and accountability 59

personal autonomy argument

arguments against protecting personal autonomy 84-85

arguments for protecting personal autonomy 78-79

autonomy, notion and behavioural premises $79-84$

implicit bias $80-84$

political imperatives and motivations $142-143$

preferential treatment, and strong and weak

affirmative action 8-9

promotion of equality test $269-278$

proportionality

AAPs 111

Mexico 198, 199

proportionality principle in design of AAPs 111

ProUni

decision 218-220

programme $210-212$

Q

quotas

Israel 127,130

Law of Quotas and education, Brazil 212-214

Nigeria 231-232, 236-238

$\mathbf{R}$

race $11-12,17-19,20,30-31,40,155,160,162$, 207-208, 212-217, 227

Brazil, AA 205-208

racial classification and racial categories 259

reflexive law 48 
reflexive regulation

autopoiesis analogy 48

independence of regulatory agencies 60

law as instrument of social change, failure 47

living- vs abstract law 47

negotiated settlements $46-47$

reflexive law 48

right to private property $45-46$

reservation in public employment 177-181

reservations (India, AA) 19-20

responsive regulation $48-50$

restorative justice $44-45$

rigorous standard of care 130-135

\section{$S$}

Sen, Amaryta 255-256

slavery 187-188, 194

social and educational backwardness 185

social identity 14-21

as central feature of affirmative action 13

race 15-19

socio-economic disparities 143-145

South Africa AA

actual disadvantage vs membership of affected class 262-264

beneficiaries 258-266

Constitutional Court's approach to AA 255-256

differentiation among members of beneficiary groups 264-266

Employment Equity Act 253-254

equal treatment principle 254-255

measure designed to protect/advance beneficiaries? 267-269

promotion of equality test $269-278$

racial classification and racial categories 259

redress 257-258

Sen, Amaryta 255-256

South African Constitution, Section 9(2): internal criteria $257-278$

standard of reasonableness 279

substantive equality 255, 262, 267

see also Employment Equity Act

standard of reasonableness 279 status as disadvantage 14

stereotyping 128

strong and weak affirmative action 8-9

substantive equality

advantage of 10-11

asymmetry of 13

constitutionality 11-13

Israel 130, 131

South African Constitution 11

$\mathbf{T}$

temporary measure nature of affirmative action 14,41

transformative equality 44

U

UN Declaration on Elimination of All Forms of Racial Discrimination 90-91

UNESCO Declaration on Race and Racial Prejudice 92-93

unfairness of AAPs, defences

argument from individual equality 67-68

burdened individuals, types of 71-72

justifications for burdening individuals 73-75

personal autonomy argument 77-86

transferring justifications $75-77$

unfairness of AAPs, objection

context 67-68

individual burdens, perceived unfairness 69

specifics $68-70$

two categories of burdened individuals 69-70

\section{United States}

demarcation of beneficiaries 26-27

Small Business Act 26-27

\section{$\mathbf{Z}$}

zoning and federal appointments in Nigerian AA $239-240$ 